\title{
ANÁLISE DE ESTRATÉGIAS DE RETIFICAÇÃO DE VIRABREQUINS AUTOMOTIVOS FORJADOS UTILIZANDO REBOLOS DE CBN VITRIFICADOS EM ALTAS VELOCIDADES
}

Tese apresentada à Escola de Engenharia de São Carlos da Universidade de São Paulo, como parte dos requisitos para obtenção do Título de Doutor em Engenharia Mecânica.

Orientador: Prof. Titular João Fernando Gomes de Oliveira 


\section{DEDICATÓRIA}

A Daniela, minha esposa, com muito amor e carinho por sua dedicação e incentivo constante, fundamentais para o início e término deste trabalho. A minha filha Lívia, um presente de Deus. Aos meus pais, Aparecida e Roberto, sempre presentes. Ao meu irmão Eduardo, um exemplo de perseverança. A minha avó Maria (in Memoriam). 


\section{AGRADECIMENTOS}

Ao Prof. Titular João Fernando Gomes de Oliveira pela orientação, pelo incentivo e apoio constantes, pela amizade sincera, pelas valiosas sugestões e pela confiança depositada no sucesso desta pesquisa.

Ao Prof. Dr. Reginaldo Teixeira Coelho pelas valiosas sugestões técnicas para a realização deste trabalho.

À FAPESP - Fundação de Amparo à Pesquisa do Estado de São Paulo, pela concessão da Bolsa de Doutorado e da Reserva Técnica, possibilitando a realização desta pesquisa.

Ao CNPq - Conselho Nacional de Desenvolvimento Científico e Tecnológico, pela concessão da Bolsa de Doutorado Sanduíche, possibilitando a realização de parte dos testes laboratoriais desta pesquisa.

Ao Prof. Dr.-Ing. Fritz Klocke pela orientação e oportunidade de realização do projeto de Doutorado Sanduíche.

À Universidade RWTH -Reinisch-Westfälischen Technischen Hochschule - e ao Laboratório WZL - Laboratorium für der Werkzeugmaschinen und Betriebslehre - Aachen Alemanha, local da realização de parte dos testes laboratoriais desta pesquisa.

Às empresas, Zema, pela construção, doação e instalação na USP-EESC- São Carlos da retificadora de $\mathrm{CBN}$ de alta velocidade, GE Fanuc (doação do $\mathrm{CNC}$ da retificadora), à Saint Gobain Abrasives (doação do Rebolo de CBN, sistema de dressagem e disco dressador) à Sensis (doação do sistema de monitoramento por emissão acústica com o respectivo sensor), 
à Micro Química (doação do fluido de corte) e à Aços Villares (doação do material dos corpos-de-prova)

Ao Instituto Fábrica do Milênio pelo apoio a esta pesquisa.

Ao Eng. MSc. Marcelo Biffi pela colaboração no projeto de implantação da retificadora de alta velocidade.

A Irene Libardi pelo apoio durante a realização desta pesquisa.

Ao Prof. Dr. Luiz Carlos Casteletti e Prof. Dr. Jaime Gilberto Duduch e aos técnicos Eliezer (Tico) e Zé Roberto pelo apoio técnico a esta pesquisa.

Aos colegas Alessandro Roger Rodrigues, Carlos Magno de Oliveira Valente, Fábio Ferraz Júnior, João Jorge de Faria Gomes, Salete Martins Alves e Ronaldo de Oliveira Martins pela colaboração direta para a realização deste trabalho.

A todos os colegas e técnicos do Laboratório de Pesquisa OPF - Grupo de Otimização dos Processos de Fabricação da Escola de Engenharia de São Carlos - EESC-USP, pela colaboração e pela convivência harmoniosa.

A todos os colegas e técnicos do Laboratório WZL - Laboratorium für der Werkzeugmaschinen und Betriebslehre - Aachen - Alemanha.

À Deus, pela saúde concedida para a realização deste trabalho. 


\section{RESUMO}

SILVA, E. J. (2004). Análise de estratégias de retificação de virabrequins automotivos forjados utilizando rebolos de CBN vitrificados em altas velocidades. Tese (Doutorado) Escola de Engenharia de São Carlos, Universidade de São Paulo, São Carlos, 2004.

O objetivo deste trabalho foi a análise de estratégias de retificação de virabrequins automotivos forjados utilizando rebolos de CBN vitrificados em altas velocidades. As estratégias analisadas foram: a retificação de mergulho (estratégia A) e a retificação axial (estratégia B). Foi proposta uma nova estratégia de retificação, denominada estratégia C retificação axial múltipla, sendo esta inédita. Nesta subdividi-se o espelho do virabrequim em trechos, retificando-se o sobremetal radial do espelho em múltiplos estágios. Os aspectos teóricos das estratégias foram determinados, apresentando-se uma formulação matemática para o cálculo da taxa de remoção de material específica ao longo do perfil do rebolo utilizado. Testes comparativos foram realizados em que os principais aspectos para uma retificação eficiente foram determinados. Primeiramente verificou-se a necessidade de uma operação de dressagem efetiva, a fim de se obter uma agressividade na face do rebolo necessária para evitar o empastamento do mesmo e a queima do espelho. Para tanto, além da escolha correta da configuração e dos parâmetros de dressagem verificou-se a necessidade de um sistema de monitoramento que permita a detecção e a avaliação de possíveis nãoconformidades. A utilização de um sistema de fluido de corte e de limpeza a alta pressão eficientes contribuíram para a redução dos cavacos alojados na porosidade do rebolo, evitando assim seu empastamento prematuro. Com base no modelo teórico proposto foi possível 
determinar-se a região de máxima solicitação do rebolo em função das estratégias adotadas, possibilitando o planejamento e a adoção das condições de usinagem mais favoráveis na redução do desgaste do rebolo e, por consequiência, os desvios geométricos da peça usinada. Nos testes comparativos entre as estratégias verificou-se a possibilidade de utilização de todas. Porém, cada qual apresentando suas particularidades. Considerando-se o mesmo tempo de corte, a retificação de mergulho (estratégia A) apresenta a menor taxa de remoção de material específica e a mais ampla região de máxima solicitação do rebolo, sendo esta fixa e igual ao sobremetal no espelho. Neste caso a área sujeita ao desgaste na ferramenta é maior. De forma oposta, a estratégia B (retificação axial) apresenta a menor região de solicitação da ferramenta, sendo esta igual ao avanço axial por volta. Todavia nesta estratégia a taxa de remoção de material específica é máxima, sendo função do sobremetal radial da peça, diferença entre os raios máximo e mínimo do espelho. Nesta, a área desgastada será mínima, porém, esta região sofrerá a máxima solicitação e maior desgaste, com risco de empastamento do rebolo e queima da peça. A adoção da retificação axial múltipla (estratégia C) permite combinar a flexibilidade da alteração da região de máxima solicitação do rebolo com variações na taxa de remoção de material específica para cada estágio, reduzindo a tendência de queima e empastamento do rebolo, caracterizando-se como uma solução intermediária entre a retificação de mergulho e a axial. Verificou-se que a variação no número de estágios tem influência direta no volume de material removido e no desgaste radial do rebolo. Uma simulação foi desenvolvida para o desgaste radial do rebolo para cada estratégia testada.

Palavras-chave: retificação, alta velocidade, rebolo, CBN, virabrequim. 


\section{ABSTRACT}

SILVA, E. J. (2004). Analysis of strategies for high speed grinding of forged automotive crankshafts using vitrified CBN wheels. Ph.D. Thesis - São Carlos Engineering School, University of São Paulo, São Carlos, 2004.

The aim of this study was the analysis of grinding strategies for high speed grinding of forged automotive crankshaft using vitrified $\mathrm{CBN}$ wheels. The grinding strategies tested were: the plunge grinding (strategy A) and the face grinding (strategy B). A new grinding strategy was proposed, the multi-steps face grinding, which is innovative. In this strategy, the sidewall is divided into circular regions, removing the sidewall stock into multiple steps. The theoretical aspects of each strategy were determinate and the mathematic formulation for the specific material removal rate calculation along the wheel profile is presented. Comparative tests were performed in which the main aspect for an efficient grinding operation were determinate. First of all, the necessity of a high efficient dressing operation was detected, in which the achieving the adequate sharpness of the dressed wheel sidewall is mandatory to avoid the wheel loading and the workpiece sidewall burning. For that, besides the correct configuration and selection of the dressing parameters, it was noticed that a monitoring system is essential for the detection of non-adequate dressing operations. The adoption of an improved cutting fluid application system and scrubbers (high pressure nozzles) leaded to chips clogging reduction and premature wheel loading. Based on the proposed theoretical model it was possible to determine the region of the maximal wheel strength due to the adopted grinding strategy, allowing the process design, including the most favorable cutting conditions for the workpiece 
geometrical errors avoidance. In the comparative test among the strategies, it was possible to verify that all strategies can be adopted, although each of them with their particularities, which must be taken into account. Considering the same cutting time, the plunge grinding strategy (strategy A) presented the lowest specific material removal rate and the widest affected wheel region, which is fixed and equal to the sidewall stock. In this situation, the worn area $\&$ the widest. On the other hand, the face grinding strategy (strategy B) presented the narrowest affected area, with width equal to the axial infeed. Although in this strategy, the specific material removal rate is maximal, depending on the radial stock of the sidewall. The worn region is the narrowest, but the with greatest wheel wear values will be observed in this region. The wheel loading and the workpiece burn can easily occur. The adoption of the multi-steps face grinding (strategy $\mathrm{C}$ ) allows the combination between the flexibility of changing the width of the affected wheel region and the specific material removal rate for each step, reducing the occurrence of workpiece burn and wheel loading. It is an alternative between the plunge grinding and face grinding. It was possible to verify that the number of steps has a direct influence on the volume of removed material and on the wheel wear. A simulation was developed for the wheel wear for each strategy.

Keywords : grinding, high speed, wheel, CBN, crankshaft. 


\section{LISTA DE FIGURAS}

Figura 1.1 - Cinemática da retificação cilíndrica externa de forma (Adaptado de König e

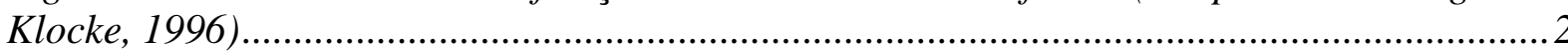

Figura 1.2 - Elementos de retificação de faces planas .............................................................. 4

Figura 2.1 - Temperatura da superfície da peça em função da velocidade periférica de rebolos CBN e óxido de alumínio (adaptado de Tawakoli, 1993) ..........................................8

Figura 2.2 - Distribuição de tensões em um rebolo de CBN segmentado (adaptado de Hitchiner, 2001).... 9

Figura 2.3 - Variações dimensionais na estrutura do flange (a esquerda - modelo convencional, a direita modelo otimizado) (adaptado de Hitchiner, 2001).

Figura 2.4 - Propriedades dos grãos convencionais e superabrasivos (Hitchiner 2001) ........11

Figura 2.5 - Características da retificação CBN a alta velocidade ......................................... 13 Figura 2.6 - Razões de esmagamento e sua influencia na rugosidade (Adaptado de Hitchiner,

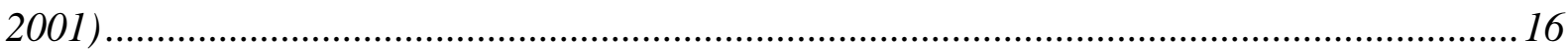

Figura 2.7 - Rugosidade Superficial ativa do rebolo (adaptado de Hitchiner, 1999)............ 18

Figura 2.8 - Fluido de corte e a barreira de ar formada em torno do rebolo durante a retificação cilíndrica (adaptado de Hitchiner 2001).

Figura 2.9 - Bico especial baseado no bico de mangueiras de incêndio (Rouse et al., 1952) (adaptado de Webster, 1995) (a esquerda) - a direita, bico especial em operação.................20 Figura 2.10 - Bocal de sapata em operação (adaptado de Klocke et al., 2000)......................23 Figura 2.11 - Bocais de sapata para a retificação de alta velocidade (adaptado de Hitchiner, 1999)

Figura 2.12 - Condicionador de fluxo Mitsubishi (adaptado de Cui, 1995)............................25

Figura 2.13 - Razão de velocidades $\left(V^{*}\right)$ para três velocidades de corte para bocal de saída com 1/16" de diâmetro (adaptado de Webster, 1995) ............................................................26

Figura 2.14 - Configuração do bocal de limpeza ( $h$ é a distância entre a saída do bocal e o rebolo; $\gamma$ é o ângulo de ataque)

Figura 2.15 - Diferentes tipos de bocais com diferentes geometrias do jato de saída (Lechler, 2004)

Figura 2.16 - Diferentes configurações de montagem ( h é a máxima distância entre a saída do bocal e a superfície do rebolo; $\beta$ é o ângulo de saída e $\delta$ é o ângulo de montagem)

(Lechler, 2004)

Figura 3.1 - Movimento de corte de três variantes da retificação cilíndrica externa (Saljé, 1991 apud Gerent 2001).

Figura 3.2 - Variações do processo de retificação cilíndrica externa de forma (Adaptado de Hegener, 1999)

Figura 3.3 - Configuração geométrica da peel-grinding com eixo X inclinado (Adaptado de

Bücker, 1997b apud Hegener, 1999)...

Figura 3.4 - Reprodução cinemática da superfície de saída (adaptado de König e Schröder, 1994 apud Hegener, 1999) 
Figura 3.5 - Formação de um processo quase-estacionário (adaptado de König e Schröder, 1994 apud Hegener, 1999)

Figura 3.6 - Condições de contato para a retificação cilíndrica externa de forma, para um rebolo com zona geométrica de desbaste ortogonal (adaptado de Hegener, 1999)

Figura 3.7 - Condições de contato para a retificação cilíndrica externa de forma, para um rebolo com zona geométrica de desbaste cônica e peça cilíndrica (Adaptado de Hegener, 1999)

Figura 3.8 - Condições de contato para a retificação cilíndrica externa de forma, para um rebolo com zona geométrica de desbaste com raio de arredondamento e peça cilíndrica (adaptado de Hegener, 1999)....

Figura 3.9 - Partes constituintes de um virabrequim - Detalhe de um munhão......................51

Figura 3.10 - Elementos constituintes de uma face plana .....................................................52

Figura 3.11 - Estratégias para a retificação de faces planas ...............................................53

Figura 3.12 - Cinemática da estratégia B (adaptado de Merbecks 2002) .............................55

Figura 3.13 - Dimensões dos Corpos-de-prova (adaptado de Merbecks 2002) ........................55

Figura 3.14 - Empastamento do rebolo na lateral quando da utilização da estratégia $B$

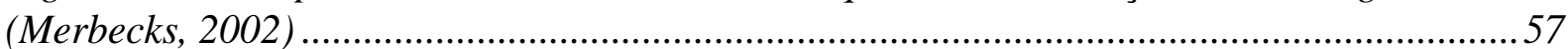

Figura 3.15 - Cálculo da área de contato para as estratégias A e B (Merbecks, 2002).........58

Figura 3.16 - Cálculo da área de contato para as estratégias A e B (Merbecks, 2002).........59

Figura 4.1 - Retificação de face plana com raio de arredondamento - Estratégia A -

Mergulho

Figura 4.2 - Modelo teórico de retificação axial....................................................................63

Figura 4.3 - Modelo teórico de retificação axial - simulação da operação de retificação ....64

Figura 4.4-Modelo teórico de retificação axial - simulação da operação de retificação ..... 65

Figura 4.5 - Modelo teórico de retificação axial - vista superior ..........................................65

Figura 4.6 - Modelo teórico de retificação axial - determinação das áreas principais de corte.

Figura 4.7 - Representação esquemática do contato rebolo peça para o cálculo da taxa de remoção específica

Figura 4.8 - Taxa de remoção de material especifica $(Q ' w)$ e de volume de material

removido específico $(V$ 'w)

Figura 4.9 - Taxa de remoção de material especifica $(Q$ 'w) e de volume de material removido específico ( $V$ 'w) - $0 \leq X_{i} \leq 0,050 \mathrm{~mm}$.

Figura 4.10 - Configuração de usinagem axial de 1 estágio..................................................76

Figura 4.11-Configuração de usinagem axial múltipla de 6 estágios - estágios 1 -2 ..........77

Figura 4.12 - Configuração de usinagem axial múltipla de 6 estágios - estágios 4 -6...........78

Figura 4.13 - Taxa de remoção específica ponto a ponto $\left(Q{ }^{\prime}{ }_{w, e f f, i}\right)$ ao longo do raio do rebolo

Figura 5.1 - Visão geral da retificadora ZEMA Numerika G800 -HS .................................... 83

Figura 5.2 - Dimensões e material dos corpos-de-prova utilizados........................................ 84

Figura 5.3 - Tela do monitor de operação da retificadora, com sistema de controle instalado

Figura 5.4 - Visão lateral do interior da máquina com sistema de dressagem na configuração

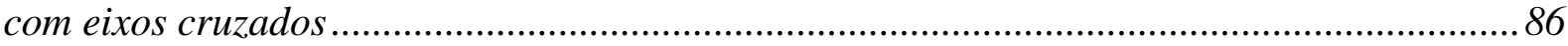

Figura 5.5 - Coordenadas do dressador capturadas durante a operação de referenciamento.

Figura 5.6 - Montagem cabeçote dressador a 70 graus em relação ao eixo do rebolo..........89

Figura 5.7 - Bocal de sapata instalado na retificadora ....................................................... 90

Figura 5.8 - Bocais "bombeiro" instalados na retificadora ................................................ 91

Figura 5.9 - Dados técnicos da retificadora Junker Quickpoint 5002/20............................. 92 
Figura 5.10 - Dimensões dos corpos-de-prova (colos de 1 a 9) ...............................................93

Figura 5.11 - Sistemas de dressagem retificadora Junker ..................................................94

Figura 5.12 - Sistemas de aplicação de fluido de corte e limpeza do rebolo ...........................95

Figura 5.13 - Sensor de emissão acústica incorporado ao eixo...............................................96

Figura 5.14 - Exemplo de queima acentuada na face plana retificada - resultado obtido na

Configuração 1 de retificação - retificação axial (estratégia B) ............................................97

Figura 5.15 - Eliminação da queima através do ajuste das condições de usinagem ..............98

Figura 5.16 - Alterações no perfil do rebolo visando a redução da área de atrito da região 2

Figura 5.17 - Configuração inicial do sistema de aplicação de fluido de corte - configuração

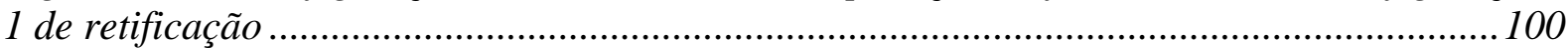

Figura 5.18 - Definição dos trechos principais de usinagem para a determinação dos

avanços de usinagem

Figura 5.19 - Mapas acústicos obtidos durante a usinagem de mergulho - aspecto visual pós-retificação

Figura 5.20 - Mapa acústico e potência elétrica obtida durante a usinagem de mergulho-

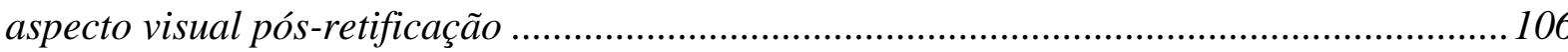

Figura 5.21 - Mapa acústico e aspecto visual da peça obtidos para a estratégia $C$ - 6

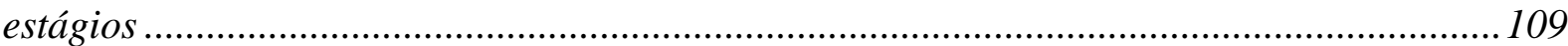

Figura 5.22 - Medição do desgaste do rebolo ..................................................................... 110

Figura 5.23 - Volume de material removido e desgaste na superfície lateral do rebolo em

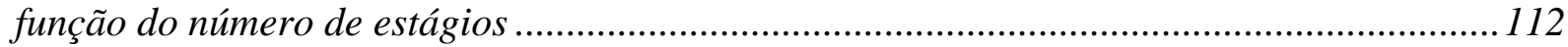

Figura 5.24 - Mapas acústicos para os testes com 1 e 2 estágios ...................................... 113

Figura 5.25 - Mapas acústicos para o teste com 3 estágios................................................ 114

Figura 5.26 - Mapas acústicos para o teste com 6 estágios.............................................. 115

Figura 5.27 Resultados de rugosidade em função do número de estágios ............................117

Figura 5.28 - Dispositivo para medição do desgaste do rebolo............................................. 119

Figura 5.29 - Perfis gerados antes e depois da retificação ............................................... 120

Figura 5.30 - Energia específica de corte - estratégia axial (B), 1 estágio...........................120

Figura 5.31 - Energia específica de corte - estratégia axial múltipla $(C), 3$ estágios.......... 121

Figura 5.32 Rugosidade $R_{z}$ - estratégia axial (B), l estágio ........................................... 122

Figura 5.33 Rugosidade $R_{z}$ - estratégia axial múltipla $(C)$, 3 estágio.................................. 122

Figura 5.34 Aspecto visual da superfície do rebolo após a retificação - estratégia axial (B), 1

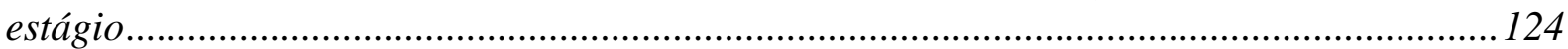

Figura 5.35 Aspecto visual da superfície do rebolo após a retificação - estratégia axial

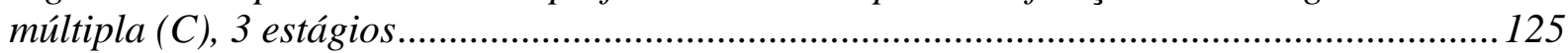

Figura 5.36 Energia de corte específica para as estratégias testadas.................................. 128

Figura 5.37 - Rugosidade $R_{z}$ para as estratégias testadas ................................................. 128

Figura 5.38 - Volumes de material removido por peça $V_{w i}$ ao longo da posição $X_{i}$ para as

estratégias: mergulho, axial e axial múltipla com 3 estágios ............................................... 132

Figura 5.39 - Evolução do perfil desgastado do rebolo em função da estratégia de retificação adotada e do número de peças no lote, para uma relação $G=1000$.................................... 134

Figura 5.40 - Evolução do perfil desgastado em formato de degrau para a estratégia axial e

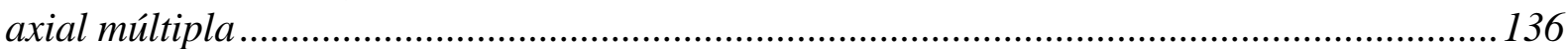

Figura Al - Configuração básica do sistema de mapeamento por EA (Oliveira et al., 2000)

Figura A2 -Procedimento construção do mapa acústico (Oliveira et al., 2000) ...................151

Figura A3 - Mapa acústico da superfície do rebolo utilizando o sistema de mapeamento

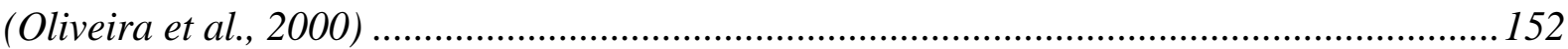

Figura A4 - Mapa obtido durante a operação de retificação, em duas condições distintas. 152 
Figura A5 Perfil da lateral esquerda do rebolo antes e depois da retificação para os testes de

1 estágio com limpeza 155

Figura A6 Perfil da lateral esquerda do rebolo antes e depois da retificação para os testes de

1 estágio sem limpeza 156

Figura A7 Perfil da lateral esquerda do rebolo antes e depois da retificação para os testes de

3 estágios com limpeza... 157

Figura A8 - Perfil da lateral esquerda do rebolo antes e depois da retificação para os testes de 3 estágios sem limpeza. 158 Figura A9 - Inspeção do perfil da lateral esquerda do rebolo para o teste estratégia axial (B), 1 estágio, sem limpeza 159 Figura A10 Perfil da lateral esquerda do rebolo antes e depois da retificação para os teste de mergulho. 160 


\section{LISTA DE TABELAS}

Tabela 3.1 - Área de contado para as estratégias A e B (Merbecks, 2002)

Tabela 4.1 - Condições geométricas de contato e as condições de usinagem utilizadas na

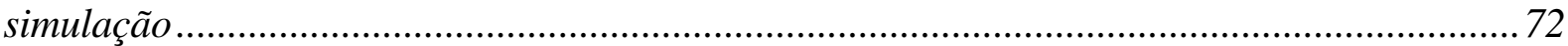

Tabela 5.1 - Trechos de usinagem e as coordenadas $X$ de comutação ................................. 103

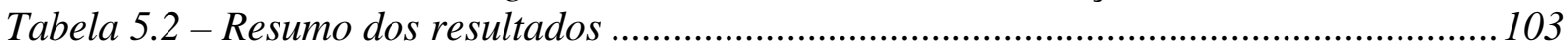

Tabela 5.3 - Tempos de ciclo para a usinagem de mergulho ............................................. 105

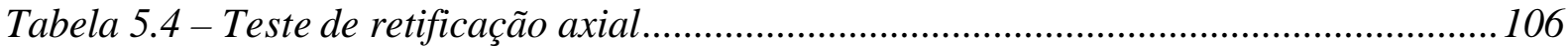

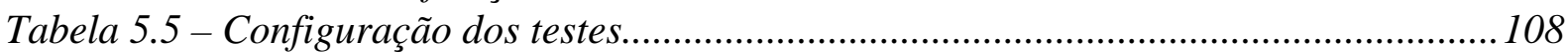

Tabela 5.6 - Metodologia de experimentação para os testes de múltiplos estágios...............111

Tabela 5.7 - Nomenclatura dos ensaios de retificação - estratégias $B$ e C ........................... 119

Tabela 5.8 - Influência do sistema de limpeza nas modificações do perfil do rebolo ............ 126

Tabela 5.9 - Nomenclatura dos ensaios de retificação........................................................... 127

Tabela 5.10 - Influência das diferentes estratégias nas modificações do perfil do rebolo ... 129

Tabela 5.11 - Resumo dos resultados obtidos para as diferentes estratégias de retificação testadas 


\section{LISTA DE SÍMBOLOS}

\section{Símbolos em letra maiúscula}

\begin{tabular}{|c|c|c|}
\hline A & {$[-]$} & fator de proporcionalidade \\
\hline$A_{f}$ & {$\left[\mathrm{~mm}^{2}\right]$} & área frontal \\
\hline $\mathrm{C}$ & {$[\mathrm{mm}]$} & distância entre centros \\
\hline$C^{\prime}$ & {$\left[\mathrm{cal} /{ }^{\circ} \mathrm{C}\right]$} & capacidade térmica do fluido \\
\hline $\mathrm{C}_{\mathrm{r}}$ & {$[-]$} & razão de contração \\
\hline $\mathrm{D}$ & {$[\mathrm{mm}]$} & diâmetro de entrada da tubulação de alimentação \\
\hline $\mathrm{D}_{\mathrm{n}}$ & [mm] & diâmetro de saída \\
\hline $\mathrm{D}_{\mathrm{p}}$ & [mm] & diâmetro do jato ou da tubulação \\
\hline G & {$[-]$} & relação G \\
\hline $\mathrm{G}_{\mathrm{i}}$ & {$[-]$} & relação $\mathrm{G}$ na posição $X_{\mathrm{i}}$ \\
\hline $\mathrm{L}$ & {$[\mu \mathrm{m}]$} & espaçamento médio entre os grãos \\
\hline $\mathrm{N}_{\text {act }}$ & {$[-]$} & número de arestas ativas de corte \\
\hline $\mathrm{N}_{\mathrm{wp}}$ & {$[-]$} & $\begin{array}{l}\text { número de arestas de corte mapeadas sobre um } \\
\text { elemento da superfície da peça }\end{array}$ \\
\hline $\mathrm{O}$ & {$[-]$} & centro do raio $r_{\mathrm{sk}}$ \\
\hline $\mathrm{O}^{\prime}$ & {$[-]$} & centro do raio $r_{s k}$ defasado de $a_{f}$ \\
\hline $\mathrm{P}$ & {$\left[\mathrm{N} / \mathrm{m}^{2}\right]$} & pressão na entrada do bocal \\
\hline$P_{1}$ & {$[-]$} & ponto de contato entre o rebolo e a peça \\
\hline $\mathrm{P}_{\mathrm{e}}$ & {$[\mathrm{W}]$} & potência de usinagem \\
\hline$Q$ & {$\left[\mathrm{~m}^{3} / \mathrm{h}\right]$} & vazão de fluido de corte \\
\hline$Q^{\prime}{ }_{w}$ & {$\left[\mathrm{~mm}^{3} / \mathrm{mm} . \mathrm{s}\right]$} & taxa de remoção de material específica \\
\hline$Q^{\prime}$ w,eff & {$\left[\mathrm{mm}^{3} / \mathrm{mm} . \mathrm{s}\right]$} & taxa de remoção de material específica efetiva \\
\hline Q' ${ }_{\text {w,eff,corr }}$ & {$\left[\mathrm{mm}^{3} / \mathrm{mm} . \mathrm{s}\right]$} & $\begin{array}{l}\text { taxa de remoção de material específica efetiva } \\
\text { corrigida }\end{array}$ \\
\hline$Q^{\prime}$ w,eff,i & {$\left[\mathrm{mm}^{3} / \mathrm{mm} . \mathrm{s}\right]$} & $\begin{array}{l}\text { taxa de remoção de material específica efetiva na } \\
\text { posição Xi }\end{array}$ \\
\hline $\mathrm{Q}_{\mathrm{w}}$ & {$\left[\mathrm{mm}^{3} / \mathrm{s}\right]$} & taxa de remoção de material \\
\hline $\operatorname{Re}$ & [-] & número de Reynolds \\
\hline $\mathrm{S}_{\mathrm{d}}$ & {$[\mathrm{mm} / \mathrm{rot}]$} & passo de dressagem \\
\hline SM & [mm] & sobremetal no espelho \\
\hline $\mathrm{U}$ & {$[-]$} & número de retificações consecutivas \\
\hline $\mathrm{V}^{*}$ & {$[-]$} & razão de velocidades \\
\hline $\mathrm{V}_{\mathrm{w}, \mathrm{corr}, \mathrm{i}}$ & {$\left[\mathrm{mm}^{3} / \mathrm{mm}\right]$} & $\begin{array}{l}\text { volume de material removido específico corrigido na } \\
\text { posição } X_{i}\end{array}$ \\
\hline$V^{\prime}{ }_{\text {wi }}$ & {$\left[\mathrm{mm}^{3} / \mathrm{mm}\right]$} & $\begin{array}{l}\text { volume de material removido específico na posição } \\
X_{\mathrm{i}}\end{array}$ \\
\hline $\mathrm{V}_{\mathrm{s}}$ & {$\left[\mathrm{mm}^{3}\right]$} & volume de rebolo desgastado \\
\hline
\end{tabular}




$\begin{array}{ll}\mathrm{V}_{\mathrm{si}} & {\left[\mathrm{mm}^{3}\right]} \\ \mathrm{V}_{\mathrm{w}} & {\left[\mathrm{mm}^{3}\right]} \\ \mathrm{X}_{0} & {[\mathrm{~mm}]} \\ \mathrm{X}_{\text {af min }} & {[-]} \\ \mathrm{X}_{\mathrm{i}} & {[\mathrm{mm}]}\end{array}$

\section{Símbolos em letra minúscula}

\begin{tabular}{|c|c|}
\hline$a_{d}$ & {$[\mu \mathrm{m}]$} \\
\hline$a_{e}$ & {$[\mathrm{~mm}]$} \\
\hline$a_{e, e f f}$ & [mm] \\
\hline$a_{e, e f f, c o r r, i}$ & {$[\mu \mathrm{m}]$} \\
\hline$a_{e, e f f, i}$ & {$[\mu \mathrm{m}]$} \\
\hline$a_{f}$ & {$[\mathrm{~mm} / \mathrm{rot}]$} \\
\hline$a_{f, c o r r, i}$ & {$[\mathrm{~mm} / \mathrm{rot}]$} \\
\hline$a_{f, c r i t, \text { corr,i }}$ & {$[\mathrm{mm} / \mathrm{rot}]$} \\
\hline$a_{f \min }$ & {$[\mathrm{mm} / \mathrm{rot}]$} \\
\hline b & {$[-]$} \\
\hline$b_{d}$ & [mm] \\
\hline$b_{h}$ & {$[\mathrm{~mm}]$} \\
\hline$b_{s}$ & [mm] \\
\hline $\mathrm{b}_{\mathrm{s}, \mathrm{z}}$ & [mm] \\
\hline$d_{s}$ & [mm] \\
\hline $\mathrm{d}_{\mathrm{w}}$ & [mm] \\
\hline $\mathrm{d}_{\mathrm{w} 1}$ & [mm] \\
\hline $\mathrm{d}_{\mathrm{w} 2}$ & [mm] \\
\hline$f_{j}$ & {$[-]$} \\
\hline h & [mm] \\
\hline $\mathrm{h}_{\text {máx }}$ & {$[\mu \mathrm{m}]$} \\
\hline j & {$[-]$} \\
\hline $1_{c}$ & {$[\mu \mathrm{m}]$} \\
\hline $\mathrm{n}_{\mathrm{w}}$ & [rpm] \\
\hline q & {$[-]$} \\
\hline $\mathrm{q}_{\mathrm{d}}$ & {$[-]$} \\
\hline $\mathrm{r}_{0 \mathrm{i}}$ & [mm] \\
\hline $\mathrm{r}_{\mathrm{mi}}$ & [mm] \\
\hline $\mathrm{r}_{\text {sidesg }}$ & [mm] \\
\hline $\mathrm{r}_{\mathrm{sk}}$ & {$[\mathrm{mm}]$} \\
\hline$r_{w i}$ & [mm] \\
\hline$t_{c}$ & [s] \\
\hline$v_{f a}$ & {$[\mathrm{~mm} / \mathrm{min}]$} \\
\hline$V_{f r}$ & {$[\mathrm{~mm} / \mathrm{min}]$} \\
\hline$v_{j}$ & {$[\mathrm{~m} / \mathrm{s}]$} \\
\hline $\mathrm{v}_{\mathrm{r}}$ & {$[\mathrm{m} / \mathrm{s}]$} \\
\hline $\mathrm{v}_{\mathrm{s}}$ & {$[\mathrm{m} / \mathrm{s}]$} \\
\hline $\mathrm{v}_{\mathrm{s} 0}$ & {$[\mathrm{~m} / \mathrm{s}]$} \\
\hline$v_{\mathrm{si}}$ & {$[\mathrm{m} / \mathrm{s}]$} \\
\hline $\mathrm{v}_{\mathrm{t}}$ & {$[\mathrm{mm} / \mathrm{min}]$} \\
\hline $\mathrm{V}_{\mathrm{w}}$ & {$[\mathrm{m} / \mathrm{s}]$} \\
\hline
\end{tabular}

volume de rebolo desgastado na posição $X_{i}$ volume de material removido posição $X$ do perfil referente a lateral do rebolo posição $X_{i}$ para $a_{f}=a_{f m i n}$ posição em $\mathrm{X}$ de um ponto qualquer ao longo do perfil do rebolo

profundidade de dressagem

penetração radial

penetração de corte efetiva

penetração de corte efetiva corrigida na posição $X_{i}$

penetração de corte efetiva na posição $X_{i}$

avanço axial por volta

avanço axial corrigido na posição $X_{i}$

avanço axial crítico, corrigido na posição $X_{i}$

avanço axial mínimo

parâmetro

largura de atuação do disco dressador

altura do segmento do rebolo

largura do rebolo

largura cilíndrica do rebolo

diâmetro externo do rebolo

diâmetro da peça

diâmetro interno do colo

diâmetro externo do colo

fator de correção temporal

distância entre a saída do bocal e o rebolo

espessura máxima do cavaco

número de peças retificadas

comprimento de contato

rotação da peça

relação de velocidades

razão de esmagamento

raio original do perfil do rebolo na posição $X_{i}$

raio médio da peça na posição $X_{i}$

raio do perfil desgastado do rebolo na posição $X_{i}$

raio de canto do rebolo

raio da peça na posição $X_{i}$

tempo de corte

velocidade de avanço axial

velocidade de mergulho

velocidade de saída do jato de fluido de corte

velocidade periférica do dressador

velocidade de corte

velocidade de corte para a posição $\mathrm{X}_{0}$

velocidade de corte para a posição $X_{i}$

velocidade de dressagem

velocidade da peça 


$\begin{array}{lll}\mathrm{V}_{\mathrm{wi}} & {[\mathrm{m} / \mathrm{s}]} & \text { velocidade da peça na posição } \mathrm{X}_{\mathrm{i}} \\ \mathrm{z} & {[\mathrm{mm}]} & \text { sobremetal }\end{array}$

\section{Símbolos utilizando o alfabeto grego}

\begin{tabular}{|c|c|c|}
\hline$\Phi_{\mathrm{i}}$ & {$\left[{ }^{0}\right]$} & ângulo para a penetração de corte efetiva em Xi \\
\hline$\Delta \theta$ & {$\left[{ }^{\circ} \mathrm{C}\right]$} & máximo aumento tolerável de temperatura do fluido \\
\hline$\alpha$ & {$\left[{ }^{\mathrm{o}}\right]$} & ângulo de entrada da região cônica \\
\hline$\alpha_{i}$ & {$\left[{ }^{0}\right]$} & ângulo de engajamento peça-rebolo \\
\hline$\beta$ & {$\left[{ }^{0}\right]$} & ângulo de saída \\
\hline$\beta_{\mathrm{i}}$ & {$\left[{ }^{0}\right]$} & ângulo de posição do raio externo da peça \\
\hline$\delta$ & {$\left[{ }^{0}\right]$} & ângulo de montagem \\
\hline$\delta_{\text {crit }}$ & {$\left[{ }^{0}\right]$} & ângulo para a penetração de corte para $\mathrm{Xi}=\mathrm{a}_{\mathrm{f}}$ \\
\hline$\delta_{\text {crit, corr }}$ & {$\left[{ }^{0}\right]$} & ângulo para a penetração de corte para $\mathrm{Xi}=\mathrm{a}_{\text {fcorr }}$ \\
\hline$\delta_{1}$ & {$\left[{ }^{0}\right]$} & $\begin{array}{l}\text { ângulo defasado de } \mathrm{a}_{\mathrm{f}} \text { para a penetração de corte } \\
\text { efetiva em Xi }\end{array}$ \\
\hline$\gamma$ & {$\left[{ }^{0}\right]$} & ângulo de ataque \\
\hline$\gamma_{\mathrm{i}}$ & {$\left[{ }^{0}\right]$} & ângulo complementar \\
\hline$\eta$ & [\%] & eficiência do bocal \\
\hline$\varphi$ & {$\left[{ }^{\mathrm{O}}\right]$} & ângulo de rotação do rebolo em torno do eixo X \\
\hline$v$ & {$\left[\mathrm{~m}^{2} / \mathrm{s}\right]$} & viscosidade cinemática do fluido \\
\hline$\theta_{\mathrm{i}}$ & {$\left[{ }^{\circ}\right]$} & ângulo de posição do raio externo do rebolo \\
\hline$\rho$ & {$\left[\mathrm{kg} / \mathrm{m}^{3}\right]$} & densidade do fluido \\
\hline$\omega_{\mathrm{s}}$ & {$\left[{ }^{\mathrm{O}}\right]$} & rotação angular do rebolo \\
\hline$\omega_{\mathrm{w}}$ & {$\left[{ }^{0}\right]$} & rotação angular da peça \\
\hline$\xi$ & {$\left[{ }^{0}\right]$} & ângulo de hélice \\
\hline
\end{tabular}


DEDICATÓRIA ........................................................................................................................ I

AGRADECIMENTOS .......................................................................................................................II

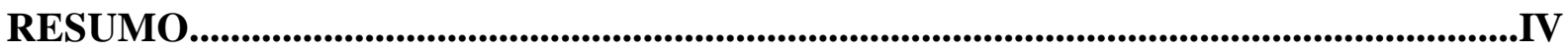

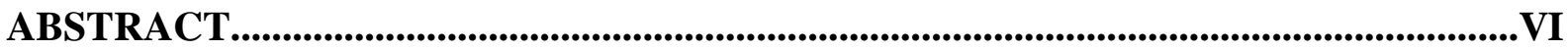

LISTA DE FIGURAS ....................................................................................................VIII

LISTA DE TABELAS ........................................................................................................XII

LISTA DE SÍMBOLOS ..........................................................................................................XIII

1. INTRODUÇÃO......................................................................................................................................1

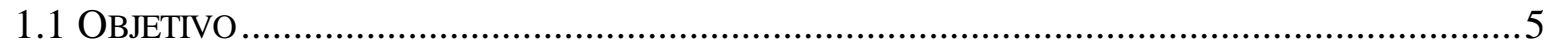

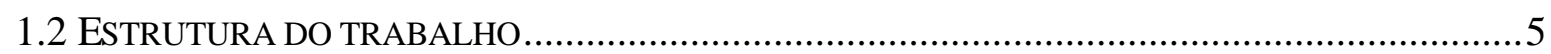

\section{REQUISITOS TÉCNICOS PARA A RETIFICAÇÃO EM ALTA VELOCIDADE} COM REBOLOS DE CBN .....................................................................................................7

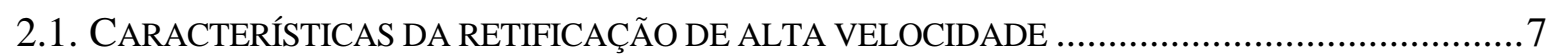

2.2. CARACTERÍSTICAS TÉCNICAS DOS REBOLOS DE CBN

2.3. OS FLUIDOS DE CORTE NA RETIFICAÇÃO DE ALTA VELOCIDADE ...................................... 19

2.4. SISTEMAS DE LIMPEZA A ALTA PRESSÃO DA SUPERFÍCIE DO REBOLO. .............................27

3. RETIFICAÇÃO CILÍNDRICA EXTERNA DE FORMA..............................................31

3.1 OPERAÇÕES CONVENCIONAIS DE RETIFICAÇÃO CILÍNDRICA EXTERNA …..........................33

3.2 OPERAÇÕES DE RETIFICAÇÃO CILÍNDRICA EXTERNA DE FORMA.........................................

3.3 FUNDAMENTOS DA RETIFICAÇÃO CILÍNDRICA EXTERNA DE FORMA DE ALTO DESEMPENHO

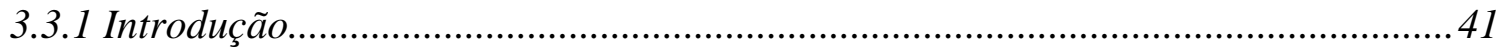

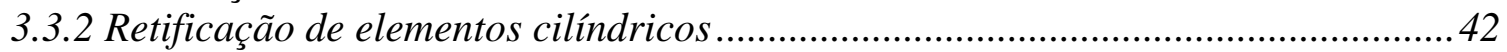

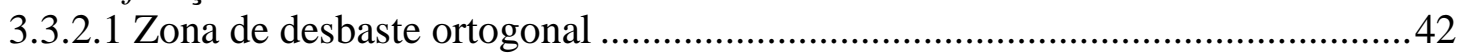

3.3.2.2 Zona de desbaste cônica ...............................................................................4 44

3.3.2.3 Zona de desbaste com raio de arredondamento ...........................................47

3.4 RETIFICAÇÃO CILÍNDRICA EXTERNA DE FORMA DE ALTO DESEMPENHO NA RETIFICAÇÃO

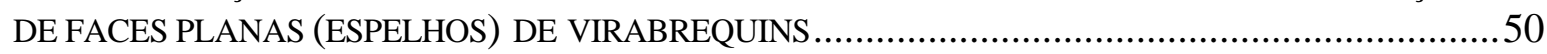

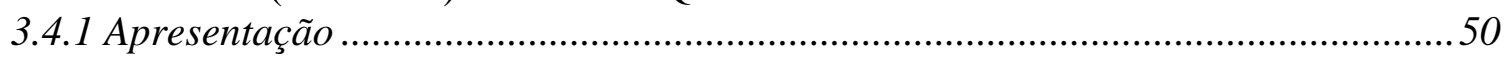

4. ANÁLISE TEÓRICA E MODELOS SOBRE A OPERAÇÃO DE RETIFICAÇÃo CILÍNDRICA EXTERNA DE FORMA APLICADA À RETIFICAÇÃO DE FACES PLANAS COM EIXOS PARALELOS .................................................................................60

4.1. ASPECTOS TEÓRICOS DA RETIFICAÇÃO DE MERGU LHO - ESTRATÉGIA A..........................60

4.2. ASPECTOS TEÓRICOS DA RETIFICAÇÃO AXIAL - ESTRATÉGIA B …...................................62

4.2.1. Modelo geométrico considerando um rebolo com zona de desbaste com raio de

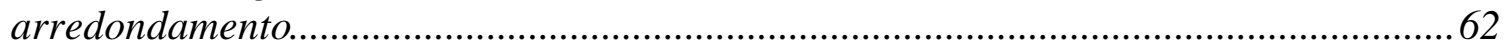

4.2.2. Modelo para o cálculo da taxa de remoção específica de material e volume específico de material para a retificação axial (estratégia B) ..........................................67

4.3 ESTRATÉGIA DE RETIFICAÇÃO AXIAL MÚLTIPLA- ESTRATÉGIA C -................................75

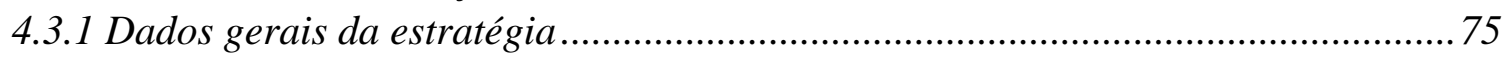

4.4. CONSIDERAÇÕES SOBRE AS CARACTERÍSTICAS DAS TAXAS DE REMOÇÃO ESPECÍFICA DE MATERIAL PARA ESTRATÉGIA DE MERGULHO, AXIAL E AXIAL MÚLTIPLA ..............................79 


\section{ANÁLISE EXPERIMENTAL DA OPERAÇÃO DE RETIFICAÇÃO CILÍNDRICA EXTERNA DE FORMA APLICADA À RETIFICAÇÃO DE FACES PLANAS COM EIXOS PARALELOS}

5.1 CONFIGURAÇÃO 1 DE RETIFICAÇÃO.

5.2. CONFIGURAÇÃO 2 DE RETIFICAÇÃO

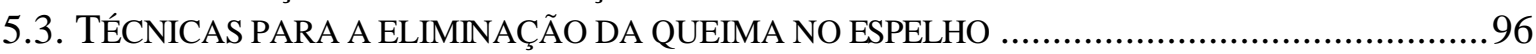

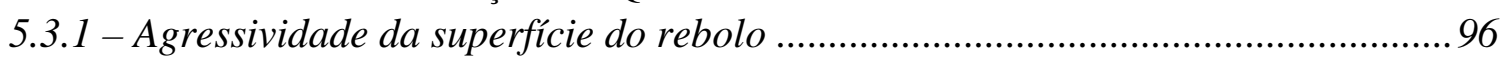

5.3.2 - Modificações no perfil do rebolo.................................................................................99

5.3.3 - Eficiência do sistema de aplicação de fluido de corte e limpeza do rebolo ........ 100

5.4. RETIFICAÇÃO DE FACES PLANAS EMPREGANDO-SE A ESTRATÉGIA A - MERGULHO ........ 102

5.5. RETIFICAÇÃO DE FACES PLANAS EMPREGANDO-SE A ESTRATÉGIA B - RETIFICAÇÃO

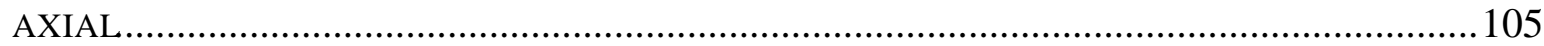

5.6. RETIFICAÇÃO DE FACES PLANAS EMPREGANDO-SE A ESTRATÉGIAC - RETIFICAÇÃO AXIAL MÚLTIPLA

5.6.1 Análise da influência da introdução de diferentes estágios de retificação para a estratégia $C$ - axial múltipla

5.6.2 Análise da influência do sistema de limpeza a alta pressão da superfície do rebolo para a estratégia $C$ - axial múltipla.

5.7. ANÁLISE COMPARATIVA ENTRE AS ESTRATÉGIAS DE MERGULHO, AXIAL E AXIAL MÚLTIPLA 126

5.8. SIMULAÇÃO DO PERFIL DESGASTADO DO REBOLO PARA AS ESTRATÉGIAS DE MERGULHO, AXIAL E AXIAL MÚLTIPLA 130 5.9. QUADRO RESUMO COMPARATIVO DOS RESULTADOS OBTIDOS PARA AS ESTRATÉGIAS DE RETIFICAÇÃO TESTADAS.

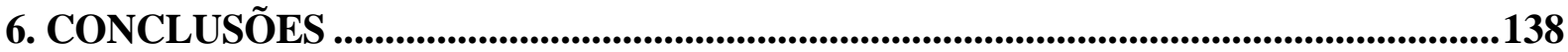

7. SUGESTÕES PARA TRABALHOS FUTUROS ............................................................140

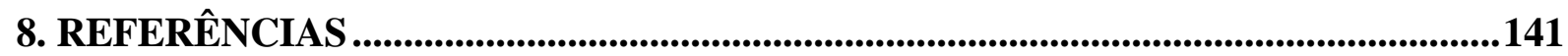

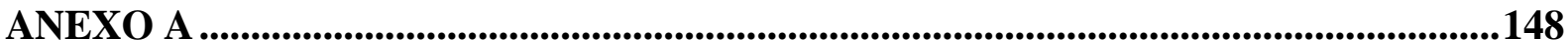

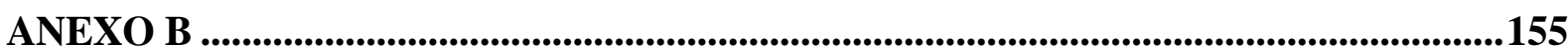




\section{INTRODUÇÃO}

Durante os últimos anos, a racionalização da produção através da otimização individual dos processos de fabricação teve como objetivo a redução da seqüência produtiva. Esta se inicia na concepção teórica do produto e encerra-se nos procedimentos para seu descarte (Klocke e Saxler, 1997 apud Hegener, 1999). O potencial de redução encontra-se na aglutinação de diferentes estágios de fabricação e na substituição de outros.

Um outro impulsionador sustentável para o desenvolvimento dos processos de fabricação tem sido a demanda crescente por flexibilidade de produção, resultado da diversidade de componentes a serem produzidos, menor prazo de entrega e as constantes alterações das necessidades dos mercados. Todavia o ganho de flexibilidade através de reduções na qualidade e na produtividade não é desejado (Klocke e Saxler, 1997 apud Hegener, 1999).

De forma complementar, a inovação se tornou o conceito-chave da modernidade industrial, permitindo a obtenção de vantagens competitivas e resultados industriais sustentáveis (Klocke, Pfeifer e Weck, 1999 apud Gerent, 2001). Na cadeia produtiva, de forma geral, a retificação surge como o processo final, sendo responsável por assegurar a obtenção das qualidades dimensional e de forma do componente usinado e ao mesmo tempo corrigir possíveis não-conformidades ocorridas nas operações anteriores. Muitas vezes, limitações técnicas do processo não permitem a correção destas conformidades ou mesmo a redução da seqüência produtiva. 
Neste âmbito, a síntese em laboratório do nitreto de boro cúbico (CBN), no final dos anos 60 iniciou um processo de inovações, partindo-se da utilização industrial deste novo elemento como matéria-prima de grãos abrasivos (König e Klocke, 1996 e Meyer, 1997 apud Gerent, 2001). Na seqüência de desenvolvimento, com os novos grãos, denominados superabrasivos, surgiram novas tecnologias de dressagem, novos ligantes para os rebolos de CBN bem como novas máquinas-ferramenta. Com a introdução dos rebolos de CBN foram desenvolvidas as bases para a tecnologia de retificação com elevadas axas de remoção e em altas velocidades de corte. Favorecida por este campo de desenvolvimento e pela introdução de novas tecnologias de fabricação Near-Net-Shape, a retificação passou de um mero processo final na cadeia produtiva para um processo intermediário, dividindo o campo de aplicação com processos de torneamento e fresamento (Meyer, 1997 apud Gerent, 2001).

A inovação gerada pela introdução dos rebolos de CBN, somada à necessidade de uma maior flexibilidade da produção e uma redução na cadeia de fabricação de elementos cilíndricos, estabeleceu as bases para o desenvolvimento, a partir de 1985, da retificação cilíndrica externa de forma (Figura 1.1), uma variante do processo de retificação cilíndrica externa de passagem.

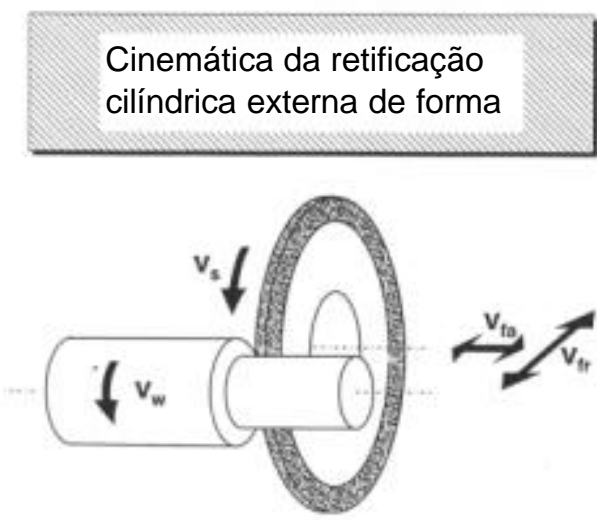

Figura 1.1 - Cinemática da retificação cilíndrica externa de forma (Adaptado de König e Klocke, 1996) 
Através da interpolação via comando numérico do avanço principal na direção axial e do avanço adjacente na direção radial, o objetivo principal desta variante de retificação é a usinagem completa de diferentes geometrias com eixo de rotação simétrico, em uma única fixação, removendo-se todo o sobremetal num passe único. Diferentes perfis de peça podem ser retificados, sendo estes: cilíndricos, cônicos, com chanfros, com faces paralelas e com perfis côncavos e convexos. Quando a velocidade de avanço radial é igual a zero, a cinemática do movimento é igual a da retificação cilíndrica externa de passagem (König e Klocke, 1996).

Comparando-se com o processo de retificação cilíndrica externa de perfil, na qual o perfil de um rebolo é reproduzido sobre a peça, a principal vantagem da retificação cilíndrica externa de forma é que um mesmo perfil de rebolo pode retificar diferentes contornos de peças. Devido a sua grande flexibilidade, esta variante de retificação é utilizada especialmente em lotes pequenos (König e Klocke, 1996).

Dentre os elementos de um perfil com eixo rotação simétrico, a retificação das faces planas representa um dos desafios a serem vencidos, já que a dos demais elementos do perfil assemelha-se à cinemática de uma retificação cilíndrica externa de passagem. Nesta última, os mecanismos de desgaste do rebolo e a influência dos parâmetros de entrada do processo (perfil do rebolo, ângulo de entrada, avanço axial, dentre outras) nas variáveis de saída do processo (forças de retificação e rugosidade) já foram objetos de estudo e as suas correlações identificadas (Opitz e Frank, 1961, Verkerk, 1976 apud Hegener, 1999). As principais limitações da retificação das faces planas estão relacionadas com a obtenção de superfícies dentro das tolerâncias geométricas e de forma, isenta de danos térmicos e que possibilitem o menor desgaste do rebolo na execução desta operação. De forma esquemática, a Figura 1.2 apresenta diferentes configurações de retificação cilíndrica para uma face plana. Os principais elementos geométricos deste perfil são apresentados dentre os quais se destaca o sobremetal a 
ser removido, o qual tem papel fundamental no comportamento do processo. Um dos exemplos de utilização de retificação de face plana é a retificação dos espelhos de um virabrequim. Outro exemplo é a retificação da face superior de válvulas de motores que tem sido feita com eixos do rebolo e peça paralelos e ferramentas de CBN em altas velocidades.

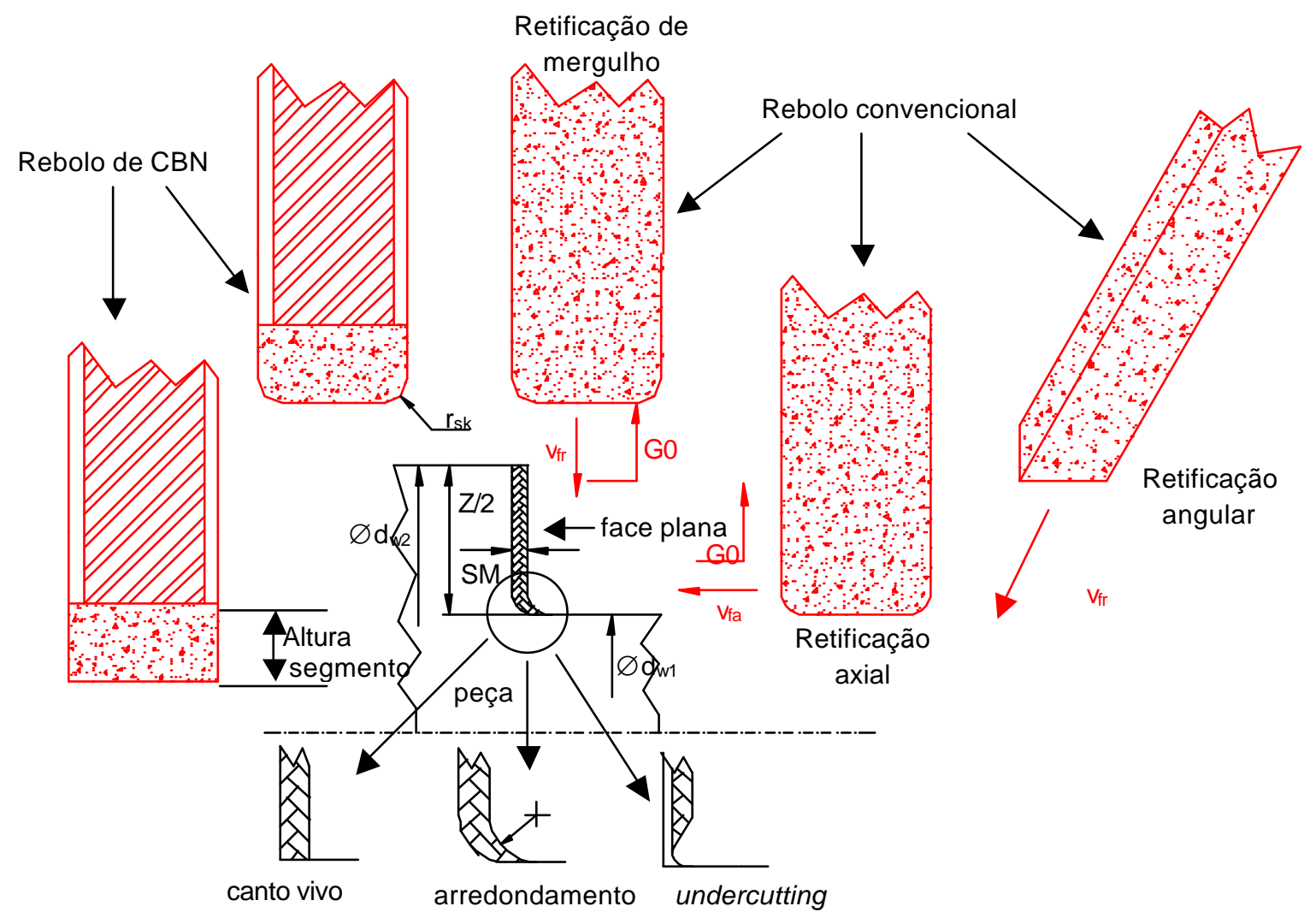

Figura 1.2 - Elementos de retificação de faces planas

Os principais problemas decorrentes da retificação de faces planas estão relacionados às elevadas taxas de remoção nas extremidades dos rebolos, a baixa eficiência de refrigeração e lubrificação na interface rebolo-face plana e a elevada área de contato, o que aumenta a geração de calor, levando a maior incidência de danos térmicos. Adicionalmente, a geometria do cavaco gerado leva a uma maior tendência ao entupimento das porosidades (empastamento) na superfície do rebolo.

Muitos dos resultados obtidos baseiam-se em valores práticos. A influência das diferentes variantes de retificação e de seus parâmetros de entrada nas variáveis de saída é 
conhecida apenas de forma pontual. Torna-se necessário estabelecer o embasamento teórico que permita a adoção da estratégia mais adequada.

\subsection{Objetivo}

O objetivo deste trabalho é a realização de um estudo de aplicação de rebolo de CBN vitrificado na retificação de faces planas em operações cilíndricas de eixos paralelos. Este englobará a determinação de diferentes estratégias de retificação, sendo que os aspectos teóricos de cada estratégia serão determinados. Testes comparativos serão realizados, considerando-se os requisitos atuais para a retificação a alta velocidade de CBN, em termos de dressagem da ferramenta, sistema de aplicação de fluidos de corte e limpeza do rebolo, cuja determinação fazem parte do escopo deste trabalho. As vantagens e desvantagens de cada estratégia serão determinadas, permitindo-se a identificação daquela mais adequada.

\subsection{Estrutura do trabalho}

A seguir faz-se uma breve apresentação da estrutura deste trabalho.

- No capítulo 2 são apresentados os requisitos técnicos para a retificação em alta velocidade utilizando-se rebolos de $\mathrm{CBN}$, destacando-se as características técnicas necessárias para a utilização eficaz dos rebolos de CBN, dos fluidos de corte e dos sistemas de limpeza a alta pressão da superfície do rebolo.

- No capítulo 3 são definidos os aspectos teóricos e fundamentos da operação de retificação cilíndrica externa de forma.

- O capítulo 4 engloba a análise teórica e os modelos sobre a retificação cilíndrica externa de forma aplicada à retificação de faces planas com eixos paralelos. São definidas as estratégias de retificação atuais e a desenvolvida neste trabalho. Os 
aspectos teóricos de cada estratégia proposta são apresentados, bem como o modelo para o cálculo da taxa de remoção específica de material.

- O capítulo 5 apresenta a análise experimental da operação de retificação cilíndrica externa de forma aplicada à retificação de faces planas com eixos paralelos. A metodologia utilizada é descrita e os resultados obtidos nos testes comparativos entre as estratégias de retificação são apresentados. São analisandos os aspectos particulares das estratégias e o desempenho comparativo entre as mesmas.

- No capítulo 6 são apresentadas as conclusões deste trabalho.

- No capítulo 7 são apresentadas as sugestões para trabalhos futuros.

- No capítulo 8 são apresentadas as referências bibliográficas. 


\section{REQUISITOS TÉCNICOS PARA A RETIFICAÇÃO EM ALTA VELOCIDADE COM REBOLOS DE CBN}

\subsection{Características da retificação de alta velocidade}

No processo de retificação, a velocidade de corte do rebolo tem grande influência sobre o fenômeno de corte. Na Europa e no Japão, muitos estudos foram realizados no sentido de se aumentar a velocidade de corte dos rebolos para $120 \mathrm{~m} / \mathrm{s}$ e até $300 \mathrm{~m} / \mathrm{s}$. Porém, nos EUA, conforme apresentado por Shih et al. (1998), devido às normas de segurança e a não disponibilidade de ferramentas e máquinas apropriadas, a velocidade limite dos trabalhos nessa área manteve-se em torno de $120 \mathrm{~m} / \mathrm{s}$.

Entretanto, o benefício trazido pelo aumento da velocidade de corte é evidente, pois, segundo Shih et al. (1998), com o aumento da velocidade ocorre uma redução da espessura teórica do cavaco, e, conseqüentemente, um aumento na taxa de remoção de material. Outro benefício é a redução das forças por grão, o que faz com que a pressão de contato sobre o mesmo seja menor e proporcione um aumento da relação $G$ (relação entre o volume removido de material e o volume de rebolo gasto).

Outro aspecto muito importante na retificação é quanto ao problema da dissipação do calor gerado no processo. Segundo Tawakoli (1993), o aumento da velocidade de corte acima de $100 \mathrm{~m} / \mathrm{s}$ provoca a redução da temperatura da superfície da peça, conforme apresentado na Figura 2.1 . 


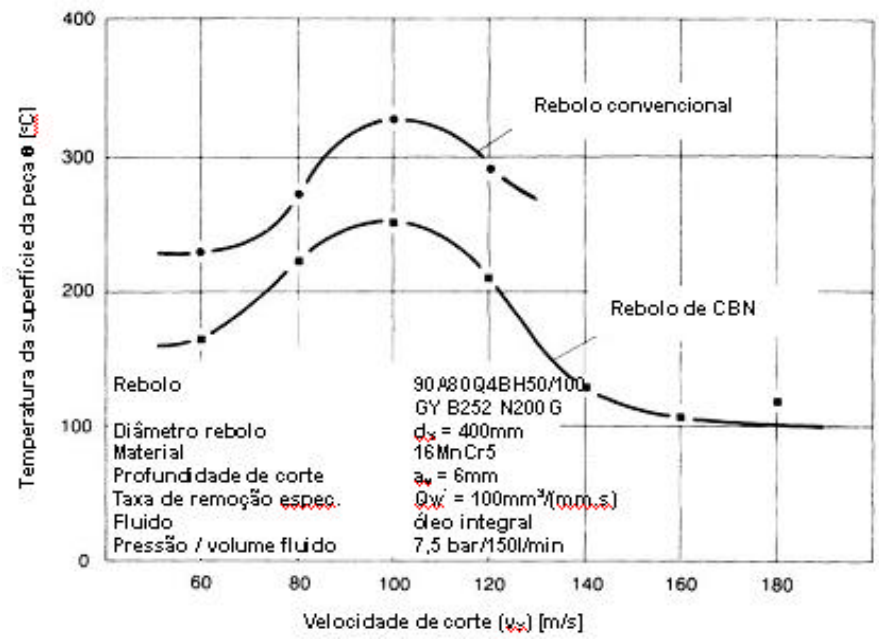

Figura 2.1 - Temperatura da superfície da peça em função da velocidade periférica de rebolos CBN e óxido de alumínio (adaptado de Tawakoli, 1993)

Com a redução da temperatura da peça, reduz-se a probabilidade do aparecimento de danos térmicos e a queima da mesma. A explicação mais plausível para esse fenômeno é que o corte de material acontece tão rapidamente que não há tempo suficiente para que o calor gerado se propague para a peça. Neste caso, a maior parte do calor é dissipada pelos grãos abrasivos e pelos cavacos removidos.

Com o aumento da velocidade periférica do rebolo, alguns malefícios são inevitáveis. O primeiro problema resultante deste fato é que os rebolos vitrificados convencionais não permitem velocidades periféricas acima de $120 \mathrm{~m} / \mathrm{s}$. Porém aplicações acima de $100 \mathrm{~m} / \mathrm{s}$ são consideradas especiais e, portanto, o custo dessas ferramentas é muito alto. Outro problema é que acima de $80 \mathrm{~m} / \mathrm{s}$ os rebolos convencionais apresentam um desgaste muito acentuado, ficando cegos rapidamente. Isso leva a um incremento das forças de retificação, gerando o aumento da temperatura da peça e, portanto, o risco de surgirem danos térmicos e queimas superficiais.

Outros fatores a serem considerados com o aumento da velocidade de corte são a solicitação mecânica da estrutura dos rebolos a esta velocidade e a variação dimensional de seu corpo, resultados da ação das forças inerciais. Diversas pesquisas vêm sendo realizadas nesta área, as quais têm levado ao dimensionamento de novos corpos, e testes de resistência 
mecânica dos rebolos. Nestes testes, os rebolos são submetidos a rotações de trabalho, aplicando-se a esta rotação um fator majorador, o qual depende das descrições contidas nas normas seguidas por cada fabricante. Na Figura 2.2 é apresentada a simulação por elementos finitos da distribuição de tensões num rebolo segmentado de CBN, submetido a uma determinada rotação de trabalho.

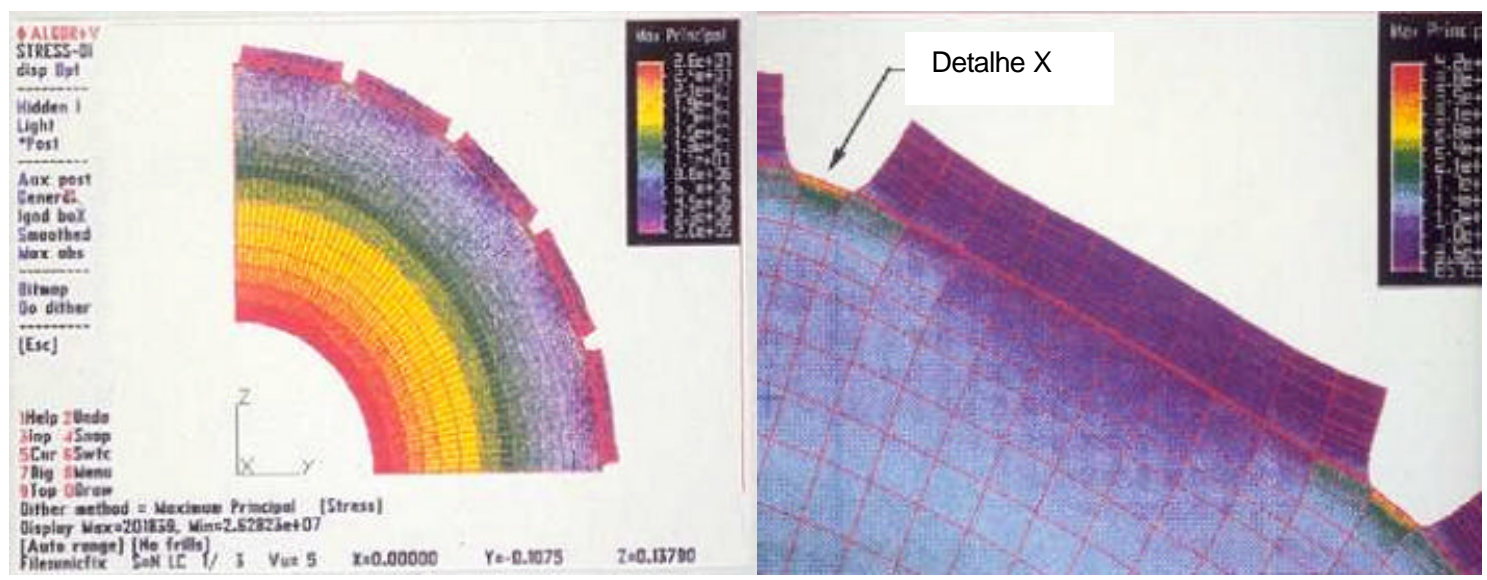

Figura 2.2 - Distribuição de tensões em um rebolo de CBN segmentado (adaptado de Hitchiner, 2001)

A Figura 2.3 apresenta um exemplo das variações nas dimensões interna e externa de corpos rebolos, quando submetidos a velocidades de corte superiores a $120 \mathrm{~m} / \mathrm{s}$. A otimização do projeto do corpo, dimensionando-o para aplicações de alta velocidade leva a redução de sua variação dimensional. Estas variações devem ser consideradas quando do projeto de novos rebolos e flanges para retificação de alta velocidade.
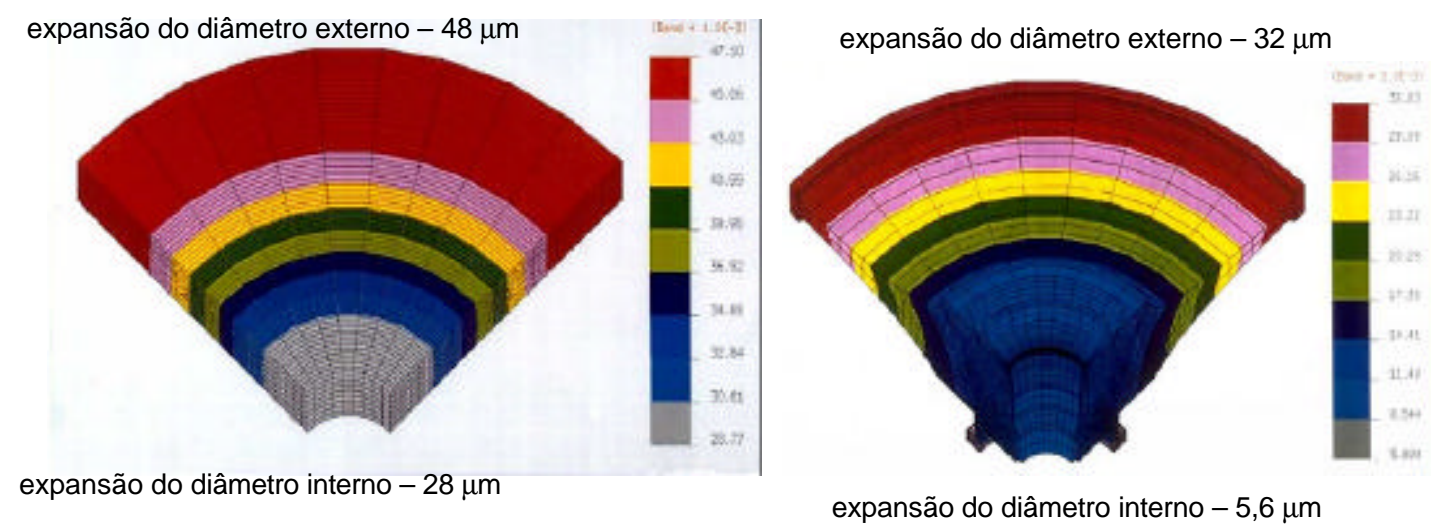

Figura 2.3 - Variações dimensionais na estrutura do flange (a esquerda - modelo convencional, a direita modelo otimizado) (adaptado de Hitchiner, 2001) 
Ao contrário dos rebolos convencionais, os quais são confeccionados numa estrutura única, os rebolos de $\mathrm{CBN}$ segmentados podem ser utilizados em velocidades de corte superiores a $120 \mathrm{~m} / \mathrm{s}$. Como exemplo, os rebolos de CBN com ligante vitrificado possuem, na maioria dos casos, um corpo metálico no qual os segmentos pré-moldados são colados. Assim, materiais específicos de maior resistência podem ser utilizados na confecção deste corpo e sistemas de fixação mais eficientes podem ser utilizados na colagem dos segmentos. A espessura dos segmentos pode ser então dimensionada de acordo com a máxima velocidade de corte, evitando-se a fratura.

\subsection{Características técnicas dos rebolos de CBN}

Diferentemente do que ocorre com os rebolos convencionais, atualmente, em muitas operações de retificação em alta velocidade, o CBN é aplicado com grande sucesso. De acordo com Tönshoff e Falkenberg (1998), nos últimos anos, com o surgimento dos rebolos de CBN de alto desempenho, aliado ao desenvolvimento de novos equipamentos, máquinas e comandos, criou-se condições para a otimização dos processos de retificação. Tal sucesso, porém, deve-se às excelentes propriedades físicas, químicas e mecânicas apresentadas pelos grãos de CBN, destacando-se a não reação química com materiais ferrosos. Segundo Carius (1999), os grãos abrasivos de CBN apresentam diversas vantagens sobre os abrasivos convencionais, tais como maior dureza, maior resistência à abrasão e à fratura e maior condutividade térmica. A Figura 2.4 mostra algumas propriedades dos grãos CBN comparadas com as de outros materiais. 

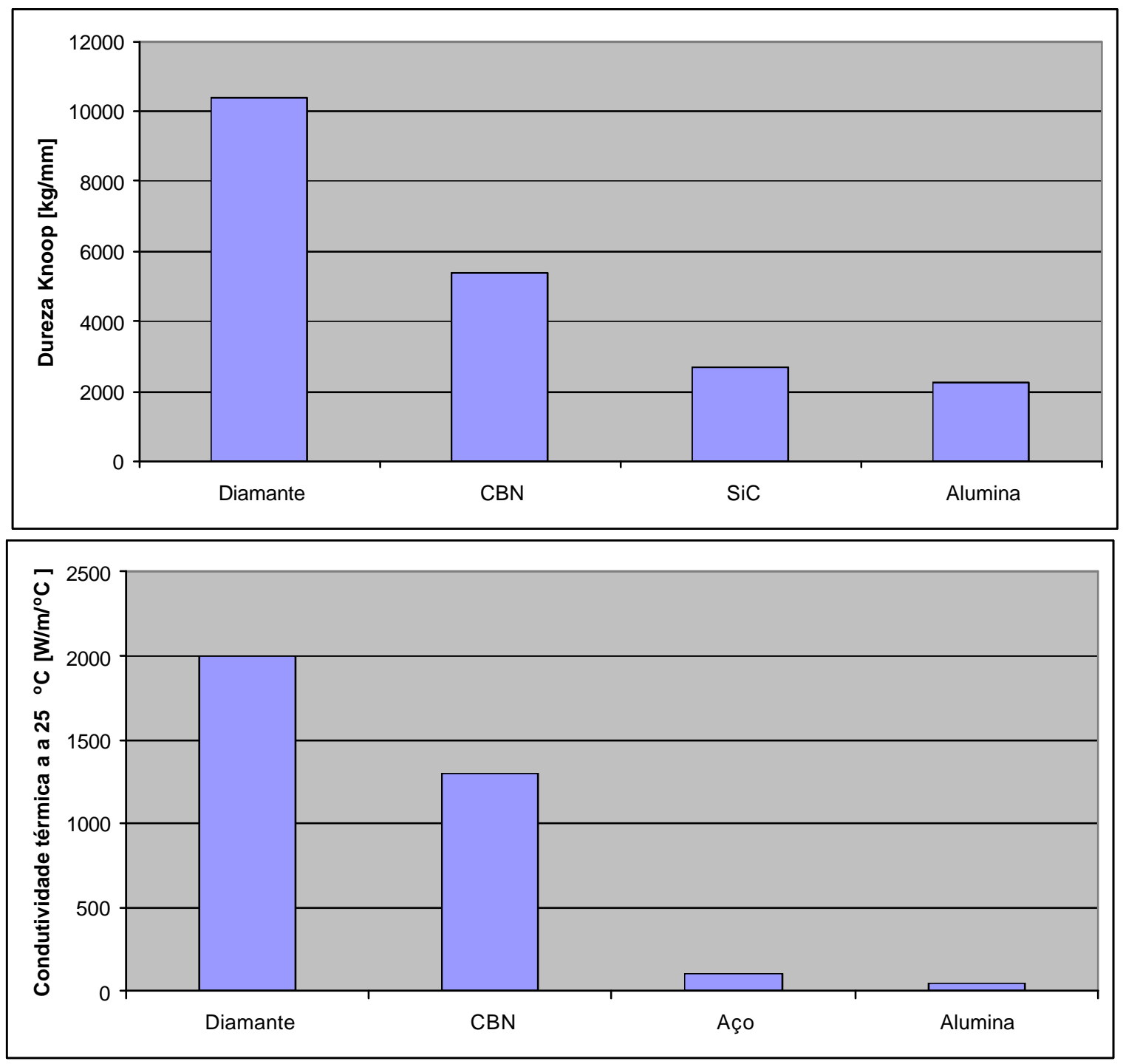

Figura 2.4 - Propriedades dos grãos convencionais e superabrasivos (Hitchiner 2001)

Segundo Malkin (1985), os danos térmicos gerados quando da retificação com rebolos superabrasivos de CBN são, geralmente, inferiores aos que ocorrem quando da retificação com rebolos convencionais. Utilizando-se rebolos de CBN, a queima da peça raramente ocorre e as tensões residuais são predominantemente de compressão (Tönshoff e Grabner, 1984; Vansevenat, 1989). Isto indica que menores temperaturas de retificação são geradas na região de corte. Estas, segundo Kohli et al. (1995), são atribuídas parcialmente à menor energia gasta para a retificação com rebolos de $\mathrm{CBN}$, devido à maior dureza de seus grãos (dureza Knoop do grão de $\mathrm{CBN}$ é de 4.500 e do grão de $\mathrm{Al}_{2} \mathrm{O}_{3}$ é de $2.500 \mathrm{~kg} / \mathrm{mm}^{2}$ ). Isto 
mantém a capacidade de corte do rebolo por mais tempo. Todavia, tem-se atribuído as menores temperaturas geradas na retificação com rebolos de $\mathrm{CBN}$ à maior condutividade térmica de seus grãos abrasivos, quando comparadas com os de óxido de alumínio (condutividade térmica do grão de $\mathrm{CBN}$ é de 3,3 e do grão de $\mathrm{Al}_{2} \mathrm{O}_{3}$ é de 0,08 cal/ ${ }^{\circ} \mathrm{C} . \mathrm{cm} . \mathrm{s}$ ). Sendo assim uma fração muito maior do calor gerado é transportado para fora da zona de retificação pela ferramenta abrasiva, ao invés do mesmo fluir para a peça (Lavine et al., 1989).

A evolução tecnológica das máquinas ferramenta e dos comandos numéricos é um dos três principais fatores apontados por Redington e Sullivan (1998) que impulsionaram a aplicação do CBN. Nas retificadoras mais modernas é possível se trabalhar com altas velocidades de corte, em torno de $120 \mathrm{~m} / \mathrm{s}$ a $180 \mathrm{~m} / \mathrm{s}$. Portanto a solicitação sobre o grão abrasivo também aumenta na mesma proporção. Apesar da menor força por grão, devido à menor espessura de cavaco removida, nessa velocidade os grãos abrasivos sofrem um atrito mais intenso em altas velocidades de deslizamento. Com isso, a utilização de grãos de CBN é mais apropriada devido às suas excelentes propriedades mecânicas. Contudo as altas velocidades de corte, de acordo com Yui e Lee (1996), reduzem as forças de retificação, especialmente quando as taxas de remoção de material são altas. A redução destas forças no processo minimiza a incidência de possíveis vibrações, de erros geométricos das peças retificadas, de deformações da máquina, etc.

Comparando-se a qualidade superficial obtida com a retificação com CBN em alta velocidade e a retificação convencional, fica nítida a vantagem dos rebolos de $\mathrm{CBN}$, como descrito por Tso (1995). A Figura 2.5 resume as principais características da retificação com rebolos de $\mathrm{CBN}$ em alta velocidade. 


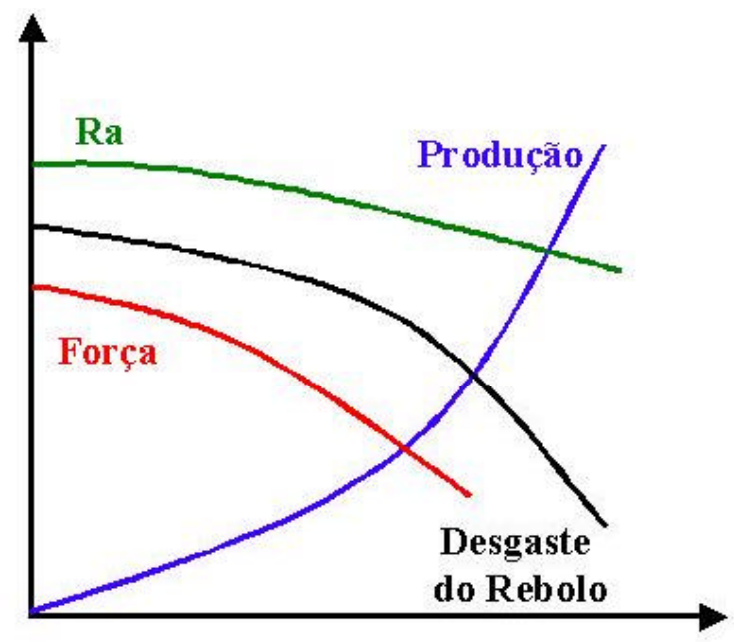

Velocidade de corte

Figura 2.5 - Características da retificação CBN a alta velocidade

A vida dos rebolos de CBN é em torno de 500 vezes maior que a dos convencionais, e conforme Hitchiner (1999), os valores de G podem variar de 1000 a 5000 para alguns casos de retificação com rebolos $\mathrm{CBN}$ eletrolíticos, dependendo do tipo de refrigerante.

Hoje se pode encontrar diversas aplicações de $\mathrm{CBN}$ nas indústrias, sendo as mais comuns no ramo automobilístico, para produção de virabrequins e eixos comando de válvula, e na indústria aeroespacial, na retificação de ligas especiais. Entretanto, apesar do custo dos rebolos ser muitas vezes maior que os convencionais, ainda torna-se interessante a utilização de CBN, pois é possível reduzir o custo total da operação, os custos com filtragem de óleo, paradas de máquina, trocas de rebolo, manutenções, etc.

A obtenção dos benefícios proporcionados pela utilização de rebolos de CBN está intimamente ligada com a execução de uma operação de dressagem eficiente. Segundo Hitchiner (1999), o entendimento das limitações e dos requerimentos da dressagem de rebolos de CBN com ligante vitrificado tem sido o fator chave para a utilização de novas tecnologias, tais como os sensores acústicos para a detecção de contato, novas tecnologias de ligantes, etc.

Os rebolos de CBN eletrodepositados, em sua maioria não são dressados, já que este possui apenas uma fina camada de grãos superbrasivos de $\mathrm{CBN}$, fixada ao corpo metálico por 
eletrodeposição. Quando comparados aos rebolos de CBN com ligante resinóide, os rebolos de CBN com ligante vitrificado apresentam como maior vantagem, a habilidade de ter seus grãos renovados automaticamente sem a necessidade de nenhuma operação subseqüente de condicionamento. Isto é obtido através da combinação de um ligante com características frágeis e com habilidade de introduzir porosidades (Hitchiner 1999). Em conjunto, estas características permitem que a estrutura do ligante seja esmagada durante a dressagem, apresentando perda preferencial do ligante e exposição do grão superabrasivo.

Os seguintes termos podem ser aplicados a operações de condicionamento inicial de rebolos superabrasivos, cada um com seu significado específico (Hitchiner, 1999):

- Perfilamento (Truing): permite criar um rebolo com periferia geometricamente corrigida, concêntrica ao seu eixo de rotação, gerando, se necessário, um perfil particular na face do rebolo;

- Avivamento (Conditioning): remoção preferencial do ligante em torno dos grãos;

- Dressagem (Dressing): operação simultânea de perfilamento do rebolo e condicionamento de sua superfície, conferindo ao rebolo a agressividade necessária.

Dentre os sistemas de dressagem disponíveis, a utilização de dressadores estacionários de ponta única ou multi-pontas são menos indicados, pois apesar do diamante ter dureza de aproximadamente 1,5 vez a do $\mathrm{CBN}$, vários grãos de $\mathrm{CBN}$ estarão se chocando com um ou poucos grãos de diamante causando maior desgaste aos diamantes, modificando o perfil final do rebolo e gerando mais calor, ficando sua aplicação mais indicada para rebolos de pequenos diâmetros com baixas: granulometria, concentração e velocidade periférica (Hitchiner, 1999).

Comumente, todos os processos de dressagem para a retificação em produção com rebolos de $\mathrm{CBN}$ requerem a utilização de discos rotativos metálicos, denominados como discos dressadores, discos perfiladores ou rolos de forma, dependendo da aplicação, da 
disposição e da quantidade de diamante em uma dada matriz. A configuração entre o rebolo de CBN e o diamante dressador pode assumir várias formas:

- Dressagem transversal uniaxial de perfis de forma simples ou retos, usando discos dressadores estreitos ou dressadores tipo copo, com eixo de rotação do disco dressador e do rebolo paralelos;

- Dressagem transversal de eixos cruzados de perfis usando discos dressadores estreitos; com eixo de rotação do disco dressador e do rebolo formando um ângulo de 90 graus e com disco dressador montado ;

- Dressagem transversal uniaxial usando dressadores com perfil de forma;

- Dressagem de forma de mergulho usando rolos diamantados, de crushing, sinterizados ou depositados por processos reversos.

Como elementos acionadores das ferramentas rotativas existem, essencialmente, três opções disponíveis: acionadores elétricos, hidráulicos e pneumáticos. Acionadores elétricos são os mais populares e flexíveis, utilizados tanto como acionadores diretos ou em transmissões por correia (Hitchiner, 1999). Eles podem fornecer um torque razoável aliado à possibilidade de variação de velocidades. Acionadores hidráulicos são mais baratos que os elétricos e fornecem um alto torque. Porém, eles apresentam elevado aquecimento, levando ao surgimento de erros decorrentes de expansão térmica. Os pneumáticos são os mais baratos. Não geram aquecimentos excessivos e alcançam elevadas velocidades. Porém apresentam baixo torque. Seu uso é limitado em retificadoras internas, usando dressadores tipo copo de pequeno diâmetro.

Em função do tipo de configuração adotada entre dressador-rebolo, fatores específicos podem afetar o processo de dressagem e características finais da superfície do rebolo. Um desses fatores é a razão de esmagamento $\left(\mathrm{q}_{\mathrm{d}}\right)$, definida segundo a equação 2.1: 


$$
\mathrm{q}_{\mathrm{d}}=\mathrm{v}_{\mathrm{r}} / \mathrm{v}_{\mathrm{s}}
$$

onde: $\mathrm{v}_{\mathrm{r}}$ é a velocidade periférica do dressador e $\mathrm{v}_{\mathrm{s}}$ é a velocidade de corte do rebolo.

Um q concordante (+), leva a uma ação de esmagamento mais efetiva. Para diferentes valores de $\mathrm{q}_{\mathrm{d}}$ pode-se obter diferentes regimes de fratura do grão, passando de uma microfratura para uma macro-fratura (Ishikawa e Kumar, 1991). A micro-fratura ocasiona uma elevada concentração de abrasivo na superfície do rebolo e conseqüentemente, uma maior vida do rebolo, porém gerando maiores forças de retificação. A macro-fratura, com a sua baixa concentração de grãos na superfície do rebolo, leva a uma menor vida do rebolo, porém gera menores forças de retificação. Alterando-se $\mathrm{q}_{\mathrm{d}}$ de $+0,2$ para $+0,8$ o nível de macro-fratura aumenta drasticamente, sendo acompanhado pela perda de ligante. Segundo Takagi e Liu (1996), a rugosidade do componente tende a aumentar com o aumento de q. Este fato pode ser observado na Figura 2.6.

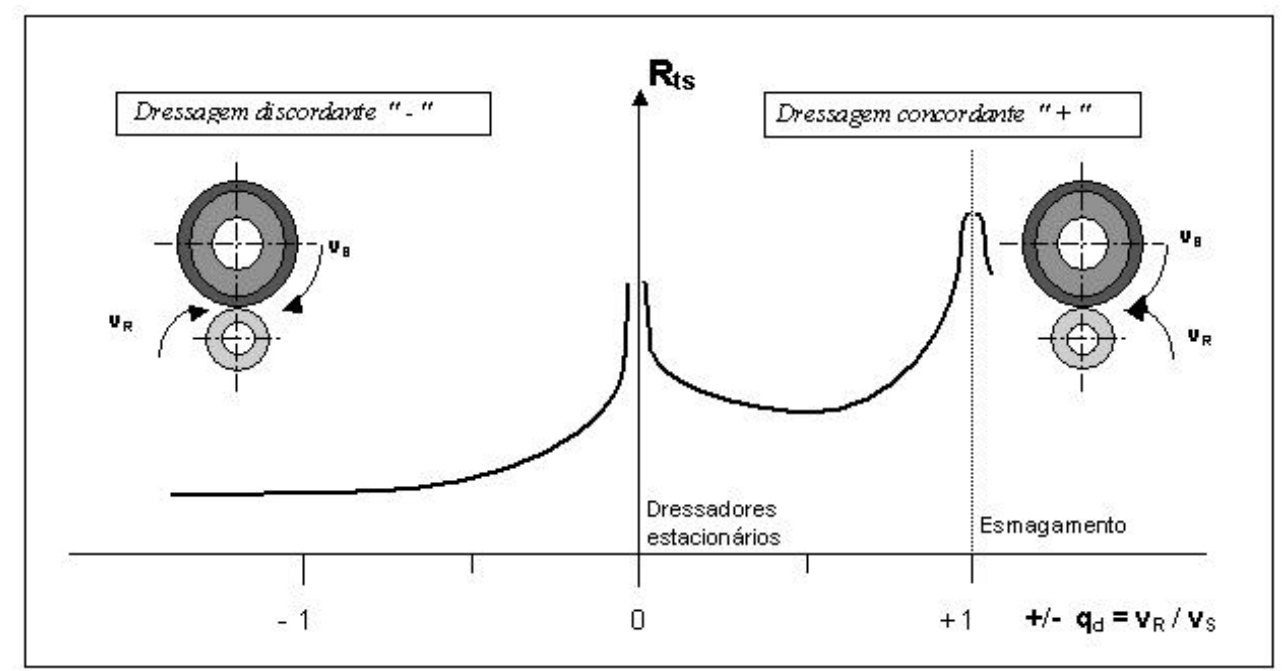

Figura 2.6 - Razões de esmagamento e sua influencia na rugosidade (Adaptado de Hitchiner, 2001)

Quanto mais próximo o $\mathrm{q}_{\mathrm{d}}$ tender a 1,0, maior será a rugosidade da superfície do rebolo, deixando-o mais agressivo. Porém quando essa relação for igual a 1,0, há o problema 
de puro esmagamento, no qual as forças são tão altas que geram as macro-fraturas dos grãos e da liga. Segundo Hitchiner (1999), um q da ordem de $+(0,6-0,8)$ é requerido para se obter uma boa agressividade do rebolo.

O projeto do disco dressador e a sua velocidade de deslocamento transversal influenciam na característica final da superfície gerada no rebolo. O controle do espaçamento médio entre os grãos do dressador e a adoção de velocidades de deslocamento transversal adequadas podem diminuir o efeito de cegamento dos grãos de CBN do rebolo durante a dressagem. Isto é obtido reduzindo-se o número de colisões consecutivas que um mesmo grão abrasivo sofre durante a dressagem (Brinksmeier e Çinar, 1995), o que leva a uma redução nos esforços de retificação.

A penetração do disco de dressagem também é um fator que pode alterar a característica de fratura do grão e o estado final da superfície do rebolo. Com pequenas variações, como de $1 \mu \mathrm{m}$, pode-se passar de um regime de micro para macro-fratura. Adicionalmente, a profundidade total de penetração durante a dressagem também é um fator importante a ser considerado.

A superfície de um rebolo é significativamente afetada quando comparada com a sua estrutura. O processo de dressagem fratura e remove partículas abrasivas e o ligante (Hitchiner, 1999). Yokogawa foi o primeiro pesquisador a descrever esta camada afetada, nomeando como "Tsukidashiryo", também conhecida como "Rugosidade da Superfície Ativa”. Esta pode variar em profundidade, de poucos microns até mais que $30 \mu \mathrm{m}$ (Yonekura e Yokogawa, 1983; Mindek, 1992). Para a maioria das aplicações de média e alta remoção de material, com o início da retificação, os cavacos irão erodir, preferencialmente, o ligante e aumentar a camada afetada (Figura 2.7). Isto é acompanhado por uma queda nas forças de retificação e um aumento da rugosidade, principalmente nas primeiras peças executadas após 
a dressagem. A queda nas forças é acompanhada por um aumento inicial da taxa de desgaste do rebolo e um aumento da rugosidade superficial.

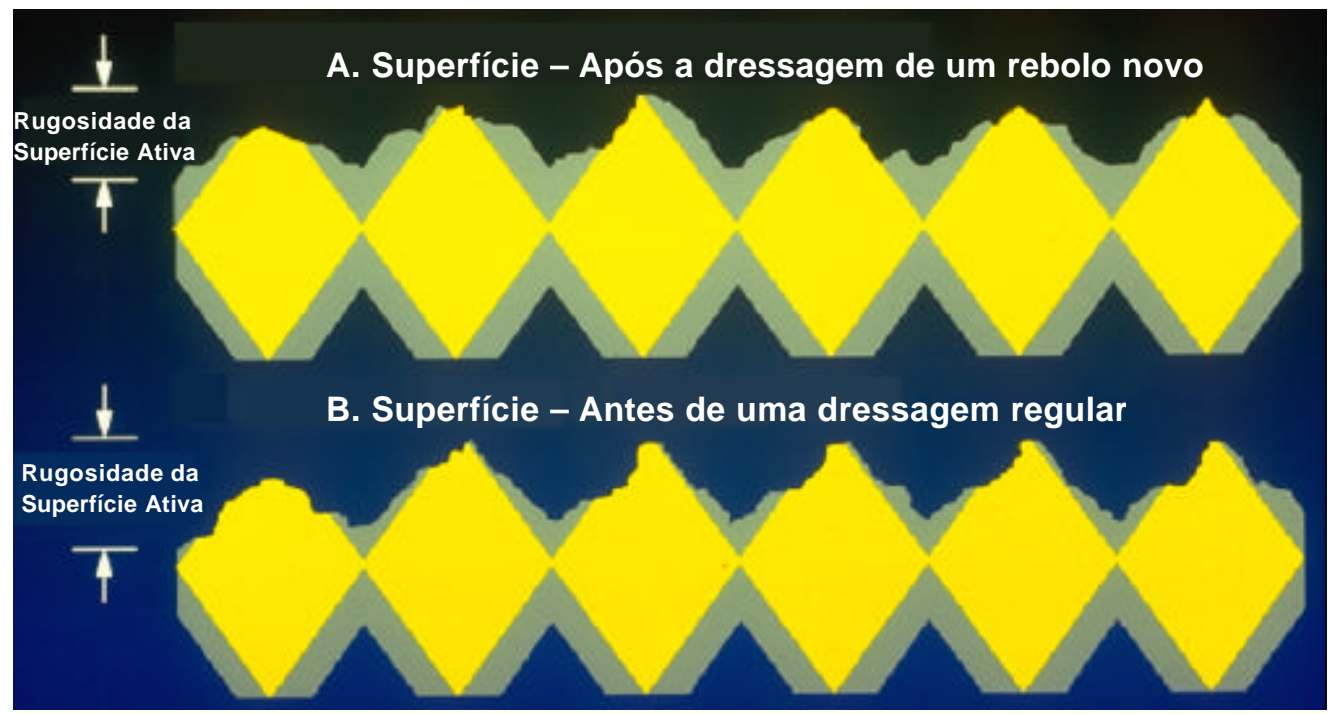

Figura 2.7 - Rugosidade Superficial ativa do rebolo (adaptado de Hitchiner, 1999)

A rápida queda na força de corte pode ser reduzida através da otimização dos parâmetros de dressagem. Porém, esta é raramente eliminada. Quando da dressagem de um rebolo convencional, uma possível queda na força de corte durante a retificação ocorrerá de forma muito rápida, não afetando a qualidade do componente usinado. Além disso, a quantidade de material removida em cada passe do dressador é tamanha que qualquer camada afetada é removida e uma nova é criada a cada dressagem. De forma oposta, a profundidade de dressagem para rebolos de CBN é de somente $3 \mu \mathrm{m}$. Um rebolo novo, logo após a primeira dressagem, terá a sua rugosidade superficial ativa aumentada com o decorrer da retificação. No caso de um rebolo estar propenso a gerar queima superficial, esta irá ocorrer na primeira peça retificada. Para a segunda dressagem, se a profundidade total dressada for insuficiente, o número de peças obtidas por dressagem será reduzido e se o inverso ocorrer (remoção de uma profundidade total excessiva), a rugosidade superficial ativa do rebolo retornará ao estado de um rebolo novo (Hitchiner, 1999). Na realidade, uma profundidade adequada deve ser removida durante a dressagem, a qual dependerá do processo de retificação em questão. 
Desta forma, torna-se claro que não só a profundidade de cada passo de dressagem é importante, mas também a profundidade total removida. Estes aspectos são extremamente importantes e governam, não só o mecanismo de fratura dos grãos abrasivos, mas também a rugosidade da superfície ativa do rebolo.

\subsection{Os fluidos de corte na retificação de alta velocidade}

A seleção do tipo mais adequado de fluido de corte e sua forma mais eficaz de aplicação estão no centro do debate da utilização de rebolos de CBN em aplicações de alta velocidade (Hitchiner, 1999). Sistemas baseados na utilização de óleo integral com fluido de corte necessitam de, no mínimo, duas vezes mais capacidade de filtração e de resfriamento do que os sistemas que utilizam fluidos de base aquosa. Além disso, dispositivos de extração da névoa gerada e sistemas anti-chamas são requeridos quando da utilização do óleo integral. Com o aumento das velocidades de corte e as necessidades de aplicação mais efetiva do fluido, através do aumento de sua velocidade de aplicação, maior se torna a necessidade da remoção desta névoa. O sistema de aplicação de fluido de corte torna-se crítico à medida que maiores velocidades de corte são requeridas. Novos bicos de aplicação do fluido, maiores velocidades e vazões adequadas são fundamentais para o desempenho satisfatório dos fluidos de corte (Webster, 1995, 1999).

O principal obstáculo para a aplicação correta dos fluidos de corte é a barreira de ar a ser suplantada, resultado da própria rotação do rebolo. Isto pode ser efetuado, aplicando-se o fluido de corte com velocidade igual à velocidade periférica do rebolo (Webster, 1995, 1999). Este efeito da barreira de ar pode ser visualizado na Figura 2.8. Entretanto, um projeto inadequado do bico de aplicação de fluido e das tubulações leva à dispersão do jato de fluido, quando da tentativa de se aumentar a velocidade de saída do mesmo (Webster, 1999). 


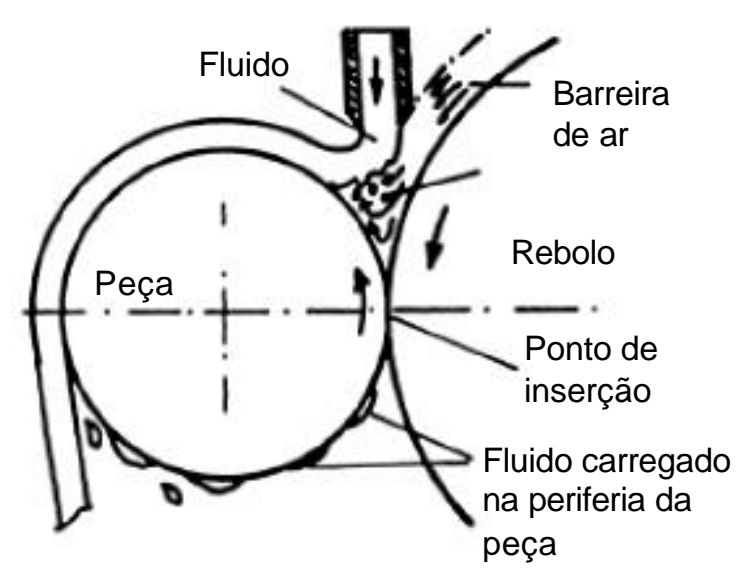

Figura 2.8 - Fluido de corte e a barreira de ar formada em torno do rebolo durante a retificação cilíndrica (adaptado de Hitchiner 2001)

O desempenho dos fluidos de corte será aumentado se todo o sistema de aplicação for otimizado (bomba, projeto do bico e tubulações). Bicos especiais, baseados naqueles utilizados em mangueiras de incêndio (Rouse et al., 1952) podem ser adotados para aumentar a coerência do jato (Webster, 1995). A representação deste bico especial é apresentada na Figura 2.9.

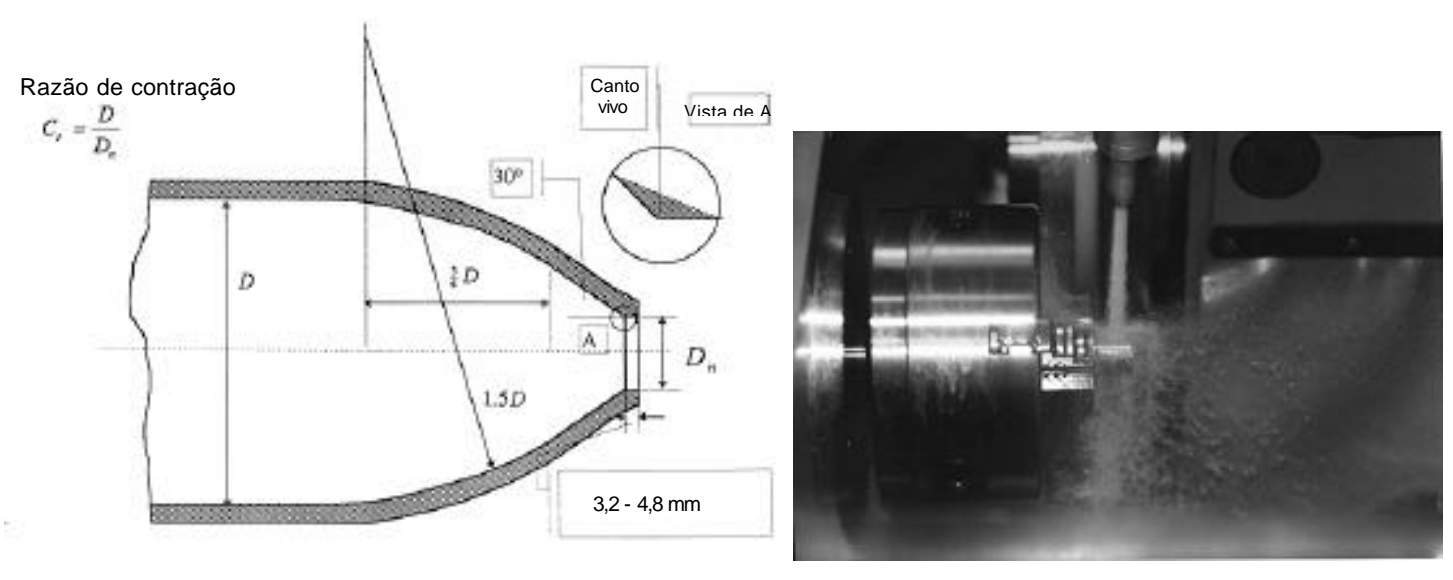

Figura 2.9 - Bico especial baseado no bico de mangueiras de incêndio (Rouse et al., 1952) (adaptado de Webster, 1995) (a esquerda) - a direita, bico especial em operação.

A geometria do bico especial é muito importante, onde: $\mathrm{C}_{\mathrm{r}}$ é a razão de contração; $\mathrm{D}$ é o diâmetro de entrada da tubulação de alimentação; $\mathrm{D}_{\mathrm{n}}$ é o diâmetro de saída. 
A velocidade de saída do fluido de corte deve ser aumentada para igualar-se a velocidade de corte do rebolo e vencer a barreira de ar criada na região de retificação. Segundo Webster (1995, 1999), a razão unitária de velocidades torna-se adequada para a maioria das aplicações, exceto aquelas em que a pressão requerida e os custos para a instalação de bombas de alta pressão são excessivos. A velocidade de saída do fluido de corte é proporcional ao quadrado da pressão na entrada do bocal. Em outras palavras, quatro vezes mais pressão é requerida para dobrar a velocidade de saída do jato. De acordo com a equação de Bernolli:

$$
\mathrm{P} \propto 0,5 \rho \mathrm{v}_{\mathrm{j}}^{2}
$$

onde: P é a pressão na entrada do bocal, $\rho$ é a densidade do fluido e $v_{\mathrm{j}}$ é a velocidade de saída do jato de fluido de corte

$\mathrm{Na}$ retificação de alta velocidade (acima de $100 \mathrm{~m} / \mathrm{s}$ ), uma grande quantidade de fluido de corte a alta pressão é requerida para igualar a sua velocidade de saída à de corte do rebolo. Os valores de pressão requeridos podem facilmente exceder os 40 bar (Webster, 1999), levando à limitações técnicas e financeiras para a instalação de bombas com conjugado elevado de pressão e vazão. Nestes casos, aumentam-se os custos envolvidos e os esforços requeridos em filtração e resfriamento do fluido. Todavia, razão de velocidades $V^{*}\left(v_{j} / v_{s}\right)$ inferiores a 1 podem ainda ser utilizadas, desde que bocais de aplicação de fluido de corte otimizados sejam utilizados, corretamente posicionados. O objetivo é a obtenção de um jato de fluido de corte com coerência melhora e pressão adequada, o qual atinja a zona de retificação de maneira efetiva (Silva et al., 2003; Silva, 2000).

Além de se gualar a velocidade do fluido à do rebolo e aplicá-lo de forma adequada, a determinação da vazão de fluido de corte necessária é de difícil previsão. Esta deve prevenir a 
incidência de queima, a ocorrência de erros geométricos, lubrificar adequadamente a região de corte e promover a troca de calor por convecção. Uma série extensa de fatores influencia na determinação da vazão requerida, podendo-se citar: a porosidade do rebolo; as propriedades mecânicas e térmicas da peça; o tipo de fluido de corte; a taxa de remoção de material imposta na operação de retificação; tolerâncias dimensionais e geométricas das peças, etc.

Webster (1999), baseando-se em ensaios laboratoriais realizados, apresenta indicações de vazão em função das condições de usinagem, da especificação do rebolo e o tipo de material. Outros pesquisadores têm desenvolvido modelos para estimar a vazão requerida para as operações de retificação. Silliman, apud Webster (1999), sugere um valor de $8-10$ 1/min por kW de potência de usinagem consumida. Campbell (1997) apresenta a equação da mínima vazão de fluido de corte de Metzger (1986), na qual determina-se a vazão de fluido de corte necessária $(\dot{Q})$ em função da potência de usinagem $\left(\mathrm{P}_{\mathrm{e}}\right)$, a eficiência do bocal $(\eta)$, capacidade térmica do fluido (C'), densidade do fluido $(\rho)$ e o máximo aumento tolerável de temperatura do fluido $(\Delta \theta)$. Hitchiner (1999) sugere uma vazão de 25 galões por minutos por polegada de largura de rebolo utilizada (4 litros por minuto por mm de largura do rebolo). Segundo Klocke et al. (2000), somente uma quantidade específica de fluido de corte pode fluir através da região de corte, contribuindo para a redução do atrito entre o rebolo e a peça. Isto significa que uma vazão de fluido de corte excessiva, acima daquela que pode escoar entre a zona de retificação, tende a somente aumentar a força normal de retificação, não trazendo nenhum benefício para o processo.

Uma das possibilidades de redução dos requisitos de pressão em operações de retificação de alta velocidade é a adoção de bocais em formato de sapatas (shoe-nozzles). Os bocais de sapata são especialmente apropriados para a retificação de alta velocidade utilizando rebolos de CBN e óleo integral (Klocke et al., 2000). Uma das possíveis geometrias 
é apresentada na Figura 2.10. O bocal cerca o rebolo em três lados. O fluido de corte é alimentado praticamente à pressão atmosférica, sendo depositado num reservatório localizado no interior do bocal. O fluido então é acelerado pelo próprio rebolo em direção a uma estreita fenda, emergindo nas proximidades do ponto de contato, de onde ele se desloca com a mesma velocidade periférica do rebolo, aderido à sua superfície. Esta tecnologia está presente desde a década de 60 e está sendo incorporada na maioria das retificadoras de alta velocidade hoje lançadas (Hitchiner, 1999). Estes bocais podem reduzir os requisitos de pressão de 40 bar para 4 bar, através da quebra da barreira de ar e usando o rebolo como bomba aceleradora de fluido. Outros exemplos deste tipo de bocais são apresentados na Figura 2.11.
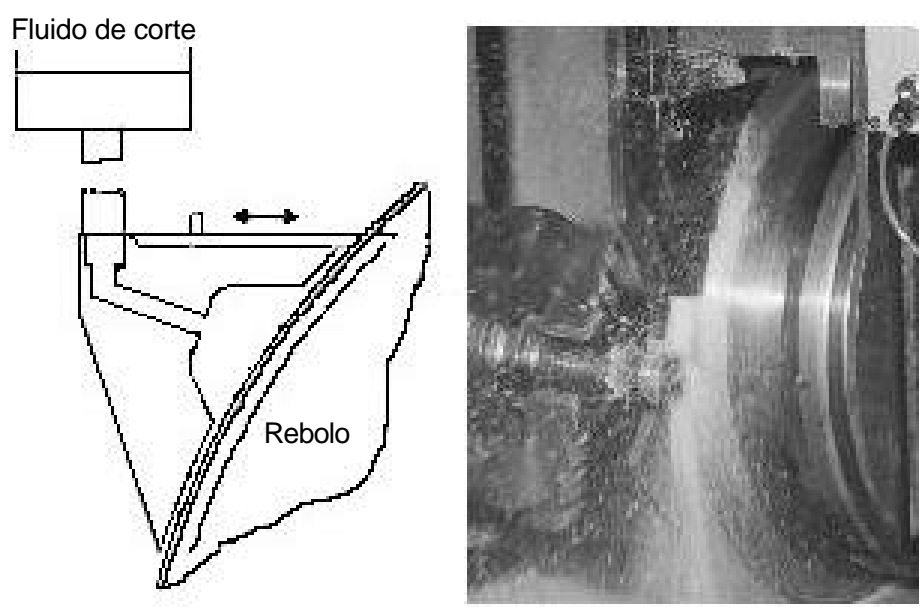

Figura 2.10 - Bocal de sapata em operação (adaptado de Klocke et al., 2000)

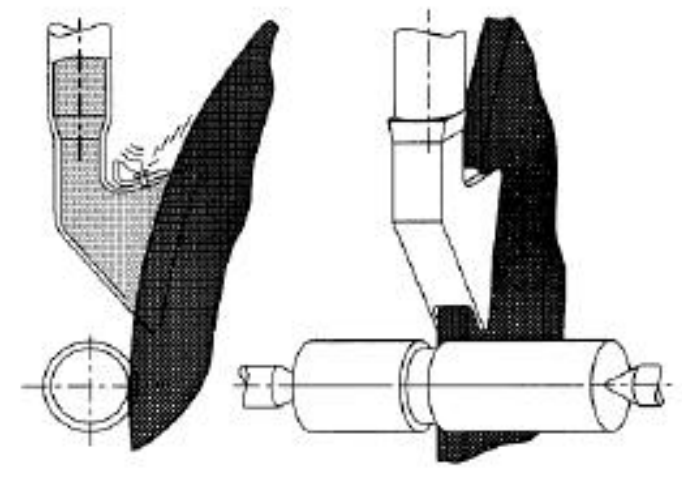

Shaw (1996)

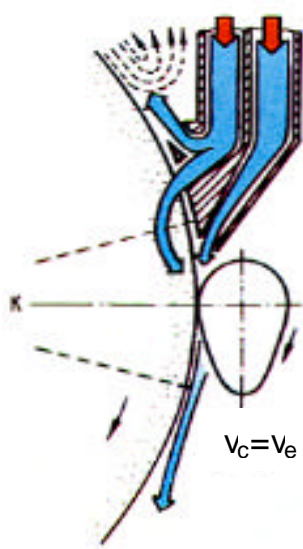

Cui (1995)

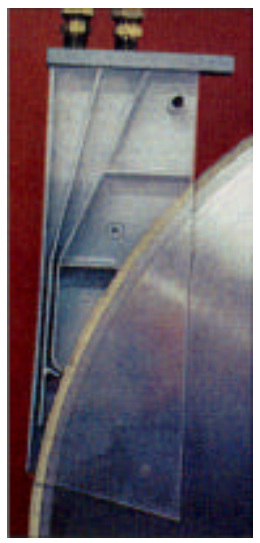

Hitchiner (1999)

Figura 2.11 - Bocais de sapata para a retificação de alta velocidade (adaptado de Hitchiner, 1999) 
Todavia, a totalidade dos projetos dos bocais baseados na utilização do próprio rebolo como bomba de fluido são sensíveis ao posicionamento do bocal que deve estar posicionado, no mínimo, $10 \mathrm{~mm}$ com relação à superfície do rebolo, e de uma forma idealizada, $3 \mathrm{~mm}$. Quando a instalação do bocal sofre a interferência da peça a ser retificada, uma nova estratégia deve ser adotada. Nestes casos, a utilização dos bocais especiais, baseados nos de mangueiras de incêndio, podem ser uma alternativa.

As velocidades de aplicação de fluido de corte devem ser igualadas a velocidade do rebolo com a minimização da vazão requerida, enquanto a vazão de fluido de corte deve ser otimizada através da criação de um fluxo laminar, a fim de prevenir a dispersão do jato na saída do bocal. Atuando neste sentido, Webster et al. (1995) e Cui (1995) investigaram métodos de produção de escoamento laminar para a mínima queda de pressão na linha de alimentação. O número de Reynolds é definido como sendo (equação 2.3):

$$
\operatorname{Re}=\left(v_{j} \cdot D_{p}\right) /\left(v \cdot 10^{3}\right)
$$

onde: $\mathrm{D}_{\mathrm{p}}$ (diâmetro do jato ou da tubulação) $(\mathrm{mm}), v$ é a viscosidade cinemática do fluido $\left(\mathrm{m}^{2} / \mathrm{s}\right) ; \mathrm{v}_{\mathrm{j}}$ é a velocidade de saída do jato de fluido de corte $(\mathrm{m} / \mathrm{s})$

O Número de Reynolds é uma medida da qualidade do escoamento, onde quanto menor este número, melhor, podendo-se sair de um escoamento turbulento para um laminar. A viscosidade cinemática da água é $10^{-6} \mathrm{~m}^{2} / \mathrm{s}$. Se um sistema é projetado para utilizar um fluido de base aquosa, então o Número de Reynolds com óleo integral será menor, uma vez que a viscosidade do óleo é maior do que a do fluido aquoso. A fim de se produzir um jato de fluido de corte com coerência, o Número de Reynolds calculado na descarga do fluido deve ser inferior a 13.000. Este valor é impraticável para os fluidos de corte sendo que valores de 
Reynolds até 10.000 ainda permitem obter-se um jato com coerência adequada. Se, ao igualar-se as velocidades do fluido à periférica do rebolo obtêm-se como resultado um Número de Reynolds inadequado, dois ou mais jatos podem ser utilizados para substituir o jato de maior diâmetro. A refrigeração do fluido, especialmente quando da utilização de óleo integral, aumenta a viscosidade do fluido e diminui o Número de Reynolds. A fim de se obter um escoamento laminar, Webster et al. (1995) e Cui (1995), propuseram um sistema otimizado, o qual consistia de um condicionador de fluxo in-line Mitsubishi, originalmente projetado para criar um escoamento laminar em sistemas de medição de vazão de tubulações de fornecimento de água para cidades, conforme mostrado na Figura 2.12.
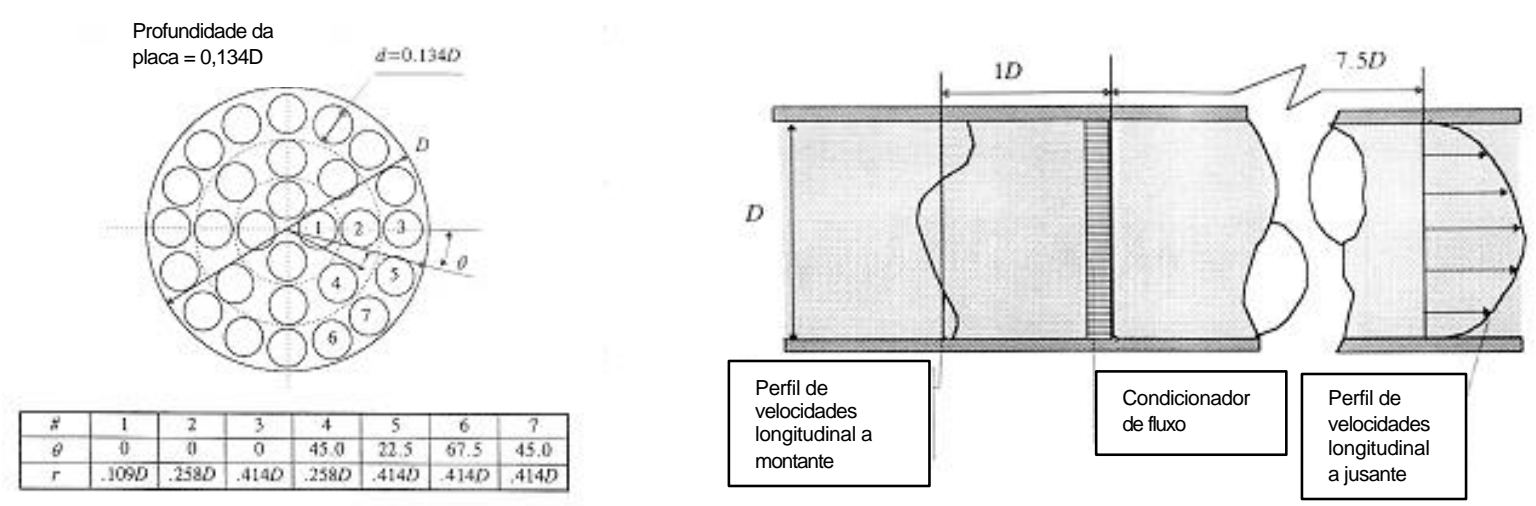

Figura 2.12 - Condicionador de fluxo Mitsubishi (adaptado de Cui, 1995)

Para investigar o efeito da velocidade de corte $\left(\mathrm{v}_{\mathrm{s}}\right)$ versus a velocidade do jato $\left(\mathrm{v}_{\mathrm{j}}\right)$, Webster (1995) realizou testes nos quais o fluxo de calor para três velocidades de corte foi medido, onde $V^{*}$ é a razão de velocidades: $\left(\mathrm{v}_{\mathrm{j}}\right)$ sobre $\left(\mathrm{v}_{\mathrm{s}}\right)$. Estes resultados são apresentados na Figura 2.13 . 


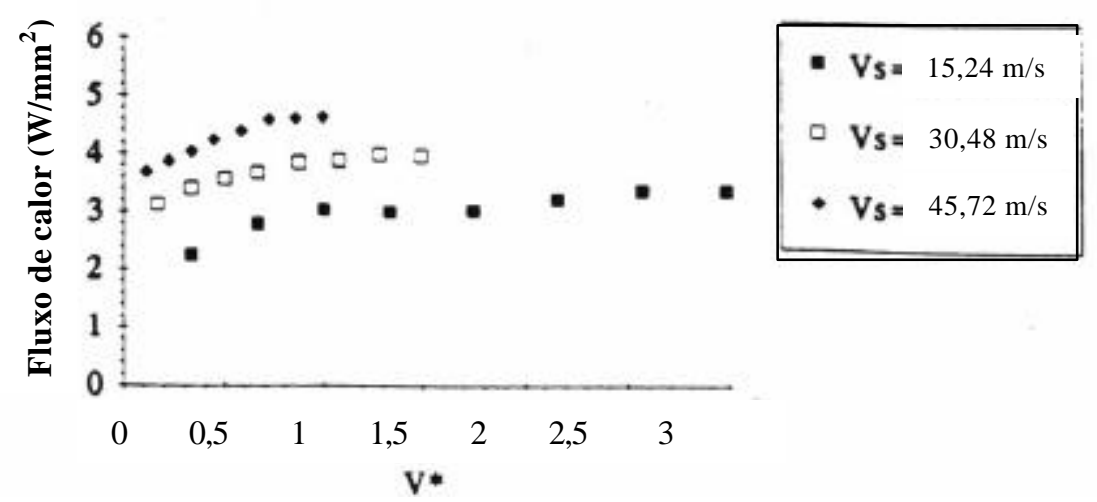

Figura 2.13 - Razão de velocidades $\left(\mathrm{V}^{*}\right)$ para três velocidades de corte para bocal de saída com 1/16" de diâmetro (adaptado de Webster, 1995)

Pode-se notar na Figura 2.13 que maiores fluxos de calor indicam uma maior eficácia de refrigeração da configuração proposta. Os resultados indicam que, acima de V" igual a 1, o fluxo se estabiliza, mantendo-se constante a capacidade de remoção de calor da região de corte.

Medições da pressão hidrodinâmica podem ser utilizadas para a otimização da aplicação do fluido de corte, em termos de direção, velocidade e vazão. Além disso, a presença de pressões positivas na região de corte indica que o efeito da evaporação do filme de fluido de corte está ocorrendo e, conseqüentemente, a taxa de remoção de material deve ser reduzida, a fim de se evitar a ocorrência da queima da peça (Wesbter, 1995).

Uma vazão de fluido de corte adequada aumenta a eficácia da remoção de calor por convecção e previne a completa evaporação do filme de fluido de corte da zona de retificação. A eficácia da aplicação de fluido de corte em alta velocidade aumenta à medida que a velocidade do jato aumenta até o valor $\mathrm{V}^{*}$ igual a 1 (Figura 2.3). Como resultado, as forças de retificação, o desgaste do rebolo e a queima são reduzidos, levando a uma otimização do processo. Segundo Webster (1999), existe uma vazão crítica de aplicação de fluido de corte, a uma apropriada velocidade de aplicação, acima da qual a queima da peça pode ser eliminada.

A filtração do fluido de corte é um fator essencial para a obtenção de peças retificadas de qualidade, principalmente se rebolos de CBN são utilizados. Segundo Leal (1993), se o 
fluido de corte apresentar uma quantidade excessiva de partículas abrasivas e cavacos, o rebolo sofrerá um empastamento prematuro. Como resultado, tem-se um aumento do número de operações de dressagem e dos custos de retificação. Com uma filtração ineficiente, ocorrerão problemas nas bombas de sucção, decorrentes do desgaste abrasivos entre as partículas dissolvidas no cavaco e as partes internas das bombas.

\subsection{Sistemas de limpeza a alta pressão da superfície do rebolo.}

O empastamento do rebolo é um problema comum durante a retificação, principalmente quando da usinagem de ligas a base de níquel. O cavaco formado pode alojarse nas porosidades do rebolo, reduzindo assim a capacidade de corte do mesmo (Chen e Feng, 2002). Uma forma de remoção destes cavacos alojados é através da dressagem. Todavia, quando da utilização de rebolos de $\mathrm{CBN}$, o aumento do número de dressagens causa o aumento dos custos relacionados à utilização da ferramenta.

O uso de rebolos com maior porosidade e a aplicação de fluido de corte de maneira eficiente (vazão e pressão adequados) reduzem a tendência ao empastamento. Todavia, o aumento da porosidade do rebolo leva à redução do número de grãos ativos e à maior tendência ao enfraquecimento do ligante (Cai et al., 2002).

O mecanismo de empastamento do rebolo está relacionado ao processo de usinagem, de forma mais específica ao mecanismo de formação do cavaco, e a relação entre o volume de cavaco gerado e ao volume disponível para alojamento nas porosidades do rebolo. $\mathrm{O}$ empastamento é acelerado quando da produção de cavacos finos e alongados. A geometria deste cavaco gerado dependerá da combinação entre as condições de usinagem e o material da peça.

Novos métodos para a limpeza das porosidades do rebolo vêem sendo pesquisados, incluindo-se a utilização de laser. Todavia não existem vantagens com relação ao método 
convencional de dressagem (Chen e Feng, 2002). O motivo deve-se ao fato do laser de alta potência remover não somente os materiais aderidos ao ligante como também danificar os grãos do rebolo, causando um aumento dos esforços de corte e do desgaste do rebolo. A magnitude deste desgaste leva a um aumento dos erros de forma e a desgastes inaceitáveis para rebolos de CBN.

O método mais utilizado para a limpeza das porosidades do rebolo é a utilização de bocais de alta pressão (Hitchiner, 1999). Nesta configuração (Figura 2.14) um jato de fluido de corte a alta pressão é aplicado na superfície do rebolo removendo os materiais aderidos às porosidades do mesmo.

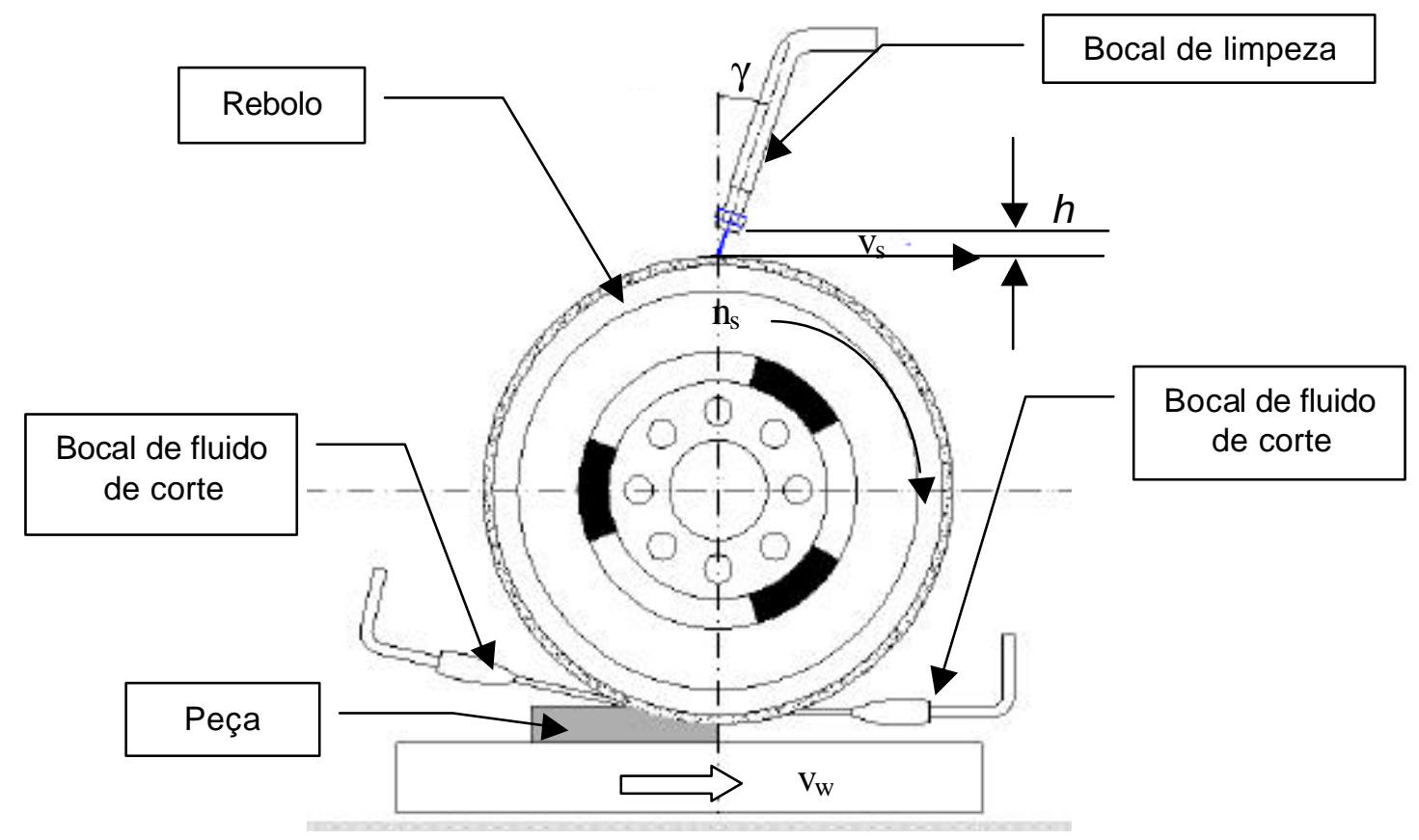

Figura 2.14 - Configuração do bocal de limpeza (h é a distância entre a saída do bocal e o rebolo; $\gamma$ é o ângulo de ataque)

Uma efetiva ação de limpeza envolve uma série de fatores, os quais são apresentados na seqüência:

- Tipo do bocal: Existem vários tipos de bocais de saída. Para cada um deles, as diferenças básicas envolvem a geometria de saída do jato (Figura 2.15) e o ângulo de 
saída ( $\beta$ ) (Figura 2.16). Este ângulo é importante para definir a máxima distância $h$ entre a saída do bocal e a superfície do rebolo. O ângulo e o volume de saída para cada tipo de bocal pode ser escolhido dentre um largo espectro de componentes padronizados (Hitchiner, 1999).

- Montagem dos bocais: A montagem deve ser escolhida a fim de se obter a melhor ação de limpeza. As montagens típicas são: normal e tandem (Figura 2.16).
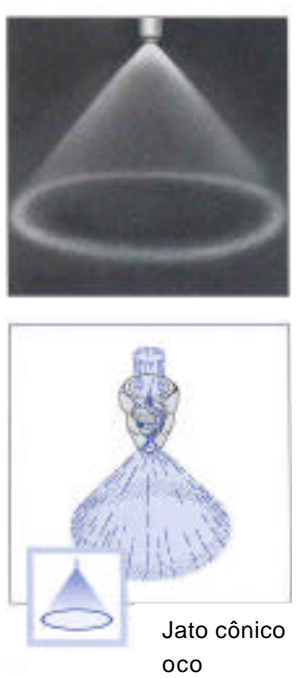
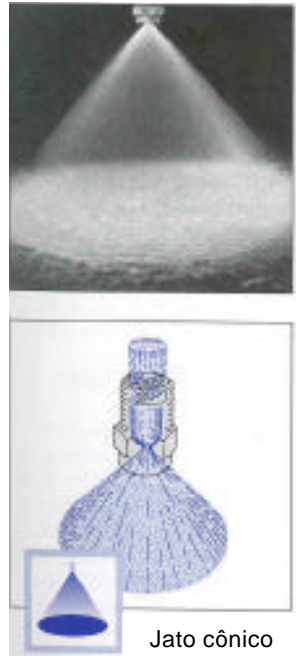

sólido
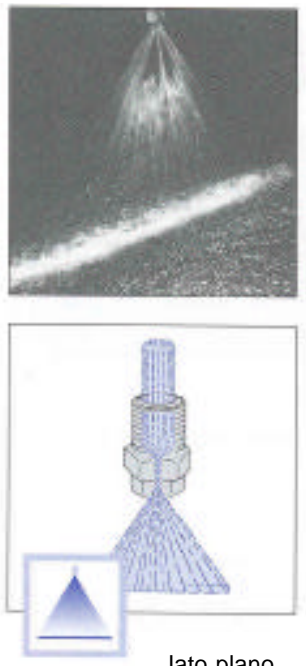

Jato plano
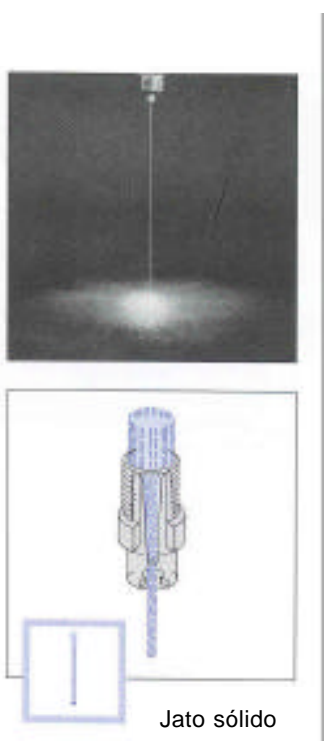

Figura 2.15 - Diferentes tipos de bocais com diferentes geometrias do jato de saída (Lechler, 2004)

- Distância " $h$ " entre a saída do bocal e a superfície do rebolo: esta distância é calculada considerando-se o ângulo de saída do jato $\beta$, o tipo de bocal e tipo de montagem e a energia de saída desejada do jato. Esta última é reduzida a medida que se aumenta a distância $h$ mantendo-se constante a pressão do jato.

- Ângulo de ataque $\gamma$ : este parâmetro define o ângulo entre o jato e a superfície do rebolo (Figura 2.14).

- Pressão (p) e vazão de fluido $(\dot{Q})$ : estes dois parâmetros estão relacionados com a quantidade de movimento do jato de fluido e, conseqüentemente, com a sua ação de limpeza. Tipicamente, a pressão requerida varia entre 55 - 69 bar com uma vazão 
entre 0,3 - 0,45 L / (min.mm). Pressões abaixo de 55 bar levarão à redução da ação de limpeza, enquanto acima de 69 bar podem levar à erosão do ligante (Hitchiner, 1999). A maioria das informações disponíveis são baseadas em dados práticos.

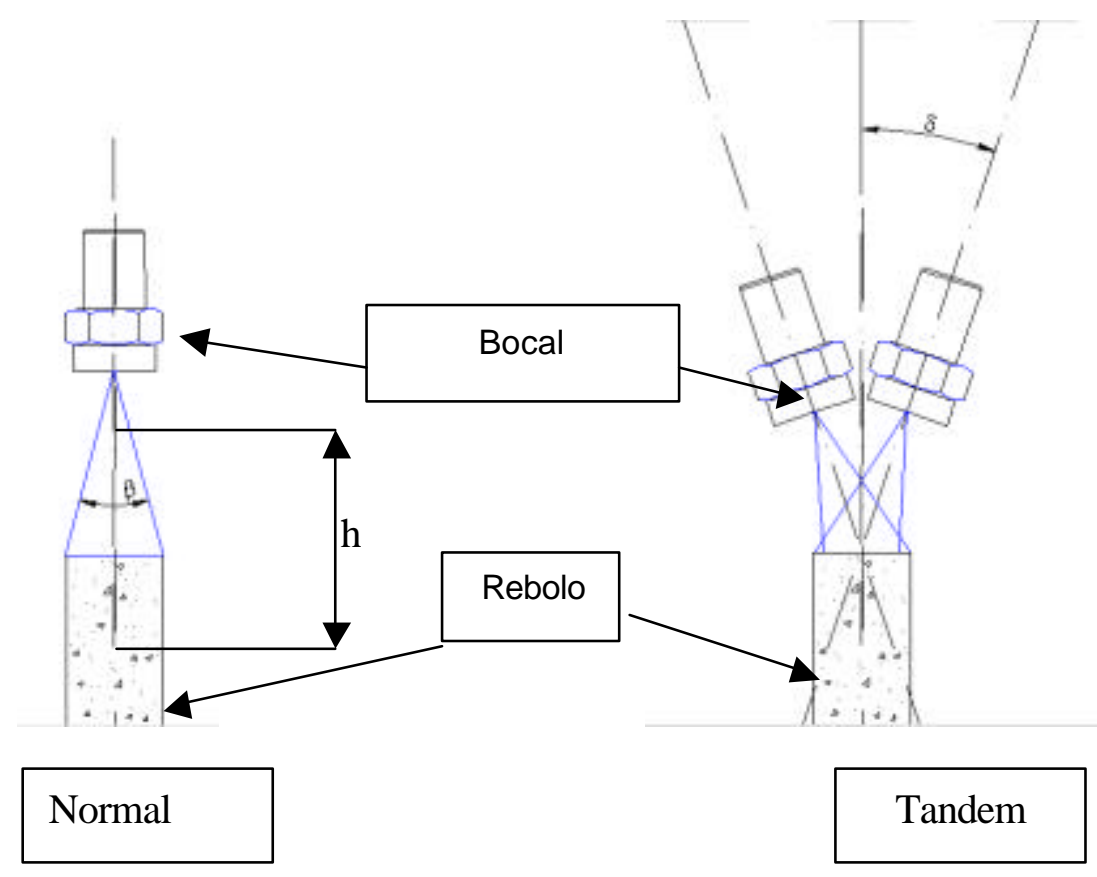

Figura 2.16 - Diferentes configurações de montagem ( $h$ é a máxima distância entre a saída do bocal e a superfície do rebolo; $\beta$ é o ângulo de saída e $\delta$ é o ângulo de montagem) (Lechler, 2004) 


\section{RETIFICAÇÃO CILÍNDRICA EXTERNA DE FORMA}

$\mathrm{Na}$ norma DIN/ISO, as variantes do processo de retificação são classificadas em função do tipo de usinagem, contorno e movimento da peça (Basic ..., 1989, Saljé, 1991 apud Gerent 2001). Nessa classificação as condições de corte e a forma de remoção do sobremetal não são levados em consideração. $\mathrm{O}$ avanço principal e a superfície do rebolo que envolve o processo de formação do cavaco são elementos cruciais para a classificação das variantes de retificação. A retificação entre centros divide-se em retificação cilíndrica externa de mergulho e retificação cilíndrica externa transversal com avanços principais na direção radial e axial, respectivamente (Figura 3.1). Um movimento principal é aquele que promove a produção contínua de cavaco, resultado do movimento de corte e da penetração (König e Klocke, 1996 apud Gerent 2001).

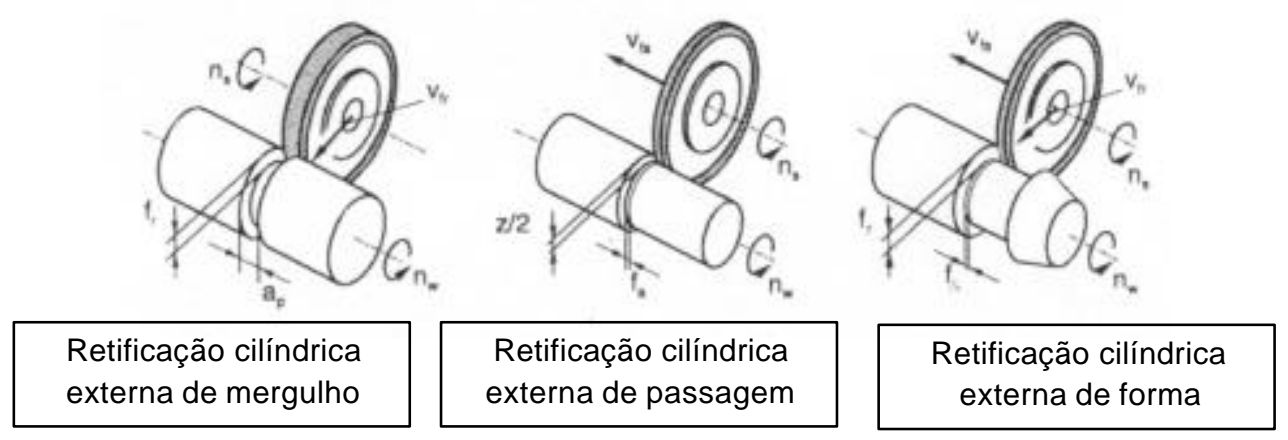

Figura 3.1 - Movimento de corte de três variantes da retificação cilíndrica externa (Saljé, 1991 apud Gerent 2001)

Considerando-se a peça entre centros e utilizando-se um rebolo cuja largura é menor que a largura a ser retificada da peça, geralmente são utilizados os processos de retificação 
pendular de passagem, peel-grinding e retificação de múltiplos mergulhos em diferentes posições axiais da peça. (Wünsche, 1992 apud Hegener, 1999).

Baseando-se no princípio da retificação peel-grinding, a partir da metade dos anos 80 foi desenvolvido o processo de retificação cilíndrica externa de forma, com as seguintes variantes (Figura 3.2):

- Retificação cilíndrica externa de forma de alto desempenho;

- Peel-grinding com eixo X inclinado (Quickpoint $\left.{ }^{\circledR}\right)$ (Verfahren ..., 1984 apud Hegener, 1999);

- Retificação angular (Verfahren ..., 1987 apud Hegener, 1999)

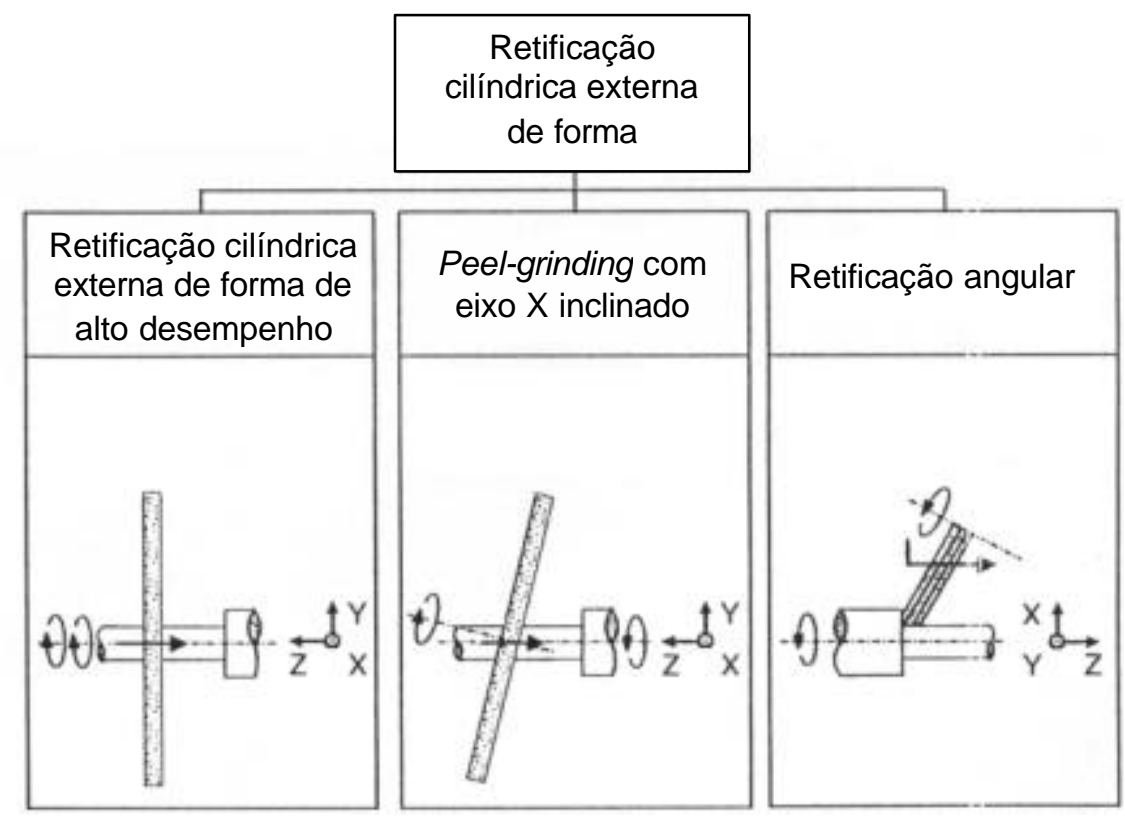

Figura 3.2 - Variações do processo de retificação cilíndrica externa de forma (Adaptado de Hegener, 1999)

$\mathrm{Na}$ retificação cilíndrica externa de forma, a usinagem do contorno desejado ocorre através da interpolação via CNC dos avanços na direção axial (componente principal) e radial. Quando um dos movimentos de avanço é igual a zero obtêm-se a mesma cinemática de um processo de retificação cilíndrica externa de mergulho ou transversal. 
Tipicamente o rebolo de CBN utilizado na retificação cilíndrica externa de forma tem largura em torno de 5 a 6 mm (Klocke, Hegener e Deacu, 1996 apud Hegener, 1999). Essa largura de rebolo, menor e ao mesmo tempo mais resistente ao desgaste, é o requisito para uma usinagem efetiva e com maior flexibilidade de contornos. Em oposição a isso, os rebolos utilizados em peel-grinding apresentam largura da ordem de 30 a $100 \mathrm{~mm}$. Estes rebolos possuem grãos convencionais, o que resulta numa menor resistência ao desgaste se comparados aos de CBN (Wünsche, 1992 apud Hegener, 1999).

\subsection{Operações convencionais de retificação cilíndrica externa}

\section{Retificação cilíndrica externa pendular de passagem}

Segundo a norma DIN8589 apud Hegener (1999) a retificação cilíndrica externa pendular de passagem é caracterizada pela retificação do sobremetal em vários passes. Em cada passe, ao final do movimento transversal, executa-se a nova penetração radial, invertendo-se o sentido de movimento na direção axial. Durante a movimentação axial, o processo de desbaste é seguido por um processo de acabamento, sendo que um mesmo ponto da superfície da peça é retificado várias vezes durante um passe de retificação. Esta característica leva a um melhor acabamento superficial se comparado a uma operação de retificação de mergulho (Opitz e Frank, 1961 apud Hegener,1999).

O desgaste observado na superfície do rebolo pode ser classificado como do tipo em “degraus” (Opitz e Frank, 1961, Verkerk, 1976 apud Hegener,1999). A largura deste degrau corresponde ao avanço axial por volta da peça. Com base neste comportamento de desgaste, alguns autores propõem mudanças na geometria de entrada dos rebolos, alterando-se a forma cilíndrica inicial para uma superfície cônica de entrada ou a introdução de um raio, ambas produzidas durante a dressagem (Nakajima, Okamura e Uno, 1984 apud Hegener, 1999), 
melhorando a distribuição superficial do sobremetal a ser removido. Melhorias no processo são propostas, tais como a introdução de diferentes granulometrias nas regiões de desbaste e de acabamento do rebolo.

\section{Peel-grinding com rebolo convencional}

A retificação peel-grinding caracteriza-se pela remoção de todo o sobremetal em um único passe (Wünsche, 1992 apud Hegener, 1999). Uma das diferenças básicas entre a retificação pendular e a peel-grinding é a geometria do rebolo. Considerando-se um mesmo sobremetal a ser removido para uma mesma largura ativa do rebolo durante a retificação, utiliza-se um rebolo com geometria de entrada cônica para a peel-grinding, ao invés de um rebolo "reto" (sem chanfro de entrada ou raio de arredondamento). Neste caso, o ângulo de entrada da região cônica $(\alpha)$ varia entre $0,5-1,5^{\circ}$ até $11^{\circ}$ (Wirtschaftliches, 1940 apud Hegener, 1999). O ângulo $(\alpha)$ e o avanço axial $\left(a_{f}\right)$ são definidos pelas equações 3.1 e 3.2, respectivamente (Wünsche, 1992 apud Hegener, 1999), permitindo assim a otimização da operação em questão:

$$
\begin{aligned}
& \alpha=\arctan \left(\frac{z}{2 \cdot b_{s}}\right)+\left(\frac{U \cdot Q^{\prime}{ }_{w}}{2 \cdot b_{s} \cdot v_{w}}\right) \\
& a_{f}=b_{s} \cdot \frac{2 \cdot Q^{\prime}{ }_{w}}{z \cdot v_{w}+2 \cdot U \cdot Q^{\prime}{ }_{w}}
\end{aligned}
$$

onde: b é a largura do rebolo, z/2 é o sobremetal radial, Q' ${ }_{w}$ é a taxa de remoção de material específica, $v_{\mathrm{w}}$ é a velocidade da peça e $\mathrm{U}$ é o número de retificações consecutivas. Este último é definido pela equação 3.3: 
$U=\frac{b_{s}}{a_{f}}$

\subsection{Operações de retificação cilíndrica externa de forma}

Peel-grinding com rebolo rotacionado em torno do eixo X (Quickpoint $\left.{ }^{\circledR}\right)$

A retificação peel-grinding com rebolo rotacionado em torno do eixo $\mathrm{X}$ diferencia-se da retificação cilíndrica externa de alto desempenho e da retificação angular pelo diferente arranjo geométrico entre o eixo do rebolo e o da peça (Verfahren ..., 1984 apud Hegener, 1999). Nesta configuração, o eixo de rotação do rebolo é inclinado de $\varphi=0,5^{\circ}$, verticalmente em relação ao eixo de rotação da peça, conforme apresentado na Figura 3.3. Para a retificação de faces planas, o ângulo de inclinação do rebolo deve ser retornado a zero, para que a face plana possa ser retificada corretamente (Bücker, 1997b apud Hegener, 1999).

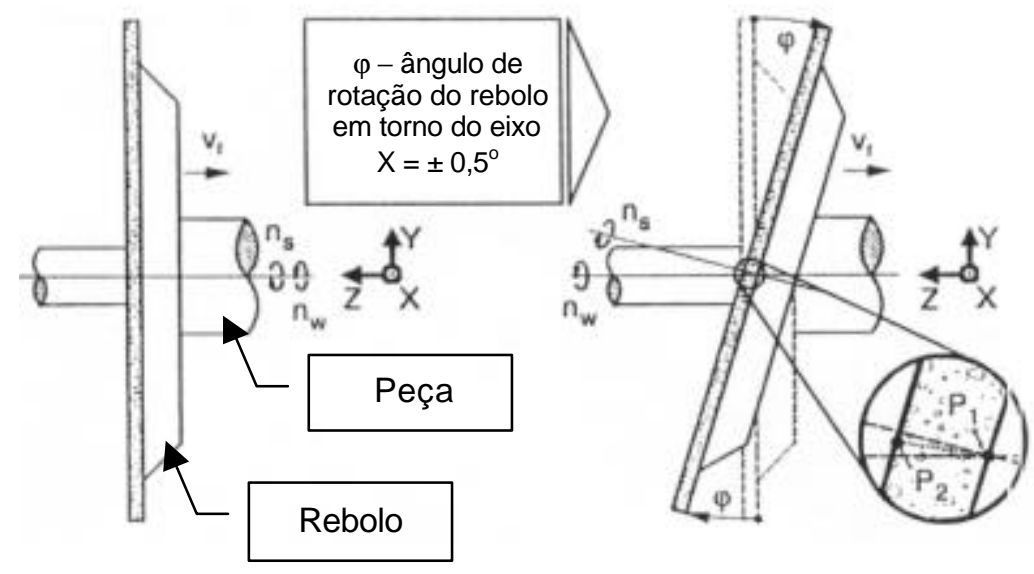

Figura 3.3 - Configuração geométrica da peel-grinding com eixo X inclinado (Adaptado de Bücker, 1997b apud Hegener, 1999)

Enquanto a retificação de elementos de geometria cilíndrica gera um ponto de contato $\left(\mathrm{P}_{1}\right)$ entre o rebolo e a peça (Bildstein, 1987; Bildstein, 1993, apud Hegener, 1999), a inclinação de $0,5^{\circ}$ do rebolo em torno do eixo $\mathrm{X}$ gera uma folga de alguns nanômetros na 
superfície de saída do rebolo em relação à superfície da peça (Figura 3.3). Através da inclinação do rebolo Bücker (Bücker, 1997a apud Hegener, 1999) não pôde identificar padrões na superfície retificada. Neste caso mantêm-se as perguntas se é possível detectar-se, de forma visual, um padrão ou a criação de um espiral na superfície retificada da peça.

Para um contorno de desbaste ortogonal, a retificação peel-grinding com rebolo rotacionado em torno do eixo $\mathrm{X}$ e retificando no sentido concordante gera uma menor área de contato que uma retificação discordante (Bücker, 1997a apud Hegener, 1999), gerando assim menores forças de corte. Devido à menor largura de contato, a força para a formação do cavaco é menor. Para esta operação, a utilização de um arrastador torna-se desnecessária, já que o momento de giro requerido para rotação da peça pode ser conferido via atrito.

Partindo do modelo de desgaste de Verkerk (Verkerk, 1976 apud Hegener, 1999) Bücker desenvolveu as bases teóricas para a determinação de um modelo de desgaste do rebolo para operação de retificação peel-grinding com rebolo rotacionado em torno do eixo X. A velocidade de desgaste da largura do rebolo na direção axial é determinada, conforme a equação 3.3, sendo função do avanço axial $a_{f}$, da penetração radial $a_{e}$, o fator de proporcionalidade $A$, o parâmetro $b$, o número de peças retificadas $\mathrm{j}$, o fator de correção temporal $f_{j}$ e o ângulo de inclinação da ponta do rebolo $\varphi$.

$$
\dot{b_{s}}=A \cdot \frac{a_{f} \cdot \cos \varphi}{f_{j}} \cdot\left(\frac{a_{e}}{j}\right)^{b}
$$

A forma do desgaste é influenciada pelo parâmetro $b$. Para o caso $b=1$ obtêm-se um formato de desgaste espaçado e de forma eqüidistante. Para o caso de b > 1 ocorre uma deformação constante, na qual amplifica-se a zona de engajamento do rebolo. Para a vida útil 
do rebolo $\mathrm{T}_{\mathrm{SE}}$, até ser alcançado o critério de dressagem do rebolo, Bücker descreve a equação

$T_{S E}=\frac{1}{A \cdot a_{e}^{b-1}} \cdot \sum_{j=1}^{k_{S E}}\left(f_{j} \cdot j^{b-1}\right)$

$\mathrm{O}$ intervalo-limite $\mathrm{k}_{\mathrm{SE}}$ descreve o intervalo para disposição de um número fixo de degraus de desgaste no rebolo. A precisão do cálculo depende da estimativa dos parâmetros A e b.

Bücker também investigou a influência do avanço axial, do sobremetal, da rotação da peça, da velocidade de passagem do rebolo e da largura da superfície de saída do rebolo (superfície de alisamento) nas forças de retificação, na rugosidade da peça e no desvio de forma quando da utilização da configuração de retificação peel-grinding com rebolo rotacionado em torno do eixo $\mathrm{X}$. Ele percebeu que o avanço axial, o sobremetal e a rotação da peça tem grande influência sobre as forças de retificação. A rugosidade da peça e os erros de forma são influenciados pela superfície de saída do rebolo. Devido ao efeito dinâmico, a rotação da peça tem grande influência no erro de forma.

A diferente cinemática de formação do cavaco, resultado das diferenças cinemáticas entre a retificação peel-grinding com rebolo rotacionado em torno do eixo $\mathrm{X}$ e a retificação cilíndrica externa de alto desempenho pode gerar diferentes comportamentos de desgaste do rebolo e nos esforços de corte. A transferência dos resultados da retificação peel-grinding com rebolo rotacionado em torno do eixo $\mathrm{X}$ para a retificação cilíndrica externa de alto desempenho é ainda duvidosa.

\section{Retificação angular}

A operação de retificação angular é a utilizada para retificação de peças que apresentem faces planas e elementos cilíndricos (Verfahren ..., 1987; Wick, 1988, apud 
Hegener, 1999). Nesta variante de retificação o eixo porta-rebolo é inclinado num valor entre 25 e 30 graus em relação ao plano ortogonal que contém os eixos de rotação da peça e do rebolo (eixo $\mathrm{Y}$ ou $\mathrm{B}$ ). $\mathrm{O}$ rebolo de $\mathrm{CBN}$ engajado permite a retificação da face plana com o canto da lateral do rebolo e com a face do mesmo o diâmetro da peça. A região de entrada da face do rebolo pode ainda apresentar uma superfície cônica. Como resultado deste arranjo geométrico entre rebolo e peça surgem limitações para a produção de certos contornos, sendo necessário abranger outras operações de retificação subseqüentes.

\section{Retificação cilíndrica externa de forma de alto desempenho}

A retificação cilíndrica externa de forma de alto desempenho é um melhoramento da retificação peel-grinding utilizando rebolo convencional. O processo é caracterizado pela utilização de rebolos de $\mathrm{CBN}$ resistentes ao desgaste, com velocidades de corte acima de 80 m/s (Klocke, Hegener e Deacu, 1996 apud Hegener, 1999). De forma oposta à retificação angular e à retificação peel-grinding com eixo $\mathrm{X}$ inclinado, a configuração geométrica é de eixos paralelos (König, Schröder e Treffert, 1993 apud Hegener, 1999). Em casos particulares de usinagem, como por exemplo, a retificação de um elemento com geometria cônica, o eixo do rebolo pode ser inclinado em relação ao plano que contem os eixos de rotação do rebolo e da peça, o conhecido eixo Y (B). Como na maioria dos processos de retificação cilíndrica externa, a de forma de alto desempenho é efetuada de forma discordante (König e Klocke, 1996), já que devido às configurações cinemáticas de formação do cavaco pode-se obter uma melhor rugosidade da peça.

König e Schröder descreveram o comportamento de desgaste quando da utilização de rebolos de CBN com ligante metálico (König e Schröder, 1994 apud Hegener, 1999). Eles estabeleceram uma inter-relação entre o número de retificações consecutivas sobre a zona de 
retificação cilíndrica $U$, a relação de velocidades $q\left( \pm v_{\mathrm{s}} / \mathrm{v}_{\mathrm{w}}\right)$ e a rugosidade $\mathrm{R}_{\mathrm{z}}$, conforme apresentado na Figura 3.4.

1. Representaçẫo da cinemática

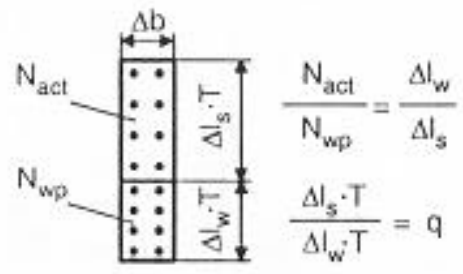

2. Influência do número de retificaçổes consecutivas sobre a rugosidade

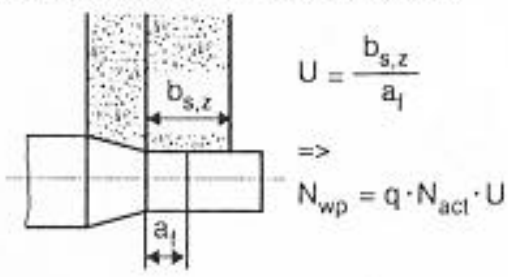

3. Obtençẫo de rugosidades equivalentes

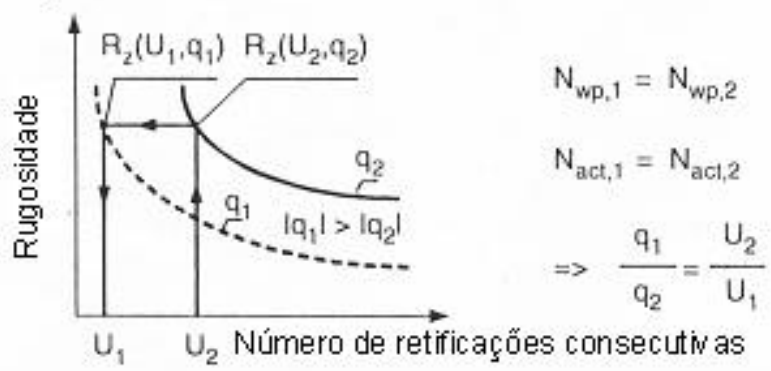

Figura 3.4 - Reprodução cinemática da superfície de saída (adaptado de König e Schröder, 1994 apud Hegener, 1999)

Partindo-se da caracterização de uma região do rebolo, a qual pode ser definida pelo número de arestas ativas de corte $\mathrm{N}_{\mathrm{act}}$ sobre um elemento da superfície do rebolo, calcula-se o número de arestas de corte mapeadas sobre um elemento da superfície da peça, através da equação 3.5:

$\mathrm{N}_{\mathrm{wp}}=\mathrm{q} \cdot \mathrm{N}_{\mathrm{act}} \cdot \mathrm{U}$

Quando o número de arestas de corte mapeadas sobre um elemento da superfície $\left(\mathrm{N}_{\mathrm{wp}}\right)$ permanece constante, sobre condições de contorno de uma topografia de rebolo constante e uma mesma largura de rebolo da região de acabamento, obtêm-se uma rugosidade constante da peça. Este é sempre o caso quando da igualdade da inter-relação entre o número de 
retificações consecutivas e o coeficiente de velocidades, conforme a equação 3.6 (König, Schröder e Treffert, 1993 apud Hegener, 1999):

$\mathrm{U}_{1} \cdot \mathrm{q}_{1}=\mathrm{U}_{2} \cdot \mathrm{q}_{2}$

Um outro fenômeno investigado por König e Schröder (1994) apud Hegener (1999) descreve o comportamento de desgaste quando da utilização de um rebolo de CBN com ligante metálico. Após atingir-se o estado estacionário de retificação e de desgaste (Figura 3.5), o perfil do raio original é modificado para um perfil cônico. Na seqüência do processo obtém-se uma pequena variação da geometria de desgaste e das forças do processo.

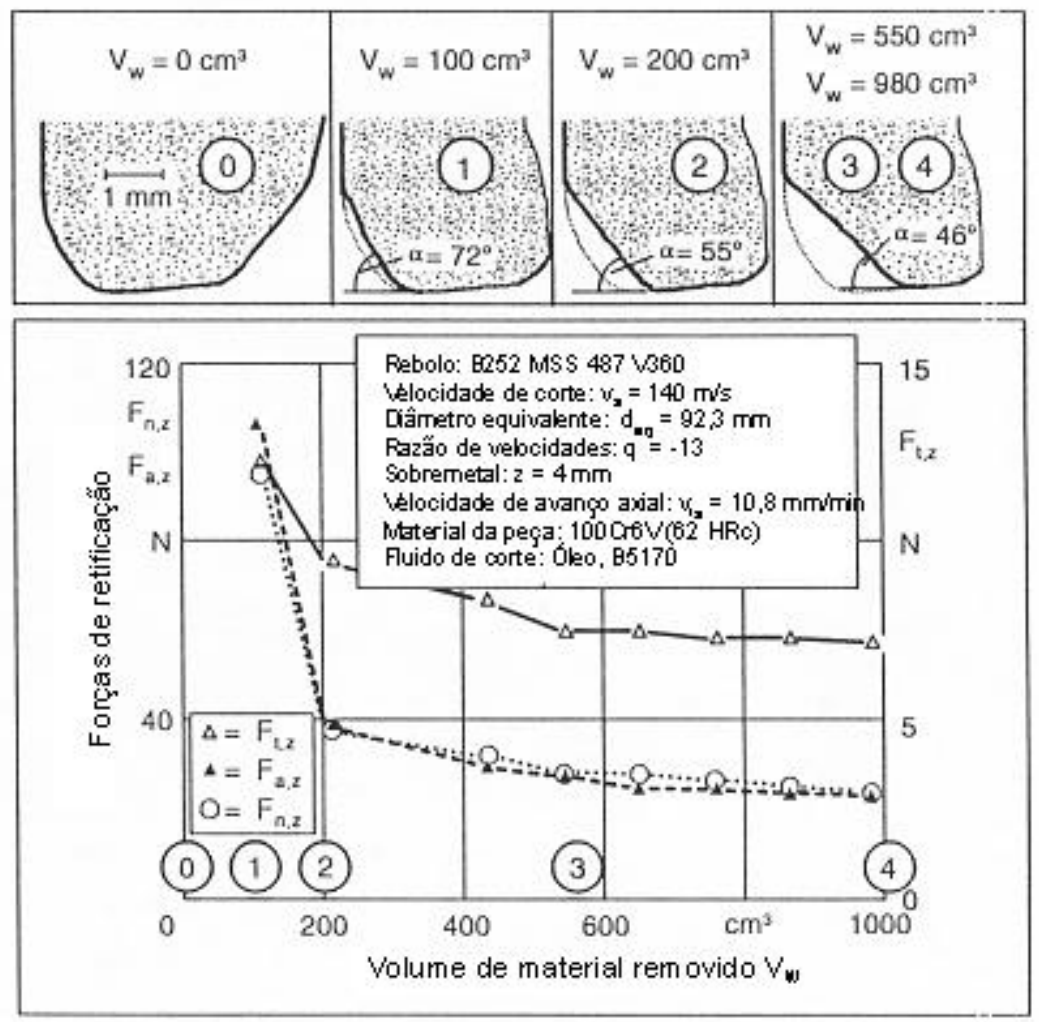

Figura 3.5 - Formação de um processo quase-estacionário (adaptado de König e Schröder, 1994 apud Hegener, 1999)

A grande resistência à abrasão do ligante metálico é na verdade uma vantagem para o processo de retificação, mas causa significantes problemas para a engenharia de aplicação 
deste tipo de ferramentas (Tönshoff, Falkenberg e Friemuth, 1996 apud Hegener, 1999). Já os ligantes vitrificados permitem uma retificação livre e de auto-afiação. Progressos tecnológicos vêm melhorando a resistência ao desgaste destas ligas, a qual é a principal desvantagem em relação aos ligantes metálicos, aumentando assim sua aplicação industrial, principalmente na retificação cilíndrica externa de forma (Gespräche ..., 1997 apud Hegener, 1999).

\subsection{Fundamentos da retificação cilíndrica externa de forma de alto desempenho}

\subsubsection{Introdução}

A geometria do rebolo utilizado na retificação cilíndrica externa de forma não é diretamente relacionada com o contorno da peça e pode ser escolhida de forma livre. O requisito básico para a escolha do perfil a ser utilizado é a possibilidade da usinagem do perfil desejado (Hegener, 1999). Em dependência da combinação geométrica, a estratégia de retificação e os parâmetros de usinagem são escolhidos, a fim de que se possa obter uma retificação dentro dos tempos de usinagem requeridos, sem que haja o comprometimento da qualidade especificada das peças. A análise das condições de contato para os diferentes arranjos rebolo-peça fornece o embasamento teórico para o planejamento do processo de retificação desejado.

O caso mais comum de aplicação da retificação cilíndrica externa de forma é a usinagem da superfície de um elemento de geometria cilíndrica, como por exemplo, um assento de rolamento em um eixo. Uma peça pode apresentar elementos cilíndricos com diferentes comprimentos e diâmetros. Variações no raio, recessos ou raios de arredondamento no contorno da peça fornecem as condições para a escolha da geometria mais adequada do do perfil do rebolo a ser utilizado. 
A retificação cilíndrica externa de forma é qualificada não só para a retificação de elementos com geometria de contorno cilíndrica, mas também para a retificação de faces planas e de variações de contorno cônicas em eixos. A retificação de raios de arredondamento é também um caso de aplicação (Produktinformation ..., 1988 apud Hegener, 1999).

Através da variação do perfil do rebolo e do arranjo geométrico entre os eixos do rebolo e da peça surgem inúmeras possibilidades para o projeto do processo. A seguir são apresentadas as possibilidades básicas de geometria do rebolo:

- rebolo com zona de desbaste ortogonal;

- rebolo com zona de desbaste cônica e

- rebolo com zona de desbaste com raio de arredondamento;

possibilitando assim a usinagem de:

- elemento de peça cilíndrico;

- elemento de peça cônico e

- elemento de peça com geometria arbitrária.

A avaliação de diferentes formatos de rebolo considerando-se suas aptidões para a realização do perfil desejado permite a escolha e o projeto da geometria mais adequada, proporcionando a melhor solução para a retificação dos diferentes elementos de forma presentes na peça retificada em questão. A seguir são apresentados os aspectos teóricos sobre a retificação de elementos cilíndricos em regime de forma (equivalente à retificação de passagem) considerando diversas possíveis geometrias da zona de desbaste.

\subsubsection{Retificação de elementos cilíndricos}

\subsubsection{Zona de desbaste ortogonal}


Através de uma dressagem linear com configuração de eixos paralelos obtém-se um perfil de rebolo com zona de desbaste ortogonal. A cinemática do processo equivale a variante de retificação cilíndrica externa de passagem. A diferença básica entre esta e a de forma de alto desempenho está na maior penetração e menor avanço axial utilizados nesta última.

A Figura 3.6 apresenta o caso da retificação cilíndrica externa de um elemento cilíndrico com zona de desbaste ortogonal, mostrando a secção transversal do plano de corte.

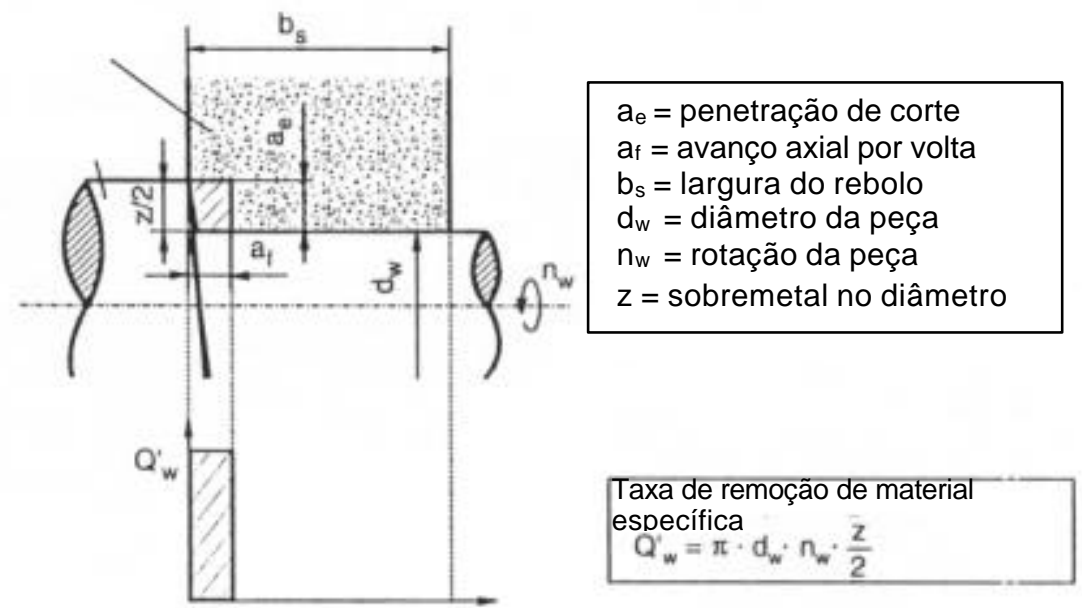

Figura 3.6 - Condições de contato para a retificação cilíndrica externa de forma, para um rebolo com zona geométrica de desbaste ortogonal (adaptado de Hegener, 1999)

A condição de trabalho resulta do arranjo geométrico, numa região do rebolo cuja largura equivale ao avanço axial por volta. A penetração de corte $\left(\mathrm{a}_{\mathrm{e}}\right)$ equivale à metade sobremetal no diâmetro (equação 3.7):

$a_{e}=\frac{z}{2}$

A taxa de remoção de material $\left(\mathrm{Q}_{\mathrm{w}}\right)$ determina-se através do diâmetro da peça $\left(\mathrm{d}_{\mathrm{w}}\right)$, da rotação da peça $\left(\mathrm{n}_{\mathrm{w}}\right)$, do avanço axial por volta $\left(\mathrm{a}_{\mathrm{f}}\right)$ e do sobremetal $(\mathrm{z})$ (equação 3.8) 
$Q_{w}=\pi \cdot d_{w} \cdot n_{w} \cdot a_{f} \cdot \frac{z}{2}$

A taxa de remoção de material específica $\left(Q^{\prime}{ }_{w}\right)$ é calculada através do coeficiente entre a taxa de remoção de material e a largura efetiva de retificação, sendo esta última igual ao avanço axial (equação 3.9).

$$
Q^{\prime}{ }_{w}=\pi \cdot d_{w} \cdot n_{w} \cdot \frac{z}{2}
$$

Considerando-se um rebolo ideal com formato cilíndrico, não susceptível ao desgaste, tem-se que a taxa de remoção de material específica ( $\left.Q_{w}{ }_{w}\right)$ é independente do avanço axial. Entretanto, um aumento do avanço causa um alargamento da zona efetiva de desbaste do rebolo, acarretando em um aumento da taxa de remoção de material $\left(\mathrm{Q}_{\mathrm{w}}\right)$.

O parâmetro (U), o qual descreve o número de vezes consecutivas que um mesmo elemento de área da superfície da peça é retificado, é descrito conforme a equação 3.10.

$$
U=\frac{b_{s}}{a_{f}}
$$

Desta forma, um aumento no avanço axial causa uma diminuição no parâmetro (U).

\subsubsection{Zona de desbaste cônica}

Uma das formas de se evitar o carregamento localizado do rebolo quando da utilização de uma geometria ortogonal é a introdução, através do processo de dressagem, de uma região de desbaste cônica em rebolos convencionais empregados na retificação peel-grinding 
(Wünsche, 1992 pud Hegener, 1999). Uma desvantagem desta configuração cônica encontrase na redução da flexibilidade da operação, não sendo possível produzir-se uma transição em canto vivo entre uma face cilíndrica para uma face plana (König, Schröder e Treffert, 1993 apud Hegener, 1999).

As condições de contato, quando se adota uma zona de desbaste cônica, são apresentadas na Figura 3.7. A projeção do plano de corte evidencia uma distribuição da região efetiva de corte em várias outras de largura a. Como a penetração de trabalho não é constante ao longo de toda a região de corte do rebolo, deve-se calcular a penetração efetiva ae,eff , para se determinar o carregamento das diversas regiões do rebolo. Quatro regiões distintas podem ser identificadas:

- Região I: A penetração efetiva $a_{e, e f f}$ aumenta de zero até seu valor máximo;

- Região II: A penetração efetiva $\mathrm{a}_{\mathrm{e}, \mathrm{eff}}$ apresenta um valor constante;

- Região III: A penetração efetiva $\mathrm{a}_{e, \text { eff }}$ decresce do valor máximo até zero;

- Região IV: A penetração efetiva $\mathrm{a}_{\mathrm{e}, \mathrm{eff}}$ é, teoricamente igual a zero.

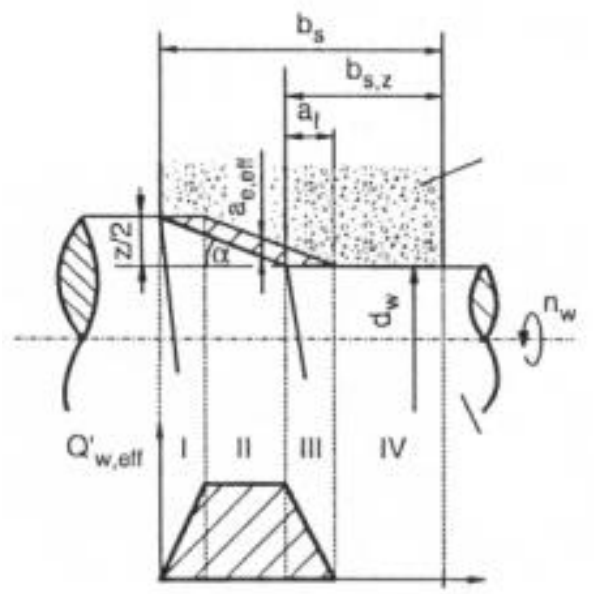

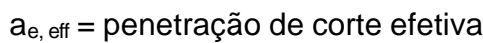

$a_{\mathrm{f}}=$ avanço axial por volta

$\mathrm{b}_{\mathrm{s}}=$ largura ativa do rebolo

$\mathrm{b}_{\mathrm{s}, \mathrm{z}}=$ largura cilíndrica do rebolo

$\mathrm{d}_{\mathrm{w}}=$ diâmetro da peça

$\mathrm{n}_{\mathrm{w}}=$ rotação da peça

$\mathrm{z}=$ sobremetal no diâmetro

$\alpha=$ ângulo de entrada da zona de desbaste

Região II para $\quad \tan \alpha<\frac{z}{2 \cdot a_{f}}$

$\mathrm{Q}_{w, \text { eft }}^{\prime}=\pi \cdot \mathrm{d}_{\mathrm{w}} \cdot \mathrm{n}_{\mathrm{w}} \cdot \mathrm{a}_{\mathrm{i}} \cdot \tan \alpha$

Figura 3.7 - Condições de contato para a retificação cilíndrica externa de forma, para um rebolo com zona geométrica de desbaste cônica e peça cilíndrica (Adaptado de Hegener, 1999)

As regiões I e II são identificadas como sendo as regiões de desbaste. A região III é a de acabamento, onde praticamente não se executa a remoção de material, sendo responsável 
por influenciar a rugosidade da peça, através do parâmetro U. A região IV é a região de sparkout.

$\mathrm{O}$ cálculo da taxa de remoção de material $\left(\mathrm{Q}_{\mathrm{w}}\right)$ é independente da geometria de desbaste e é calculada através da equação 3.8. Todavia a taxa de remoção de material específica efetiva $Q_{\text {w,eff }}$ é dependente da geometria do rebolo e é calculada através da equação 3.11 .

$Q_{w, e f f}^{\prime}=\pi \cdot d_{w} \cdot n_{w} \cdot a_{e, e f f}$

Três condições cinemáticas podem ser identificadas:

- Caso 1: $\tan \alpha<\frac{z}{2 \cdot a_{f}}$

Para esta condição de usinagem, a penetração efetiva na região II e a taxa de remoção de material específica efetiva são dadas pelas equações 3.13 e 3.14, respectivamente:

$a_{e, e f f}=a_{f} \cdot \tan \alpha$

$Q^{\prime}{ }_{w, e f f}=\pi \cdot d_{w} \cdot n_{w} \cdot a_{f} \cdot \tan \alpha$

No caso de um ângulo plano e um avanço axial pequeno as áreas de borda I e II podem ser negligenciadas, podendo-se assumir um valor constante para a taxa de remoção de material específica efetiva $\left(\mathrm{Q}_{\mathrm{w}, \mathrm{eff}}\right)$ para toda a região de desbaste. De forma oposta à

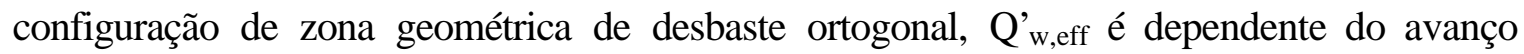
axial af é independente do sobremetal z. 
- Caso 2: $\tan \alpha=\frac{z}{2 . a_{f}}$

Para este caso marginal não incide uma penetração efetiva constante. Esta cresce a um valor máximo ao longo da região de desbaste e cai imediatamente na zona plana. A máxima penetração efetiva é calculada pela equação 3.16 .

$a_{e, e f f}=\frac{z}{2}$

- Caso 3: $\tan \alpha>\frac{z}{2 \cdot a_{f}}$

Para este caso as larguras das regiões I e III são menores que o avanço axial $a_{f}$ Conseqüentemente, obtém-se na região II uma penetração efetiva constante, a qual equivale ao sobremetal radial (equação 3.16). Para $\alpha=90^{\circ}$ têm-se uma geometria de desgaste ortogonal.

Num rebolo com geometria cônica, a região de spark-out envolve a geração da rugosidade da peça. O número de retificações consecutivas sobre a zona de retificação cilíndrica U é descrito conforme a equação 3.18 .

$U=\frac{b_{s, z}}{a_{f}}$

\subsubsection{Zona de desbaste com raio de arredondamento}


A utilização de uma geometria com raio de arredondamento têm por objetivo evitar o carregamento localizado do rebolo obtido quando da utilização de uma geometria ortogonal. De forma comparativa com o perfil cônico, existem menores restrições quanto ao formato da peça possível de ser usinada. Transições de contorno na região dos assentos de espelhos (faces planas) podem ser usinadas através da utilização de rebolos com raios de arredondamentos dressados via CNC.

As condições de contato através da adoção de uma zona geométrica de desbaste com raio de arredondamento são apresentadas na Figura 3.8.
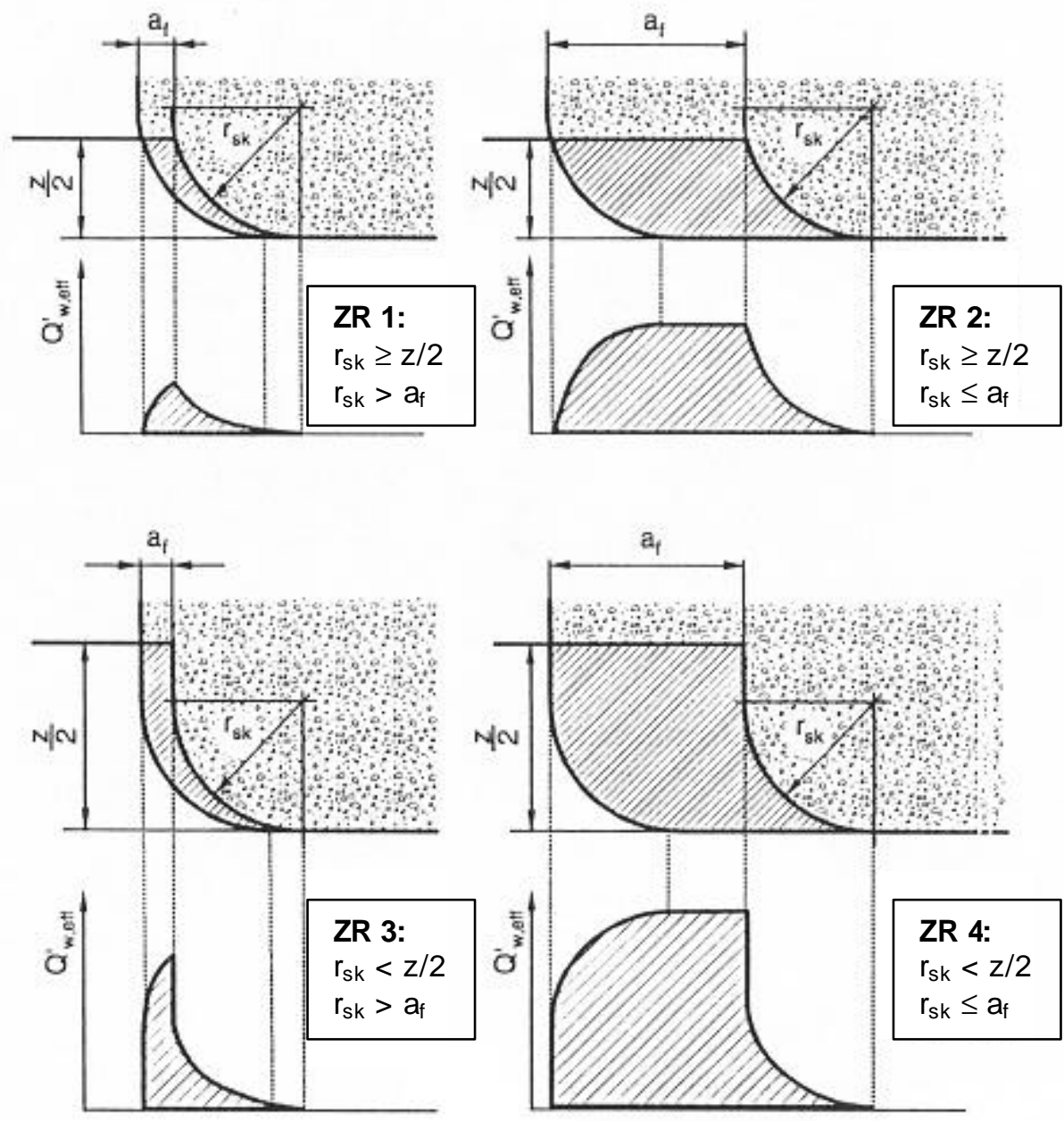

Figura 3.8 - Condições de contato para a retificação cilíndrica externa de forma, para um rebolo com zona geométrica de desbaste com raio de arredondamento e peça cilíndrica (adaptado de Hegener, 1999) 
Nesta condição, a penetração efetiva $a_{e, \text { eff }}$ varia ao longo da região de desbaste, resultando em carregamentos locais na zona de desbaste. A determinação da taxa de remoção de material específica local é dada pela equação 3.11. Diferentes condições de contato, considerando-se diferentes carregamentos na região de desbaste são obtidas, os quais dependem dos seguintes fatores: raio de canto do rebolo $\mathrm{r}_{\mathrm{k}}$, sobremetal da peça $\mathrm{z}$ e avanço axial af.

- Caso 1: $r_{s k} \geq \frac{z}{2} \mathrm{e} r_{s k}>a_{f}$

Para esta variante o sobremetal radial e o avanço axial são menores que o raio de canto do rebolo. Obtém-se um carregamento na zona de desbaste constante, similar com que ocorre no caso da geometria cônica. A principal vantagem desta configuração é a redução da penetração efetiva a,,eff. Considerando-se a face plana como referência, o máximo valor de penetração ocorre a uma distância mais afastada da face, o que reduz a incidência de danos térmicos.

- Caso 2: $r_{s k} \geq \frac{z}{2} \mathrm{e} r_{s k} \leq a_{f}$

Para este caso a penetração efetiva Ł,eff cresce de zero até um valor máximo, mantendo-se neste patamar por um determinado trecho, decrescendo novamente a zero. A condição de carregamento (solicitação/força) na região de desbaste do rebolo é da mesma forma elevada como ocorre na retificação com zona de desbaste ortogonal.

- Caso 3: $r_{s k}<\frac{z}{2}$ e $r_{s k}>a_{f}$ 
Para esta variante tem-se um sobremetal elevado e um pequeno avanço axial, originando uma região estreita de elevada solicitação. De forma similar ao caso 1, a máxima penetração efetiva ocorre a uma distância afastada do contorno final do rebolo. Este efeito é favorável para a prevenção dos danos térmicos. O máximo carregamento localizado é maior que o observado no caso 1, o que levará a um maior desgaste do rebolo.

- Caso 4: $r_{s k}<\frac{z}{2} \mathrm{e} r_{s k} \leq a_{f}$

Para esta condição de usinagem, em que o sobremetal e o avanço axial são maiores que o raio de canto do rebolo, tem-se que a penetração efetiva $a_{e, \text { eff }}$ equivale ao sobremetal radial. Esta condição de usinagem é tão desfavorável quanto a condição com geometria de desbaste ortogonal.

\subsection{Retificação cilíndrica externa de forma de alto desempenho na retificação de faces planas (espelhos) de virabrequins}

\subsubsection{Apresentação}

A retificação cilíndrica externa de forma de alto desempenho é um processo de retificação flexível no qual diferentes elementos com simetria no eixo de rotação podem ser usinados. Elementos não cilíndricos, como por exemplo, uma face plana em um eixo de acoplamento ou como a região denominada "espelho" de um virabrequim (Figura 3.9) podem ser retificados com esta técnica. 

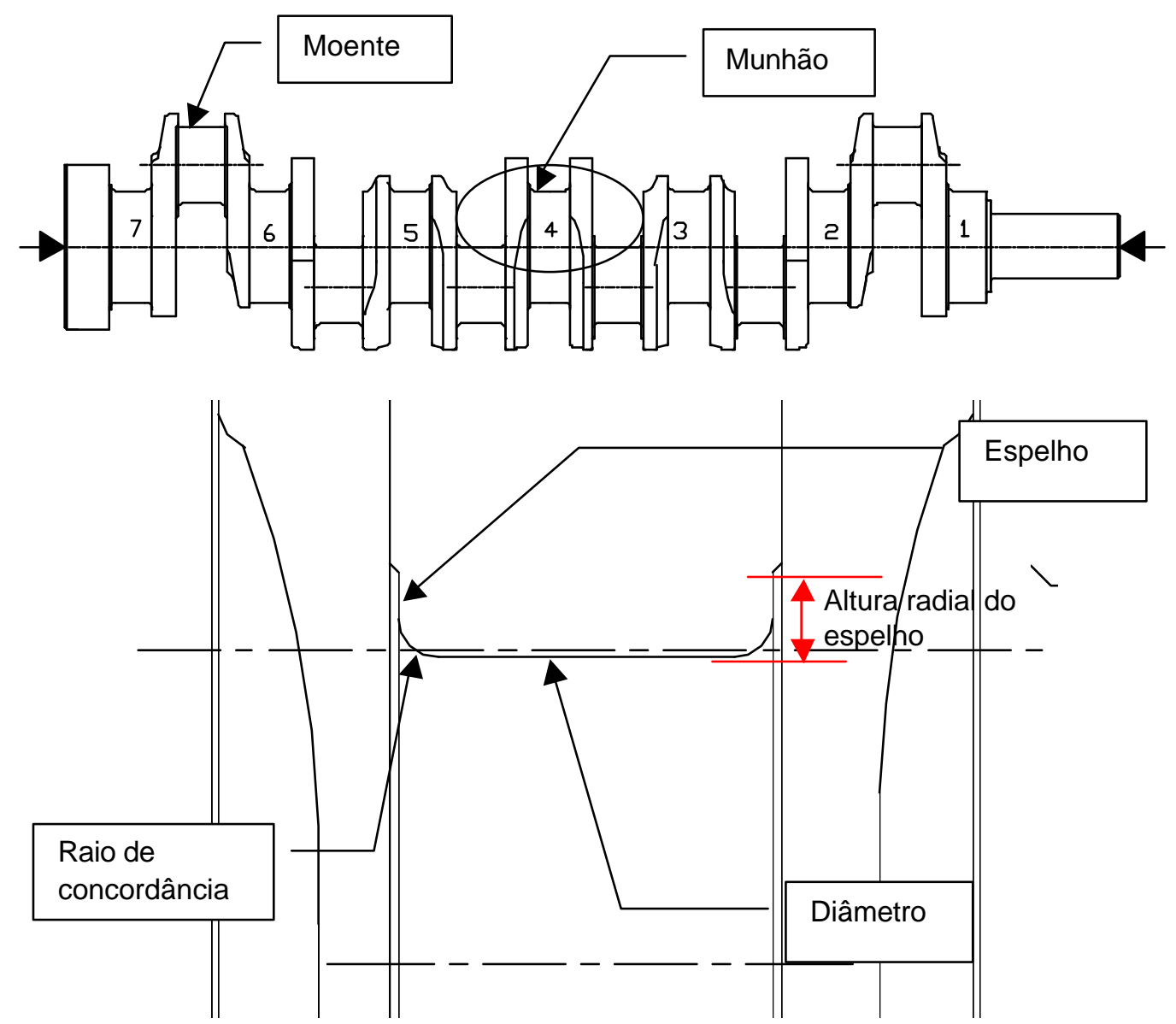

Figura 3.9 - Partes constituintes de um virabrequim - Detalhe de um munhão

Os elementos básicos para a retificação das faces planas são apresentados na Figura 3.10. A principal variação geométrica neste elemento encontra-se na transição entre a face ortogonal e a face paralela ao eixo de rotação da peça. Esta pode apresentar um raio de arredondamento, o qual deverá ser reproduzido no rebolo. A segunda variante encontra-se na execução de um rebaixo (undercutting), sendo que neste caso é possível a utilização de uma zona geométrica de desbaste de forma livre.

As forças associadas com a retificação dos diâmetros são moderadas não se apresentando como limitação para o desempenho da operação. Já a retificação dos espelhos representa um limitante para o ciclo de retificação, resultado da solicitação extrema dos 
cantos do rebolo. A elevada pressão de contato proporciona uma excessiva liberação de grãos do rebolo, causando a degradação de seu perfil, gerando erros de forma na peça retificada.

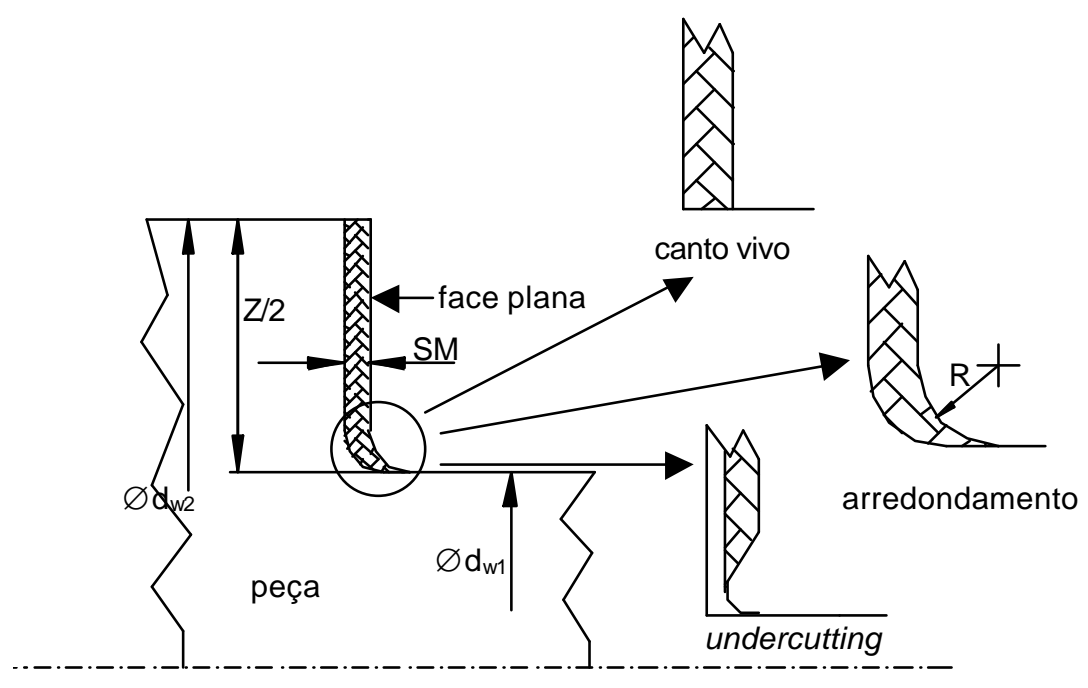

Figura 3.10 - Elementos constituintes de uma face plana

As dimensões e a qualidade superficial do raio de concordância entre o espelho e o diâmetro do colo são essenciais para a resistência mecânica e para o desempenho dos virabrequins. A altura radial dos espelhos podem atingir valores acima de $6 \mathrm{~mm}$ e o sobremetal a ser removido pode variar entre 0,2 e $0,6 \mathrm{~mm}$ ao longo de todo o perfil, dependendo do tipo e tamanho do virabrequim (Sheldon e Shuyuan, 1995).

O método preferencial para a retificação dos espelhos é através de mergulho utilizando-se avanços radiais elevados, muitas vezes superiores ao utilizados para a retificação do diâmetro do colo. As altas taxas de remoção de material específica $\left(\mathrm{Q}_{\mathrm{w}}{ }_{\mathrm{w}}\right)$ e os requisitos de um raio de arredondamento suave entre o espelho e o diâmetro do colo levam a uma condição de sobrecarga no canto do rebolo.

O surgimento de um ressalto ou de um "ombro" no raio de aredondamento, resultado do desgaste não-uniforme do rebolo é uma das maiores causas da rejeição do virabrequim retificado. Nestes casos, o rebolo deve ser dressado a fim de se restabelecer o perfil desejado. 
Devido às diferenças entre as propriedades dos grãos e ligantes, bem como as distintas velocidades de corte empregadas, rebolos convencionais e de CBN apresentam desempenho distintos quando da operação de retificação dos espelhos. Rebolos convencionais são dressados a cada colo usinado. Já no caso de rebolos de CBN, o número de ciclos realizados é significativamente maior (500 colos, por exemplo). A variação no número de peças por dressagem é resultado da sobrecarga nas extremidades do rebolo, já que o desvio no perfil obtido na peça resulta na necessidade de nova dressagem.

Alternativas vêem sendo estudadas, visando-se reduzir o desgaste das extremidades do rebolo. Estas incluem: a adoção de rebolos de CBN com diferentes durezas de ligante ao longo da estrutura do rebolo, concentrando-se a de maior dureza nas laterais do mesmo, além do estudo de novas estratégias de retificação, objeto deste trabalho.

Desta forma, o fator principal para a execução econômica desta retificação encontra-se na escolha da estratégia de usinagem mais adequada. De forma geral, para a retificação de faces planas surgem duas estratégias principais (Figura 3.11):

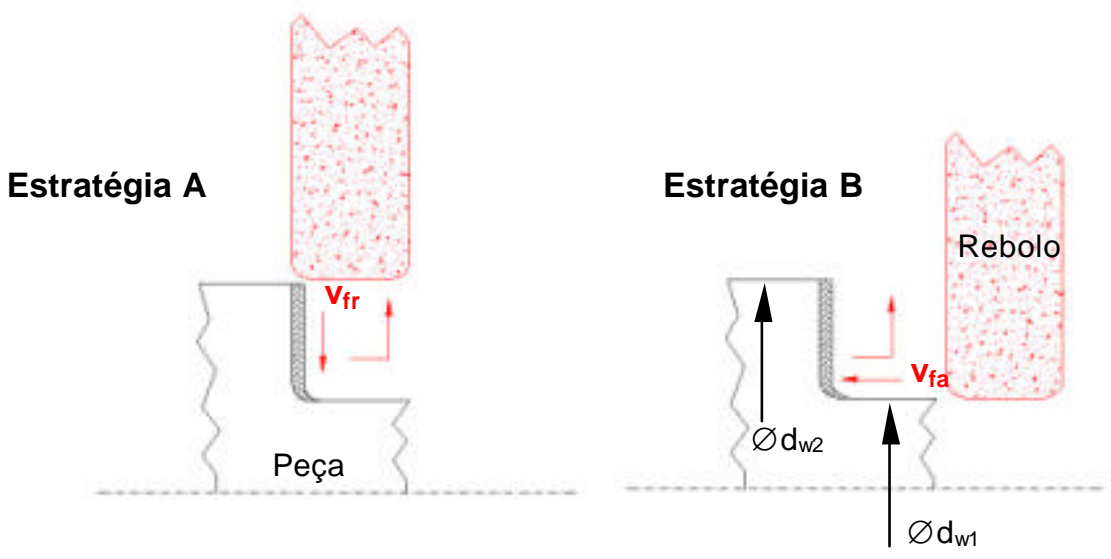

Figura 3.11 - Estratégias para a retificação de faces planas

A estratégia de retificação de mergulho é a estratégia usualmente aplicada (estratégia A). Nesta utiliza-se um rebolo com todo o perfil do colo (raios de arredondamento ou canto vivo) copiado em sua superfície, o qual é gerado durante a operação de dressagem. Neste 
caso, existe apenas uma operação de mergulho, usinando-se a face retificada. A velocidade de mergulho é na direção radial $\left(\mathrm{v}_{\mathrm{fr}}\right)$. Ao final do movimento na direção radial, o rebolo é movimentado axialmente, afastando-se do espelho, para retornar a posição de início de ciclo. Já a estratégia B caracteriza-se pela usinagem do espelho do virabrequim partindo nas proximidades da posição acabada em $\mathrm{X}$, com velocidade de avanço na direção axial ( $\left.\mathrm{v}_{\mathrm{fa}}\right)$, removendo-se o sobremetal utilizando-se o canto do rebolo. Atingindo-se a posição acabada em Z, o rebolo é retornado axialmente à posição de origem.

Para a estratégia A, a taxa de remoção de material específica ( $\left.Q_{w}^{\prime}\right)$ é calculada através da equação 3.23:

$$
Q^{\prime}{ }_{w}=\pi \cdot d_{w} \cdot v_{f r}
$$

Segundo Merbecks (2002) a determinação de Q' w para estratégia B é, de forma oposta a estratégia $\mathrm{A}$, não tão claramente definida. $\mathrm{O}$ processo da estratégia $\mathrm{B}$ aproxima-se de uma retificação rotativa lateral de mergulho, cuja cinemática é apresentada na Figura 3.12. Para esta estratégia aumentam-se as exigências quanto ao perfil do rebolo e à aplicação de fluido de corte. 


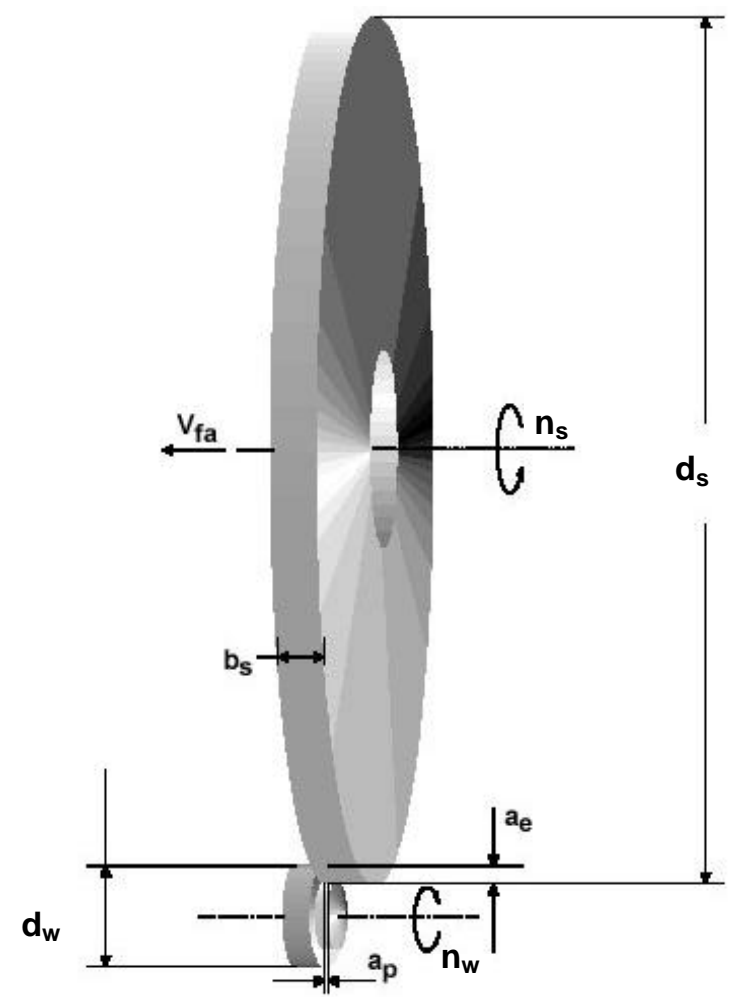

Figura 3.12 - Cinemática da estratégia B (adaptado de Merbecks 2002)

Merbecks (2002) realizou testes de retificação de espelhos avaliando as duas estratégias mencionadas (A e B) num aço $16 \mathrm{MnCr} 5$ (61 HRc). Faces planas de peças com três diferentes diâmetros $\mathrm{d}_{\mathrm{w} 2}(40,50$ e $60 \mathrm{~mm})$ foram retificadas. Para todos os diâmetros, o sobremetal radial (altura do espelho) foi igual a 5 mm (Figura 3.13).

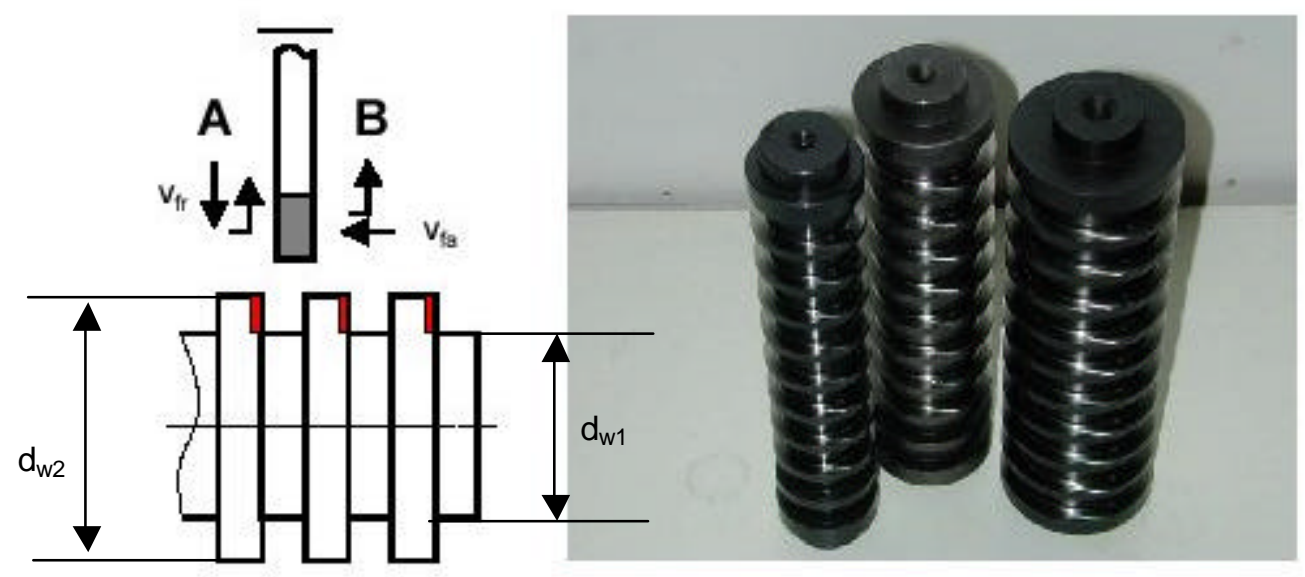

Figura 3.13 - Dimensões dos Corpos-de-prova (adaptado de Merbecks 2002) 
As condições de usinagem e dressagem foram as seguintes:

- Dressagem:

○ Rolo diamantado: SG71P 250 0,6 (D602);

○ Velocidade de corte $\mathrm{v}_{\mathrm{s}}$ durante a dressagem: $100 \mathrm{~m} / \mathrm{s}$;

○ razão de velocidades durante a dressagem $q_{d}=+0,7$;

- Retificação:

○ Rebolo B126VSS2804 J1 SLV 450 E

○ Velocidade de corte $\mathrm{v}_{\mathrm{s}}: 100 \mathrm{~m} / \mathrm{s}$;

○ razão de velocidades $q=-60$ (discordante);

○ Estratégia A (retificação de mergulho):

- $\mathrm{Q}^{\prime}{ }_{\mathrm{w}}=18,6,37,2$ e $55,8 \mathrm{~mm}^{3} / \mathrm{mm} . \mathrm{s}$;

- Tempo de corte $\left(t_{c}\right)=36,4,18,2,12,1 \mathrm{~s}$.

- Sobremetal no espelho (SM) 0,1, 0,3 e $0,5 \mathrm{~mm}$

○ Estratégia B (retificação axial):

- $\mathrm{v}_{\mathrm{fa}}=1,2,5$ e $5 \mathrm{~mm}^{3} / \mathrm{mm} . \mathrm{s}$;

- Sobremetal no espelho (SM) 0,1,0,3 e 0,5 mm

- Parâmetros de avaliação das duas estratégias:

○ Força normal e tangencial

○ Rugosidade $\mathrm{R}_{\mathrm{Z}}$

- Presença de dano térmico na peça

Merbecks 2002 verificou que os menores valores de força normal e tangencial e de rugosidade $\mathrm{R}_{\varepsilon}$ foram observados quando da utilização da estratégia $\mathrm{A}$, não ocorrendo também a incidência de danos térmicos na peça. $\mathrm{O}$ máximo valor de rugosidade $\mathrm{R}_{\mathrm{z}}$ foi igual à $2,12 \mu \mathrm{m}$ para o diâmetro igual a $60 \mathrm{~mm}$, com sobremetal no espelho igual a $0,5 \mathrm{~mm}$. Para o diâmetro 
de $60 \mathrm{~mm}$ e sobremetal $0,5 \mathrm{~mm}$ também foram detectados os maiores valores de força normal e tangencial, sendo eles 0,98 e $2,35 \mathrm{~N}$, respectivamente.

Quando da realização dos testes com a estratégia B, durante os testes preliminares bi detectado o empastamento do rebolo (Figura 3.14). A configuração de dressagem na retificadora utilizada por Merbecks não permitia a dressagem da lateral do rebolo, sendo que o material empastado no rebolo era removido através de uma operação de avivamento utilizando-se um bloco de SiC. A retificadora ainda não possuía um sistema de limpeza a alta pressão. Assim, dos avanços inicialmente propostos foram testados os avanços igual a 1 e 2,5 $\mathrm{mm} / \mathrm{min}$, sendo este último o avanço limite para uma rotação da peça de $528 \mathrm{rpm}$. Excluiu-se ainda o teste com sobremetal igual a $0,5 \mathrm{~mm}$.
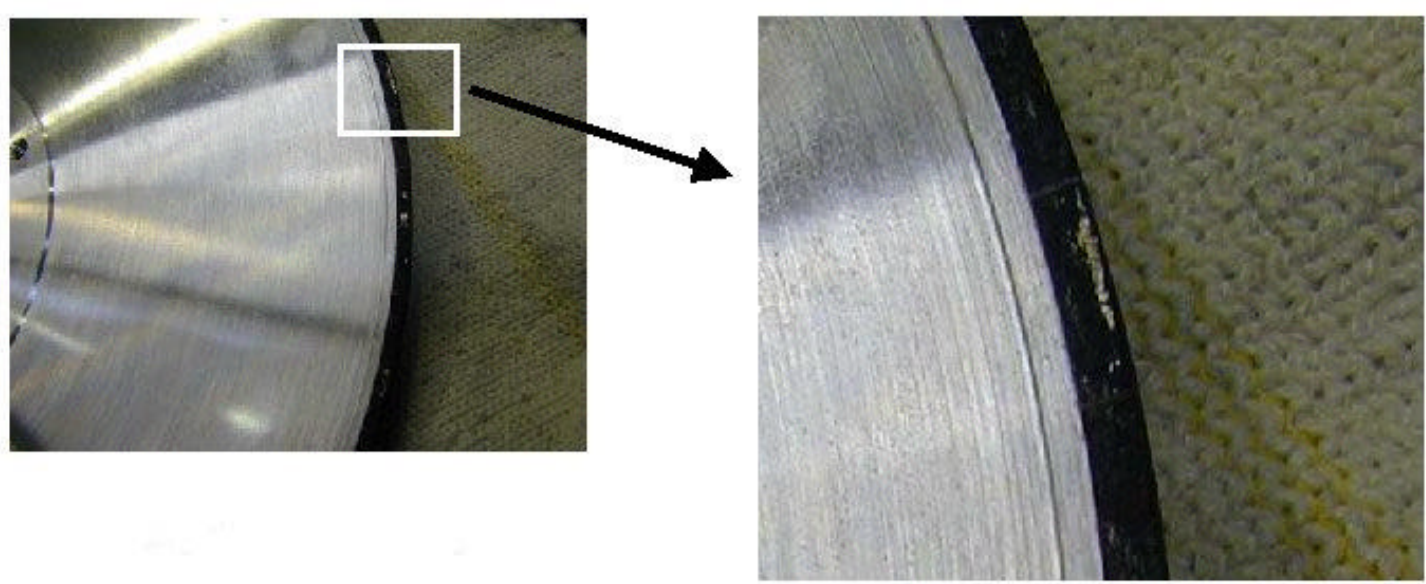

Figura 3.14 - Empastamento do rebolo na lateral quando da utilização da estratégia B (Merbecks, 2002)

Para a estratégia B (retificação axial) foram verificados os maiores valores de rugosidade e forças tangencial e normal, sendo que os maiores valores foram observados para o diâmetro de $60 \mathrm{~mm}$ para o sobremetal no espelho igual a $0,3 \mathrm{~mm}$. Obteve-se uma rugosidade $R_{z}$ igual a 2,6 $\mu \mathrm{m}$ e forças normal e tangencial iguais a 29 e $16 \mathrm{~N}$, respectivamente. Segundo Merbecks (2002), as causas para o aumento das forças de retificação estão relacionadas à topografia da lateral do rebolo e a maior área de contato 
observada para a estratégia B. Uma aproximação para o cálculo da área de contato para as estratégias A e B é apresentada na Figura 3.15.
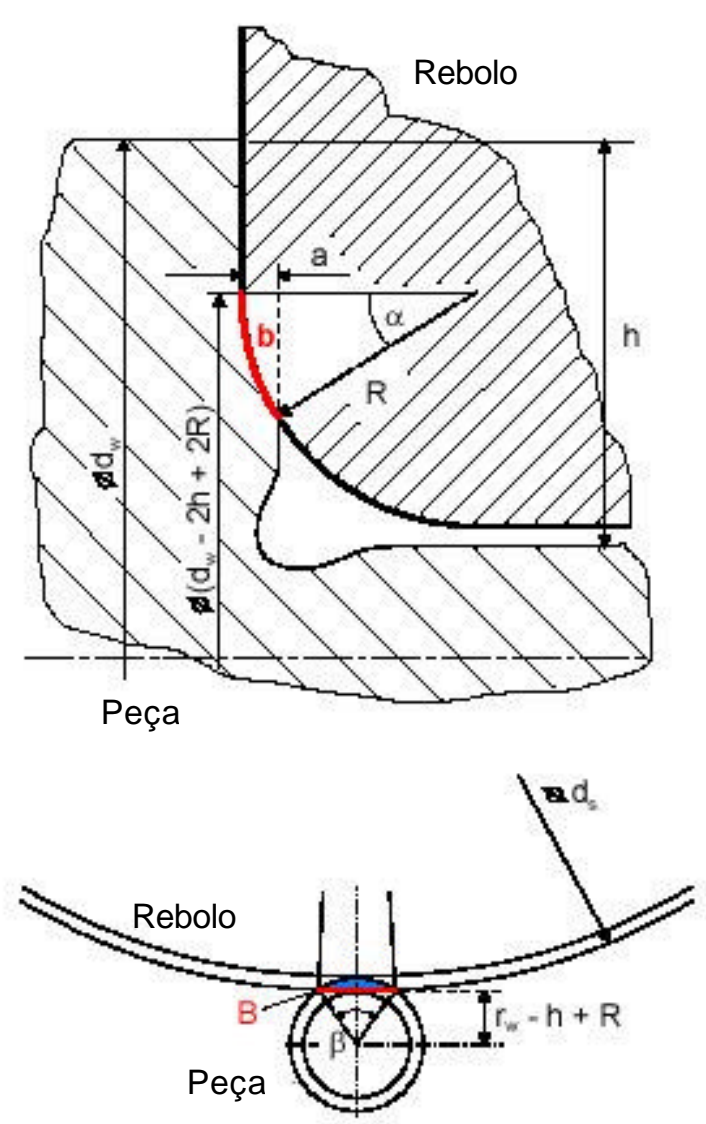

$\mathrm{F}_{\text {Varianis } \mathrm{A}}=\mathrm{bB}$

$\frac{b}{2 \Pi R}=\frac{\alpha}{360^{\circ}}$

$\cos \alpha=\frac{\mathrm{R}-\mathrm{a}}{\mathrm{R}}$

$b=\frac{2 \Pi R}{360^{\circ}} \arccos \left(\frac{R-a}{R}\right)$

$r_{w}{ }^{2}=\left(\frac{B}{2}\right)^{2}+\left(r_{w}-h+R\right)^{2}$

$B=2 \sqrt{d_{n}(h-R)+2 h R-h^{2}-R^{2}}$

$\mathrm{F}_{\text {Variante B }}=\mathrm{F}_{\text {Variante A }}+\mathrm{F}_{\text {Face lateral }}$

$F_{\text {Face lateral }}=F_{\text {semi-circulo }}-F_{\text {triângulo }}$

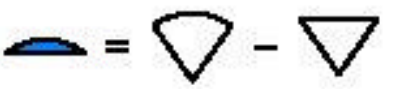

$F_{\text {semi-circulo }}=\Pi r_{w}{ }^{2}\left(\frac{\beta}{360^{\circ}}\right)$

$\cos \frac{\beta}{2}=\frac{r_{w}-h+R}{r_{w}}$

$F_{\text {triangulo }}=2 B\left(r_{w}-h+R\right)$

Figura 3.15 - Cálculo da área de contato para as estratégias A e B (Merbecks, 2002)

A Tabela 3.1 apresenta a comparação entre as áreas de contato $\left[\mathrm{mm}^{2}\right]$ para as estratégias A (retificação de mergulho) e B (retificação axial) (Merbecks, 2002).

Tabela 3.1 - Área de contado para as estratégias A e B (Merbecks, 2002)

\begin{tabular}{|c|c|c|c|c|c|c|}
\cline { 2 - 7 } \multicolumn{1}{c|}{} & \multicolumn{6}{c|}{ Sobremetal no espelho [mm] } \\
\cline { 2 - 7 } \multicolumn{1}{c|}{} & \multicolumn{2}{c|}{0,1} & \multicolumn{2}{c|}{0,3} & \multicolumn{2}{c|}{0,5} \\
\hline $\mathrm{d}_{\mathrm{w} 2}[\mathrm{~mm}]$ & Estrat. A & Estrat. B & Estrat. A & Estrat. B & Estrat. A & Estrat. B \\
\hline 40 & 13,4 & 91,7 & 23,4 & 101,7 & 30,5 & 108,8 \\
\hline 50 & 15,1 & 112,3 & 26,4 & 123,6 & 34,3 & 131,5 \\
\hline 60 & 16,6 & 133,6 & 29,0 & 146,0 & 37,8 & 154,8 \\
\hline
\end{tabular}

De forma oposta ao observado para a estratégia A, para os testes da estratégia $\mathrm{B}$, com diâmetro de 50 e $60 \mathrm{~mm}$ foram detectados danos térmicos decorrentes do processo de 
retificação axial, sendo que o mais intenso foi detectado para o diâmetro de $60 \mathrm{~mm}$, va $=2,5$ $\mathrm{mm} / \mathrm{min}$ e sobremetal no espelho de $0,3 \mathrm{~mm}$ (Figura 3.16).

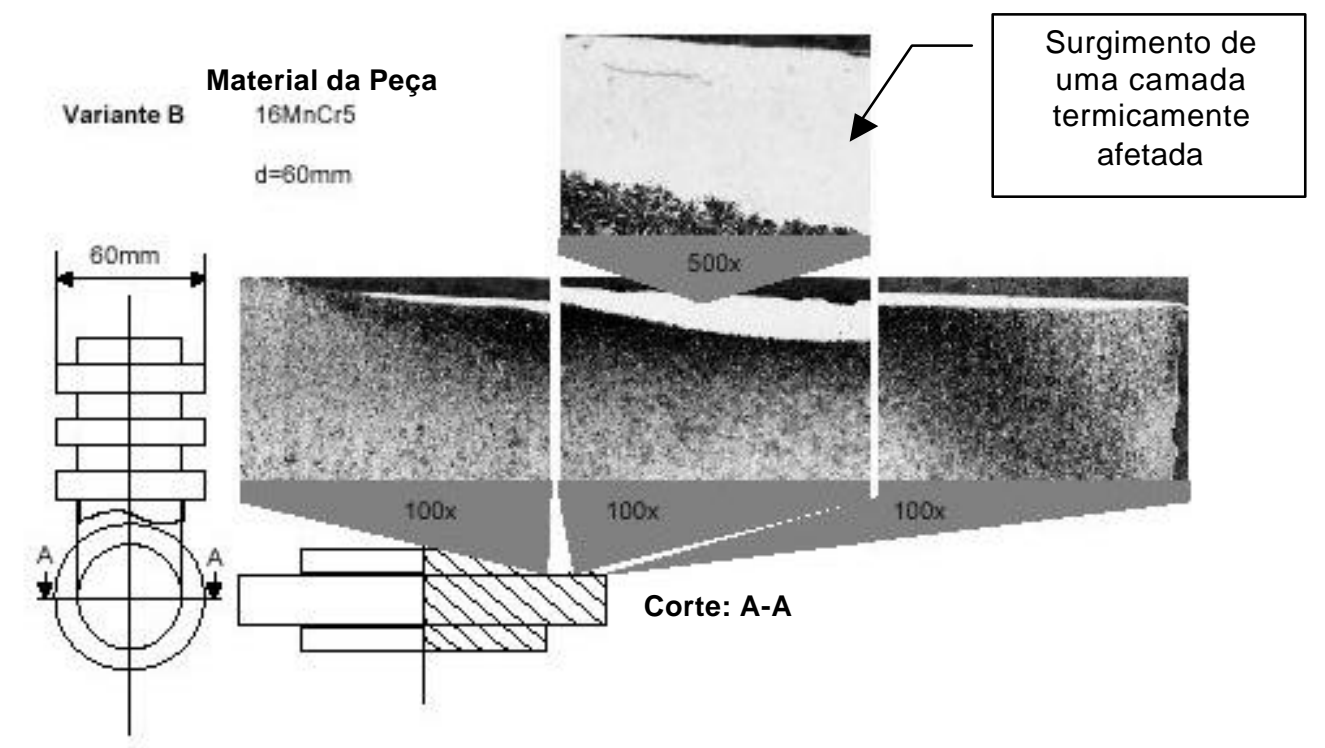

Figura 3.16 - Cálculo da área de contato para as estratégias A e B (Merbecks, 2002)

Em seu trabalho, Merbecks (2002) conclui que a estratégia A (retificação de mergulho) foi a que apresentou melhores resultados. Contudo, a não possibilidade de dressagem da lateral do rebolo, adicionalmente a maior área de contato resultante da configuração da lateral do rebolo foram fatores determinantes para os resultados obtidos na estratégia B (retificação axial), não permitindo uma comparação adequada. Todavia é sugerida a utilização da retificação de mergulho (estratégia A) em retificadoras que não possibilitem a dressagem da lateral do rebolo. 


\section{ANÁLISE TEÓRICA E MODELOS SOBRE A OPERAÇÃO DE RETIFICAÇÃO CILÍNDRICA EXTERNA DE FORMA APLICADA À RETIFICAÇÃO DE FACES PLANAS COM EIXOS PARALELOS}

Conforme apresentado no item 3.4, a retificação cilíndrica externa de forma de alto desempenho de faces planas apresenta, basicamente, duas estratégias de retificação: a retificação de mergulho (estratégia A) e a retificação axial (estratégia B). O sucesso da utilização de cada estratégia depende do conhecimento detalhado da cinemática de cada processo e como os principais fatores geométricos e variáveis do processo poderão influenciar o resultado final da operação. Os aspectos principais de cada configuração serão apresentados a seguir.

\subsection{Aspectos teóricos da retificação de mergulho - estratégia A}

Para a retificação de mergulho (estratégia A), a taxa de remoção de material específica (Q’ $\left.{ }_{w}\right)$ é calculada através da equação 3.23:

$Q^{\prime}{ }_{w}=\pi \cdot d_{w} \cdot v_{f r}$

$\mathrm{Na}$ estratégia de retificação adotada, o rebolo parte do diâmetro $\mathrm{d}_{\mathrm{w} 2}$ devendo percorrer todo o sobremetal radial $(\mathrm{Z} / 2)$ até atingir o diâmetro $\mathrm{d}_{\mathrm{v} 1}$, completando assim a retificação do espelho. 
Para uma face plana sem raio de arredondamento ou com undercutting, a variação geométrica significativa entre os diâmetros $d_{w 1}$ e $d_{w 2}$ leva a uma variação significativa na velocidade da peça ao longo do perfil retificado. Tem-se que o máximo valor da taxa de remoção de material específica $\left(\mathrm{Q}_{\mathrm{w}}{ }_{\mathrm{w}}\right)$ é calculado no diâmetro $\mathrm{d}_{\mathrm{w} 2}$. De forma análoga, o menor valor de $\mathrm{Q}_{\mathrm{w}}$ será obtido no diâmetro $\mathrm{d}_{\mathrm{wl}}$. Além disso, tomando-se a face do rebolo como referência, o valor de $\mathrm{Q}_{\text {w }}$ será constante na região do rebolo com largura igual ao valor do sobremetal da face da peça. Variações da velocidade de mergulho $\left(\mathrm{v}_{\mathrm{fr}}\right)$ também resultam em alterações no valor de Q' w.

No caso de uma face plana com raio de arredondamento (Figura 4.1), a distribuição de Q' ${ }_{\text {w }}$ ao longo do perfil do rebolo segue a mesma distribuição verificada para o caso anterior. Adicionalmente tem-se uma distribuição de Q' ${ }_{\text {w }}$ ao longo do raio do rebolo à medida que este toca as porções do raio da peça $\left(d_{w j}\right)$. Todavia, em ordem de magnitude, os valores de $Q^{\prime}$ w observados são significativamente menores que os da porção do rebolo referente ao sobremetal removido na parede do espelho.
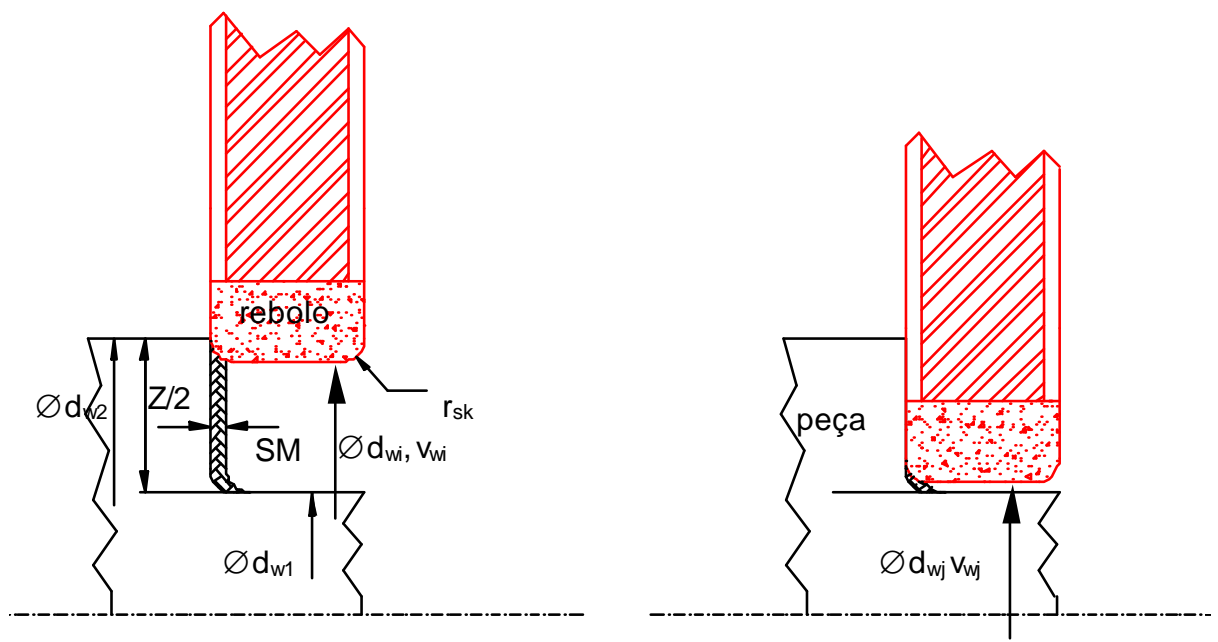

Figura 4.1 - Retificação de face plana com raio de arredondamento - Estratégia A - Mergulho 


\subsection{Aspectos teóricos da retificação axial - estratégia B}

\subsubsection{Modelo geométrico considerando um rebolo com zona de desbaste com raio de arredondamento}

Um modelo teórico de retificação é aqui proposto para a retificação axial, com a indicação das regiões de formação de cavaco, conforme apresentado na Figura 4.2. Nesta temse: $a=$ avanço axial por volta; $\gamma_{i}=$ ângulo complementar; $\alpha_{i}=$ ângulo de engajamento peçarebolo; $\xi$ = ângulo de hélice; $d$ = diâmetro externo do rebolo; $d_{\mathrm{wl}}=$ diâmetro interno do colo; $\mathrm{d}_{\mathrm{w} 2}=$ diâmetro externo do colo; $\mathrm{t}=$ tempo de corte; $\mathrm{v}_{\mathrm{fa}}=$ avanço axial; $\mathrm{h}_{\text {náx }}=$ espessura máxima do cavaco; $\mathrm{L}=$ espaçamento médio entre os grãos; $\mathrm{l}=$ comprimento de contato; $\mathrm{n}_{\mathrm{v}}=$ rotação da peça; $\mathrm{v}_{\mathrm{s}}=$ velocidade de corte $; \mathrm{v}_{\mathrm{w}}=$ velocidade da peça.

O modelamento teórico proposto da retificação axial (retificação do espelho de virabrequins) apresenta três regiões de formação de cavaco. A região 1 é a frente principal de corte, onde a grande maioria do avanço por volta é usinado. A região 3 é a de remoção de material na parte posterior do rebolo, reduzindo a porção do avanço por volta removido pela região 1. Já a região 2 é caracterizada pela menor remoção de material do avanço por volta e pela maior incidência de geração de calor por atrito e riscamento. 


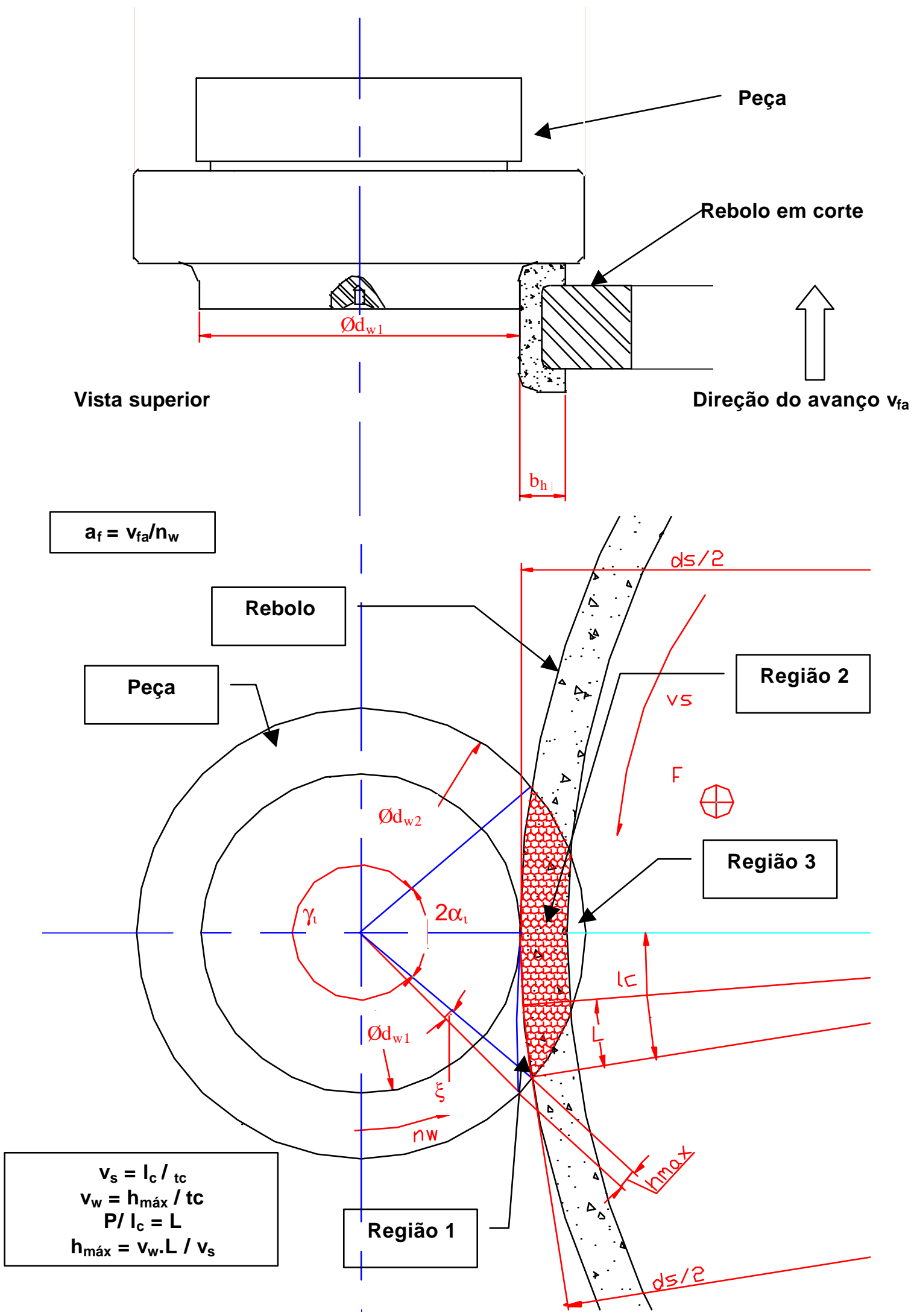

Figura 4.2 - Modelo teórico de retificação axial 
Uma simulação da cinemática do processo de retificação axial em três dimensões foi efetuada utilizando-se o programa AutoCad conforme apresentado na Figura 4.3. Nesta simulação foram reproduzidas as dimensões da peça e do rebolo, determinando-se uma região correspondente ao avanço por volta (anel em azul) na direção axial.
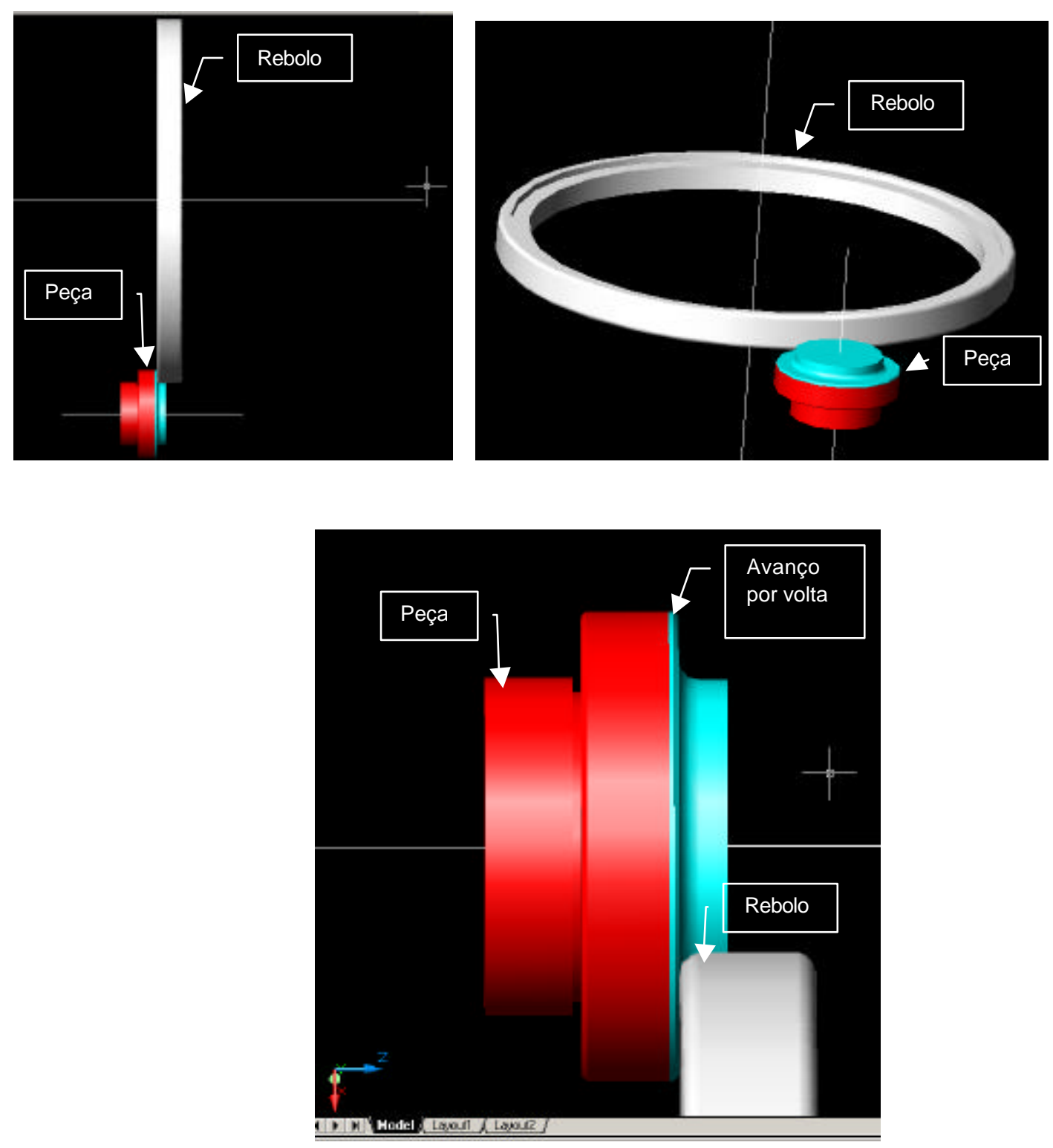

Figura 4.3 - Modelo teórico de retificação axial - simulação da operação de retificação

O avanço por volta foi dividido em 36 partes iguais, correspondendo cada parte a um deslocamento axial do rebolo após um giro de $10^{\circ}$ da peça sobre seu eixo de rotação. Efetuava-se a subtração entre os sólidos gerados, obtendo-se, ao final de um giro completo da 
peça $\left(360^{\circ}\right)$ a seguinte imagem apresentada na Figura 4.4. Nesta, cada setor colorido representa uma porção angular do avanço por volta total.

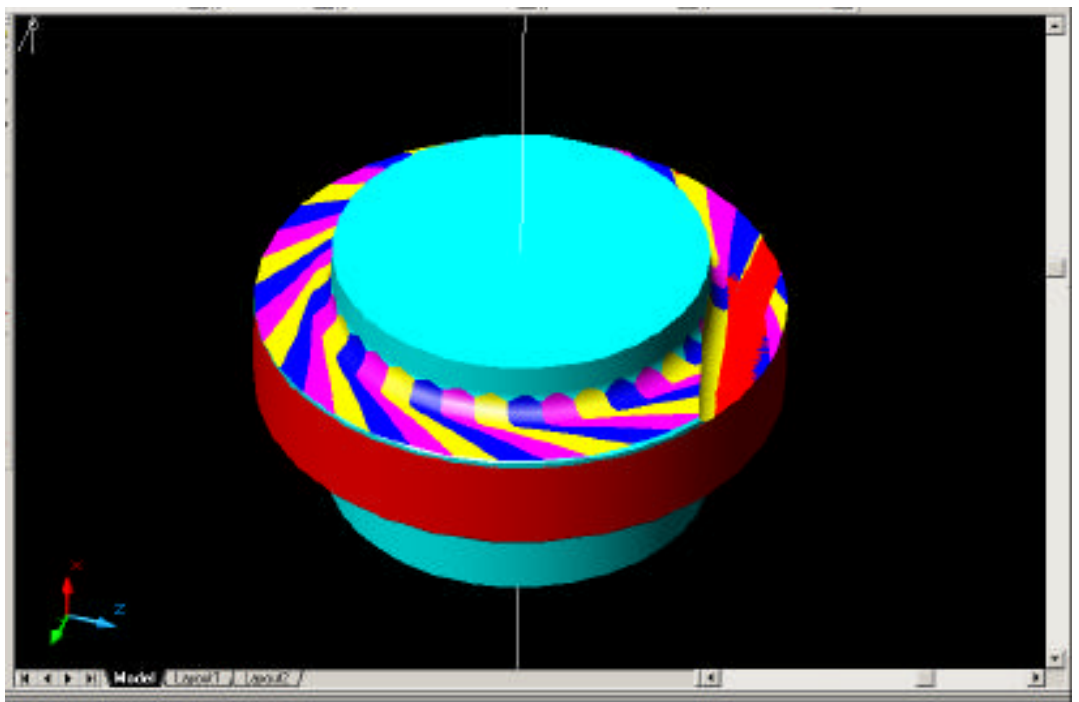

Figura 4.4 Modelo teórico de retificação axial - simulação da operação de retificação

A vista superior do sólido gerado é apresentada na Figura 4.5. As áreas principais de remoção de material apresentadas no modelo planificado foram identificadas e apresentadas na Figura 4.6.

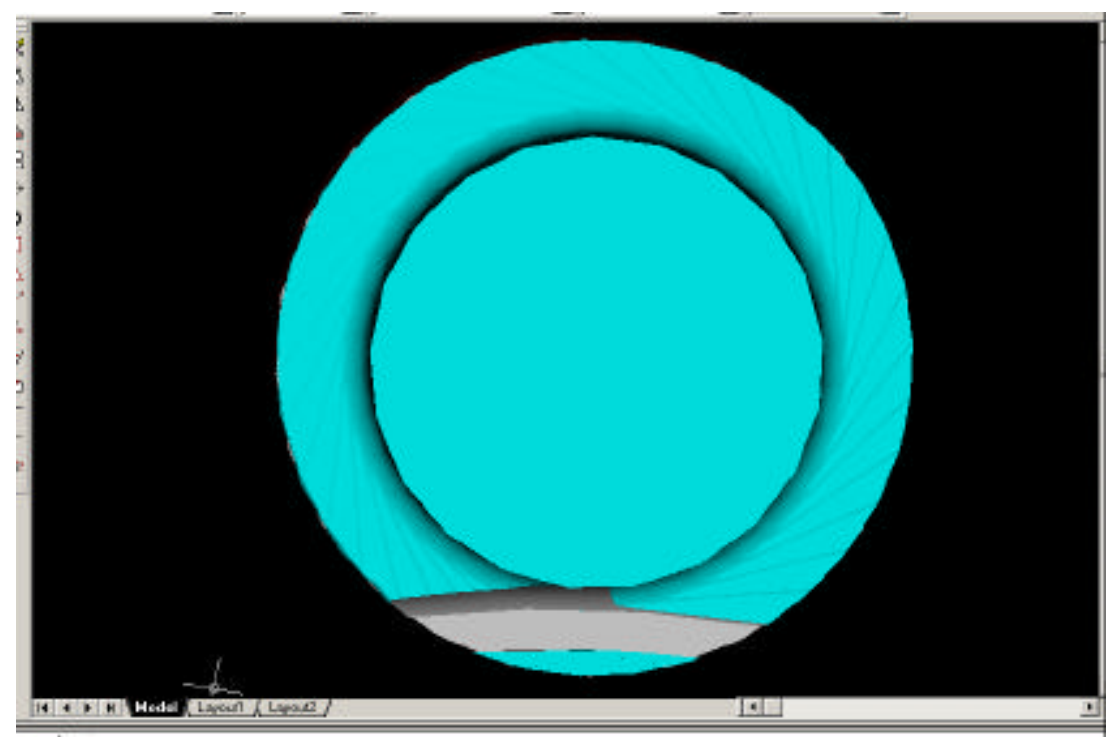

Figura 4.5 - Modelo teórico de retificação axial - vista superior 

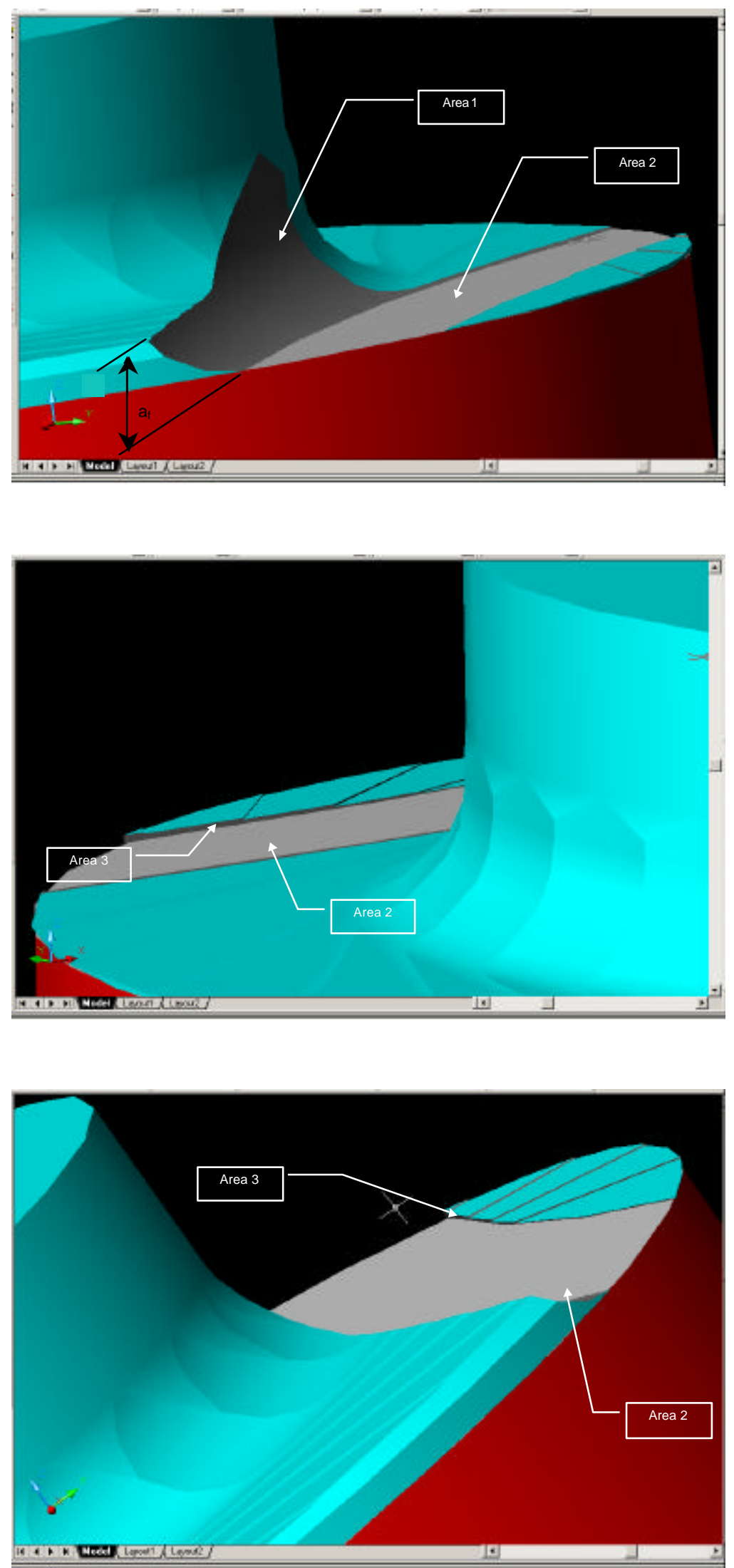

Figura 4.6 - Modelo teórico de retificação axial - determinação das áreas principais de corte 
A identificação das áreas através do modelo teórico revelou que a área 1 é a principal frente de corte, com variações no comprimento de corte ao longo desta. O maior valor do comprimento observado dá-se na interface raio-espelho, região esta de maior solicitação durante a usinagem.

\subsubsection{Modelo para o cálculo da taxa de remoção específica de material e volume específico de material para a retificação axial (estratégia B)}

Conforme apresentado no item 3.3.2.3, para uma zona de desbaste com raio de arredondamento, Hegener (1999) propõe uma representação gráfica para a taxa de remoção específica de material efetiva ( $\left.Q_{\text {w,eff }}\right)$ em função dos seguintes parâmetros: raio de canto do rebolo $\left(\mathrm{r}_{\mathrm{sk}}\right)$, avanço axial $\left(\mathrm{a}_{\mathrm{f}}\right)$ e sobremetal radial (Z/2) (Figura 3.8).

A Figura 4.7 apresenta a vista em corte da secção transversal das condições de contato entre rebolo e peça durante a retificação axial, onde são apresentados os elementos a serem considerados para o cálculo da taxa de remoção de material específica efetiva (Q'w,eff) (equação 4.1). Em virtude da configuração geométrica em questão, esta taxa deve ser calculada ponto a ponto $\left(Q_{w, e f f, i}^{\prime}\right)$, já que a penetração efetiva $\left(a_{e, e f f, i}\right)$ e o diâmetro da peça $d_{w i}$ são função da posição $X_{i}$ ao longo do perfil do rebolo, com origem na lateral do mesmo e tem, como valor máximo a dimensão do raio de arredondamento do canto do rebolo $\left(\mathrm{r}_{\mathrm{sk}}\right)$.

$Q_{w, e f f, i}^{\prime}=\pi \cdot d_{w i} \cdot n_{w} \cdot a_{e, e f f, i}$

A equação 4.1 pode ser reescrita da seguinte forma:

$Q_{w, e f f, i}^{\prime}=v_{w i} \cdot a_{e, e f f, i}$ 


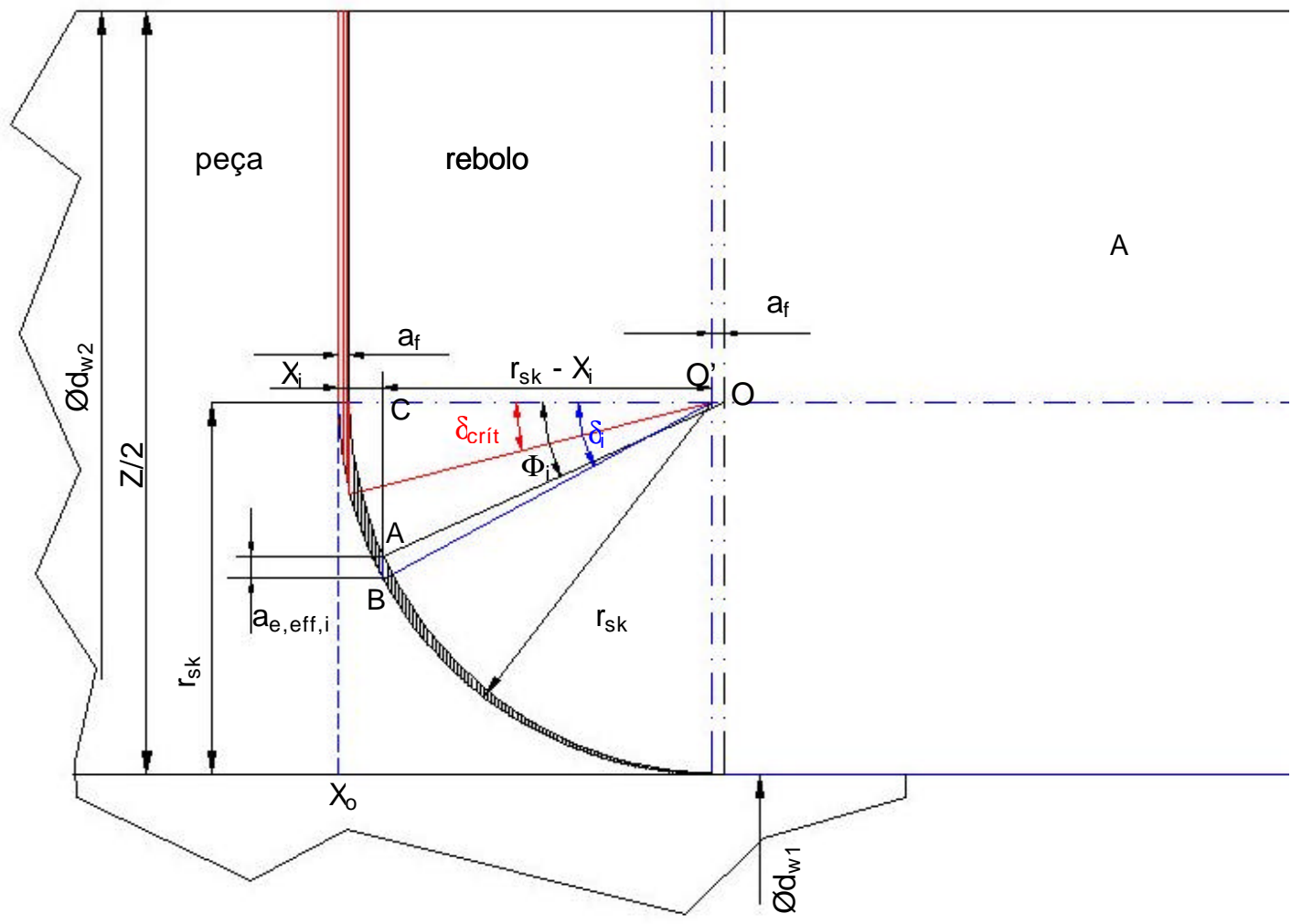

a)

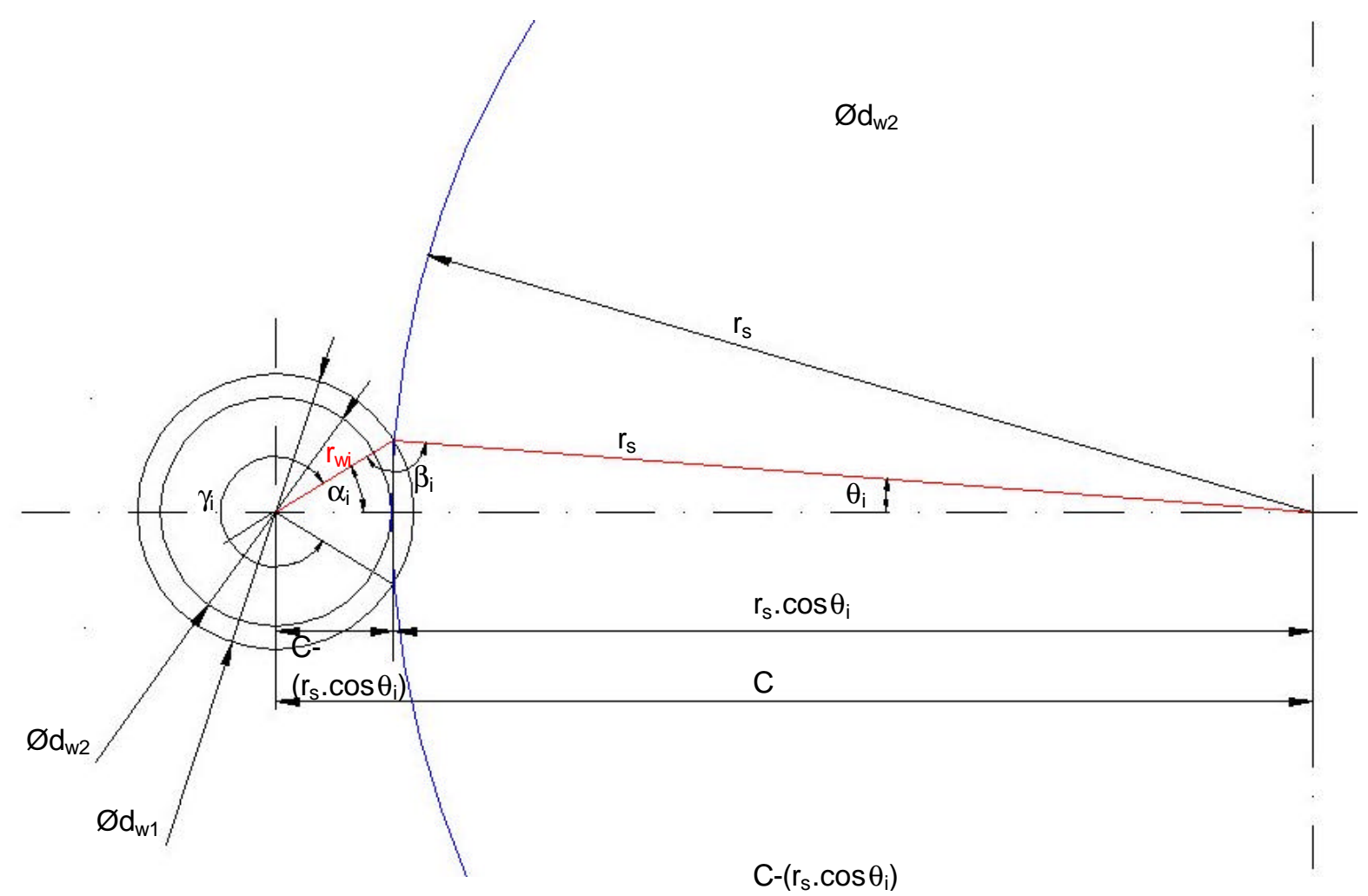

b)

Figura 4.7 - Representação esquemática do contato rebolo peça para o cálculo da taxa de remoção específica 
Considerando-se:

$$
0 \leq \delta_{i} \leq \frac{\pi}{2}
$$

e a partir das relações geométricas definidas pelos triângulos AOC e BO'C, tem-se:

$$
\begin{gathered}
\Phi_{i}=\arccos \left(\frac{a_{f}}{r_{s k}}+\cos \delta_{i}\right) \\
\delta_{\text {crítico }}=\arccos \left(\frac{r_{s k}-a_{f}}{r_{s k}}\right)
\end{gathered}
$$

onde: $\delta_{\mathrm{i}}$ é ângulo defasado de af para a penetração de corte efetiva em $X_{\mathrm{i}} ; \Phi_{\mathrm{i}}$ é o ângulo para a penetração de corte efetiva em $X_{i}, \delta_{\text {crit }}$ é o ângulo para a penetração de corte para $X_{i}=a_{f}$.

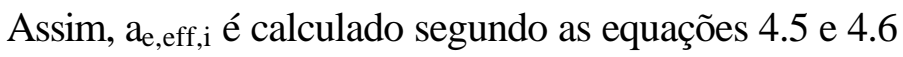

$$
\begin{aligned}
& a_{e, e f f, i}=r_{s k} \cdot\left(\operatorname{sen} \delta_{i}-\operatorname{sen} \Phi_{i}\right), \operatorname{para} \delta_{i}>\delta_{\text {crítico }} \\
& a_{e, e f f, i}=\left(r_{s k} \cdot \operatorname{sen} \delta_{i}\right)+\left(\frac{z}{2}-r_{s k}\right), \text { para } \delta_{i} \leq \delta_{c r i t i c o} \quad, \text { onde } z=d_{w 2}-d_{w 1}
\end{aligned}
$$

A posição $X_{i}$ correspondente a cada $\delta i$ é dada segundo a equação 4.7:

$$
X_{i}=r_{s k} \cdot\left(1-\cos \delta_{i}\right)
$$

De posse do valor da penetração efetiva $\left(\mathrm{a}_{\mathrm{e}, \mathrm{eff}, \mathrm{i}}\right)$, deve-se calcular a velocidade da peça na posição i $\left(v_{w i}\right)$, da seguinte forma:

$$
r_{w i}=r_{s k} \cdot\left(1-\operatorname{sen} \delta_{i}\right)+\frac{d_{w 1}}{2}
$$




$$
\begin{aligned}
& r_{m i}=\frac{2 \cdot r_{w i}+a_{e, e f f, i}}{2} \\
& v_{w i}=\omega_{w} \cdot r_{m i}
\end{aligned}
$$

A taxa de remoção de material específica efetiva ( $Q_{\text {w,eff }}$ ) é então calculada através da equação 4.2 .

Conforme verificado no modelamento teórico proposto da retificação axial (retificação do espelho de virabrequins) através da geração do modelo em 3D, a região 3 é responsável pela remoção de material na porção posterior do rebolo, reduzindo a porção do avanço por volta removido pela região 1 . Desta forma, o avanço por volta $\left(\mathrm{a}_{\mathrm{f}}\right)$ não é constante ao longo das posições $\mathrm{r}_{\mathrm{wi}}\left(\mathrm{r}_{\mathrm{wi}}\right.$ é igual a metade de $\mathrm{d}_{\mathrm{v}}$ em cada posição i do perfil), sendo necessária a correção do avanço por volta em cada posição i ( $\mathrm{a}_{\mathrm{f}, \mathrm{corr}, \mathrm{i})}$ Isto implicará em alterações no valor da penetração efetiva $\left(\mathrm{a}_{\mathrm{e}, \mathrm{eff}, \mathrm{i}}\right)$, sendo necessário o cálculo da penetração efetiva corrigida

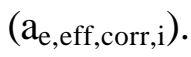

Da análise da Figura 4.7 tem-se:

$$
\begin{aligned}
& \text { Para } \frac{d_{w 1}}{2} \leq r_{w i} \leq\left(\frac{d_{w 1}}{2}+r_{s k}\right) \\
& \theta_{i}=\arccos \left(\frac{r_{s}^{2}+C^{2}-r_{w i}^{2}}{2 \cdot r_{s} \cdot C}\right) \\
& \alpha_{i}=\operatorname{arcsen}\left(\frac{r_{s} \cdot \operatorname{sen} \theta_{i}}{r_{w i}}\right) \\
& \gamma_{i}=360^{\circ}-2 \cdot \alpha_{i} \\
& a_{f, c o r r, i}=\frac{\gamma_{i}}{360^{\circ}} \cdot a_{f} \\
& \cos \delta_{c r i t, c o r r}=\frac{r_{s k}-a_{f c o r r, c r i t, i}}{r_{s k}}
\end{aligned}
$$

onde $\mathrm{a}_{\mathrm{f}, \mathrm{corr}, \text { crit }}$ é o avanço obtido para $r_{w i}=\frac{d_{w 1}}{2}+R$ 
$\Phi_{i, c o r r}=\arccos \left(\frac{a_{f, c o r r, i}}{r_{s k}} \cdot \cos \delta_{i}\right)$

A penetração efetiva corrigida $\left(\mathrm{a}_{\mathrm{e}}\right.$, eff, corr, i $)$ é calculada através das seguintes condições:

- Caso 1: $\delta_{\imath}>\delta_{\text {crit,corr }}$

$a_{e, e f f, c o r r, i}=r_{s k} \cdot\left(\operatorname{sen} \delta_{i}-\operatorname{sen} \Phi_{i, c o r r}\right)$

- Caso 2: $\delta_{\mathrm{l}}<\delta_{\text {crit, corr }}$

○ Para $X_{i} \leq X_{a f \min }$, onde $X_{\text {af min }}$ é obtido para $r_{w i}=\frac{d_{w 2}}{2}$

$$
a_{e, e f f, c o r r, i}=\left(r_{s k} \cdot \operatorname{sen} \delta_{i}\right)+\left(\frac{z}{2}-r_{s k}\right)
$$

○ Para $X_{a f \min }<X_{i} \leq X_{i, c r i t}$

$$
a_{e, e f f, c o r r, i}=\left(r_{s k} \cdot \operatorname{sen} \delta_{i}\right)+\left(r_{w i}-\frac{d_{w 1}}{2}-r_{s k}\right)
$$

onde $r_{\mathrm{wi}}$ é calculado pela equação 4.25:

$$
r_{w i}=\frac{\left(2 \cdot C \cdot \cos \alpha_{i}\right)-\sqrt{\left(-2 \cdot C \cdot \cos \alpha_{i}\right)^{2}-4 \cdot\left(C^{2}-r_{s}\right)^{2}}}{2}
$$

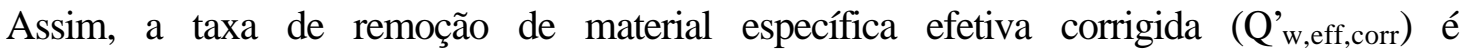
calculada pela equação 4.26 .

$Q_{w, e f f, c o r r, i}^{\prime}=v_{w i, c o r r} \cdot a_{e, e f f, c o r r, i}$

A velocidade corrigida $\mathrm{V}_{\mathrm{w}, \text { corr,i }}$ é calculada utilizando-se a equação 4.10 , sendo que para

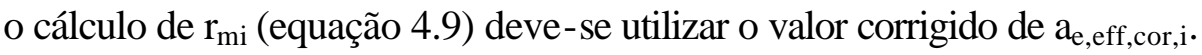

$\mathrm{O}$ volume de material removido específico ponto a ponto $\left(\mathrm{V}^{\prime}{ }_{\text {wi }}\right)$ é calculado segundo a equação 4.27: 
$V_{w i}^{\prime}=\pi \cdot\left(\left(r_{w i}+a_{e, e f f, i}\right)^{2}-r_{w i}^{2}\right)$

O valor corrigido de $\mathrm{V}_{\text {w,corr,i }}$ é calculado através da equação 4.28:

$V_{w, c o r r, i}^{\prime}=\pi \cdot\left(\left(r_{w i}+a_{e, e f f, c o r r, i}\right)^{2}-r_{w i}^{2}\right)$

A correção do avanço efetivo através da atuação da região 3 reduz a região do canto do rebolo que está sob as condições de máxima taxa de remoção de material específica e de volume de material específico removido. Utilizando-se o equacionamento proposto no item 4.2.2, uma simulação de retificação foi realizada sendo gerados como resultados, os gráficos de taxa de remoção de material especifica $\left(Q^{\prime}{ }_{w}\right)$ e de volume de material removido específico (V' $\left.{ }_{w}\right)$ com e sem a correção do avanço por volta devido a ação da região 3. A Tabela 4.1 apresenta as condições geométricas de contato e as condições de usinagem utilizadas na simulação. Destacados em azul estão os parâmetros de entrada não fixados para a simulação.

Tabela 4.1 - Condições geométricas de contato e as condições de usinagem utilizadas na simulação

\begin{tabular}{|crl|}
\hline Altura do espelho (h) & 5 & $\mathrm{~mm}$ \\
Velocidade axial (Vfa) & 3 & $\mathrm{~mm} / \mathrm{min}$ \\
Rotação da peça (nw) & 120 & $\mathrm{rpm}$ \\
avanço por volta (af) & 0,025 & $\mathrm{~mm} / \mathrm{rot}$ \\
velocidade angular da peça $\omega$ & 12,56637 & $\mathrm{rad} / \mathrm{s}$ \\
raio do canto do rebolo R & 1 & $\mathrm{~mm}$ \\
cos $\delta$ crítico & 0,975 & $\mathrm{rad}$ \\
cos $\delta$ crítico corrigido & 0,977084 & $\mathrm{rad}$ \\
af real mínimo & 0,020641 & $\mathrm{~mm} / \mathrm{rot}$ \\
hi max & 25,61111 & $\mathrm{~mm}$ \\
ki max & 0,611111 & \\
intervalo de validade & 1,570796 & $\mathrm{rad}$ \\
Distância entre centros C & 225 & $(\mathrm{ds} / 2)+(\mathrm{dw} 1 / 2)$ \\
Diâmetro interno do colo dw1 & 50 & $\mathrm{~mm}$ \\
Diâmetro externo do colo dw2 & 60 & $\mathrm{~mm}$ \\
Diâmetro do rebolo ds & 400 & $\mathrm{~mm}$ \\
cos $\theta$ máximo & 0,996944 & \\
$\theta$ máximo & 0,078194 & $\mathrm{rad}$ \\
RPM Rebolo & 4740 & $\mathrm{rpm}$ \\
Relação G na vel max. & 10000 & \\
Sobremetal no espelho & 0,3 & $\mathrm{~mm}$ \\
numero de peças & 54 & \\
\hline
\end{tabular}

A Figura 4.8 apresenta os resultados comparativos para os valores de taxa de remoção de material especifica ( $\mathrm{Q}_{\mathrm{w}, \mathrm{eff}}$ ) e de volume de material removido específico ( $\mathrm{V}_{\mathrm{w}, \mathrm{eff}}$ ) com e 
sem a correção para o perfil do raio do rebolo. A análise completa do perfil não demonstra as diferenças resultantes da correção, já que as possíveis diferenças se encontram em posições $X_{i}$ inferiores ao avanço axial por volta $\left(\mathrm{a}_{\mathrm{fi}}\right)$, o qual é igual a $0,025 \mathrm{~mm} / \mathrm{rot}$.
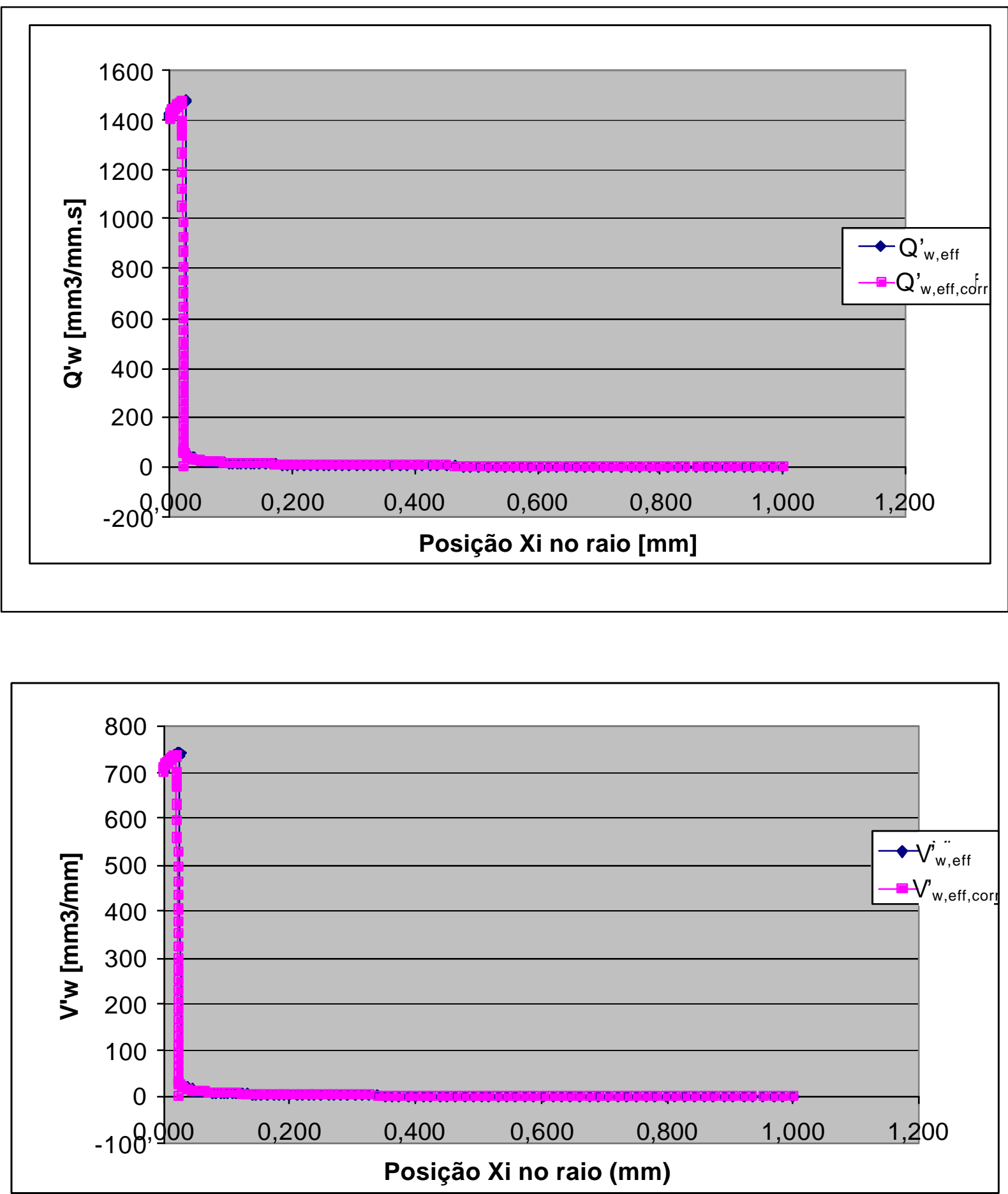

Figura 4.8 - Taxa de remoção de material especifica (Q'w) e de volume de material removido específico (V'w) 
A Figura 4.9 apresenta a análise da correção dos valores para uma faixa $X_{i}$ mais restrita $\left(0 \leq X_{i} \leq 0,050 \mathrm{~mm}\right)$. Pode-se verificar que a ação da região 3 proporciona uma redução na região de maior solicitação do perfil do rebolo. O ponto de máxima solicitação ocorre agora na posição $X_{i} 0,021 \mathrm{~mm}, 4$ mícron a menos que o avanço por volta teórico $(0,025 \mathrm{~mm})$, para as condições de usinagem simuladas. A utilização da parte posterior do rebolo para a remoção de material da peça não acarreta em significativa variação na distribuição da taxa de remoção ao longo da superfície do rebolo e sua principal influência é a de deslocar o ponto de máxima taxa de remoção de um valor correspondente a uma fração do avanço por volta. Além disso, a remoção de material na região 3 não reduz o valor da taxa de remoção específica máxima na região 1 próxima ao espelho do virabrequim. A partir deste ponto, a título de simplificação de notação, os valores efetivos corrigidos de Q' ${ }_{\text {w,eff,corr }}$ serão denominados simplesmente Q' ${ }_{\mathrm{w}}$. 

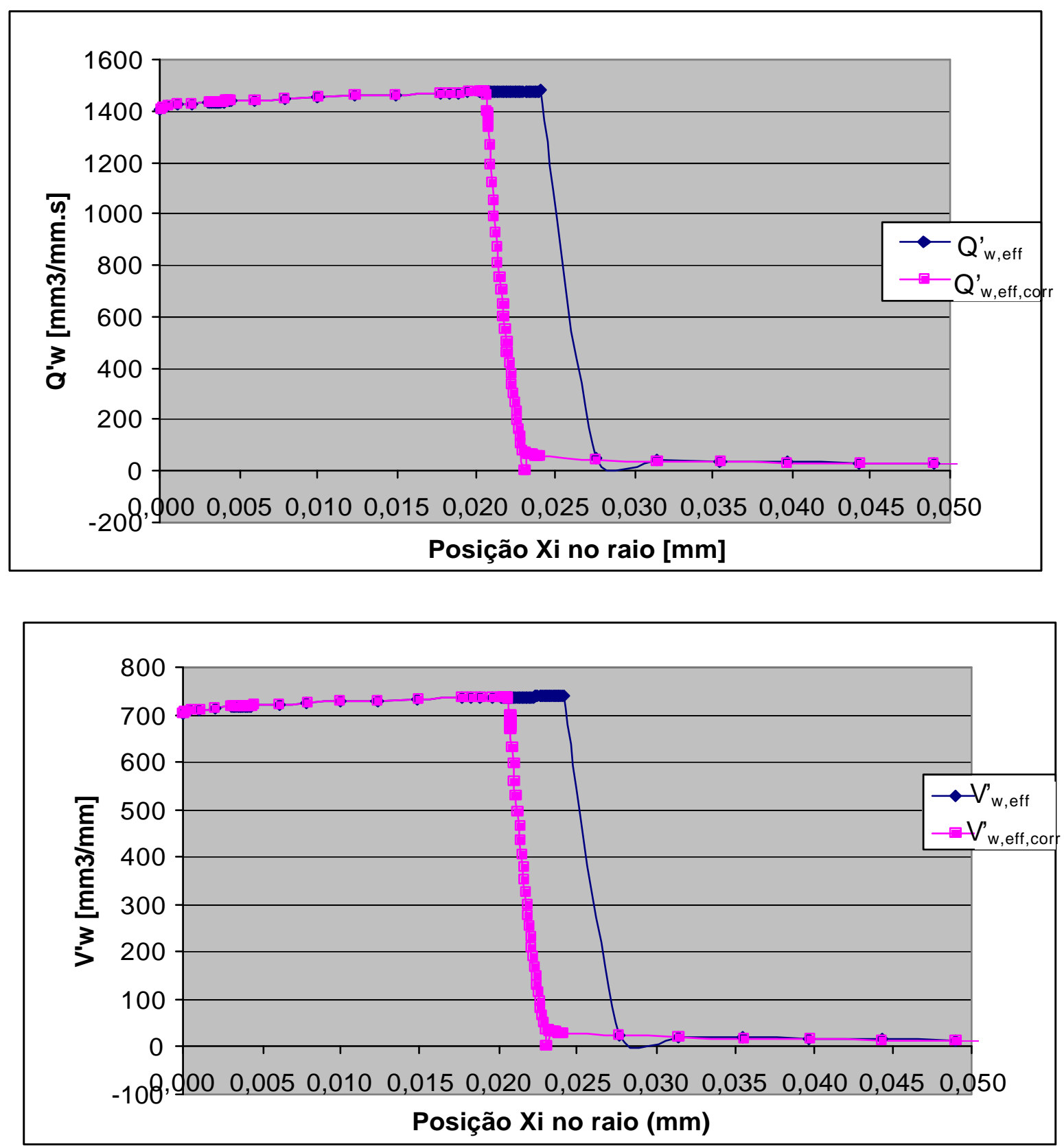

Figura 4.9 - Taxa de remoção de material especifica (Q’w) e de volume de material removido específico (V'w) - $0 \leq X_{i} \leq 0,050 \mathrm{~mm}$

\subsection{Estratégia de retificação axial múltipla- estratégia C -}

\subsubsection{Dados gerais da estratégia}

A retificação axial do espelho, quando caracterizada pela realização de um único estágio de usinagem, tem como característica principal a remoção de todo o sobremetal do 
espelho de uma única vez, sendo este distribuído na área de contato rebolo-peça, definida pelas característica geométricas de ambos, conforme apresentado na Figura 4.10.

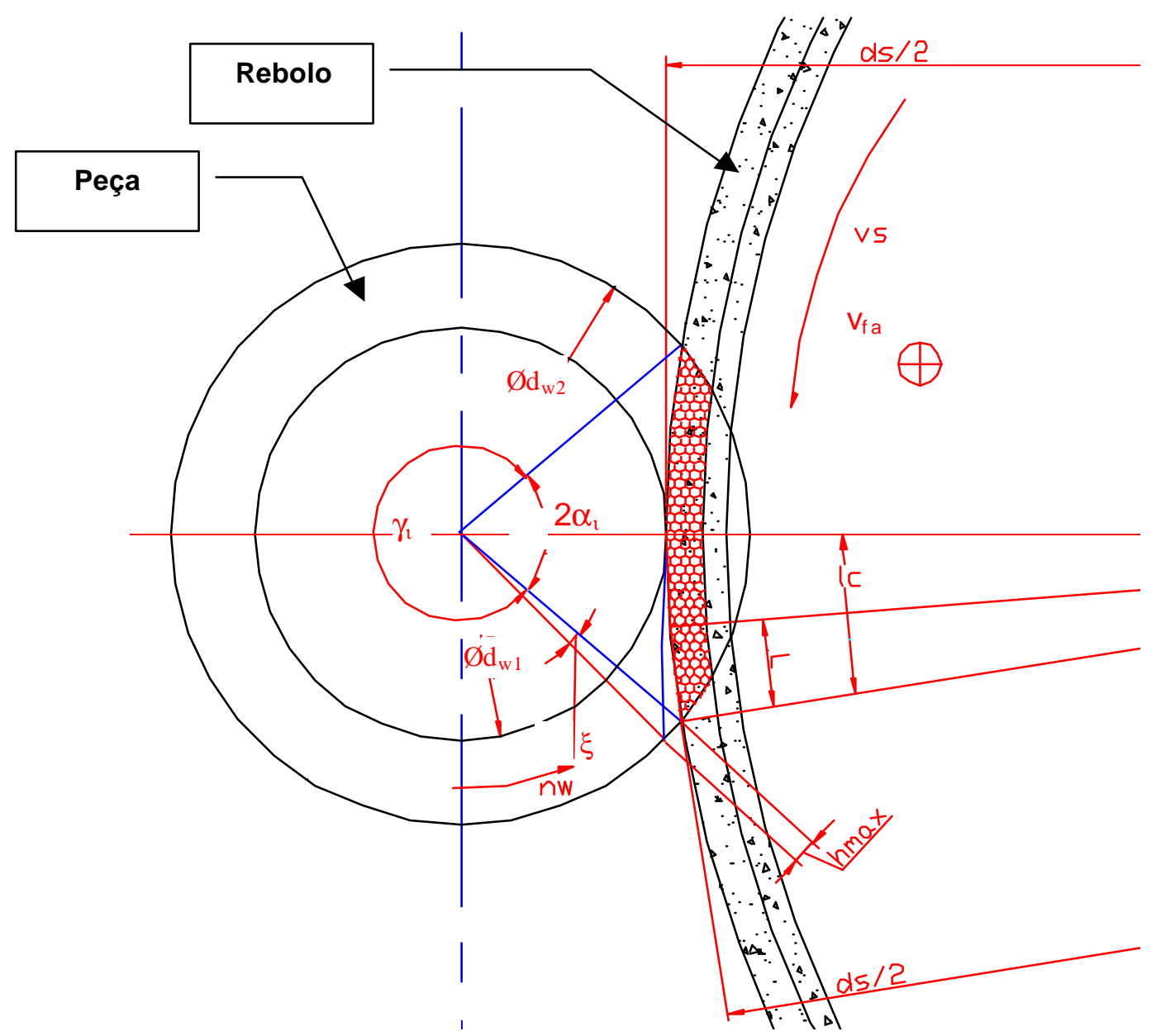

Figura 4.10 - Configuração de usinagem axial de 1 estágio

Nesta configuração (Figura 4.10), $2 \alpha$ define o ângulo de engajamento rebolo-peça, sendo que o comprimento de contato 1 também é função deste ângulo. A hachura vermelha define a projeção da área de contato rebolo-peça, para o rebolo em estudo, com raio de $4 \mathrm{~mm}$ e com trecho reto de $2 \mathrm{~mm}$ (configuração de retificação 1). Na retificação axial de 1 estágio obtêm-se a máxima área frontal de usinagem. Conforme apresentado no item 4.2.2, o máximo valor taxa de remoção de material específica $\left(Q^{\prime}{ }_{w}\right)$ ocorre na posição $X$ da lateral do rebolo correspondente ao avanço por volta. Esta taxa de remoção de material específica é fortemente influenciada não só pelas condições de usinagem, mas também pela configuração geométrica 
da face plana, onde a altura total do espelho corresponde a quase totalidade da penetração efetiva no ponto $i$.

Uma das opções para se obter maiores avanços por volta é a redução da área de contato de corte e da taxa de remoção de material específica através da divisão em trechos (estágios) do espelho a ser retificado. Assim, maiores valores de avanço por volta podem ser empregados, já que em cada estágio, apenas uma parcela do sobremetal será removida. Neste caso define-se um o ângulo $2 \alpha$ e o comprimento de contato $l_{\mathrm{c}}$ para cada estágio.

A redução proposta pode ser observada através da simulação apresentada nas Figuras 4.11 e 4.12. Nesta reproduz-se a configuração geométrica apresentada na Figura 4.10 com a introdução de, por exemplo, 6 estágios de usinagem axial. Em cada estágio remove-se um anel circular do sobremetal total, podendo-se aplicar avanços por volta distintos, em função do sobremetal removido por estágio.
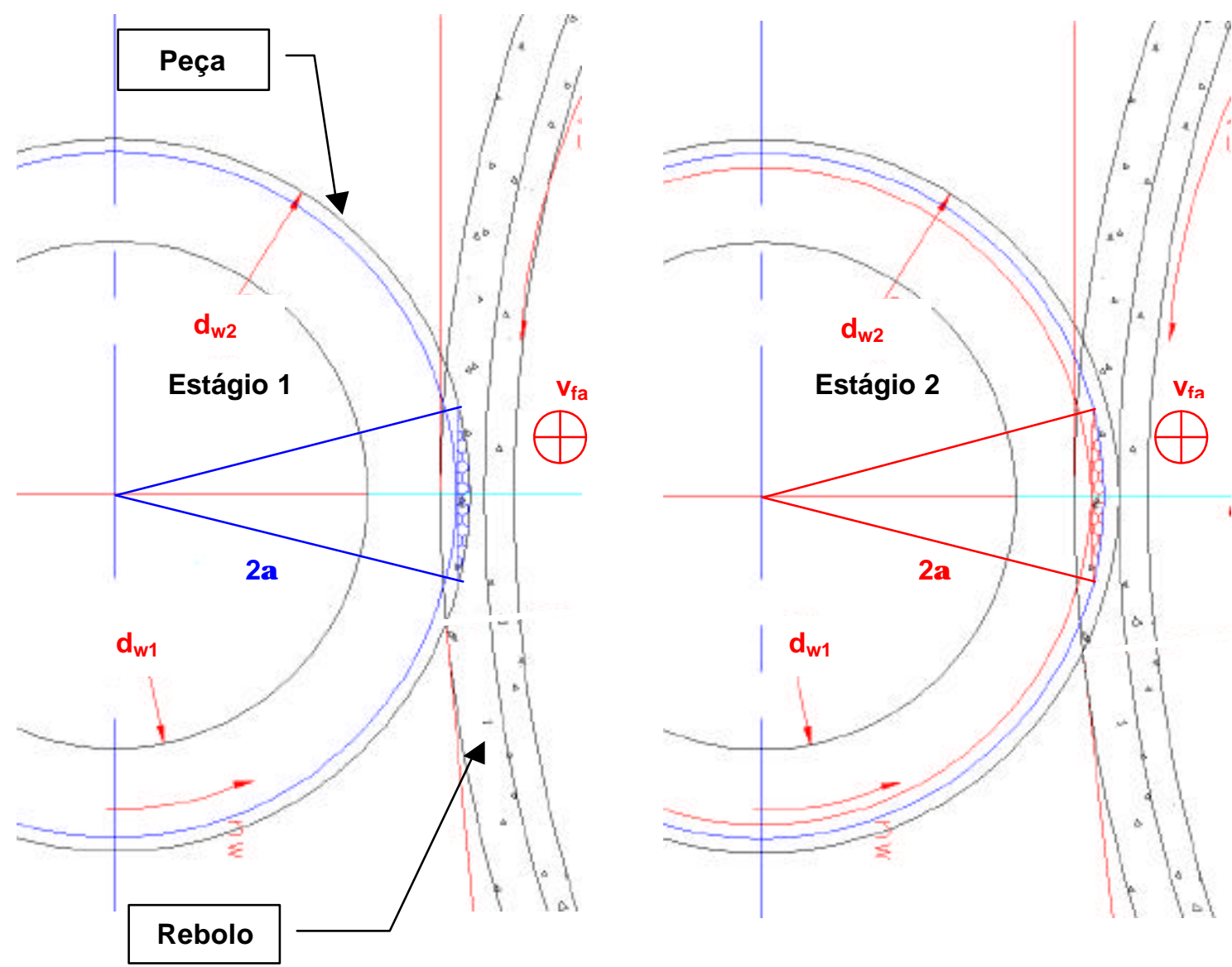

Figura 4.11- Configuração de usinagem axial múltipla de 6 estágios - estágios 1 -2 

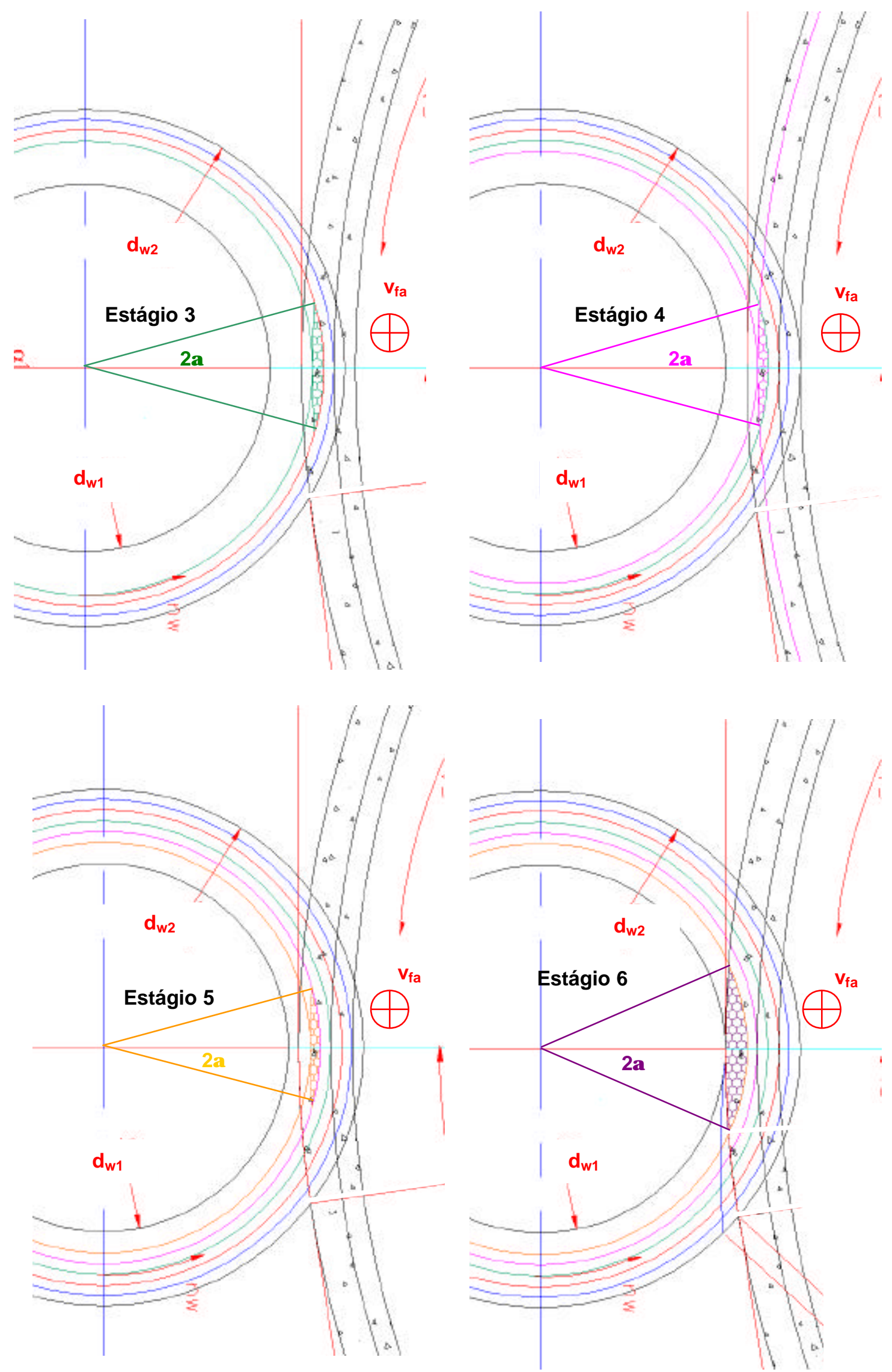

Figura 4.12 - Configuração de usinagem axial múltipla de 6 estágios - estágios 4 -6 


\subsection{Considerações sobre as características das taxas de remoção específica de material para estratégia de mergulho, axial e axial múltipla}

As estratégias propostas apresentam uma diferença básica com relação ao comportamento da zona de desbaste. A Figura 4.13 apresenta os resultados da taxa de remoção específica distribuída ponto a ponto $\left(Q^{\prime}{ }_{w}\right)$ ao longo da posição $X$ em relação à face plana da peça (e à correspondente posição no raio do rebolo). Para efeito comparativo, as condições de usinagem são idênticas, exceto as velocidades de avanço axial $\left(\mathrm{v}_{\mathrm{fa}}\right)$ e de mergulho $\left(v_{\mathrm{fr}}\right)$ a fim de se manter o mesmo tempo de usinagem $\left(t_{c}=6 \mathrm{~s}\right)$

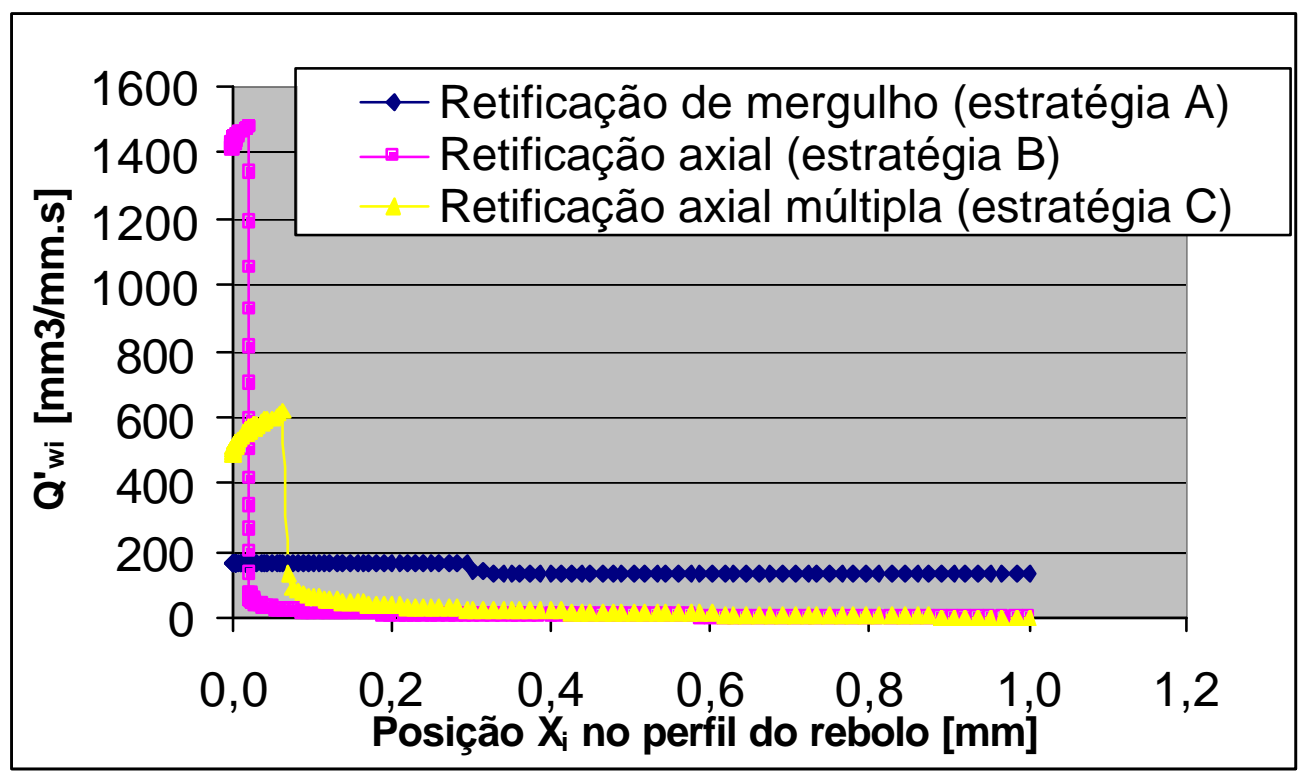

Figura 4.13 - Taxa de remoção específica ponto a ponto ( $\mathrm{Q}_{\text {w,eff,i) }}$ ao longo do raio do rebolo

As diferenças básicas entre as estratégias de mergulho e axial estão na região do rebolo de maior solicitação e na intensidade do valor da taxa de remoção. No caso da retificação axial, a região de maior solicitação ocorre na posição $X$ correspondente ao avanço por volta. No caso, o ponto de máxima solicitação ocorrerá a $0,025 \mathrm{~mm}$ da lateral do rebolo. Esta taxa de remoção é fortemente influenciada não só pelas condições de usinagem, mas também pela configuração geométrica da face plana, onde a altura do espelho corresponde à quase totalidade da penetração efetiva no ponto i. Neste caso tem-se uma maior remoção de 
material na unidade de tempo, o que levará a uma maior solicitação da ferramenta naquela região. A eficiência do sistema de aplicação de fluido de corte torna-se crítica na prevenção dos danos térmicos. Como vantagem desta estratégia existe a possibilidade do rearranjo desta curva de distribuição de taxa de remoção a fim de aumentar ou diminuir a intensidade desta curva (máximo valor de Q' ${ }_{w}$ ) e a posição do ponto $X_{\mathbf{i}}$ de máxima Q' ${ }_{w}$ através da alteração da rotação da peça e da velocidade de avanço axial $\mathrm{v}_{\text {fa. }}$. A região de máximo desgaste estará concentrada nesta região (face lateral do rebolo até a posição $\mathrm{X}_{\mathrm{i}}$ ), cuja largura poderá ser escolhida a fim de se manter a tolerância do raio do rebolo desejada.

Em contrapartida, a adoção da estratégia de mergulho implica em uma área de máximo desgaste definida e igual ao sobremetal total a ser removido (no caso da Figura 4.13 este valor é de $0,3 \mathrm{~mm}$ ). Nesta configuração, o ponto de máxima solicitação do rebolo $\left(\mathrm{X}_{\mathrm{i}}\right)$ é fixo, não sendo modificado através de variações na rotação da peça ou velocidade de mergulho $\left(\mathrm{v}_{\mathrm{fr}}\right)$. Neste caso a área de provável desgaste é maior, porém a solicitação do processo é menor, já que as taxas de remoção são menores (considerando-se o mesmo tempo de corte). Todavia, esta área de desgaste maior pode levar, na maioria dos casos, à necessidade de dressagem do rebolo em virtude de ser ultrapassada a tolerância do raio. Para a curva a estratégia de mergulho, os valores de Q' w, são máximos, já que existe uma variação de Q' ${ }_{w}$ com a variação do diâmetro instantâneo da peça.

Assim, a introdução da estratégia de retificação axial múltipla permite uma redução no valor de $\mathrm{Q}^{\prime}{ }_{\mathrm{w}}$, com conseqüente aumento da região de efetiva solicitação durante o corte, deslocando a posição do ponto X. Neste caso, temos uma distribuição mais uniforme de Q' Esta estratégia tende a ser mais efetiva para espelhos (Z/2) maiores, nos quais a remoção em um único estágio representa taxa de remoção específica $Q_{\text {w }}$ elevada. Pode-se obter uma situação intermediária entre as estratégias de mergulho e axial, ajustando-se Q' ${ }_{\text {w }}$ e a posição 
$\mathrm{X}_{\mathrm{i}}$ de máxima solicitação pela variação do número de estágios, reduzindo-se a tendência de queima da peça e empastamento do rebolo. 


\title{
5. ANÁLISE EXPERIMENTAL DA OPERAÇÃO DE RETIFICAÇÃO CILÍNDRICA EXTERNA DE FORMA APLICADA À RETIFICAÇÃO DE FACES PLANAS COM EIXOS PARALELOS
}

\author{
A metodologia de experimentação para o desenvolvimento da operação de retificação \\ cilíndrica externa de forma, aplicada a faces planas consistiu na realização de ensaios \\ laboratoriais de retificação. Duas configurações de retificação foram utilizadas, as quais são \\ apresentadas a seguir.
}

\subsection{Configuração 1 de retificação}

A "Configuração 1" denomina os testes de retificação realizados no Laboratório de Otimização dos processos de Fabricação (OPF) do Núcleo de Manufatura Avançada NUMA, da Escola de Engenharia de São Carlos (EESC), Universidade de São Paulo - USP. Para a realização dos testes laboratoriais, o desenvolvimento de um sistema de retificação foi parte integrante deste trabalho. Este englobou o projeto das modificações de uma retificadora para alta velocidade, com tecnologia nacional, que possibilitasse a utilização de rebolos de CBN. Devido ao interesse despertado pelo presente projeto, tal desenvolvimento foi feito pela Zema (que financiou e doou a construção da máquina e sua instalação na USP) numa parceria com o OPF e com apoio de outras empresas como a GE Fanuc (doação do CNC), Saint Gobain Abrasives (doação do Rebolo de CBN, sistema de dressagem e disco dressador) e da Sensis que doou o sistema de monitoramento por emissão acústica com o respectivo sensor. 
Esse foi destacadamente um dos principais ganhos desse trabalho, uma vez que hoje a Zema já comercializa a máquina desenvolvida. Deve-se citar que 5 unidades já foram vendidas sendo que duas delas estão sendo aplicadas na fabricação de virabrequins na GM do Brasil. Além disso, o projeto do rebolo de $\mathrm{CBN}$, do sistema de monitoramento e controle, o sistema de dressagem e de aplicação de fluido de corte foram partes integrantes do projeto. A conclusão do sistema permitiu a utilização da retificadora para a realização dos testes laboratoriais. O detalhamento da configuração é apresentado a seguir.

\section{- Dados técnicos da retificadora}

- Os dados técnicos da retificadora cilíndrica externa, marca ZEMA, modelo G800 são apresentados na Figura 5.1.

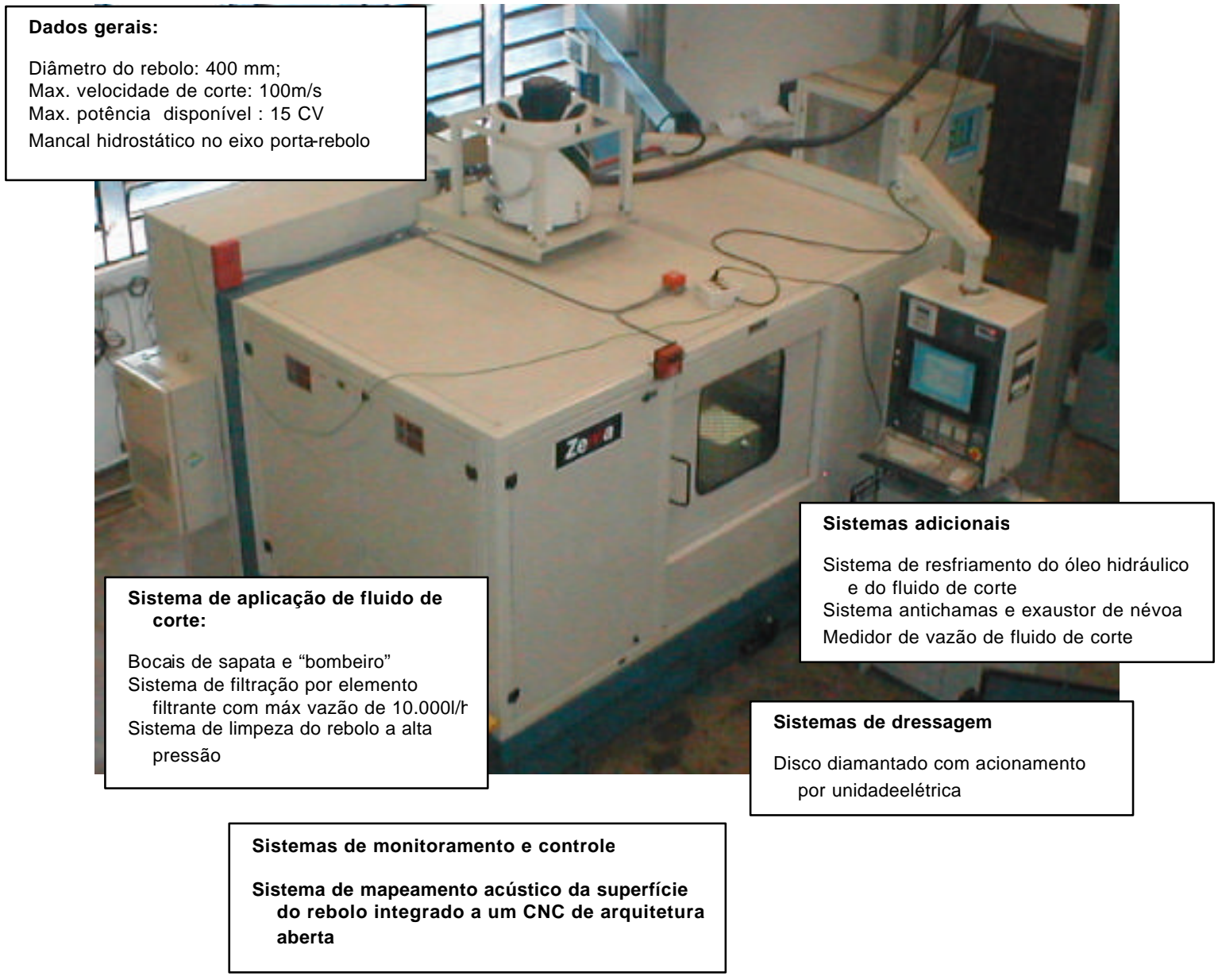

Figura 5.1 - Visão geral da retificadora ZEMA Numerika G800 -HS 


\section{- Corpos-de-prova}

○ Devido à impossibilidade da usinagem dos espelhos excêntricos de eixos virabrequins na retificadora de alta velocidade em questão, por tratar-se de uma retificadora universal, optou-se pela usinagem de corpos-de-prova com geometria e material igual à de um colo de virabrequim de motores diesel. A Figura 5.2 apresenta as dimensões dos corpos-de-prova. O material dos mesmos é o aço Din 38MnS6 (SAE 1538DH) (55-60 HRc). A altura do espelho é de $14 \mathrm{~mm}$ no raio.

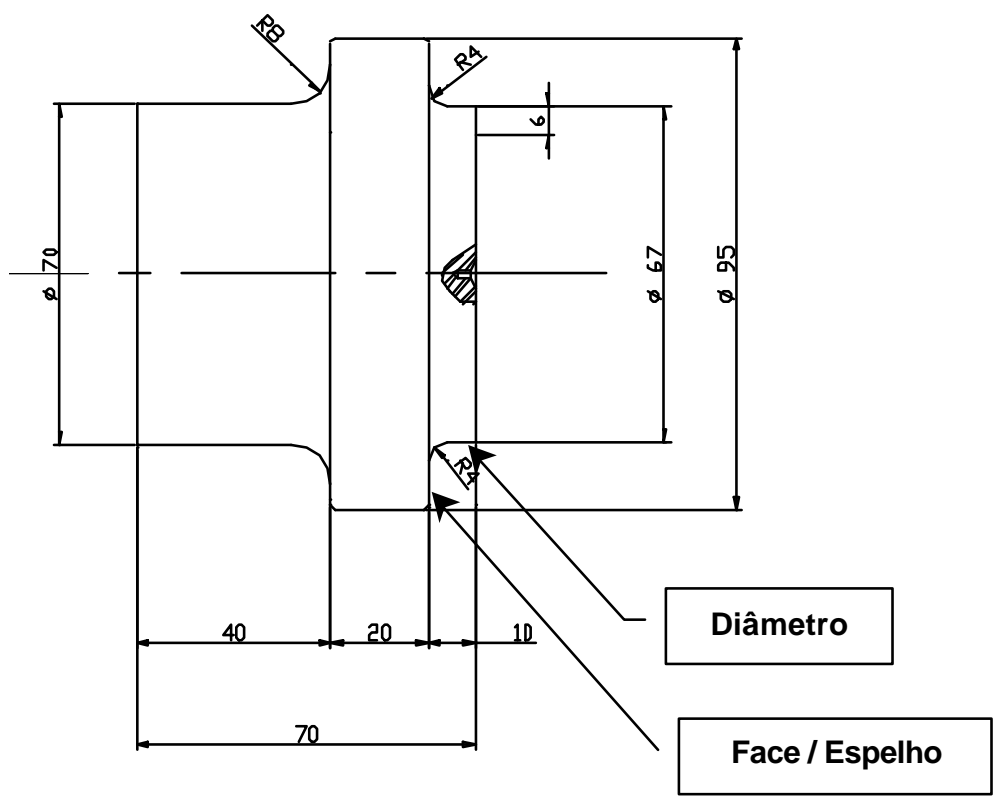

Din 38MnS6 (SAE 1538DH): C 0,36-0,40\%; Mn 1,4 - 1,55\%; Si 0,5-0,65\%; P 0,25\% (máx); S 0,550,70\%; Cr 0,10-0,20\%; Ni 0,15\% (máx); Mo 0,50\% (máx); Cu 0,25\% (máx); Al 0,10\% (máx); Ni 150-200 $\mathrm{ppm}$

Figura 5.2 - Dimensões e material dos corpos-de-prova utilizados

\section{- Dados do rebolo de CBN com ligante vitrificado}

○ Especificação: B181 VSS Q V 320

○ Dimensões: diâmetro externoØ400 x largura 28 x altura segmento $10 \mathrm{~mm}$

- Perfil do rebolo: raio de $4 \mathrm{~mm}$ nas laterais esquerda e direita 


\section{- Sistema de monitoramento e controle}

○ A Figura 5.3 apresenta a tela do monitor do painel de operação da retificadora onde à esquerda encontra-se a rotina que permite mapear acusticamente a superfície do rebolo durante as operações de dressagem e de retificação, desenvolvida utilizando-se o programa Labview por Oliveira et al. (2000). Do lado direito, o programa "CNC-Screen", da GE-FANUC, que executa as funções de operação da máquina (edição e execução de programas) além da edição e monitoramento dos demais parâmetros do CNC. Na interface gráfica apresentada ainda é possível monitorar-se o consumo de corrente elétrica do motor de acionamento do rebolo em termos percentuais.

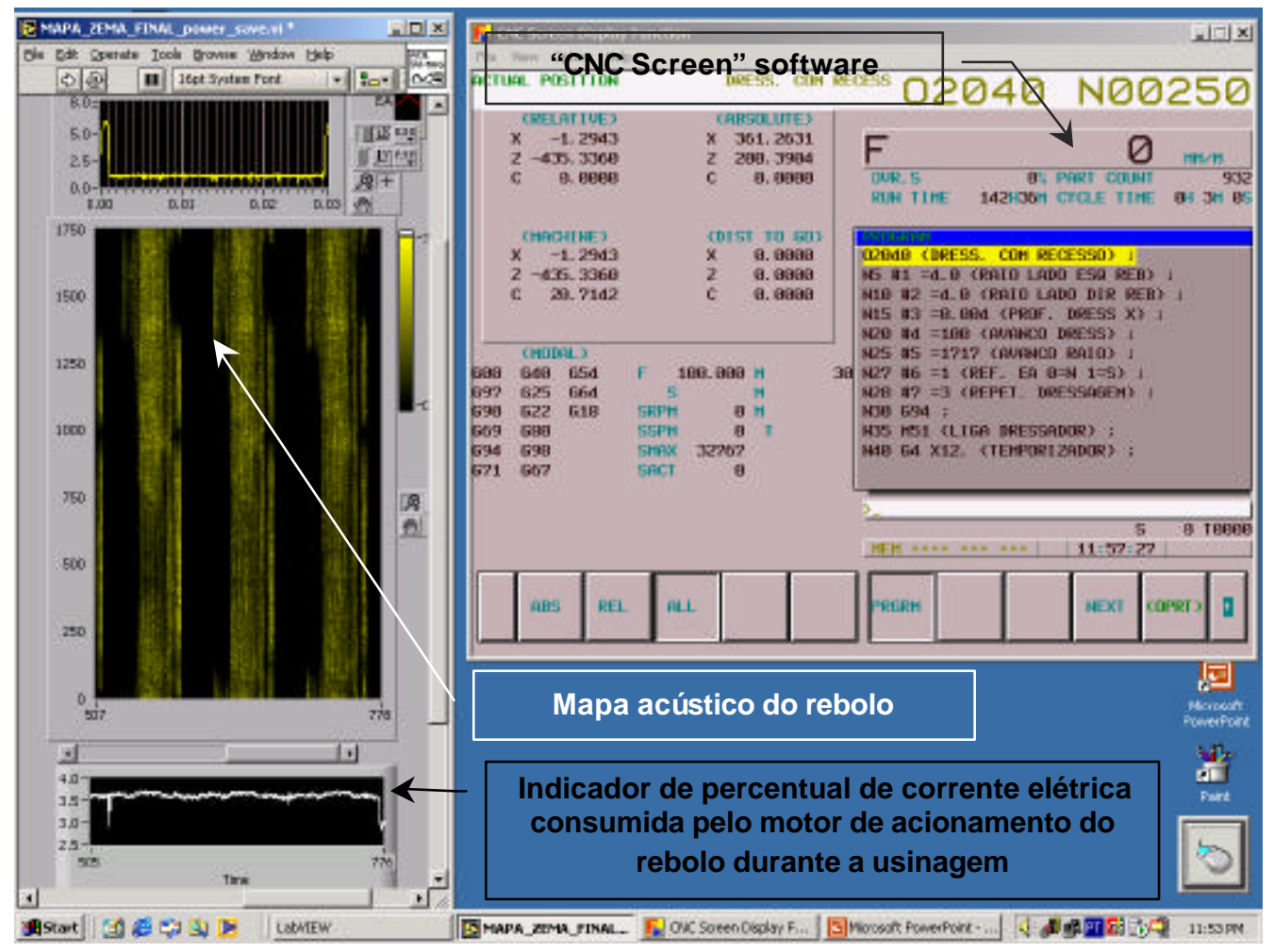

Figura 5.3 - Tela do monitor de operação da retificadora, com sistema de controle instalado

- Com a utilização desta configuração de CNC (placa controladora em PC comercial) é possível a execução de rotinas de monitoramento durante a dressagem e a usinagem (mapeamento acústico e avaliação do consumo de 
corrente no motor de acionamento do rebolo) e operação do CNC de forma simultânea à operação da máquina, utilizando-se o mesmo PC. Uma vez que as funções vitais do CNC continuam sendo executadas na "main CPU" do CNC, os demais recursos funcionais do um PC comercial no ambiente Windows (Windows 2000 Professional) podem ser utilizados durante a operação da máquina, como acesso à Internet, à intranet, à utilização de demais aplicativos para ambiente Windows, dentre outros.

\section{- Sistema de dressagem:}

Composto de um motor de acionamento elétrico e um disco diamantado estreito. $\mathrm{O}$ sistema permitia diversas configurações de dressagem, entre elas: paralela, eixos cruzados e dressagem inclinada.

Dressagem com eixos cruzados:

Nesta configuração de montagem o eixo do dressador é orientado a 90 graus em relação ao eixo do rebolo (Figura 5.4).

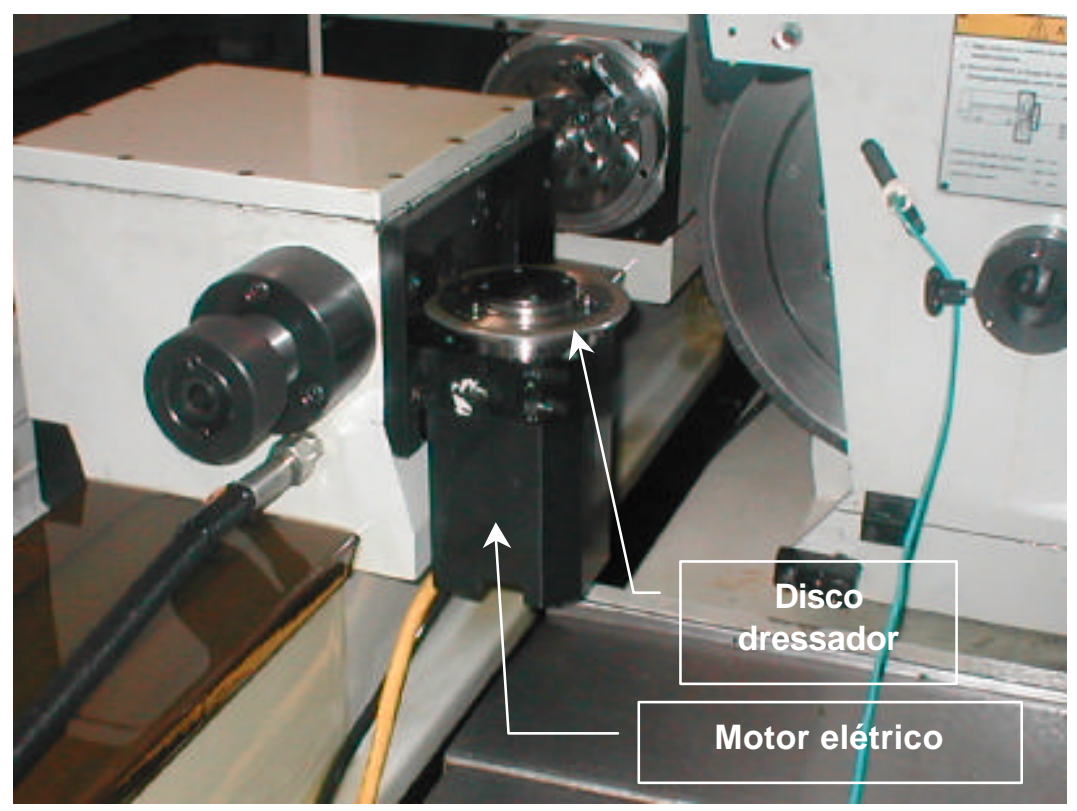

Figura 5.4 - Visão lateral do interior da máquina com sistema de dressagem na configuração com eixos cruzados 
Para a dressagem do perfil do rebolo foi desenvolvida uma metodologia de dressagem, dividindo-se o perfil a ser dressado em cinco regiões: lateral esquerda, raio esquerdo, face, raio direito e lateral direita. As dressagens das laterais e da face são efetuadas com deslocamentos lineares em G01 com velocidades de avanço específicas. As dressagens dos raios esquerdo e direito são executadas através de uma interpolação circular G03 no sentido anti-horário, com raio igual ao raio do disco dressador mais o raio a ser executado. Em função das diferentes velocidades do centro do disco dressador e do ponto de contato rebolo-disco, torna-se necessário executar a correção da velocidade de dressagem durante esta operação.

Utilizando-se o sistema de monitoramento e controle desenvolvidos efetua-se um referenciamento via emissão acústica de coordenadas pré-estabelecidas (Figura 5.5), buscando-se eliminar os ciclos de dressagem com ausência de contato. Estas coordenadas são identificadas como posição X\#500 (posição X do dressador), Z\#501 (posição Z à direita do disco dressador) e Z\#516 (posição Z à esquerda do disco dressador). Os demais parâmetros envolvidos são: diâmetro do disco dressador (\#518), largura do rebolo (\#517) e altura do segmento (\#527). 


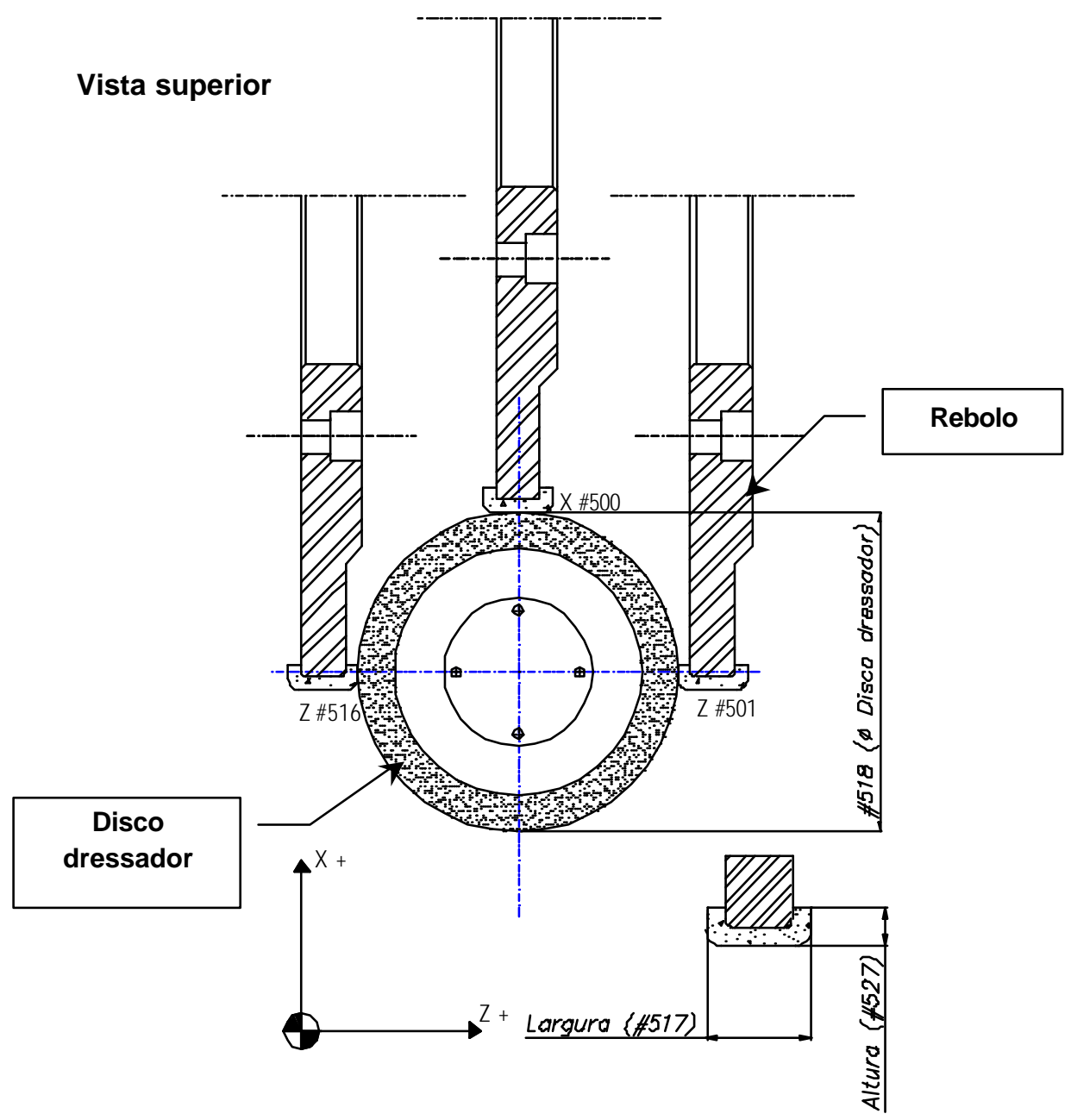

Figura 5.5 - Coordenadas do dressador capturadas durante a operação de referenciamento.

A limitação deste tipo de configuração é a necessidade de avanços programados elevados (acima de $1000 \mathrm{~mm} / \mathrm{min}$ ) em virtude da diferença entre o raio a ser dressado e o raio do disco dressador, o qual é 32 vezes maior. A largura de atuação do disco dressador ( $\left.b_{d}\right)$ neste tipo de configuração também é fator negativo para a obtenção de um perfil mais agressivo do rebolo.

\section{Dressagem inclinada:}

O objetivo desta configuração é a obtenção de uma maior agressividade do rebolo, se comparado com a estratégia anterior (eixos cruzados), sem a substituição do disco dressador. 
Para tanto, posicionou-se o cabeçote dressador a 70 graus em relação ao eixo do rebolo, conforme apresentado na Figura 5.6.

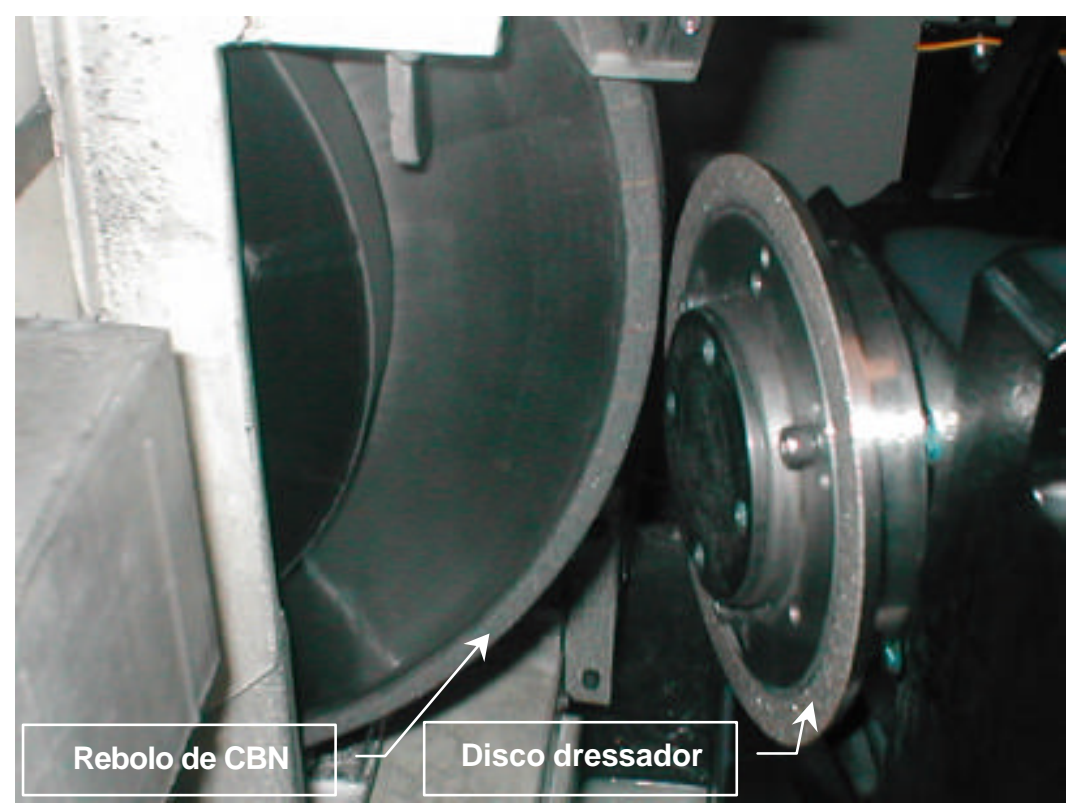

Figura 5.6 - Montagem cabeçote dressador a 70 graus em relação ao eixo do rebolo

Nesta configuração é possível dressar a lateral e o raio esquerdo do rebolo, bem como sua face. O referenciamento por EA das coordenadas de contato rebolo/disco dressador também é utilizado. As coordenadas $\mathrm{Z}$ da lateral esquerda do rebolo e $\mathrm{X}$ da face do mesmo são capturadas e atualizadas via EA. Nesta configuração o raio da ferramenta a ser considerado é o raio da largura de atuação do disco dressador $\left(b_{d}=0,3 \mathrm{~mm}\right)$ não sendo necessária a correção do avanço programado.

No caso da necessidade de dressagem de todo o perfil do rebolo seria necessária a instalação de uma nova unidade dressadora ou a substituição do disco dressador existente por um disco dressador no formato "T".

- Sistema de aplicação de fluido de corte:

O sistema de aplicação de fluido de corte permitia a utilização de dois tipos de bocais distintos, os quais foram desenvolvidos para esta pesquisa. 


\section{Bocal de Sapata (Figura 5.7):}

Vantagens: aplicação do fluido de corte com velocidade igual a velocidade periférica do rebolo. Utiliza a própria rotação do rebolo para aceleração do fluido.

Desvantagens: Consumo da potência disponível no motor de acionamento do rebolo e baixa eficiência na aplicação do fluido de corte nas laterais do rebolo.

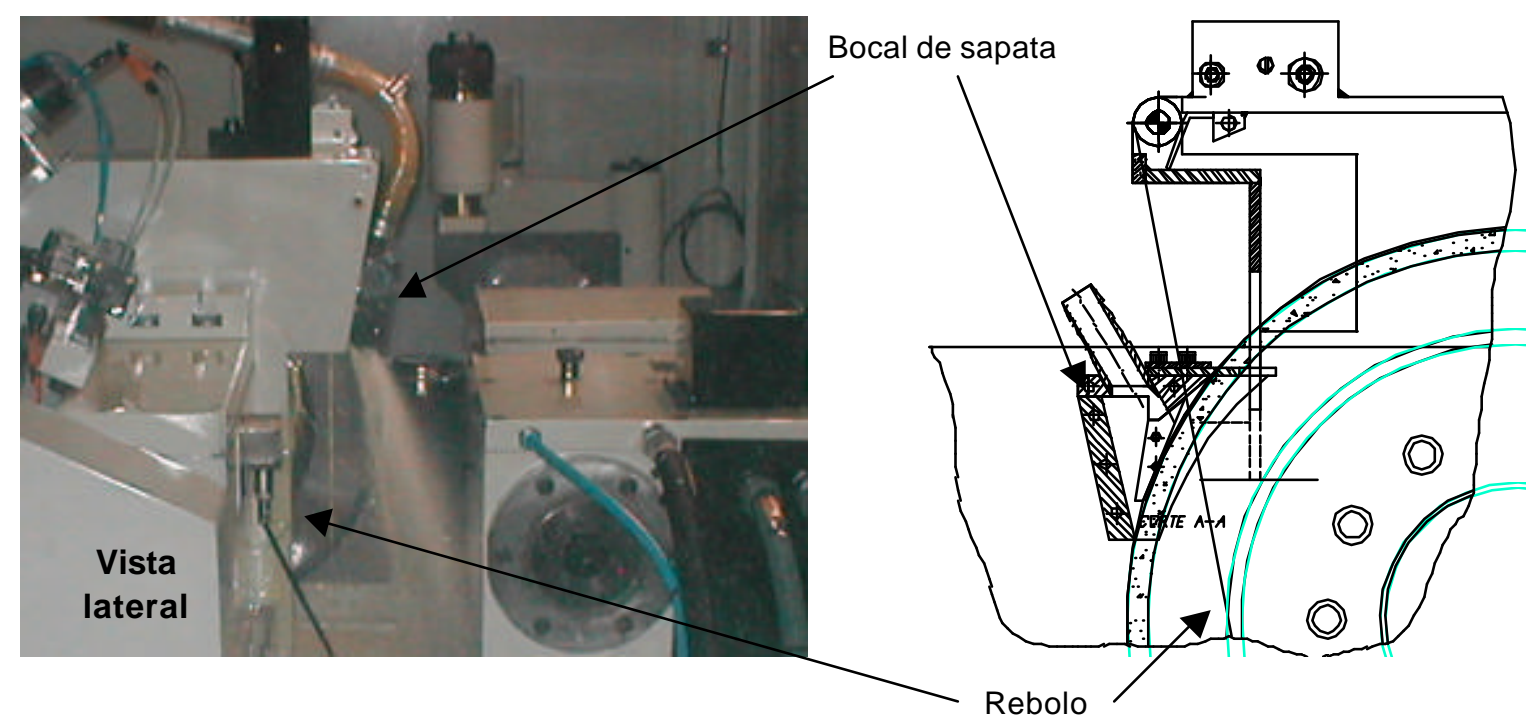

Figura 5.7 - Bocal de sapata instalado na retificadora

\section{Bocal "Bombeiro" (Figura 5.8):}

Vantagens: aplicação do fluido de corte localizada com jato coerente, mesmo afastado da região de corte.

Desvantagens: Pressão necessária elevada para se obter razões unitárias de velocidades. 


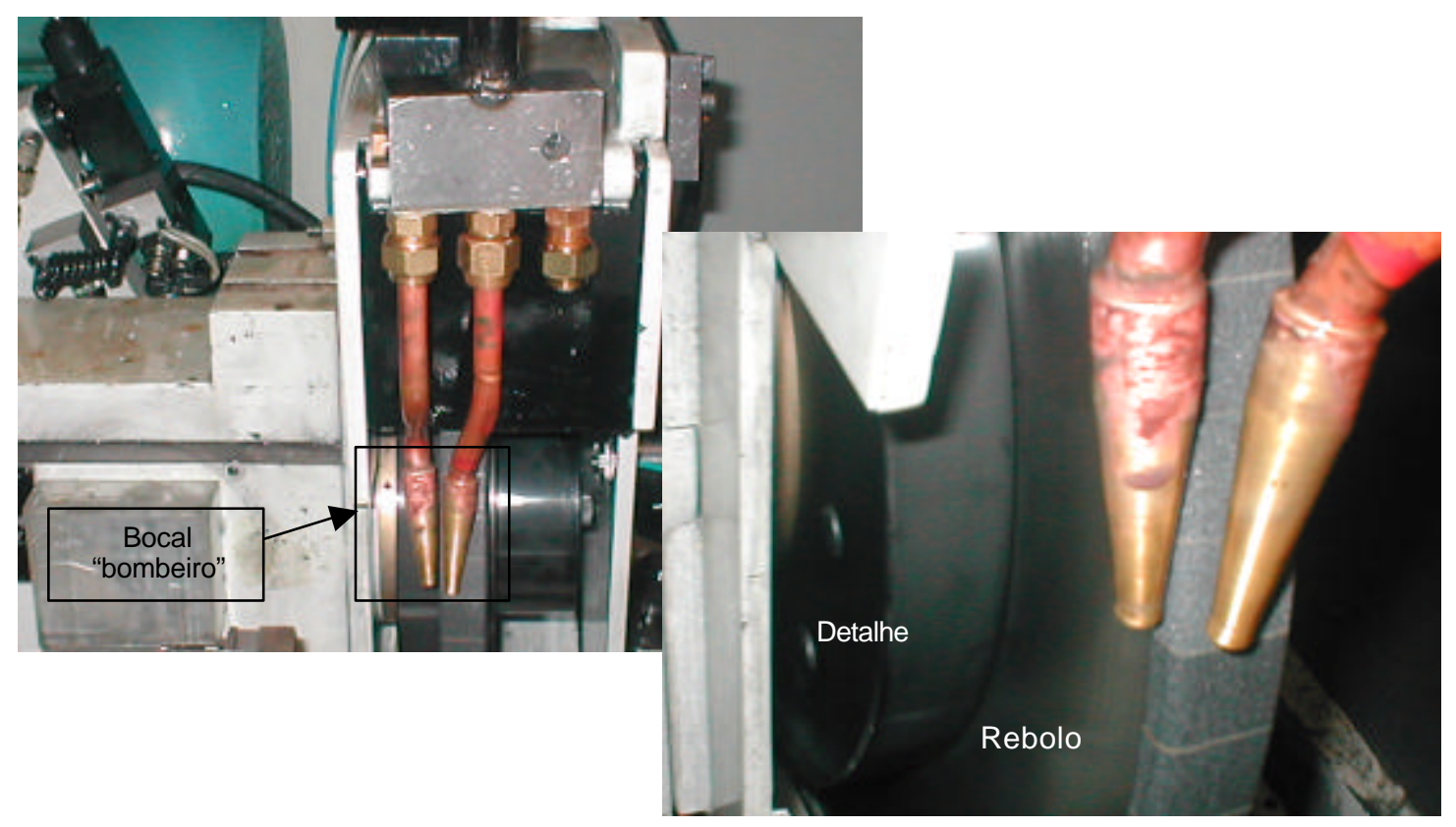

Figura 5.8 - Bocais "bombeiro" instalados na retificadora

\subsection{Configuração 2 de retificação}

A "Configuração 2" denominada os testes de retificação realizados na ReinischWestfälischen Technischen Hochschule - RWTH-Aachen - WZL - Laboratorium für der Werkzeugmaschinen und Betriebslehre - Aachen - Alemanha. A opção de efetuar testes em outra retificadora teve como objetivo validar os conceitos em equipamentos e ferramentas com características distintas de forma a não se ter influências indesejadas nas análises dos resultados. A seguir são descritos os detalhes da metodologia empregada.

\section{- Dados técnicos da retificadora}

○ Os dados técnicos da retificadora cilíndrica externa, marca Junker, modelo Quickpoint 5002/20 são apresentados na Figura 5.9. 


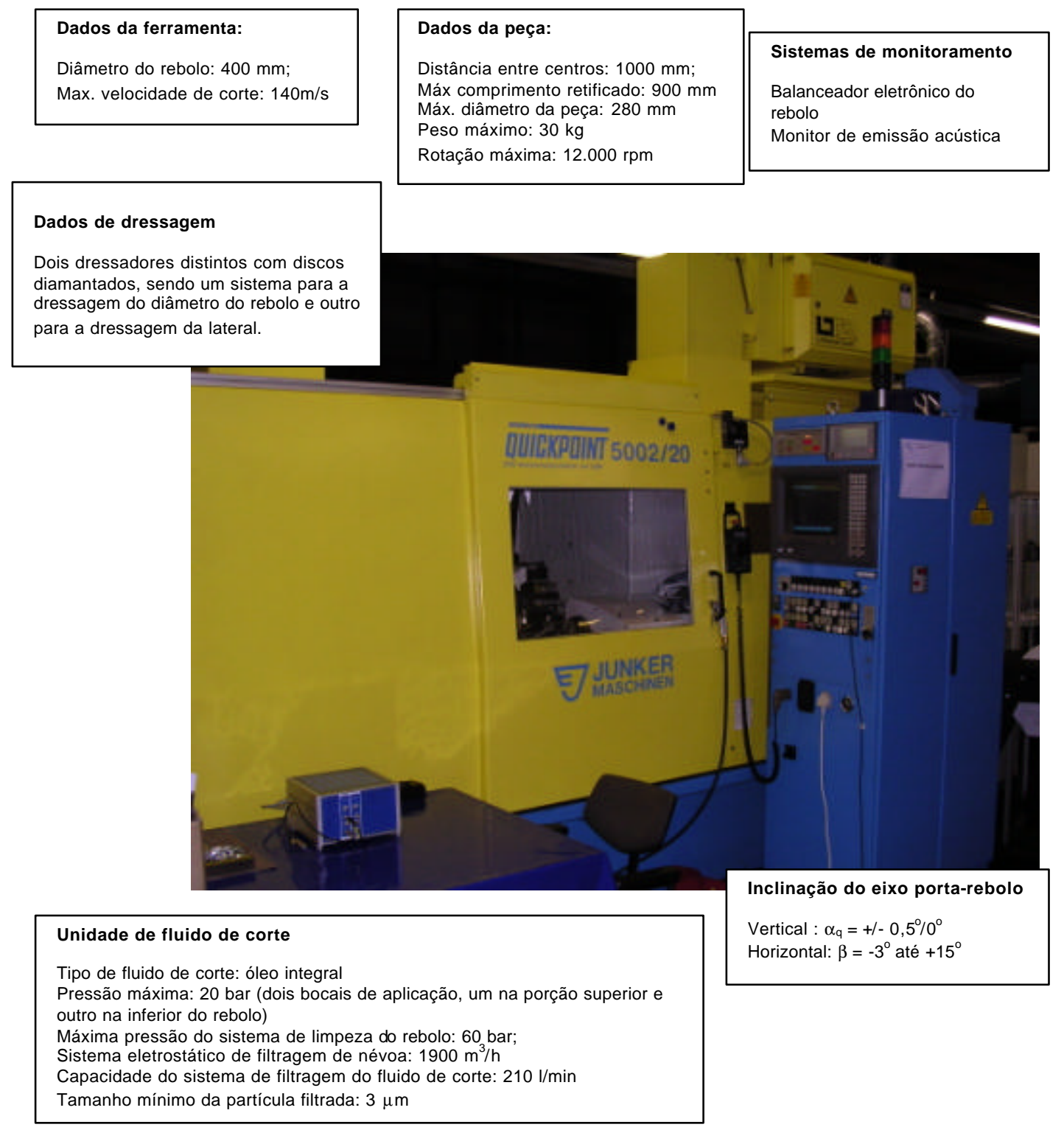

Figura 5.9 - Dados técnicos da retificadora Junker Quickpoint 5002/20

\section{- Corpos-de-prova}

- Devido à impossibilidade da usinagem dos espelhos excêntricos de eixos virabrequins na retificadora de alta velocidade em questão, por tratar-se de uma retificadora universal, optou-se pela usinagem de corpos-de-prova com geometria igual à de um colo de virabrequim. O corpo-de-prova utilizado permite a usinagem de diversos colos numa única peça. A Figura 5.10 apresenta as dimensões dos corpos-de-prova. O material dos mesmos é o aço 16MnCr5 (61 HRc, $1 \mathrm{~mm}$ de camada temperada, C (0,14-0,19\%), Si $(<0,4 \%)$, Mn (1,00-1,30\%), P (<0,035\%), S (0,035\%), Cr (0,80-1,10\%)). 

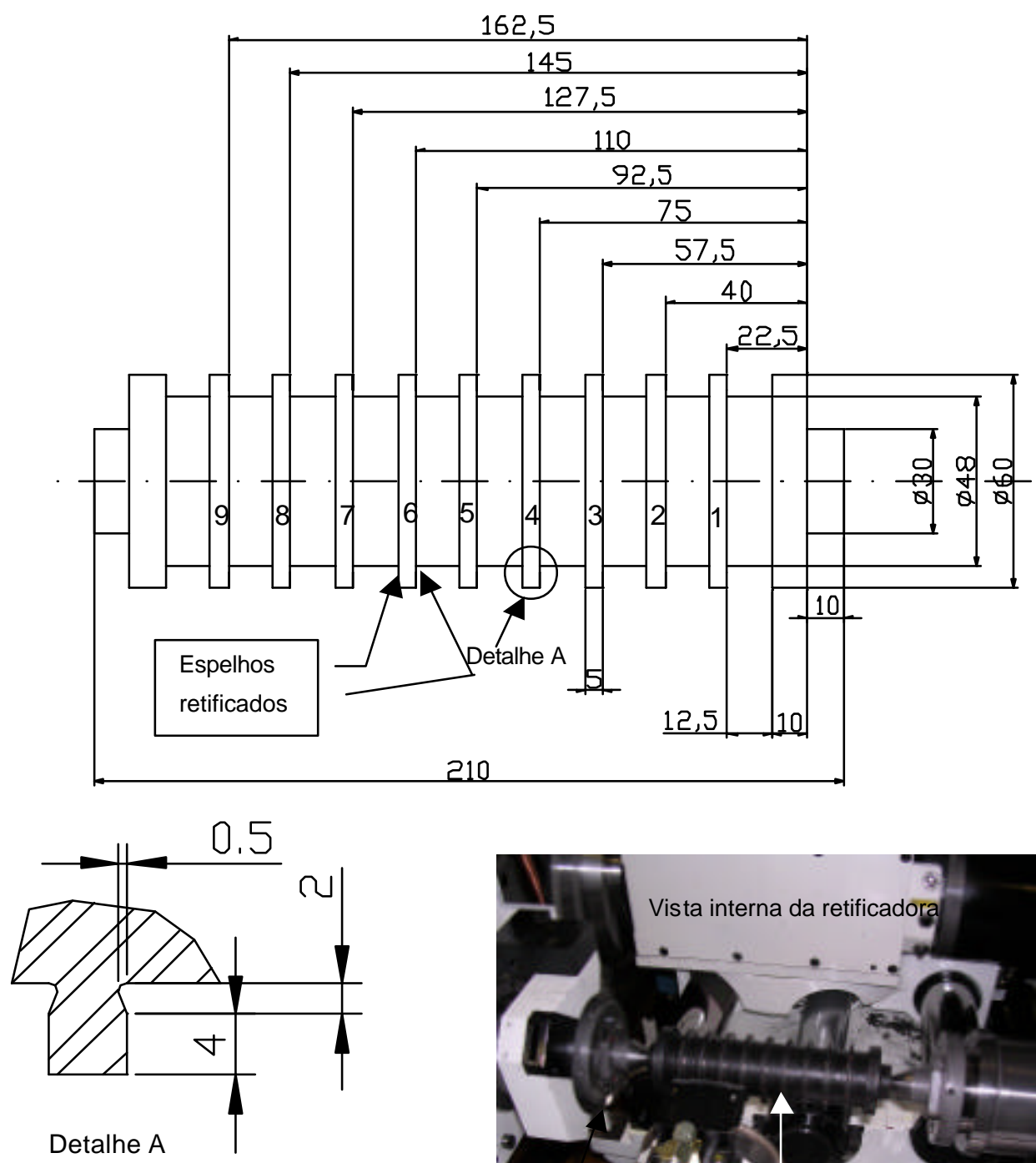

Dressador 2

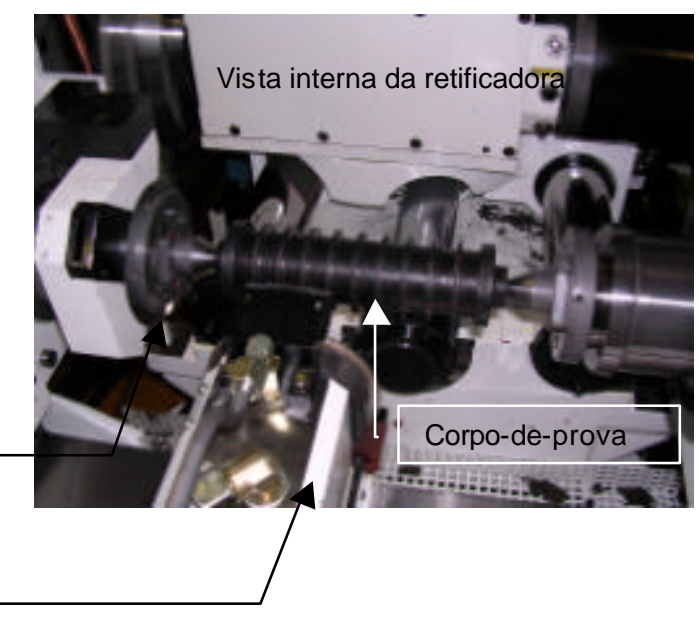

Figura 5.10 - Dimensões dos corpos-de-prova (colos de 1 a 9)

\section{- Dados do rebolo de CBN com ligante vitrificado}

○ Especificação: B126 VSS 2804 J1 SC V 360E

○ Dimensões: diâmetro externoØ400 x largura 6,5 x altura segmento $5 \mathrm{~mm}$

- Perfil do rebolo: raio de $1 \mathrm{~mm}$ nas laterais esquerda e direita 
- Sistema de dressagem:

○ O sistema de dressagem é constituído de dois dressadores, ambos contendo discos diamantados, os quais permitem a dressagem completa de todo o perfil do rebolo (Figura 5.11). Um deles está posicionado na mesa do carro porta-peças. O acionamento do disco dressador é efetuado por um motor elétrico. A dressagem das laterais do rebolo é efetuada com este dressador. O segundo sistema está posicionado no eixo porta-peças. Neste caso, o motor do eixo porta-pecas aciona este disco dressador. Com este dressador efetua-se a dressagem dos raios e a face do rebolo.
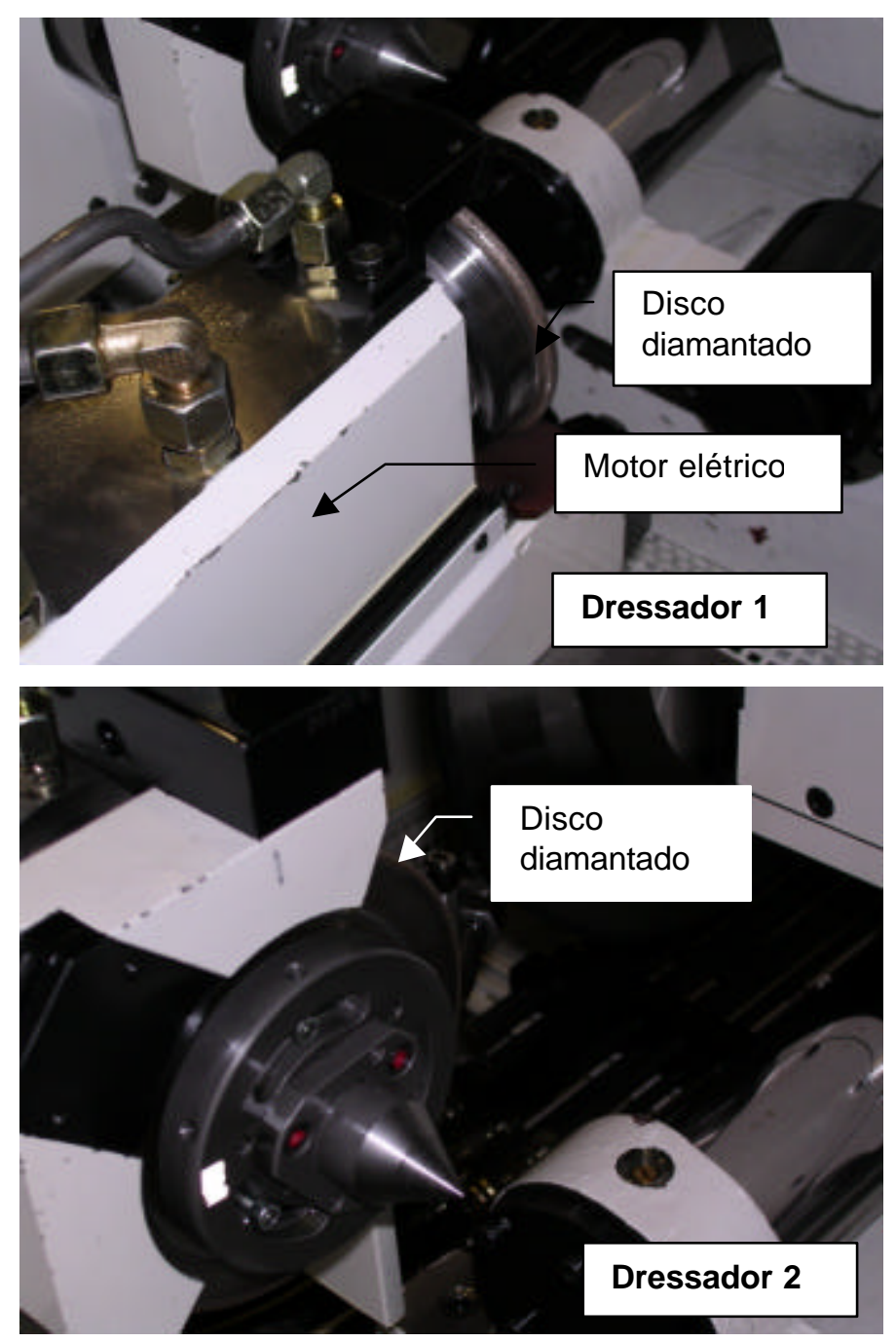

Figura 5.11 - Sistemas de dressagem retificadora Junker 
- Fluido de corte e sistema de lavagem a alta pressão

Pressão dos bocais superior e inferior de fluido de corte: 17 bar

Pressão do sistema de limpeza de fluido de corte: 60 bar (Figura 5.12); bocal jato plano.

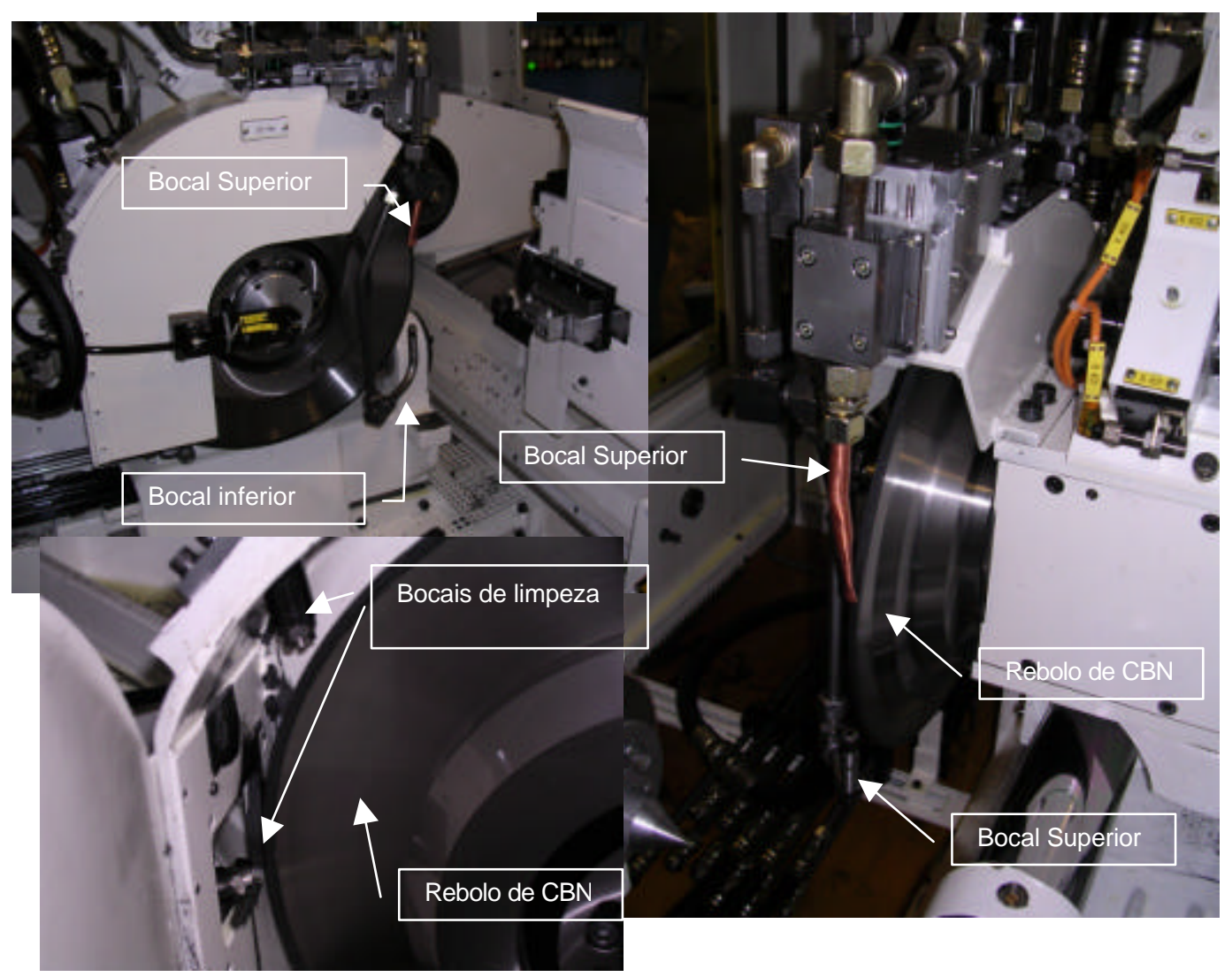

Figura 5.12 - Sistemas de aplicação de fluido de corte e limpeza do rebolo

- Sistemas de balanceamento dinâmico e monitoramento por emissão acústica

A retificadora possui um sistema de balanceamento dinâmico do rebolo e uma unidade de monitoramento da emissão acústica presente na máquina, a qual possuía um sensor de emissão acústica incorporado ao eixo da máquina (Figura 5.13). 


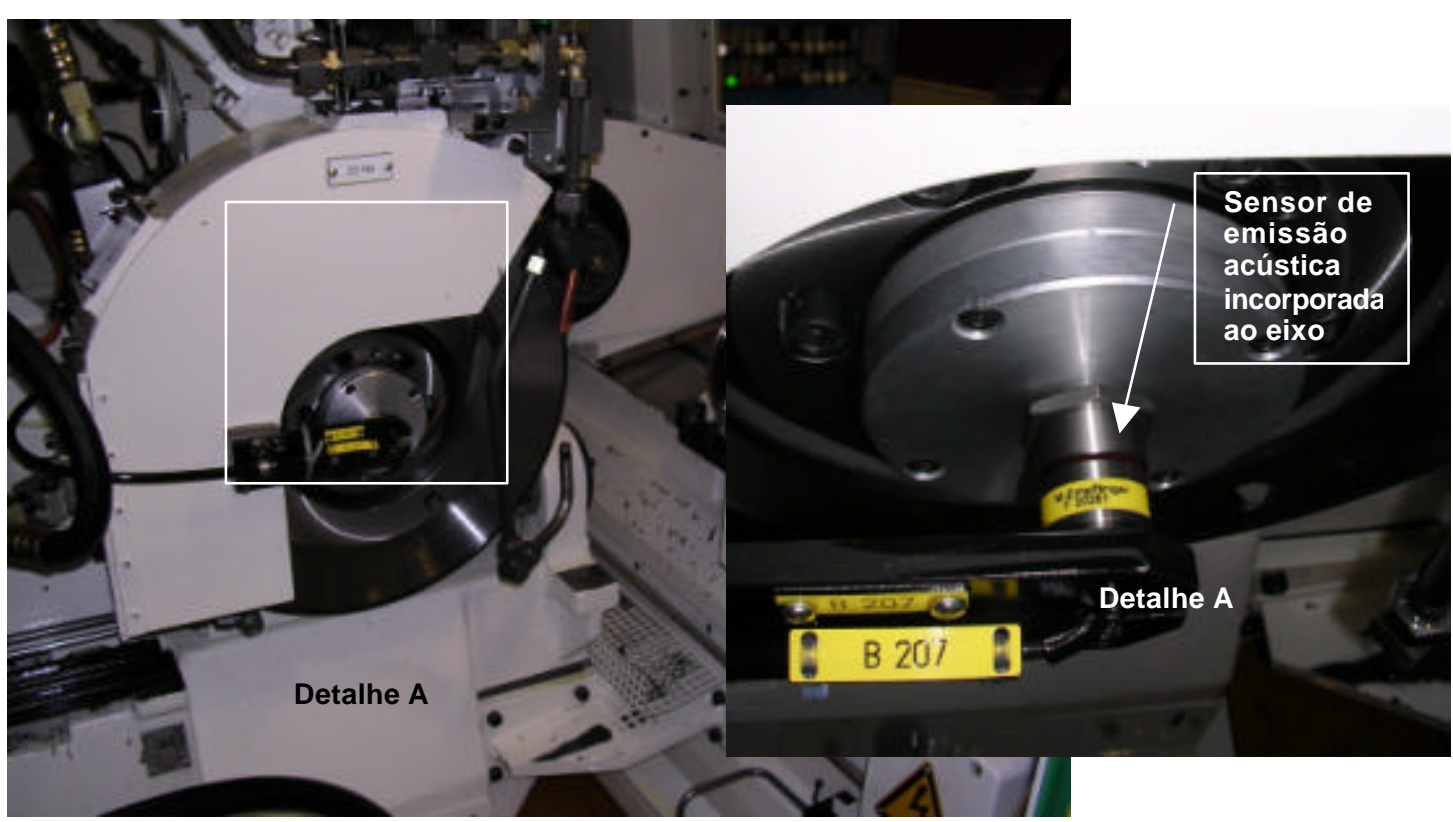

Figura 5.13 - Sensor de emissão acústica incorporado ao eixo

\subsection{Técnicas para a eliminação da queima no espelho}

O surgimento de queima na superfície retificada é um dos grandes problemas a serem enfrentados durante a usinagem das faces planas (espelhos) conforme descrito anteriormente e verificado experimentalmente por Merbecks. As causas de seu aparecimento estão relacionadas com a agressividade da superfície do rebolo, ao perfil lateral do rebolo e a eficiência do sistema de aplicação de fluido de corte.

\subsection{1 - Agressividade da superfície do rebolo}

A agressividade da superfície do rebolo tem papel mportante na incidência de queima na face retificada. Um rebolo com baixa agressividade possui uma capacidade de corte reduzida, sendo necessária uma maior quantidade de energia de retificação para a remoção de material. Paralelamente, as parcelas de geração de calor atrito e riscamento também aumentam, resultando em danos térmicos na peça. A Figura 5.14 apresenta o aspecto visual 
típico de uma retificação de face plana em que a baixa agressividade resultou em uma peça com incidência acentuada de queima.

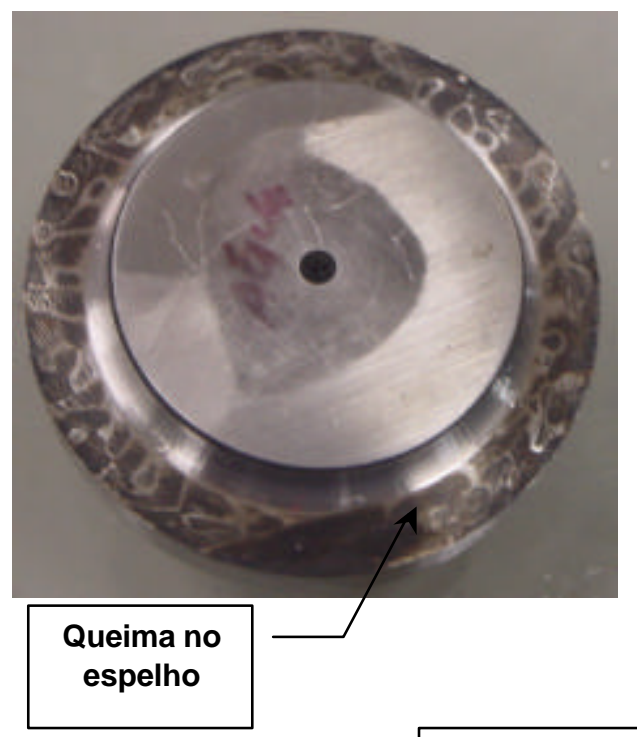

Condições de dressagem:

velocidade de corte $\left(\mathrm{v}_{\mathrm{s}}\right)=45 \mathrm{~m} / \mathrm{s}$;

velocidade periférica do disco dressador

$\left(v_{d}\right)=24 \mathrm{~m} / \mathrm{s}$, razão de esmagamento

$\left(q_{d}\right)=0,53 ;$ avanço de dressagem $\left(v_{t}\right)$

$=100 \mathrm{~mm} / \mathrm{min} ; \mathrm{ad}=2 \mu \mathrm{m}$ (ao longo de

todo perfil); tipo de dressagem - eixos

cruzados

\section{Condições de usinagem:}

Estratégia $B$, velocidade de corte $\left(v_{s}\right)=$ $100 \mathrm{~m} / \mathrm{s}$; rotação da peça $\left(\mathrm{n}_{\mathrm{w}}\right)=60 \mathrm{rpm}$; Sobremetal $(\mathrm{SM})=0,2 \mathrm{~mm}$; Velocidade axial $\left(v_{\mathrm{fa}}\right)=0,25 \mathrm{~mm} / \mathrm{min}$; Vazão de fluido de corte $(\mathrm{Q})=100 \mathrm{l} / \mathrm{min}$, Tempo de Spark-out $=10 \mathrm{~s}$, tipo de fluido: óleo integral.

\section{Configuração 1 de retificação}

Figura 5.14 - Exemplo de queima acentuada na face plana retificada - resultado obtido na Configuração 1 de retificação - retificação axial (estratégia B)

A escolha da estrutura do rebolo correta tem papel fundamental na incidência ou não de danos térmicos na peça. Uma estrutura mais "aberta" ou mais "fechada", resultado de sua porosidade induzida influencia na capacidade de alojamento dos cavacos, os quais podem entupir a porosidade do ligante do rebolo, levando ao contato metálico peça-cavaco, aumentando a geração de calor e o dano térmico. Neste caso é necessária a introdução de bicos de limpeza para a prevenção do empastamento do rebolo.

Um das formas de ajuste da agressividade do rebolo é a adoção de uma operação de retificação eficiente, a qual engloba a adoção da estratégia e das condições de dressagem adequadas. Na presente pesquisa detectou-se a influência das condições de dressagem nos resultados. 
Um dos exemplos desta influência foi verificado em testes de retificação utilizando-se a Configuração 2, em que a seleção correta dos parâmetros de dressagem foi necessária a fim de se obter espelhos retificados isentos de queima. Primeiramente detectou-se que a configuração dos discos dressadores era, a princípio, inadequada para a obtenção da agressividade desejada. Verificou-se que a geometria dos discos dressadores conferia uma largura de atuação excessiva durante a dressagem das laterais do rebolo. Para ambas estratégias de retificação obteve-se peças com queima após a dressagem e uma rugosidade extremamente baixa $\left(\mathrm{R}_{\mathrm{a}}=0,06 \mu \mathrm{m}\right.$ e $0,14 \mu \mathrm{m}$ para as estratégias A (mergulho) e B (axial) respectivamente). As condições de dressagem foram as seguintes: $\mathrm{q}_{\mathrm{d}}=+0,9 ; \mathrm{v}_{\mathrm{s}}=100 \mathrm{~m} / \mathrm{s}$; profundidade de dressagem $\left(\mathrm{a}_{\mathrm{d}}\right)=3 \mu \mathrm{m}$; Passo de dressagem $\mathrm{S}_{\mathrm{d}}: 0,105 \mathrm{~mm} / \mathrm{rot}$. Os avanços de usinagem foram: $\mathrm{v}_{\mathrm{fr}}=5 \mathrm{~mm} / \mathrm{min}$ e $\mathrm{v}_{\mathrm{fa}}=0,3 \mathrm{~mm} / \mathrm{min}$ para as estratégias A (mergulho) e $\mathrm{B}$ (axial) respectivamente $\left(\mathrm{n}_{\mathrm{w}}=120 \mathrm{rpm} ; \mathrm{v}_{\mathrm{s}}=100 \mathrm{~m} / \mathrm{s}\right)$. A solução adotada foi o aumento do passo de dressagem para $0,369 \mathrm{~mm} / \mathrm{rot}$, o que implicou num avanço de dressagem de 1750 $\mathrm{mm} / \mathrm{min}$. Eliminou-se a queima da superfície da peça (Figura 5.15).

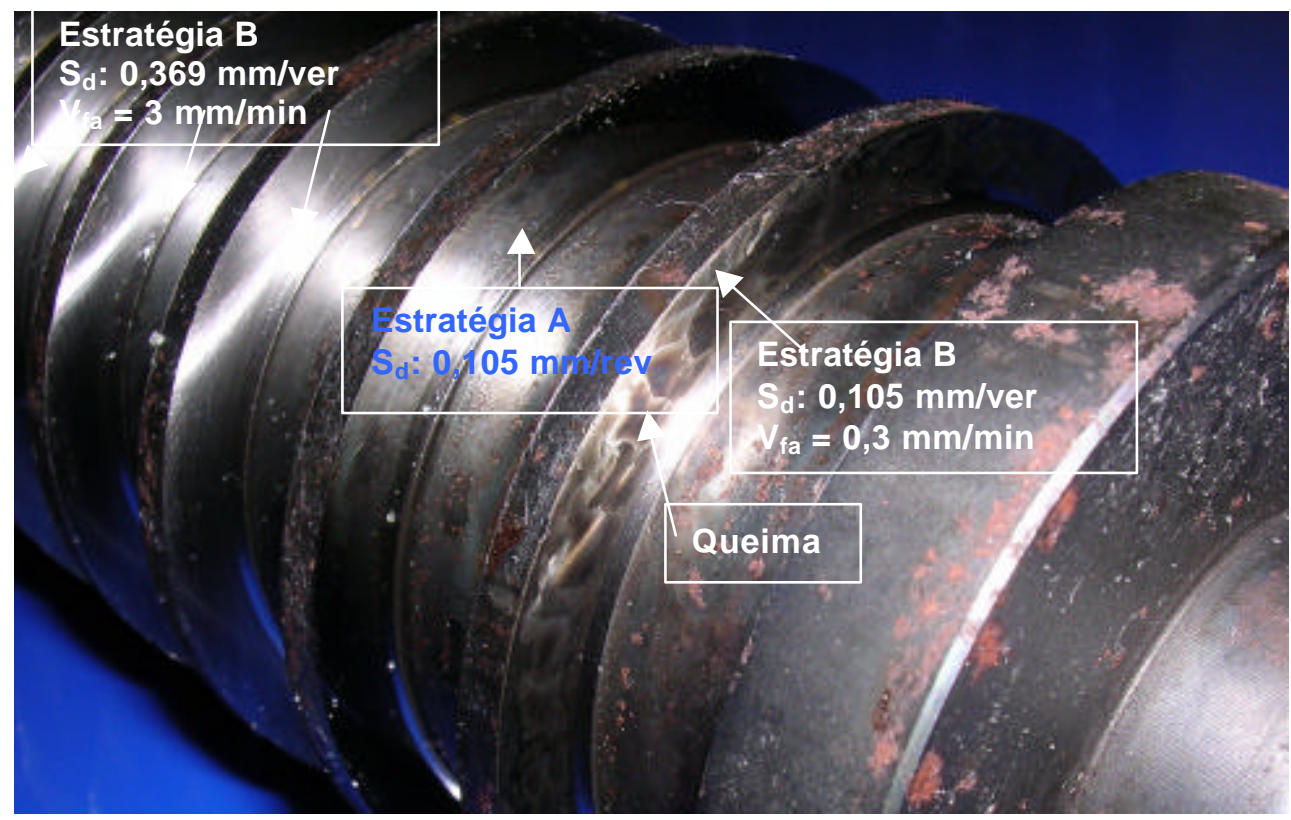

Figura 5.15 - Eliminação da queima através do ajuste das condições de usinagem 


\subsection{2 - Modificações no perfil do rebolo}

A área de contato rebolo-peça durante a utilização da estratégia B (retificação axial) é um fator importante a ser considerado na incidência de queima da face retificada. Buscandose diminuir a geração de calor por atrito na região 2, identificada no modelamento teórico proposto para a retificação axial, optou-se pela redução da área lateral de contato do rebolo com o espelho da peça. Introduziu-se no rebolo um trecho reto de $2 \mathrm{~mm}$, iniciando-se a partir da intersecção do raio de $4 \mathrm{~mm}$. No restante da parede lateral do rebolo dressou-se um chanfro de $100 \mu \mathrm{m}$. A Figura 5.16 apresenta as alterações efetuadas no perfil do rebolo (configuração 1 de retificação). Com essa modificação tem-se também um maior quantidade de material sendo removida na região 3 , o que de alguma forma deve ser benéfico para reduzir a solicitação na região 1 .

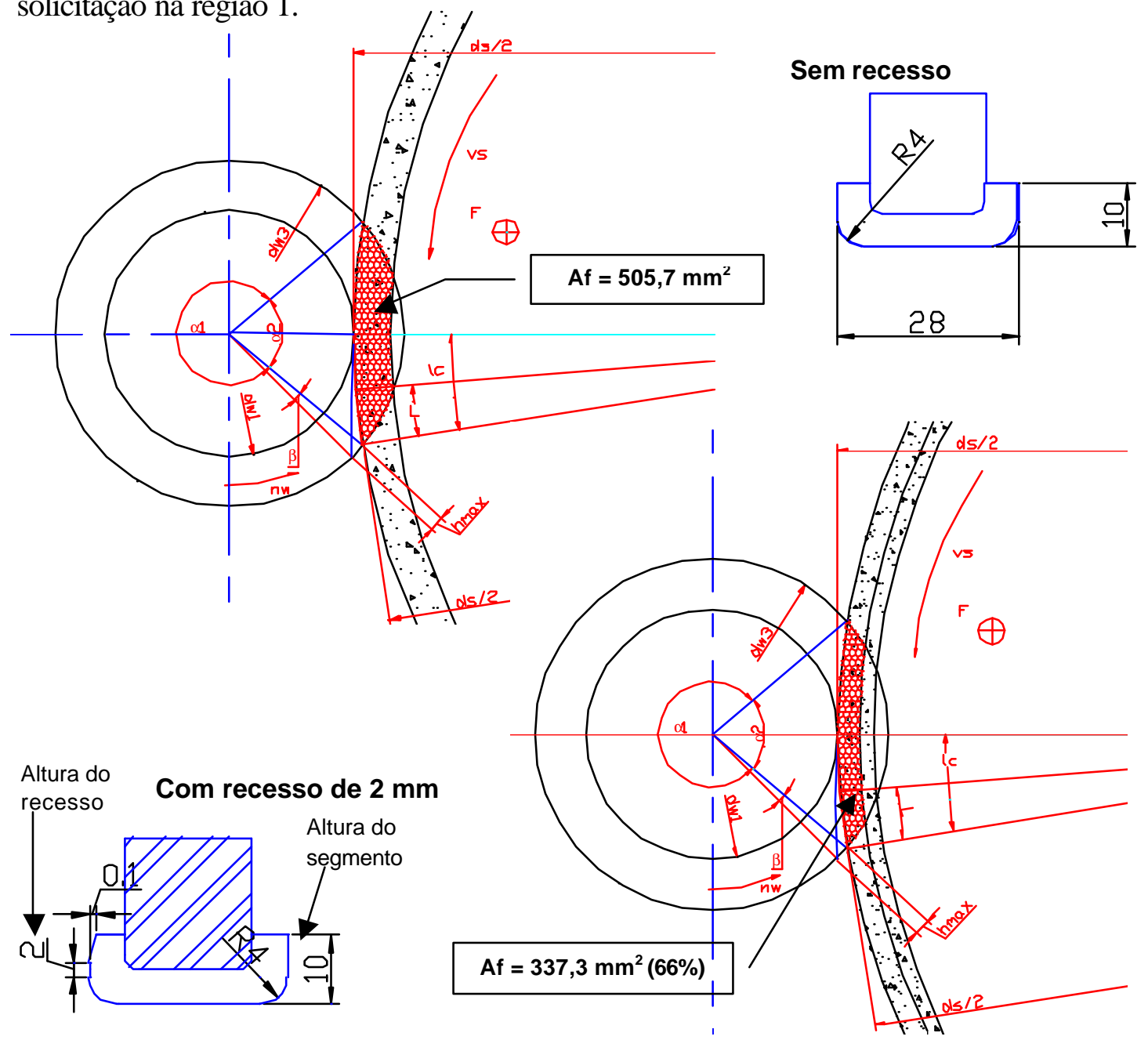

Figura 5.16 - Alterações no perfil do rebolo visando a redução da área de atrito da região 2 


\subsection{3 - Eficiência do sistema de aplicação de fluido de corte e limpeza do rebolo}

A eficiência do sistema de aplicação de fluido de corte é fundamental para a redução da tendência de queima e empastamento do rebolo. Adicionalmente, quando da utilização da estratégia B (axial), sistemas de limpeza do rebolo a alta pressão são indicados para evitar o empastamento do rebolo.

Nos testes realizados com a configuração 1 de retificação diferentes configurações de bocais foram testadas. A primeira configuração satisfatória adotada foi a combinação bocal de sapata e bicos "bombeiro", utilizando-se como fluido de corte um fluido sintético com concentração de 3\%. A introdução dos bicos "bombeiro" tinha como função básica suprir a aplicação ineficiente na interface rebolo-espelho (Figura 5.17).

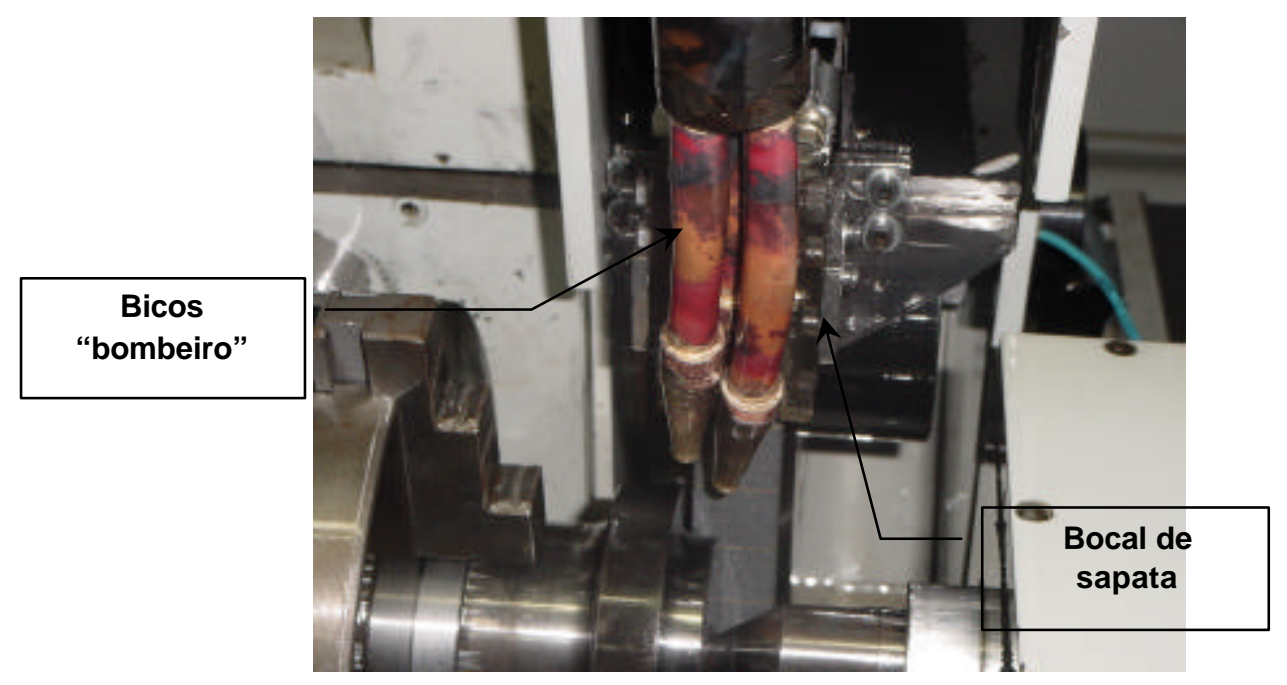

Figura 5.17 - Configuração inicial do sistema de aplicação de fluido de corte - configuração 1 de retificação

Após a substituição do fluido sintético pelo fluido de corte integral, este último apresentando uma maior lubricidade e menor poder refrigerante, tentou-se reproduzir o teste de usinagem axial padrão, mantendo-se as mesmas condições de usinagem. Todavia, peças sem queima só foram obtidas com avanços inferiores aos obtidos para o fluido sintético. A tendência ao empastamento do rebolo tornou-se acentuada. A maior lubricidade do fluido de 
corte integral tornou-se um fator negativo já que dificultou a manutenção da mesma vazão e pressão de aplicação de fluido de corte, reduzindo assim sua eficiência.

Detectou-se a necessidade da melhoria do sistema de aplicação de fluido de corte, uma vez que a refrigeração/lubrificação na região do espelho é crítica. Assim, o sistema de aplicação de fluido de corte foi substituído, retirando-se o bocal de sapata e redesenhando o bocal tipo "bombeiro", posicionando-o próximo do diâmetro externo do espelho da peça. Um dos bocais é responsável pela aplicação de fluido na lateral do rebolo enquanto o outro é responsável pela aplicação no raio do mesmo. A Figura 5.8 apresenta o novo sistema de aplicação de fluido de corte.

A configuração de retificação também foi modificada, a fim de melhorar a eficiência do sistema de aplicação de fluido de corte. Alterou-se o sentido de retificação, de discordante para concordante. Desta forma, a usinagem da frente preferencial de corte é efetuada na porção superior do rebolo, facilitando a penetração de fluido de corte. Este artifício foi utilizado a fim de se evitar a instalação de um bocal de fluido de corte na parte inferior à região de contato entre a peça e o rebolo.

A introdução do novo sistema de aplicação de fluido de corte combinado com a alteração do sentido de retificação (discordante para concordante) resultou numa melhora significativa do desempenho do processo. A tendência de empastamento do rebolo foi eliminada principalmente pela aplicação mais efetiva do fluido de corte, sendo ainda favorecida pela inversão do sentido de giro da peça.

Nos testes realizados com a configuração 2 de retificação o sistema de aplicação de fluido de corte padrão já possuía dois bocais de aplicação, um superior e outro inferior (Figura 5.12). Adicionalmente o sistema de limpeza a alta pressão tem como intuito prevenir o empastamento do rebolo. 


\subsection{Retificação de faces planas empregando-se a estratégia A - mergulho}

Testes de retificação foram efetuados buscando-se verificar quais seriam as técnicas mais eficazes a serem introduzidas quando da retificação das faces planas utilizando-se a estratégia A.

A estratégia preliminarmente adotada foi o emprego, durante o mergulho com uma velocidade constante $\mathrm{v}_{\mathrm{fr}}$ ao longo de todo o trajeto de retificação $\left(\mathrm{d}_{\mathrm{w} 2}\right.$ até $\left.\mathrm{d}_{\mathrm{w} 1}\right)$. Verificou-se uma tendência à queima da peça logo após a dressagem do rebolo, nas proximidades do raio de arredondamento (configuração 1 de retificação). Como solução efetuou-se a divisão do sobremetal em trechos onde seriam reduzidos os valores de avanço, conforme Figura 5.18.

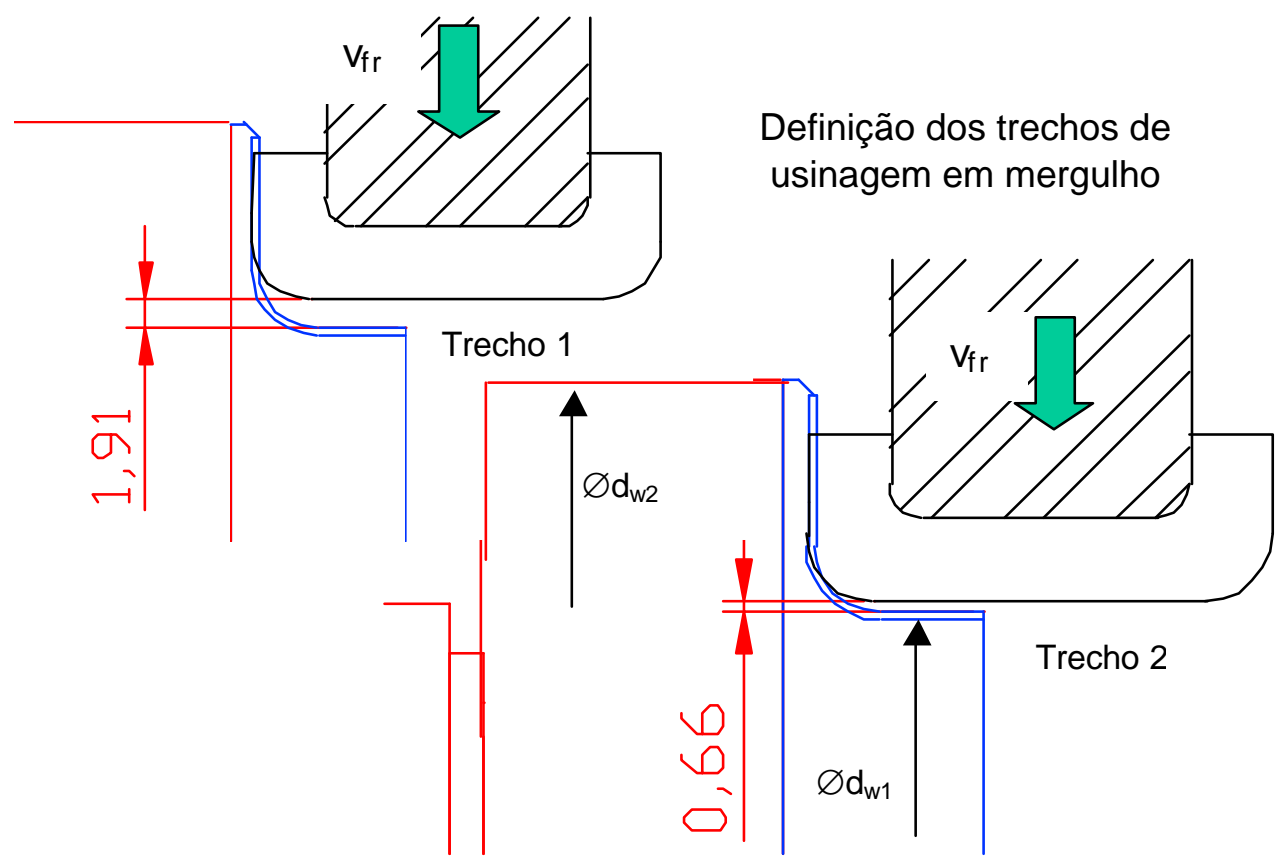

Figura 5.18 - Definição dos trechos principais de usinagem para a determinação dos avanços de usinagem

Conforme apresentado na Figura 5.18 foram definidas regiões para a comutação dos avanços de usinagem. O trecho 1 engloba o início da usinagem do espelho até o início da usinagem do raio. $\mathrm{O}$ de número 2 encerra-se ao atingir-se $50 \%$ do sobremetal do raio. $\mathrm{O}$ 
terceiro trecho é delimitado quando o rebolo atinge o diâmetro $d_{w 1}$ do colo da peça. A Tabela 5.1 apresenta as coordenadas para comutação e a denominação dos avanços para cada trecho. A altura radial do espelho (Z/2) é de $14 \mathrm{~mm}$.

Tabela 5.1 - Trechos de usinagem e as coordenadas X de comutação

\begin{tabular}{|c|c|}
\hline Trecho & Coordenada X (mm) \\
\hline 1 & $\mathrm{~d}_{\mathrm{w} 1}+4,0$ \\
\hline 2 & $\mathrm{~d}_{\mathrm{w} 1}+1,4$ \\
\hline 3 & $\mathrm{~d}_{\mathrm{w} 1}$ \\
\hline
\end{tabular}

A adoção dos trechos de usinagem resultou na eliminação da queima nas proximidades do raio. Testes de usinagem de mergulho foram efetuados, utilizando-se a nova configuração de dressagem e o novo fluido de corte (fluido sintético). Os resultados obtidos foram satisfatórios, sem a incidência de queima. A Tabela 5.2 e a Figura 5.19 apresentam o resumo do melhor resultado obtido para esta configuração. O sistema de mapeamento acústico do rebolo desenvolvido por Oliveira et al. (2000) foi utilizado como método de avaliação dos resultados. Uma descrição completa do sistema é apresentado no Anexo A.

Tabela 5.2 - Resumo dos resultados

\begin{tabular}{|c|c|}
\hline Trecho & Avanço radial (mm/min) \\
\hline 1 & 30 \\
\hline 2 & 26 \\
\hline 3 & 6,5 \\
\hline $\begin{array}{c}\text { Sobremetal = 0,4 mm (espelho) e 0,8 mm (diâmetro); } \mathrm{n}_{\mathrm{w}}= \\
100 \text { rpm; fluido sintético 3\% Brix; vazão de fluido de corte } \\
50 \text { 1/min; bocal de sapata + bocal "bombeiro" }\end{array}$ \\
\multicolumn{2}{|c|}{ Rugosidades médias: } \\
$\mathrm{R}_{\mathrm{a}}=0,06 \mu \mathrm{m} / \mathrm{R}_{\mathrm{z}}=0,32 \mu \mathrm{m}$ \\
\hline
\end{tabular}



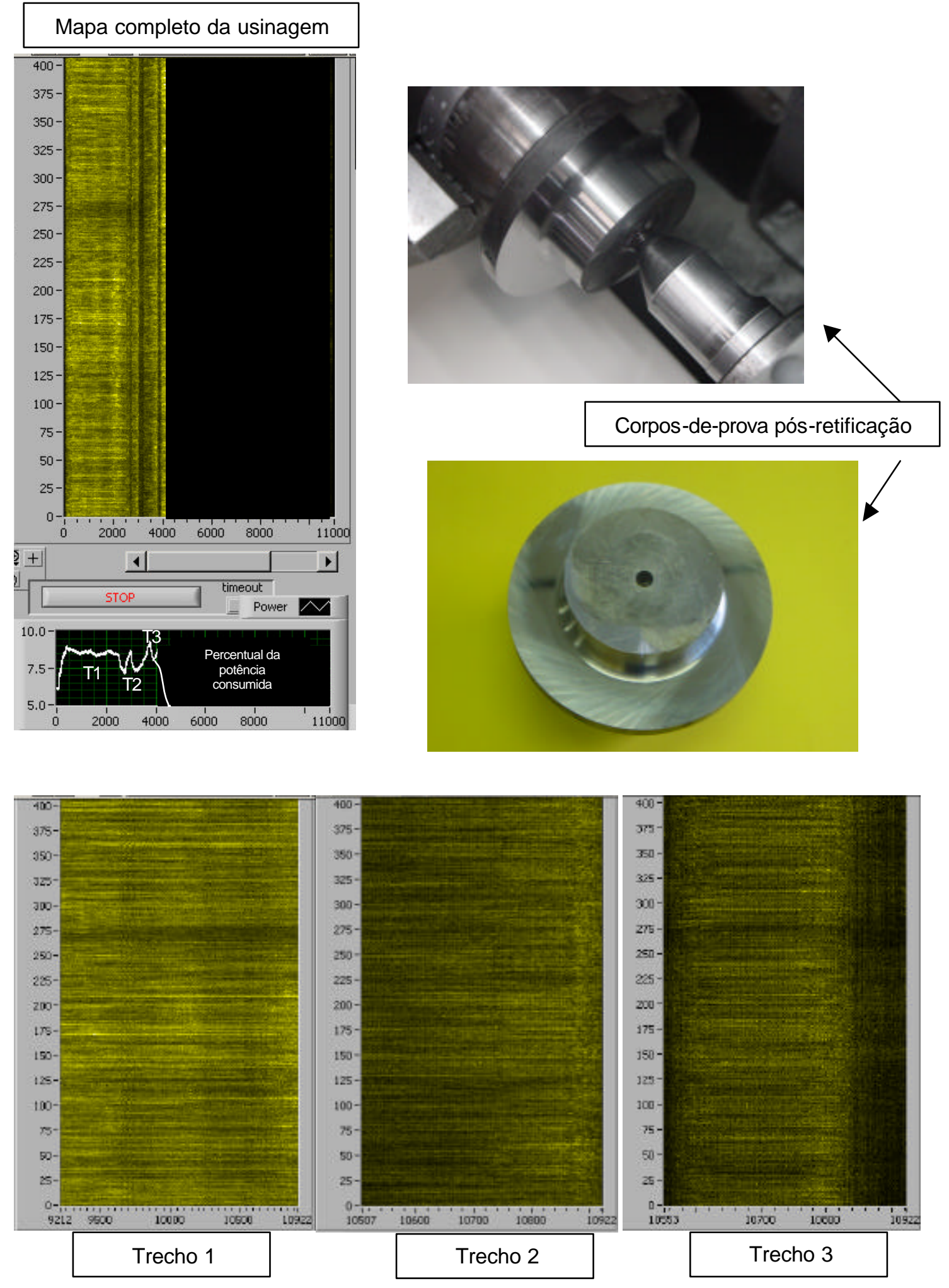

Figura 5.19 - Mapas acústicos obtidos durante a usinagem de mergulho - aspecto visual pósretificação

A Figura 5.19 apresenta os mapas acústicos obtidos durante a retificação. O mapa completo da usinagem apresenta a imagem obtida para os três trechos propostos, além do 
percentual da potência elétrica consumida no motor de acionamento do rebolo durante a usinagem (10V igual a $100 \%$ da potência disponível). Na porção inferior da Figura 5.19 são apresentados os mapas para os trechos 1 a 3 ampliados. Nestas é possível verificar-se padrões horizontais, porém estes não se mantêm ao longo de todo o ciclo, ocorrendo transformações sutis no início e final dos mesmos. Estas transformações da superfície de corte do rebolo podem ser associadas ao desgaste dos grãos ativos. Destaca-se a excelente rugosidade superficial obtida.

O tempo de ciclo obtido neste teste é apresentado na Tabela 5.3, para uma altura do espelho de $14 \mathrm{~mm}$. Os avanços dos trechos 1, 2 e podem ainda ser um pouco otimizados, já que estes encontram-se em torno de $90 \%$ da potência disponível para a retificação.

Tabela 5.3 - Tempos de ciclo para a usinagem de mergulho

\begin{tabular}{|cccccc|}
\hline Altura do espelho & & & $\mathbf{1 4}$ & $\mathbf{m m}$ & \\
Trecho & Descrição & Avanço radial $(\mathbf{m m} / \mathbf{m i n})$ & Diâmetro inicial $\mathbf{( m m})$ & Diâmetro final $(\mathbf{m m})$ & Tempo \\
1 & $\mathrm{~d}_{\mathrm{w} 1}+4,00$ & 30 & 95 & 71 & 24,0 \\
2 & $\mathrm{~d}_{\mathrm{w} 1}+1,40$ & 26 & 71 & 68,4 & 3,0 \\
3 & $\mathrm{~d}_{\mathrm{w} 1}$ & 6,5 & 68,4 & 67 & 6,5 \\
& & & & Sparkout & 5,0 \\
& & & & Total & $\mathbf{3 8 , 5}$ \\
\end{tabular}

\subsection{Retificação de faces planas empregando-se a estratégia B - retificação axial}

A realização de testes preliminares utilizando-se a configuração de retificação 1 adotando-se a estratégia B - retificação axial apresentou resultados insatisfatórios, com surgimento de queima acentuada da face plana e/ou empastamento do rebolo, limitando o avanço axial.

As condições de usinagem, de dressagem e um resumo dos resultados obtidos em um dos testes realizados são apresentados na Tabela 5.4. O mapa acústico obtido durante a usinagem da face plana é apresentado na Figura 5.20. 
Tabela 5.4 - Teste de retificação axial

Condições de dressagem: Dressagem com eixo a 70 graus:

$\mathrm{v}_{\mathrm{s}}=100 \mathrm{~m} / \mathrm{s} ; \mathrm{v}_{\mathrm{d}}=32 \mathrm{~m} / \mathrm{s} \mathrm{q_{d }}=+0,32 ; \mathrm{v}_{\mathrm{t}}=500 \mathrm{~mm} / \mathrm{min} \mathrm{em}$

todas as regiões

Condições de usinagem: Sobremetal $=0,4 \mathrm{~mm}$ (espelho);

$\mathrm{v}_{\mathrm{fa}}=0,4 \mathrm{~mm} / \mathrm{min} ; \mathrm{n}_{\mathrm{w}}=20 \mathrm{rpm}$; Spark-out: $10 \mathrm{~s}$; fluido

sintético 3\% Brix; vazão de fluido de corte 50 1/min; bocal

de sapata + bocal "bombeiro"; tempo de corte $60 \mathrm{~s}$

Resultados: sem queima da peça, porém com

empastamento do rebolo

\begin{tabular}{|c|}
\hline Rugosidades médias: \\
\hline Espelho \\
\hline $\mathrm{Ra}=0,31 \mu \mathrm{m} / \mathrm{Rz}=1,74 \mu \mathrm{m}$ \\
\hline
\end{tabular}

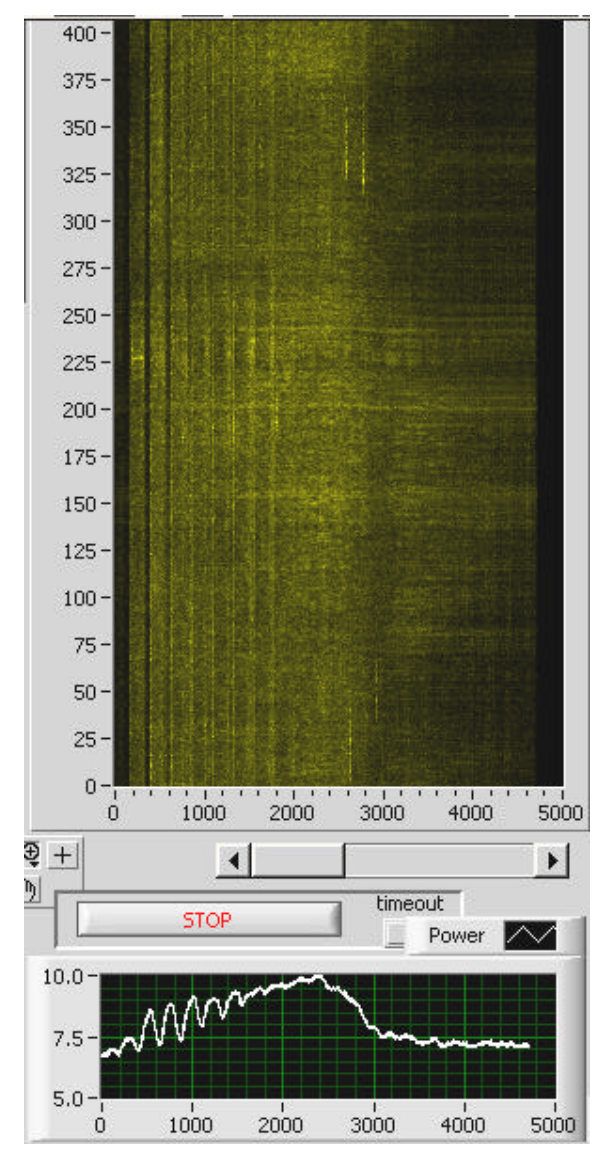

Figura 5.20 - Mapa acústico e potência elétrica obtida durante a usinagem de mergulho - aspecto visual pós-retificação 
Da análise da Tabela 5.4 verifica-se que foi obtida uma peça isenta de queima, porém houve empastamento do rebolo ao final do ciclo. Na Figura 5.20, o mapa acústico obtido da usinagem axial do espelho apresenta uma imagem sem padrão gráfico, caracterizando uma usinagem não estável, fato este demonstrado pelo gráfico de potência obtido. Após um período de oscilação inicial do sinal de potência, resultado da excentricidade da fixação da peça, observa-se um gráfico de potência, sem patamar definido. Em termos comparativos, o melhor tempo de ciclo obtido para a estratégia B (axial) foi igual a $70 \mathrm{~s}$, o que é $82 \%$ maior que o obtido para a estratégia A (mergulho).

Os resultados não satisfatórios obtidos para a usinagem axial, motivaram a busca de alternativas de usinagem, a fim de se reduzir a severidade da operação e melhorar a distribuição do sobremetal a ser removido ao longo da largura de usinagem do rebolo.

\subsection{Retificação de faces planas empregando-se a estratégia $C$ - retificação axial múltipla}

A viabilidade da técnica da usinagem proposta foi analisada através de testes de usinagem com 6 estágios. A Tabela 5.5 apresenta a configuração básica destes. 
Tabela 5.5 - Configuração dos testes

Condições de usinagem: sobremetal = 0,4 mm (espelho), altura do espelho $14 \mathrm{~mm}, \mathrm{~d}_{\mathrm{wl}}=67 \mathrm{~mm}$; fluido: óleo integral; bocal de "bombeiro" modificado, $\mathrm{n}_{\mathrm{w}}=120 \mathrm{rpm}$;

$$
\text { Spark-out }=5 \mathrm{~s}
$$

Condições de dressagem: Dressagem com eixo a 70 graus: $\mathrm{v}_{\mathrm{s}}=100 \mathrm{~m} / \mathrm{s} ; \mathrm{v}_{\mathrm{d}}=32 \mathrm{~m} / \mathrm{s} \mathrm{q}_{\mathrm{d}}=+0.32 ; \mathrm{v}_{\mathrm{t}}=1400 \mathrm{~mm} / \mathrm{min}$ (lateral do rebolo), $\mathrm{v}_{\mathrm{t}}=1000 \mathrm{~mm} / \mathrm{min}$ (raio do rebolo), $\mathrm{v}_{\mathrm{t}}$ $=600 \mathrm{~mm} / \mathrm{min}$.

\begin{tabular}{|c|c|c|}
\hline Estágio & $\begin{array}{c}\text { Coordenada } \mathrm{X} \\
\text { programada }\end{array}$ & $\begin{array}{c}\text { Avanço } \\
\text { axial } \mathrm{v}_{\mathrm{fa}} \\
(\mathrm{mm} / \mathrm{min})\end{array}$ \\
\hline 1 & $\mathrm{~d}_{\mathrm{w} 1}+20,00$ & 14,5 \\
\hline 2 & $\mathrm{~d}_{\mathrm{w} 1}+16,00$ & 14,5 \\
\hline 3 & $\mathrm{~d}_{\mathrm{w} 1}+12,00$ & 14,5 \\
\hline 4 & $\mathrm{~d}_{\mathrm{w} 1}+8,00$ & 14,5 \\
\hline 5 & $\mathrm{~d}_{\mathrm{w} 1}+4,00$ & 14,5 \\
\hline 6 & $\mathrm{~d}_{\mathrm{w} 1}$ & 7,7 \\
\hline \multicolumn{2}{|c|}{ Rugosidade no espelho $\mathrm{R}_{\mathrm{z}}=4,29 \mu \mathrm{m}$} \\
\hline \multicolumn{2}{|c|}{ tempo de corte $\left(\mathrm{t}_{\mathrm{c}}\right)=16,5 \mathrm{~s}$} \\
\hline
\end{tabular}

O mapa acústico obtido durante a retificação e o aspecto visual da peça e do rebolo após a retificação são apresentados na Figura 5.21.

A introdução da estratégia de múltiplos estágios, com a conseqüente redução da taxa de remoção de material específica por ciclo, permitiu a obtenção de peças isentas de queima e sem empastamento do rebolo (Figura 5.21). O tempo de corte foi reduzido de 60 para 16,5 s. O padrão gráfico obtido no mapa acústico não é bem definido, principalmente para os ciclos 1 a 5, indicando que existe uma alteração da distribuição da energia acústica na superfície do rebolo ao longo da usinagem o que indica a presença de desgaste. 

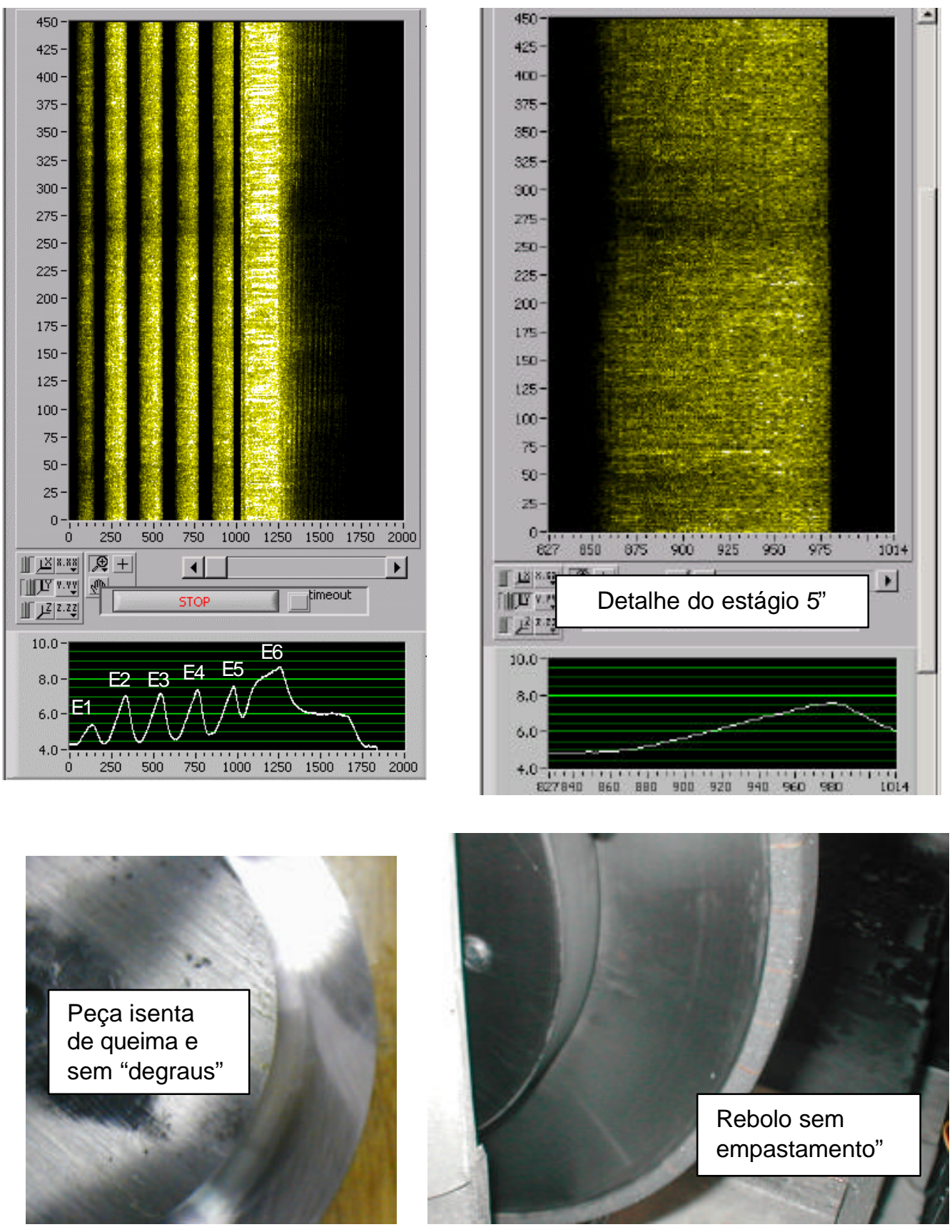

Figura 5.21 - Mapa acústico e aspecto visual da peça obtidos para a estratégia C - 6 estágios

\subsubsection{Análise da influência da introdução de diferentes estágios de retificação para a estratégia $\mathbf{C}$ - axial múltipla}

A fim de se verificar a influência da adoção de diferentes números de estágios quando da utilização da estratégia $\mathrm{C}$ optou-se pela realização de testes de usinagem axial múltipla, variando-se o número de estágios e mantendo-se um mesmo tempo total de ciclo (16,5 s). 
Desta forma, quatro testes de usinagem axial foram executados, onde em cada um deles alterou-se o número de estágios (1, 2, 3 e 6). Estes testes foram de múltiplos ciclos, sendo interrompidos quando o desgaste radial do rebolo ultrapassasse um valor préestabelecido ou quando a potência de usinagem atingisse o valor máximo disponível. A medição do desgaste foi efetuada através da avaliação da manutenção do chanfro de $0,1 \mathrm{~mm}$ do rebolo após a usinagem. Foram capturadas as coordenadas $\mathrm{Z}$ em duas posições $\mathrm{X}$ de contato disco dressador - lateral do rebolo, correspondendo ao ponto central do trecho reto de $2 \mathrm{~mm}\left(\mathrm{P}_{1}\right)$ e ao ponto mais interno do chanfro do rebolo $\left(\mathrm{P}_{2}\right)$. Estas coordenadas foram capturadas utilizando-se a detecção de contato por emissão acústica. Após a dressagem préteste, as coordenadas eram capturadas, subtraídas, determinando-se o valor efetivo do chanfro teórico de 0,1 mm. Ao final do teste de usinagem ou após um determinado número de diclos era executado o ciclo de medição do desgaste, capturando-se novamente estas coordenadas. Efetuada a subtração, avalia-se o novo valor do chanfro. O desgaste considerado era a diferença entre os valores dos chanfros calculados antes e depois da usinagem. O desgaste computado refere-se ao do trecho reto de $2 \mathrm{~mm}$, decorrente da operação de usinagem. A Figura 5.22 apresenta as regiões de medição do desgaste.

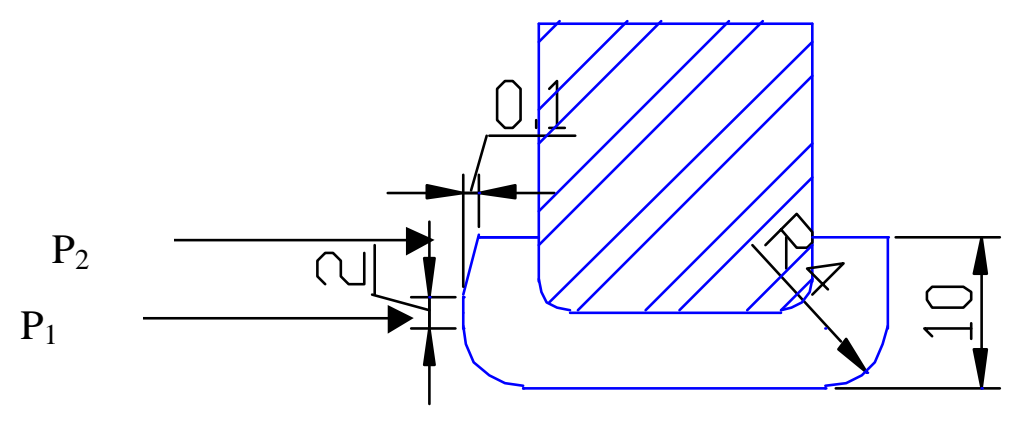

Figura 5.22 - Medição do desgaste do rebolo.

A Tabela 5.6 apresenta um resumo da metodologia de experimentação para a análise da influência do número de estágios na retificação axial de múltiplos estágios. 
Tabela 5.6 - Metodologia de experimentação para os testes de múltiplos estágios

\section{Setup de retificação:}

Configuração 1 de retificação

\section{Condições de dressagem:}

Configuração de dressagem com dressador a 70 graus; disco dressador diamantado eletrodepositado; velocidade periférica do rebolo durante a dressagem $\left(\mathrm{v}_{\mathrm{cd}}\right)=$ Velocidade de corte $\left(\mathrm{v}_{\mathrm{s}}\right)=100 \mathrm{~m} / \mathrm{s}$; razão de esmagamento $\left(\mathrm{q}_{\mathrm{d}}\right)=+0,32$; profundidade de dressagem $\left(\mathrm{a}_{\mathrm{d}}\right)=3$ $\mu \mathrm{m}$; passo de dressagem $\mathrm{S}_{\mathrm{d}}=0,293 \mathrm{~mm} /$ rot.

\section{Condições de usinagem:}

Rebolo B181 VSS Q V 320; material da peça (Din 38MnS6); velocidade de corte (vs) =100 $\mathrm{m} / \mathrm{s}$; sobremetal no espelho $=0,4 \mathrm{~mm}$, Sobremetal radial $(\mathrm{z} / 2)=14 \mathrm{~mm}$, diâmetro interno do colo $\left(\mathrm{d}_{\mathrm{w} 1}\right)=67 \mathrm{~mm}$; óleo integral, vazão $48 \mathrm{l} / \mathrm{min}$; bocal bombeiro, rotação da peça $\left(\mathrm{n}_{\mathrm{w}}\right)=120$ $\mathrm{rpm}$; Spark-out $=5 \mathrm{~s}$; tempo de corte $\left(\mathrm{t}_{\mathrm{c}}\right)=16,5 \mathrm{~s}$

\section{Classificação dos ensaios:}

\begin{tabular}{|c|c|c|c|}
\hline \multirow{2}{*}{ Teste } & Número de estágios & \multicolumn{2}{|c|}{ Velocidade de avanço axial $\left(\mathbf{v}_{\mathbf{f a}}\right)[\mathrm{mm} / \mathbf{m i n}]$} \\
\cline { 3 - 4 } & & Último estágio $\left(\mathbf{d}_{\mathbf{w} 1}\right)$ & Demais estágios \\
\hline 1 & 1 & 2,1 & {$[-]$} \\
\hline 2 & 6 & 7,7 & 14,5 \\
\hline 3 & 3 & 4,5 & 8,0 \\
\hline 4 & 2 & 3,9 & 4,6 \\
\hline
\end{tabular}

Parâmetros de avaliação: Desgaste radial do rebolo, volume de material removido, potência elétrica consumida durante a usinagem, rugosidade no espelho e mapeamento acústico da superfície do rebolo.

A Figura 5.23 traz os resultados para os testes de retificação axial de múltiplos estágios. A influência do número de estágios no desgaste radial do rebolo e no volume de material removido é apresentada. 


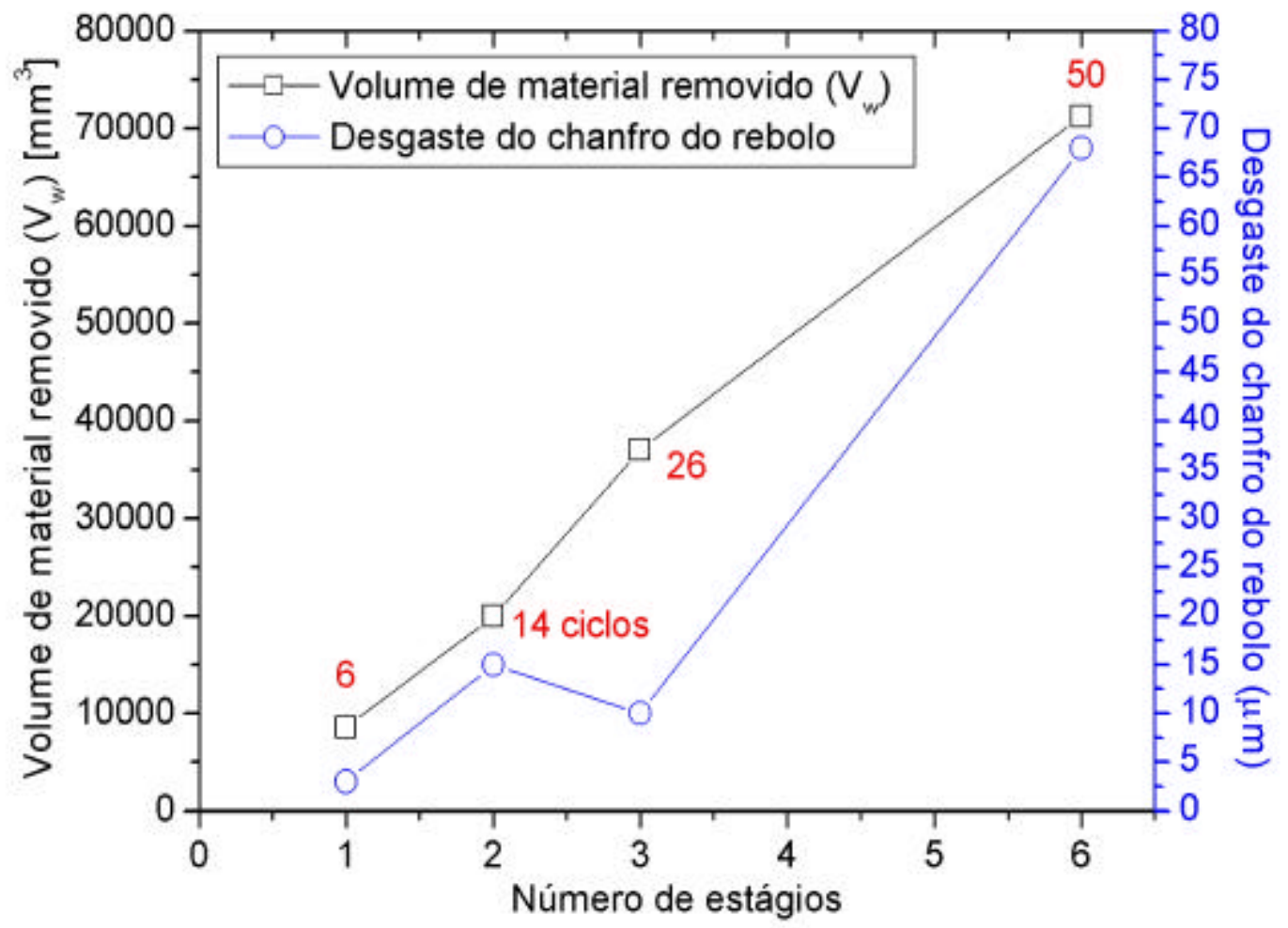

Figura 5.23 - Volume de material removido e desgaste na superfície lateral do rebolo em função do número de estágios

Os mapas obtidos para cada um dos quatro testes são apresentados nas Figuras 5.24, 5.25 e 5.26 . 


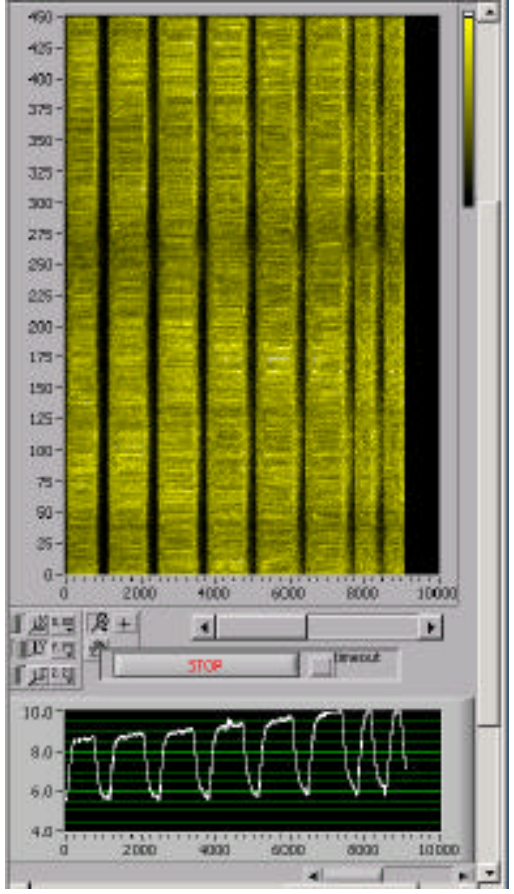

Estratégia axial (B) 1 estágio

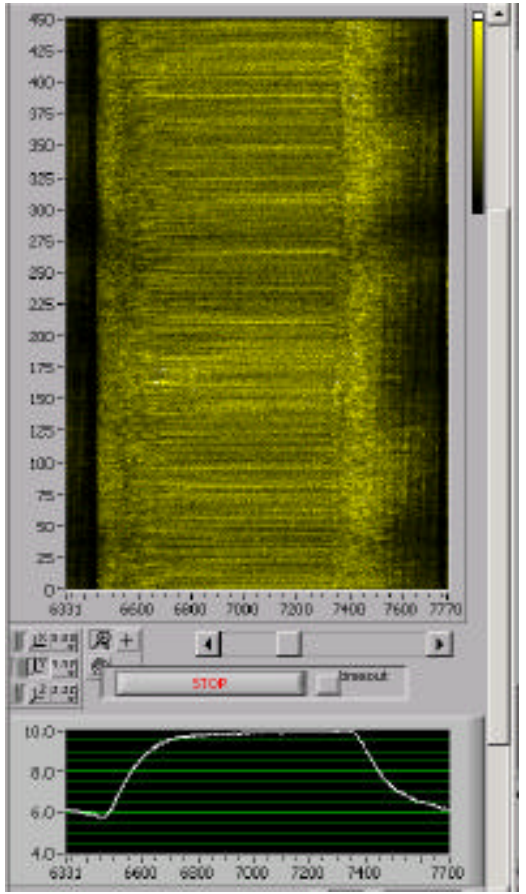

1 estágio, detalhe do ciclo 6
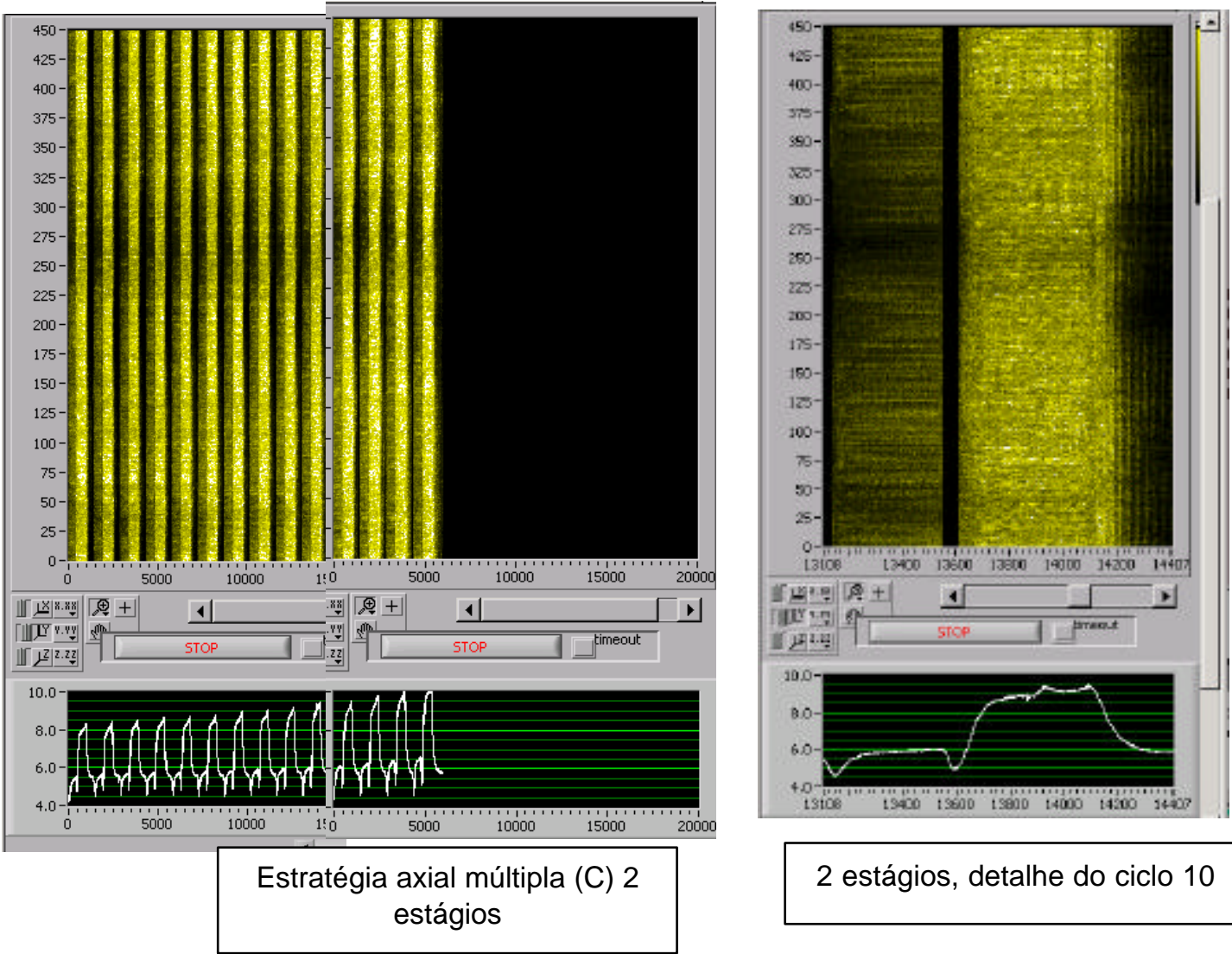

2 estágios, detalhe do ciclo 10

Figura 5.24 - Mapas acústicos para os testes com 1 e 2 estágios 

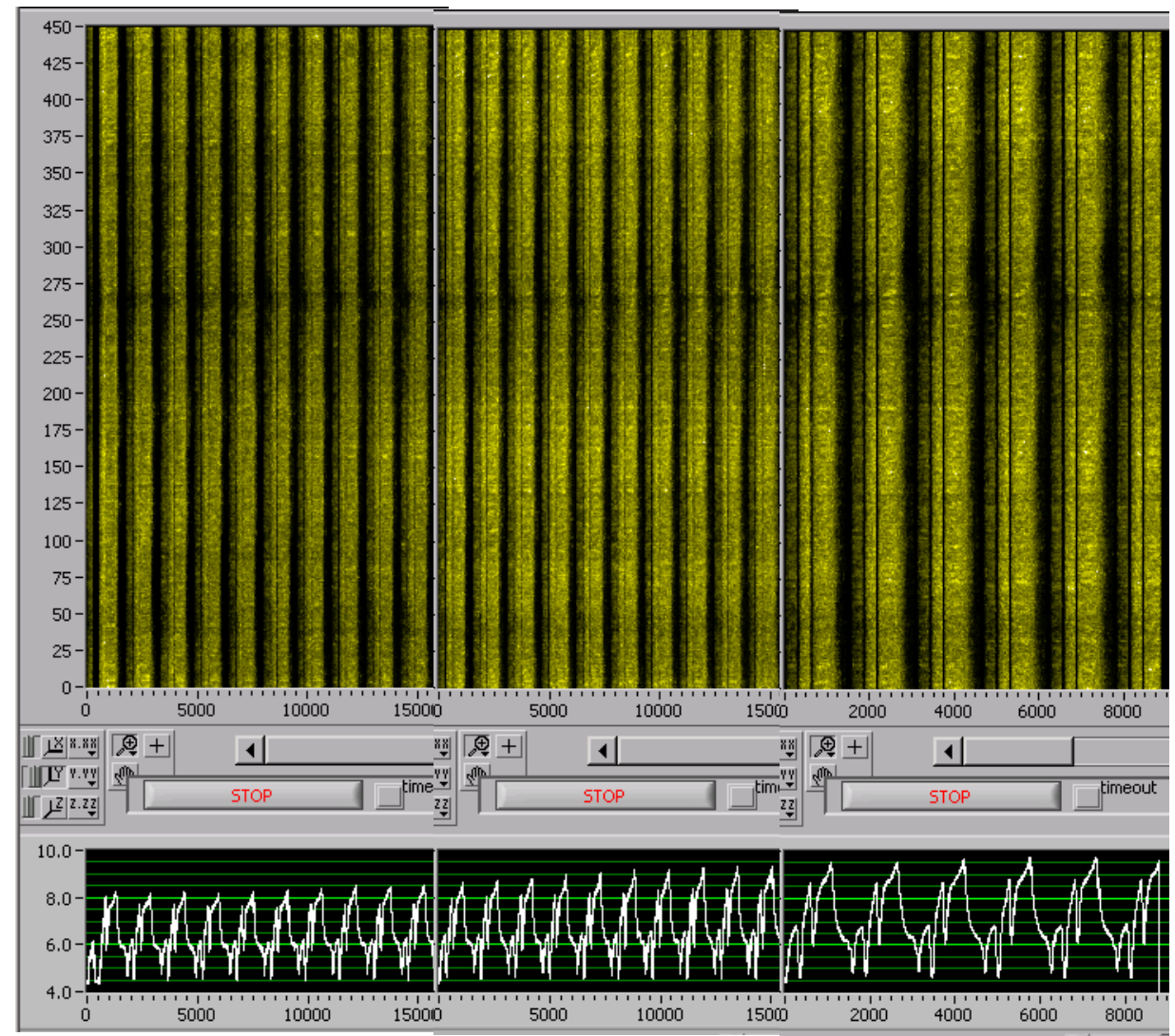

Estratégia axial múltipla $(\mathrm{C})$

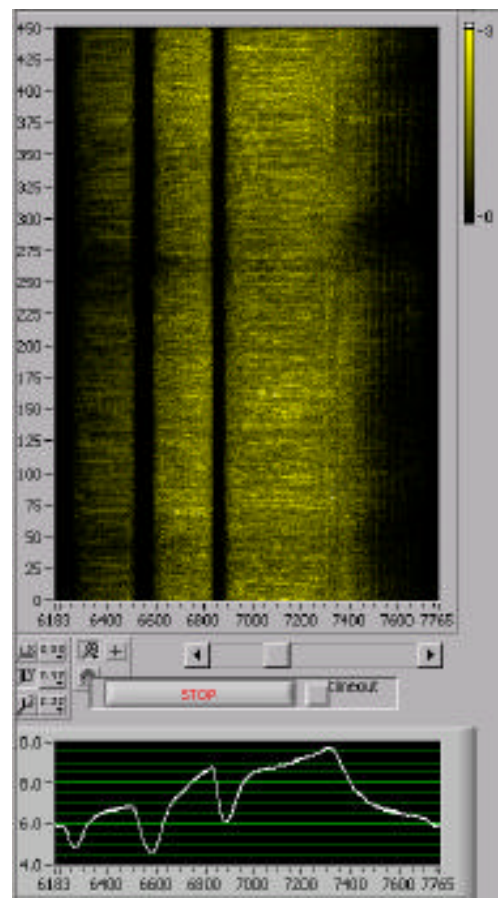
3 estágios

Figura 5.25 - Mapas acústicos para o teste com 3 estágios 


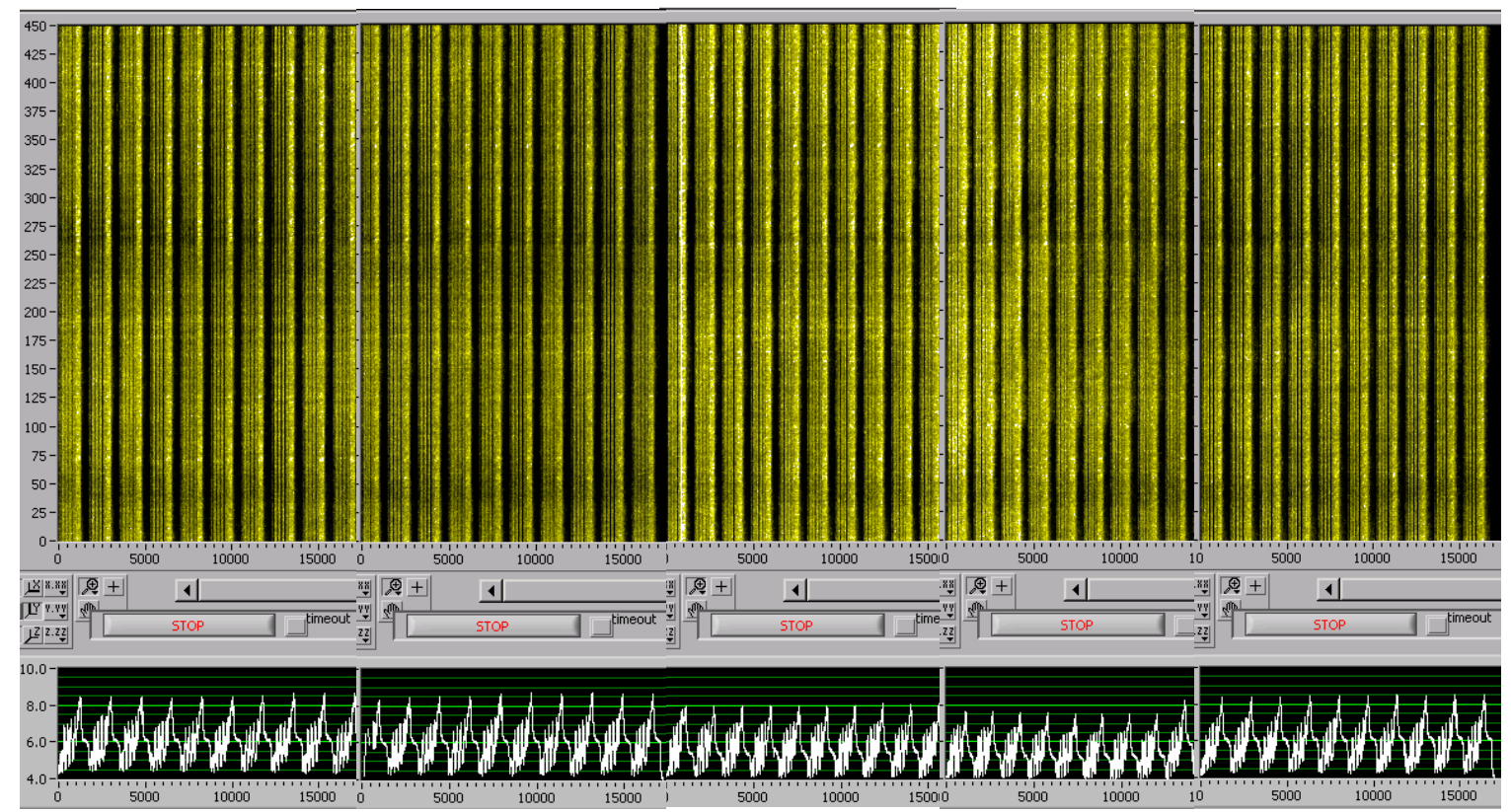

Estratégia axial múltipla (C) 6 estágios

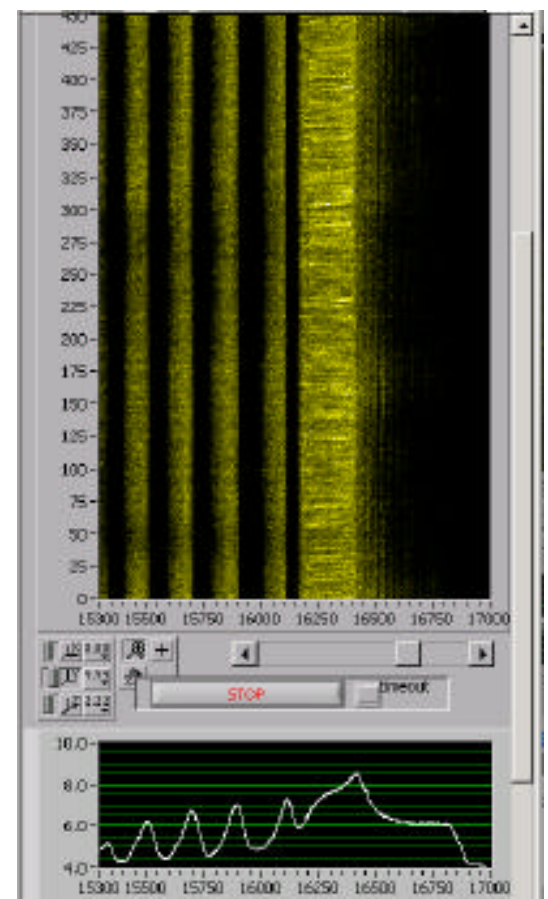

6 estágios, detalhe do ciclo 25

Figura 5.26 - Mapas acústicos para o teste com 6 estágios 
Da análise da Figura 5.23 verifica-se que existe uma relação entre o número de estágios e o volume de material removido sem dressagem, bem como o desgaste radial na superfície lateral do rebolo. Para a configuração de usinagem de 1 estágio tem-se o menor avanço por volta, sendo que neste caso existe a tendência da formação de cavacos finos e longos. Estes causam um desgaste menor do grão de $\mathrm{CBN}$, porém apresentam maior dificuldade de alojamento nas porosidades do rebolo e maior tendência ao empastamento e a erosão do ligante. Para este teste obteve-se o menor volume de material removido (volume igual a 6 ciclos de retificação). O fim de ensaio foi determinado quando a potência de usinagem atingiu o limite disponível (Figura 5.24). A potência apresentou uma tendência de rápido crescimento a cada ciclo, resultado de um possível empastamento do rebolo, já que o desgaste do rebolo foi pequeno $(3 \mu \mathrm{m})$. Analisando-se o mapa para um ciclo completo verifica-se um padrão gráfico que se mantém ao longo da usinagem, o que indica uma manutenção do perfil ativo do rebolo.

De forma oposta, a configuração de 6 estágios é caracterizada pelo maior avanço por volta, com tendência a formação de cavacos mais curtos e grossos, os quais tendem a causar um maior desgaste radial do rebolo. Para este teste, obteve-se o maior volume de material removido. Todavia, o desgaste do rebolo acompanhou o crescimento do número de ciclos. A potência de usinagem manteve-se praticamente estável ao longo do teste graças ao desgaste elevado do rebolo (Figura 5.26). Para este teste, o mapa acústico de um ciclo de usinagem não apresenta padrão gráfico definido, se comparado com o mapa de um ciclo para o teste de 1 estágio.

Comportamentos intermediários foram detectados para os testes com 2 e 3 estágios. O aumento do número de estágios leva a uma mudança no mecanismo de desgaste do rebolo, reduzindo a tendência ao empastamento do rebolo, porém aumentando o desgaste do mesmo, resultado dos maiores avanços por volta, a fim de se obter o mesmo tempo de usinagem. A 
potência de usinagem tende a manter-se estável com o aumento do número de estágios, em decorrência do maior desgaste do rebolo. Remove-se mais material com o aumento do número de estágios. Percebe-se que é possível se ajustar o mecanismo de desgaste do rebolo pela seleção do número de estágios na nova estratégia proposta. Assim, desde que haja a possibilidade de se manter o rebolo livre de entupimento nas porosidades, é possível se selecionar o número de estágios que proporcione a máxima vida do rebolo associada ao mínimo desgaste no perfil.

A Figura 5.27 apresenta os resultados de rugosidade $R_{\varepsilon}$ no espelho obtidos nos testes de múltiplos estágios (valor médio de 4 medições efetuadas no espelho, defasadas em $90^{\circ}$ ).

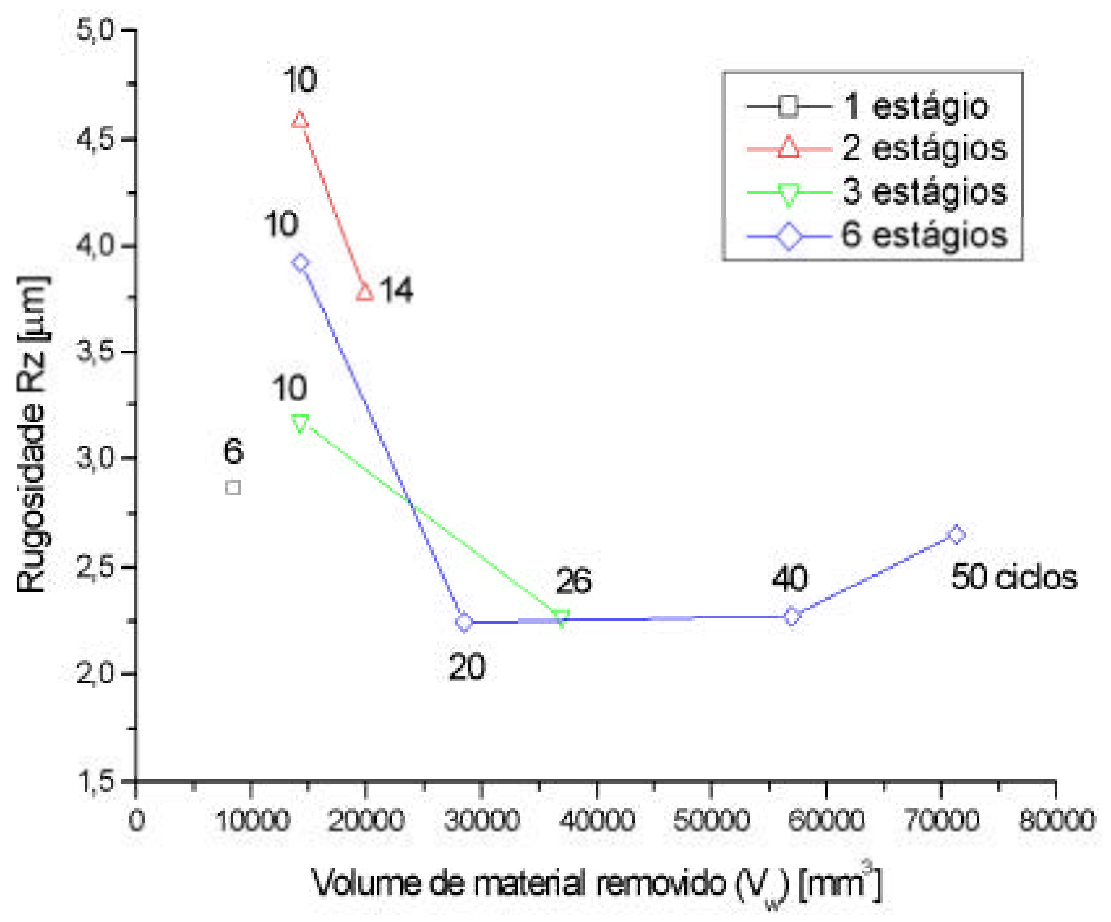

Figura 5.27 Resultados de rugosidade em função do número de estágios

A análise dos resultados de rugosidade (Figura 5.27) não permitiu estabelecer-se uma relação clara entre a variação do número de estágios e os resultados de rugosidade. Para todos os testes verificou-se uma redução dos valores de rugosidade com o aumento do volume específico de material removido. Esse comportamento coincide com o aumento de potência 
observado na retificação com menor número de estágios. No caso dos testes com 6 estágios, entende-se que a geração de irregularidades na superfície do rebolo, que normalmente ocorre em situações de altas taxas de desgaste, seja a responsável pelo aumento da rugosidade nas últimas amostras.

\subsubsection{Análise da influência do sistema de limpeza a alta pressão da superfície do rebolo para a estratégia $\mathbf{C}$ - axial múltipla}

A influência do sistema de limpeza do rebolo foi testada durante a realização dos testes de retificação axial de 1 e 3 estágios. Os parâmetros de avaliação foram energia específica de corte (obtida através dos sinais de potência elétrica consumida durante a retificação), rugosidade $R_{z}$ e desgaste do rebolo. Nestes testes foi utilizada a configuração de retificação 2 .

\section{- Condições de usinagem}

○ Velocidade de corte $v_{s}=100 \mathrm{~m} / \mathrm{s}$; Rotação da peça: $\mathrm{n}_{\mathrm{v}}=120 \mathrm{rpm}$; Relação de velocidades $\left(\mathrm{q}= \pm \mathrm{v}_{\mathrm{s}} / \mathrm{v}_{\mathrm{w}}\right)=-265$; Tempo de spark-out: $3 \mathrm{~s}$

○ Retificação dos espelhos utilizando-se apenas a lateral esquerda do rebolo

- 1 estágio: Altura do espelho em cada estágio: $5 \mathrm{~mm} ; \mathrm{V}_{\mathrm{fa}}=3 \mathrm{~mm} / \mathrm{min} ; \mathrm{t}$ $=6 \mathrm{~s} ; 3$ estágios: Altura do espelho em cada estágio: $1,67 \mathrm{~mm} ; \mathrm{V}_{\mathrm{fa}}=9$ $\mathrm{mm} / \mathrm{min} ; \mathrm{t}_{\mathrm{c}}=6 \mathrm{~s}\left(\mathrm{t}_{\mathrm{c}}\right.$ por estágio $\left.=2 \mathrm{~s}\right)$

- Sobremetal removido por ciclo na face: $0,3 \mathrm{~mm}$; Altura radial do espelho (Z/2): $5 \mathrm{~mm}$; Diâmetro $\mathrm{d}_{\mathrm{v} 1}=50 \mathrm{~mm}$; Número de ciclos por colo: 3; Total de colos retificados: 18; Volume específico de material removido $\left(\mathrm{V}_{\mathrm{w}}{ }_{\mathrm{w}}\right)$ por colo: $2592 \mathrm{~mm}^{3} / \mathrm{mm}$; Volume específico de material removido ( $\left.{ }^{\prime}{ }_{\mathrm{w}}\right)$ por ensaio: $46656 \mathrm{~mm} 33 / \mathrm{mm}$; Tipo de fluido: óleo integral; Pressão dos bocais superior e 
inferior de fluido de corte: 17 bar; Pressão do sistema de limpeza de fluido de corte: 60 bar (Figura 5.12); bocal jato plano.

- Condições de dressagem

○ Velocidade periférica do rebolo durante a dressagem $\left(\mathrm{v}_{\mathrm{cd}}\right)=\mathrm{v}_{\mathrm{s}}=100 \mathrm{~m} / \mathrm{s}$; Razão de esmagamento: $\mathrm{q}_{1}=+0,9$, Profundidade de dressagem $\left(\mathrm{a}_{\mathrm{d}}\right)=3 \mu \mathrm{m}$; Passo de dressagem: 0,369 mm/rot;

\section{- Nomenclatura dos ensaios}

Tabela 5.7 - Nomenclatura dos ensaios de retificação - estratégias B e C

\begin{tabular}{|c|c|c|c|c|c|}
\hline No do teste & $\begin{array}{c}\text { Código da } \\
\text { peça }\end{array}$ & $\begin{array}{c}\text { Estratégia de } \\
\text { retificação }\end{array}$ & $\begin{array}{c}\text { No de } \\
\text { estágios }\end{array}$ & $\begin{array}{c}\text { Limpeza do } \\
\text { rebolo }\end{array}$ & $\begin{array}{c}\text { Tempo de } \\
\text { corte (s) }\end{array}$ \\
\hline 1 & 3 & Axial múltipla (C) & 3 & SEM & 6 \\
\hline 2 & 1 & Axial (B) & 1 & COM & 6 \\
\hline 3 & 4 & Axial múltipla (C) & 3 & COM & 6 \\
\hline 4 & 5 & Axial (B) & 1 & SEM & 6 \\
\hline
\end{tabular}

- Procedimentos para a medição do desgaste do rebolo

O procedimento de medição do desgaste do rebolo consistiu na avaliação do seu perfil antes e depois da usinagem. Um dispositivo instalado na retificadora permitia a retificação de uma chapa metálica, "imprimindo" o perfil do rebolo nesta (Figura 5.28). Os perfis gerados antes e depois dos testes de retificação (Figura 5.29) eram então medidos utilizando-se um perfilômetro, obtendo-se as curvas referentes a cada perfil analisado. Estas curvas eram então analisadas a fim de se detectar e quantificar as alterações no raio e nas laterais do rebolo.

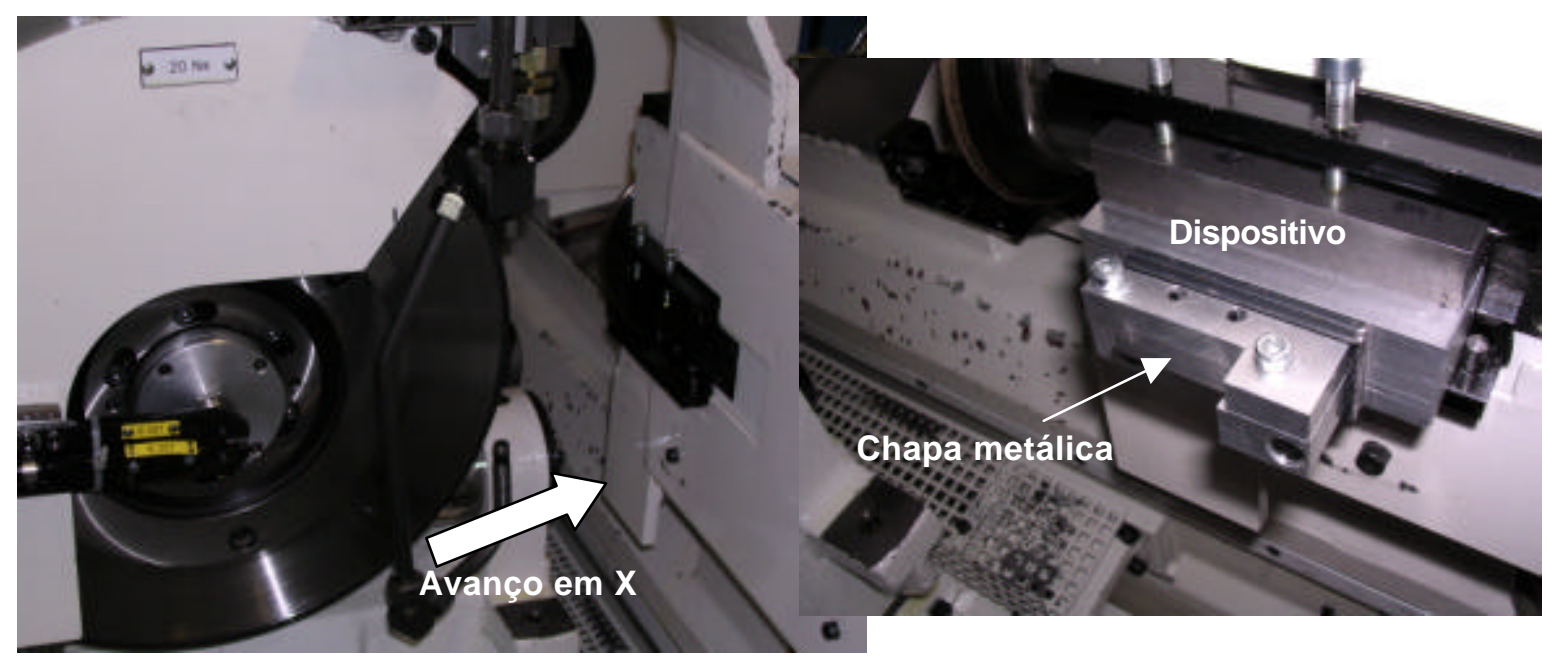

Figura 5.28 - Dispositivo para medição do desgaste do rebolo 


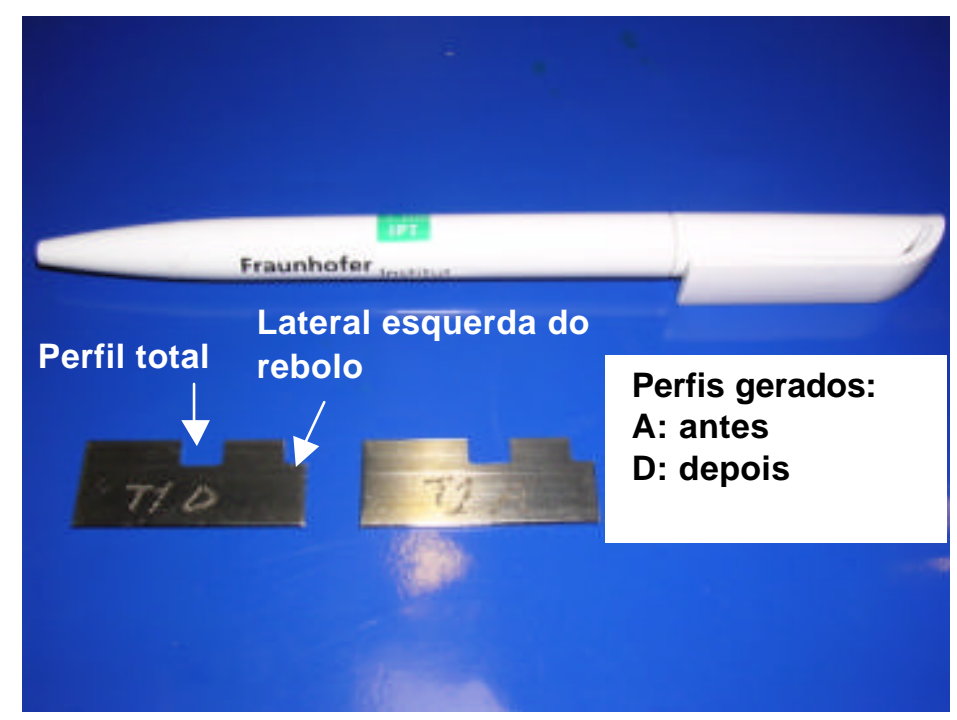

Figura 5.29 - Perfis gerados antes e depois da retificação

Resultados de energia de corte específica

Os resultados de energia de corte específica distribuída ao longo do perfil do rebolo em contato durante a usinagem para os testes de 1 e 3 estágios são apresentados nas Figuras 5.30 e 5.31 , respectivamente.

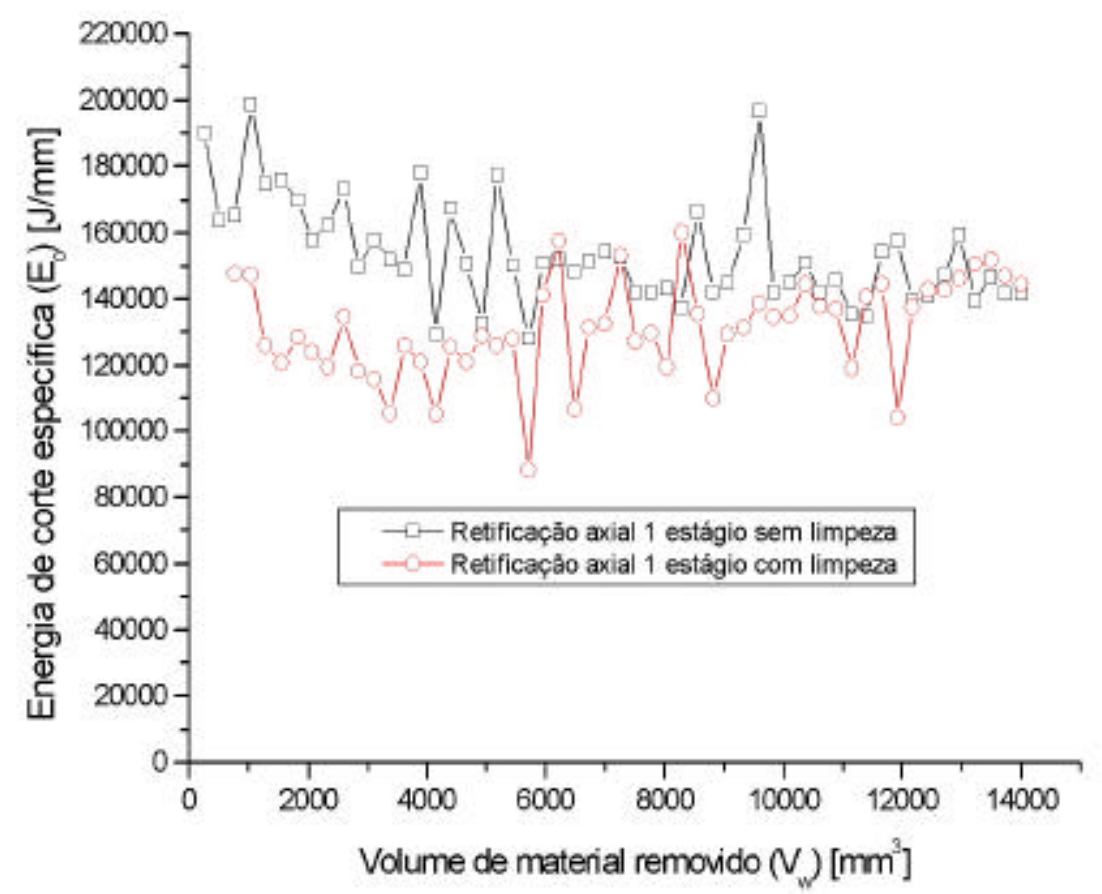

Figura 5.30 - Energia específica de corte - estratégia axial (B), 1 estágio 


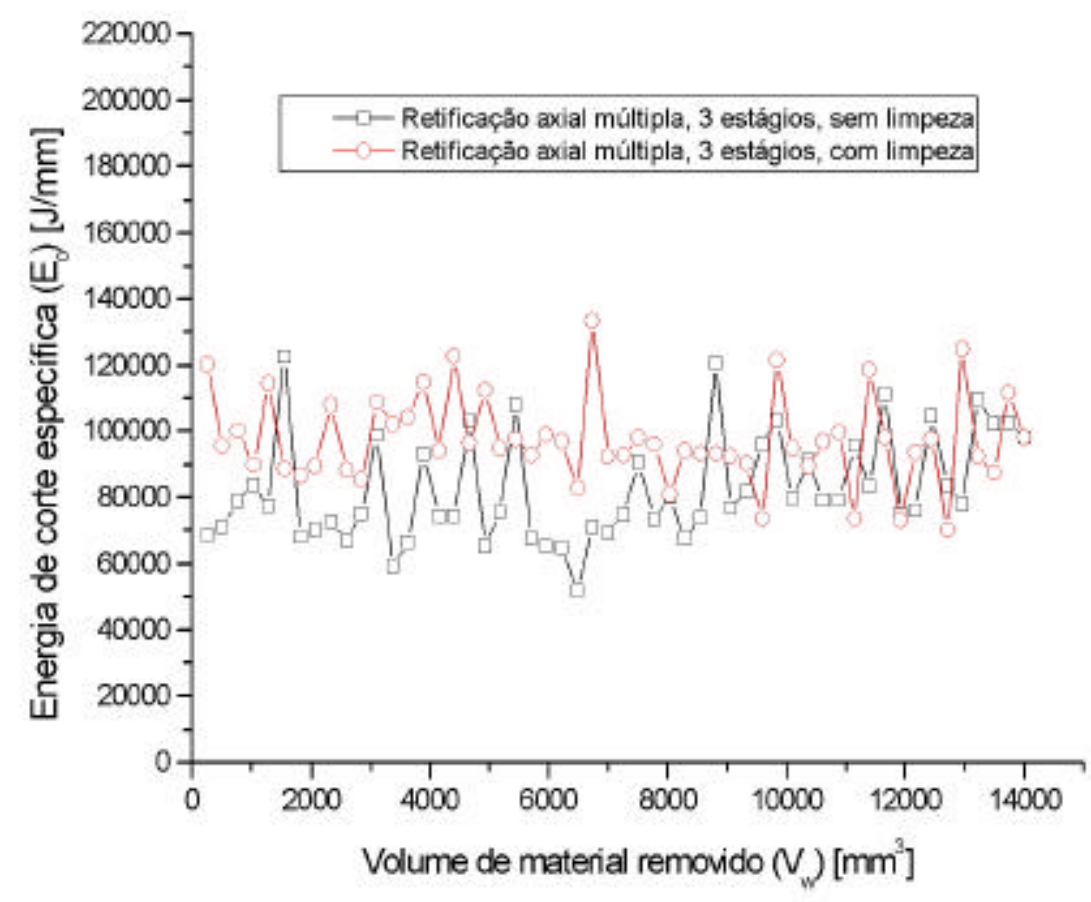

Figura 5.31 - Energia específica de corte - estratégia axial múltipla (C), 3 estágios

A utilização do sistema de limpeza do rebolo resultou numa variação inicial da energia de corte específica para os testes com 1 e 3 estágios. Todavia esta tendência não se manteve ao longo do teste, obtendo-se valores de energia específica de corte muito próximos ao final dos ensaios.

\section{Resultados de rugosidade}

Os resultados de rugosidade para os testes de 1 e 3 estágios são apresentados nas Figuras 5.32 e 5.33, respectivamente (rugosidade obtida através da média de 4 medições efetuadas no espelho, defasadas em $90^{\circ}$ ). 


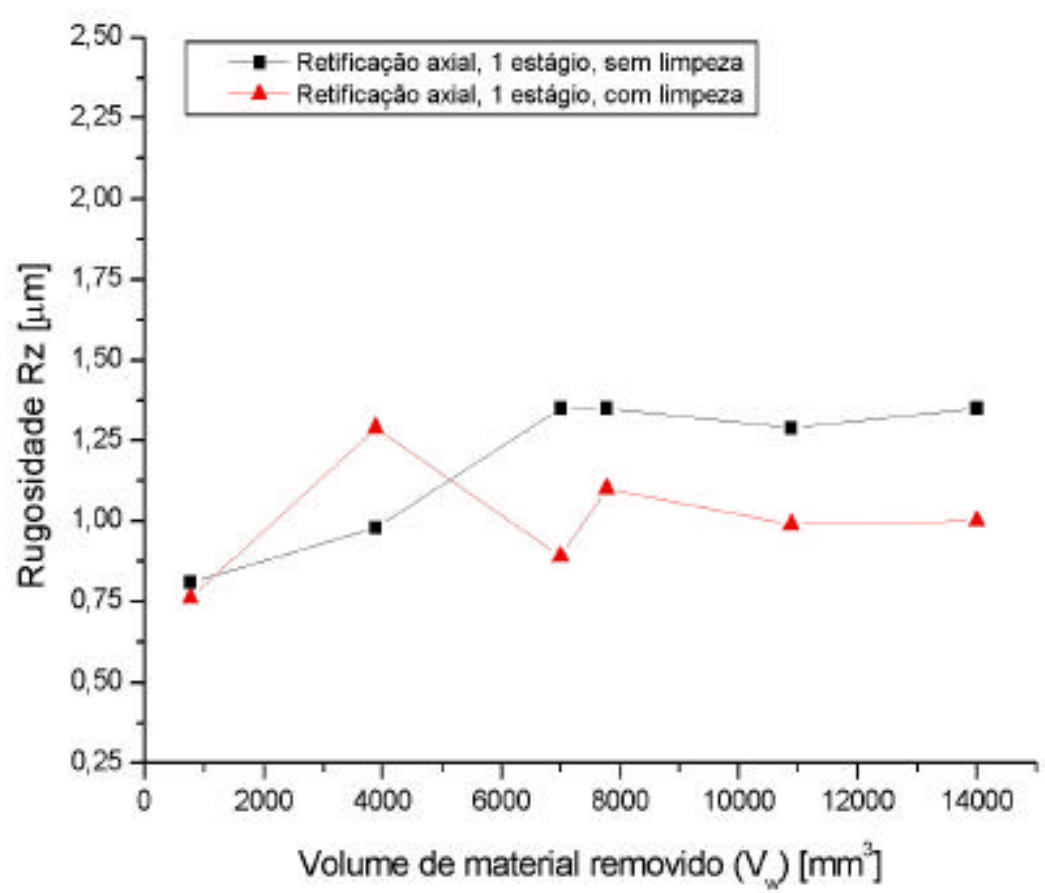

Figura 5.32 Rugosidade $\mathrm{R}_{\mathrm{z}}$ - estratégia axial (B), 1 estágio

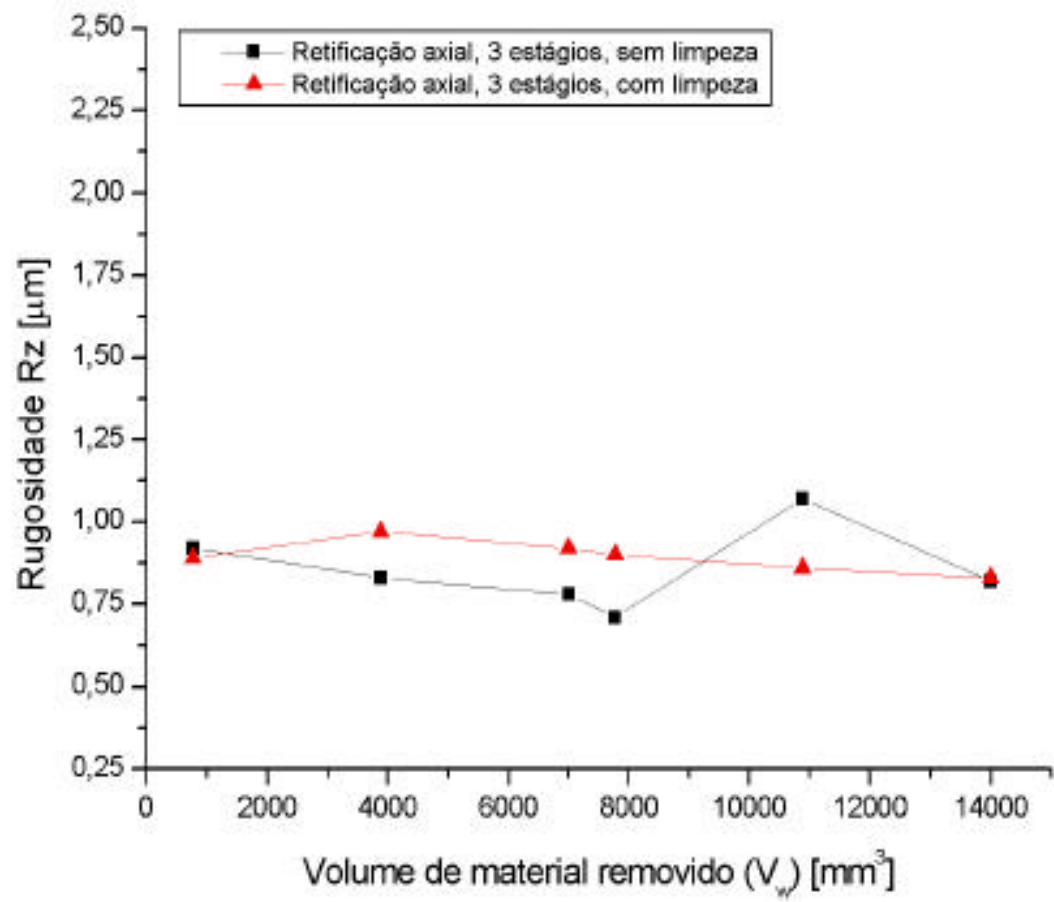

Figura 5.33 Rugosidade $\mathrm{R}_{\mathrm{z}}$ - estratégia axial múltipla (C), 3 estágio

Para o teste com 3 estágios (Figura 5.33) não se verificou uma redução dos valores de rugosidade com a utilização do sistema de limpeza. Para os testes com 1 estágio, reduções foram observadas a partir da metade do ensaio. 
Inspeção visual da superfície do rebolo

As Figuras 5.34 e 5.35 apresentam o aspecto visual da superfície do rebolo após a realização dos ensaios para os testes de 1 e 3 estágios, respectivamente. A utilização do sistema de limpeza reduziu a tendência ao surgimento de materiais aderidos à superfície do rebolo, principalmente nas proximidades do raio do mesmo.

Os resultados obtidos mostram que a utilização de um sistema de limpeza a alta pressão é sempre benéfica. Entretanto, produz melhorias mais evidentes na retificação axial em um único estágio. Assim, mais uma vez se confirmam os benefícios da nova estratégia (retificação axial múltipla) que proporciona a formação de cavacos mais curtos, reduzindo a tendência de entupimento das porosidades do rebolo. 

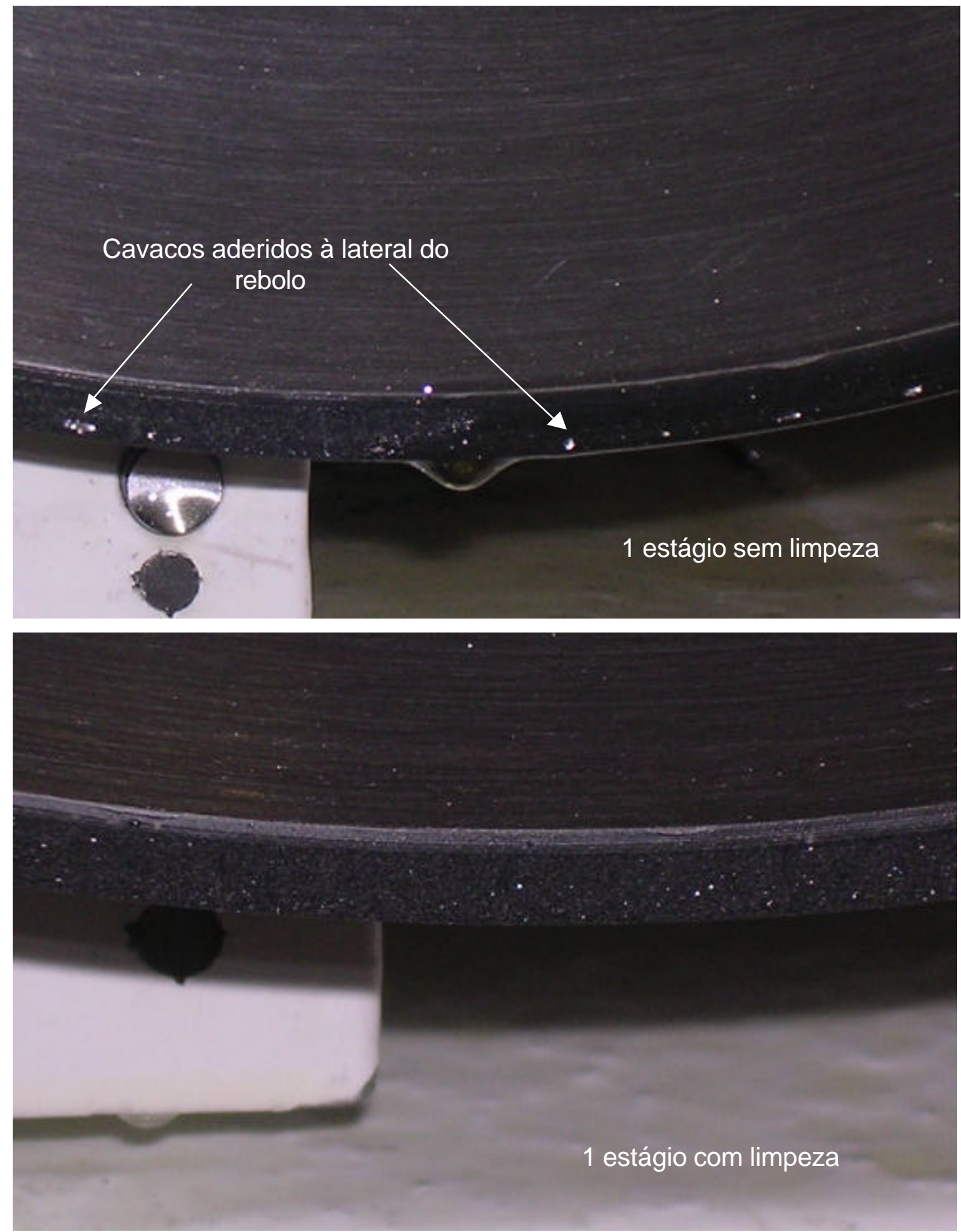

Figura 5.34 Aspecto visual da superfície do rebolo após a retificação - estratégia axial (B), 1 estágio 

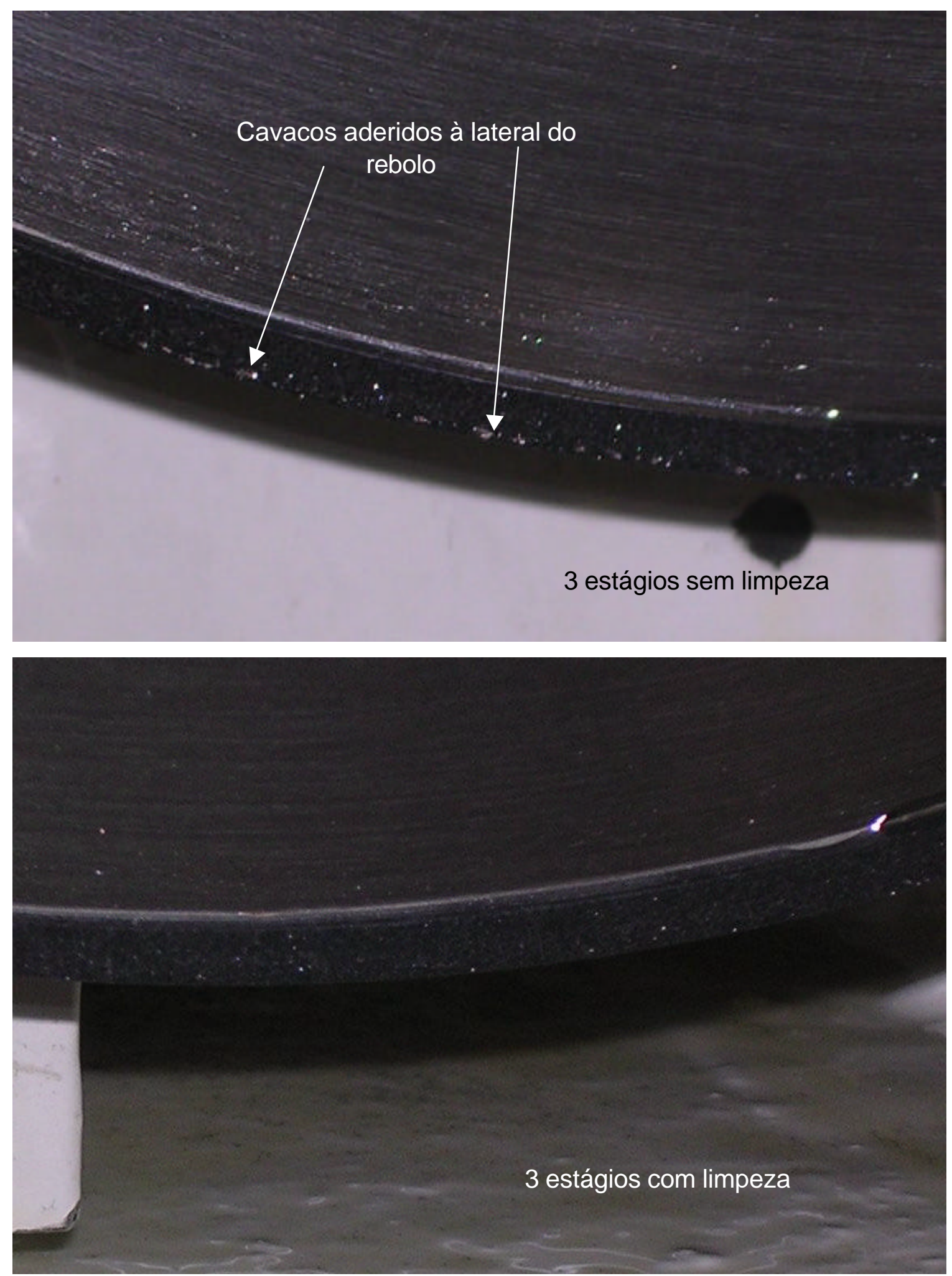

Figura 5.35 Aspecto visual da superfície do rebolo após a retificação - estratégia axial múltipla (C), 3 estágios 
Resultados de desgaste do rebolo

Para cada perfil foram avaliadas as alterações no raio esquerdo do rebolo e o ângulo formado entre a lateral e a face do rebolo. Um resumo dos resultados obtidos é apresentado na Tabela 5.8. No Anexo B, as Figuras A5 e A6 apresentam o perfil da lateral esquerda do rebolo obtido através da retificação da chapa metálica antes e após a realização dos testes de 1 estágio com e sem limpeza, respectivamente. As Figuras A7 e A8 apresentam os resultados para 3 estágios com e sem limpeza, respectivamente. A análise do teste 3 estágios sem limpeza ficou prejudicada já que o surgimento de uma rebarba no raio de arredondamento da chapa retificada impediu a medição correta do perfil copiado (Figura A9)

Tabela 5.8 - Influência do sistema de limpeza nas modificações do perfil do rebolo

\begin{tabular}{|c|c|c|c|c|c|}
\hline \multirow{2}{*}{$\begin{array}{c}\text { No de } \\
\text { estágios }\end{array}$} & \multirow{2}{*}{$\begin{array}{c}\text { Limpeza } \\
\text { do rebolo }\end{array}$} & \multicolumn{2}{|c|}{ Raio (mm) } & \multicolumn{2}{c|}{ Angulo da chapa } \\
\cline { 3 - 6 } & Antes & Depois & Antes & Depois \\
\hline 1 & COM & 0,793 & 0,765 & $90^{\circ} 02^{\prime} 04^{\prime}{ }^{\circ}$ & $90^{\circ} 02^{\prime} 03^{\prime \prime}$ \\
\hline 1 & SEM & 0,762 & 0,768 & $90^{\circ} 04^{\prime} 42^{\prime \prime}$ & $89^{\circ} 54^{\prime} 16^{\prime \prime}$ \\
\hline 3 & COM & 0,777 & 0,766 & $89^{\circ} 51^{\prime} 19^{\prime}{ }^{\prime}$ & $89^{\circ} 53^{\prime} 04^{\prime \prime}$ \\
\hline 3 & SEM & 0,820 & 0,787 & $89^{\circ} 59^{\prime} 33^{\prime \prime}$ & $90^{\circ} 16^{\prime} 22^{\prime}$ \\
\hline
\end{tabular}

Da análise dos resultados obtidos verificou-se que o volume retificado $\left(\mathrm{V}_{\mathrm{w}}=13.997\right.$ $\mathrm{mm}^{3}$ ) não permitiu que fosse observado desgaste significativo no perfil do rebolo.

\subsection{Análise comparativa entre as estratégias de mergulho, axial e axial múltipla}

A análise comparativa entre as estratégias de mergulho, axial e axial múltipla foi realizada utilizando-se a configuração 2 de retificação. A comparação foi efetuada entre os testes de 1 e 3 estágios com sistema de limpeza (apresentados no item 5.6.2) e um novo teste adotando-se a retificação de mergulho (estratégia A), também utilizando-se o sistema de 
limpeza a alta pressão. A Tabela 5.9 apresenta a nomenclatura dos ensaios para a análise comparativa.

Tabela 5.9 - Nomenclatura dos ensaios de retificação

\begin{tabular}{|c|c|c|c|c|c|}
\hline$N^{N}$ do teste & $\begin{array}{c}\text { Código da } \\
\text { peça }\end{array}$ & $\begin{array}{c}\text { Estratégia de } \\
\text { retificação }\end{array}$ & $\begin{array}{c}\text { No de } \\
\text { estágios }\end{array}$ & $\begin{array}{c}\text { Limpeza do } \\
\text { rebolo }\end{array}$ & $\begin{array}{c}\text { Tempo de } \\
\text { corte (s) }\end{array}$ \\
\hline 2 & 1 & Axial (B) & 1 & COM & 6 \\
\hline 3 & 4 & Axial múltipla (C) & 3 & COM & 6 \\
\hline 5 & 7 & Mergulho (A) & - & COM & 6 \\
\hline
\end{tabular}

As condições de dressagem e usinagem são as mesmas apresentadas no item 5.6.2, exceto para o teste 5, mergulho (estratégia A), onde tem-se:

$$
\text { ○ } \operatorname{Para~}_{\mathrm{w} 1}=60 \mathrm{~mm}, \mathrm{Q}_{\mathrm{w}}^{\prime}=157,0 \mathrm{~mm}^{3} / \mathrm{mm} . \mathrm{s} ; \mathrm{V}_{\mathrm{fr}}=50 \mathrm{~mm} / \mathrm{min}
$$

\section{Resultados de energia de corte específica}

Os resultados de energia de corte específica para a retificação de mergulho, axial com 1 e 3 estágios são apresentados na Figura 5.36. Para todos os testes, o sistema de limpeza do rebolo foi utilizado durante todo o ensaio.

Para as estratégias testadas, o tempo de corte foi idêntico (igual a 6 s). Verificou-se que os menores valores de energia de corte específica foram observados para a retificação de mergulho. Isto se deve ao fato da menor taxa de remoção e da área de contato rebolo-peça quando da utilização desta estratégia. $\mathrm{O}$ aumento da força de corte quando da utilização da retificação axial também foi verificado por Merbecks (2002), obtendo-se valores até 15 vezes maiores. 


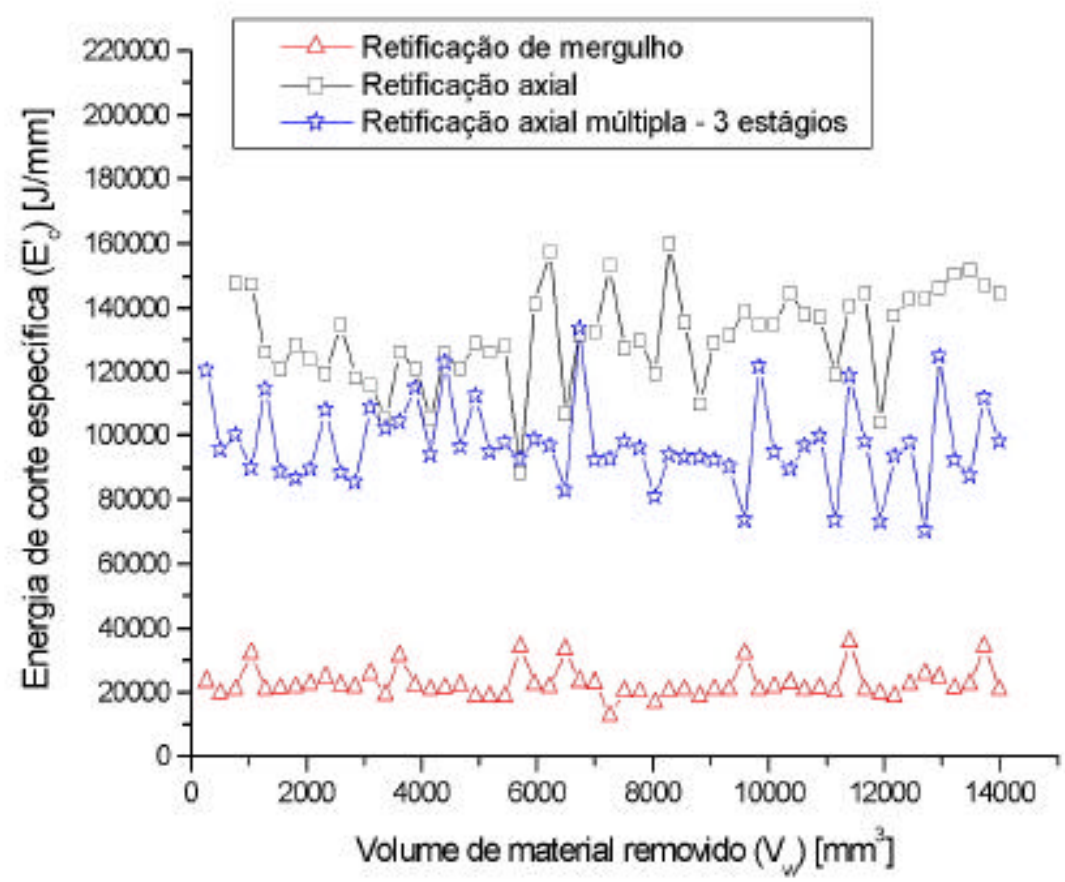

Figura 5.36 Energia de corte específica para as estratégias testadas

Resultados de rugosidade

Os resultados de rugosidade $\mathrm{R}_{\mathrm{z}}$ são apresentados na Figura 5.37.

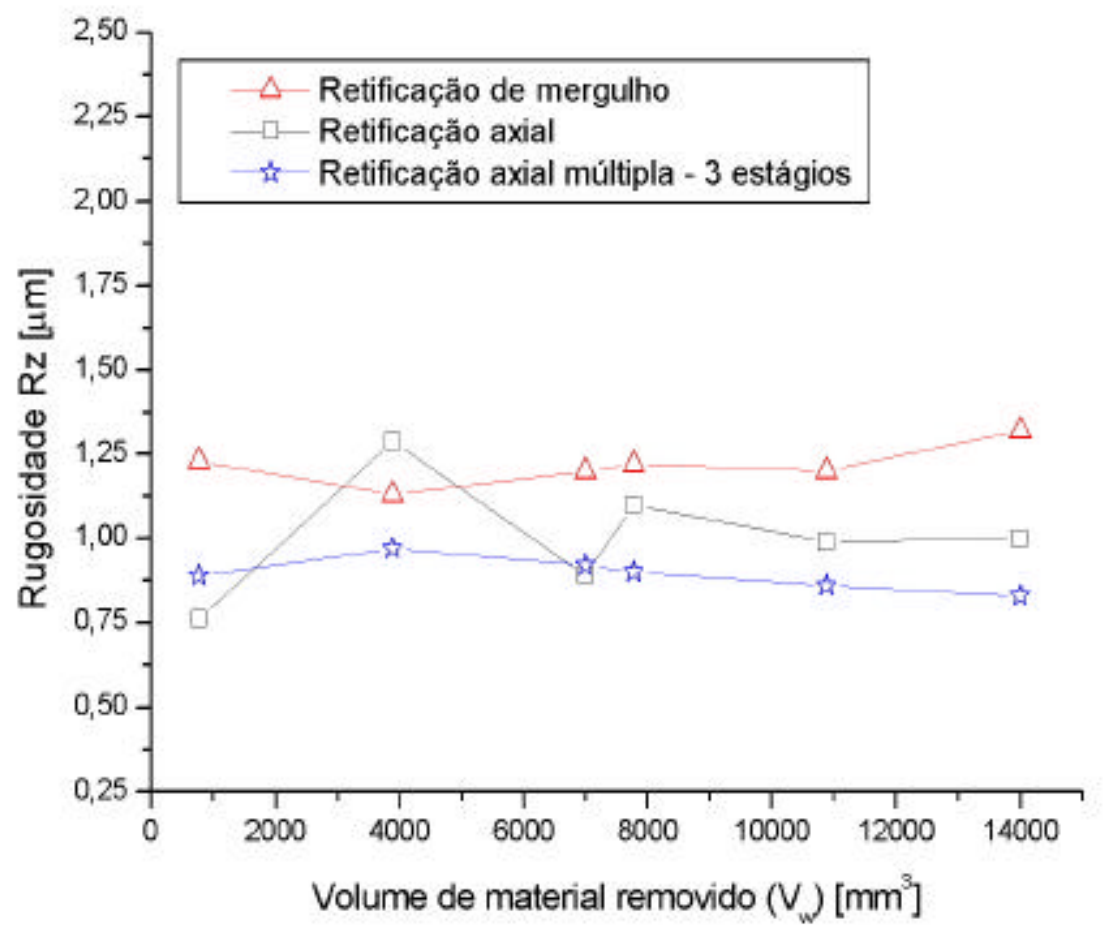

Figura 5.37 - Rugosidade $\mathrm{R}_{\mathrm{z}}$ para as estratégias testadas 
Os resultados de rugosidade apresentados na Figura 5.37 apresentam uma ligeira vantagem a favor da utilização da estratégia de retificação axial múltipla. Desta forma, obteve-se valores de rugosidade inferiores a $1 \mu \mathrm{m}$ ao longo de todo ensaio, quando da utilização da retificação axial para 3 estágios. Todas as estratégias testadas resultaram em valores inferiores a $2 \mu \mathrm{m}$, valor este limite desejado para a operação efetuada.

\section{Resultados de desgaste radial}

As alterações no raio esquerdo do rebolo e no ângulo formado entre a lateral e a face do rebolo são apresentadas na Tabela 5.10, para as estratégias testadas. No Anexo B, na Figura A10 é apresento o perfil da lateral esquerda do rebolo obtido através da retificação da chapa metálica antes e após a realização dos testes de mergulho.

Tabela 5.10 - Influência das diferentes estratégias nas modificações do perfil do rebolo

\begin{tabular}{|c|c|c|c|c|c|}
\hline \multirow{2}{*}{ Estratégia } & \multirow{2}{*}{ Estágios } & \multicolumn{2}{|c|}{ Raio (mm) } & \multicolumn{2}{c|}{ Ângulo da chapa } \\
\cline { 3 - 6 } & & Antes & Depois & Antes & Depois \\
\hline A & - & 0,761 & 0,750 & $89^{\circ} 50^{\prime} 56^{\prime \prime}$ & $89^{\circ} 46 ' 19^{\prime}$ \\
\hline B & 1 & 0,793 & 0,765 & $90^{\circ} 02^{\prime} 04^{\prime \prime}$ & $90^{\circ} 02^{\prime} 03^{\prime \prime}$ \\
\hline C & 3 & 0,777 & 0,766 & $89^{\circ} 51^{\prime} 19^{\prime \prime}$ & $89^{\circ} 53^{\prime} 04^{\prime \prime}$ \\
\hline
\end{tabular}

Da análise dos resultados obtidos da Tabela 5.10 verificou-se que as diferentes estratégias de retificação não resultaram em alterações significativas no desgaste do rebolo, para o volume de material removido, não sendo possível detectar diferenças significativas entre os perfis.

Da análise conjunta dos resultados de energia de corte específica, rugosidade e de desgaste do perfil do rebolo verificou-se a possibilidade da utilização de todas as estratégias propostas. Observa-se ainda que para o volume removido sob as novas condições foi possível obter um desgaste muito reduzido em relação àqueles medidos na configuração 1 . Isso pode ser atribuído às diferenças entre os materiais e os rebolos utilizados nos dois casos. 
Desta forma, visando-se elucidar o comportamento de desgaste do perfil do rebolo para as diferentes estratégias testadas optou-se pela simulação deste desgaste, através de um modelamento teórico, o qual é apresentado a seguir.

\subsection{Simulação do perfil desgastado do rebolo para as estratégias de mergulho, axial e axial múltipla}

Segundo Malkin (1989), a relação G pode ser definida como sendo a relação entre o volume de material removido durante a retificação $V_{w}$ e o volume de rebolo gasto $V_{s}$ (equação 5.1).

$$
G=\frac{V_{w}}{V_{s}}
$$

A relação $G$ tem seu valor reduzido para menores velocidades periféricas do rebolo (Lindsay, 1984). No caso de pequenas variações da velocidade periférica, pode-se estabelecer uma correlação aproximadamente linear com a relação G. Assim, no caso de perfis de rebolo com alteração de sua geometria, como por exemplo, raios de canto $\left(\mathrm{r}_{\mathrm{sk}}\right)$, o valor da relação $\mathrm{G}$ pode ser aproximado para cada posição $\mathrm{X}$ (em relação à lateral do rebolo) ao longo do perfil do mesmo, segundo a equação 5.2, resultado da variação da velocidade periférica:

$$
G_{i}=G \cdot \frac{v_{s i}}{v_{s 0}}
$$


onde: $\mathrm{G}$ é a relação $\mathrm{G}$ na posição $\mathrm{X}$ do perfil do rebolo, $\mathrm{k}_{\mathrm{i}}$ é a velocidade de corte para a posição $X_{i}$ do perfil do rebolo e $\aleph_{0}$ é a velocidade de corte para a posição $X_{0}$ do perfil do rebolo de máximo diâmetro e $\mathrm{G}$ é o valor da relação de desgaste nesta posição.

O valor de $\mathrm{V}_{\mathrm{s}}$ é calculado através da equação 5.3, onde $\omega_{\mathrm{s}}$ é a velocidade angular do rebolo e rs $\mathrm{i}_{\mathrm{i}}$ é o raio do rebolo na posição $\mathrm{X}_{\mathrm{i}}$ do seu perfil.

$v_{s i}=\omega_{s} \cdot r_{s i}$

A equação 5.1 pode ser reescrita de forma a permitir o cálculo de $\mathrm{V}_{\mathrm{s}}$ para cada posição $\mathrm{X}_{\mathrm{i}}$, resultando no parâmetro $\mathrm{V}_{\mathrm{si}}$ (equação 5.4). $\mathrm{O}$ volume de material removido por peça ponto a ponto $\left(\mathrm{V}_{\text {wi }}\right)$ é calculado segundo a equação 5.5 (para a estratégia de retificação axial).

$V_{s i}=\frac{V_{w i}}{G_{i}}$

$V_{w i}=V^{\prime}{ }_{w i} \cdot \frac{S M}{a_{f r}}$

onde SM é o sobremetal a ser removido na direção axial para a retificação de uma peça e $\mathrm{a}_{\mathrm{fr}}$ é

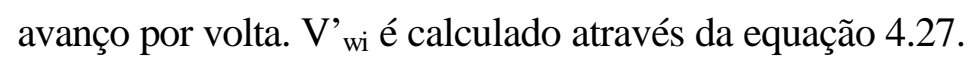

Conhecendo-se o valor de $\mathrm{V}_{\mathrm{si}}$, calcula-se o raio do rebolo desgastado na posição $\mathrm{X}$ através da equação 5.6:

$r_{\text {sidesg }}=\sqrt{\frac{\pi \cdot r_{0 i}^{2}-V_{s i}}{\pi}}$ 
onde $\mathrm{r}_{0 \mathrm{i}}$ é o raio original do perfil do rebolo na posição $\mathrm{X}_{\mathrm{i}}$.

A Figura 5.38 apresenta os volumes de material removido por peça $V_{\text {wi }}$ ao longo da posição $\mathrm{X}_{\mathrm{i}}$ para as estratégias testadas: mergulho, axial e axial múltipla, adotando-se as condições de usinagem apresentadas no item 5.7 "Análise comparativa entre as estratégias de mergulho, axial e axial múltipla".

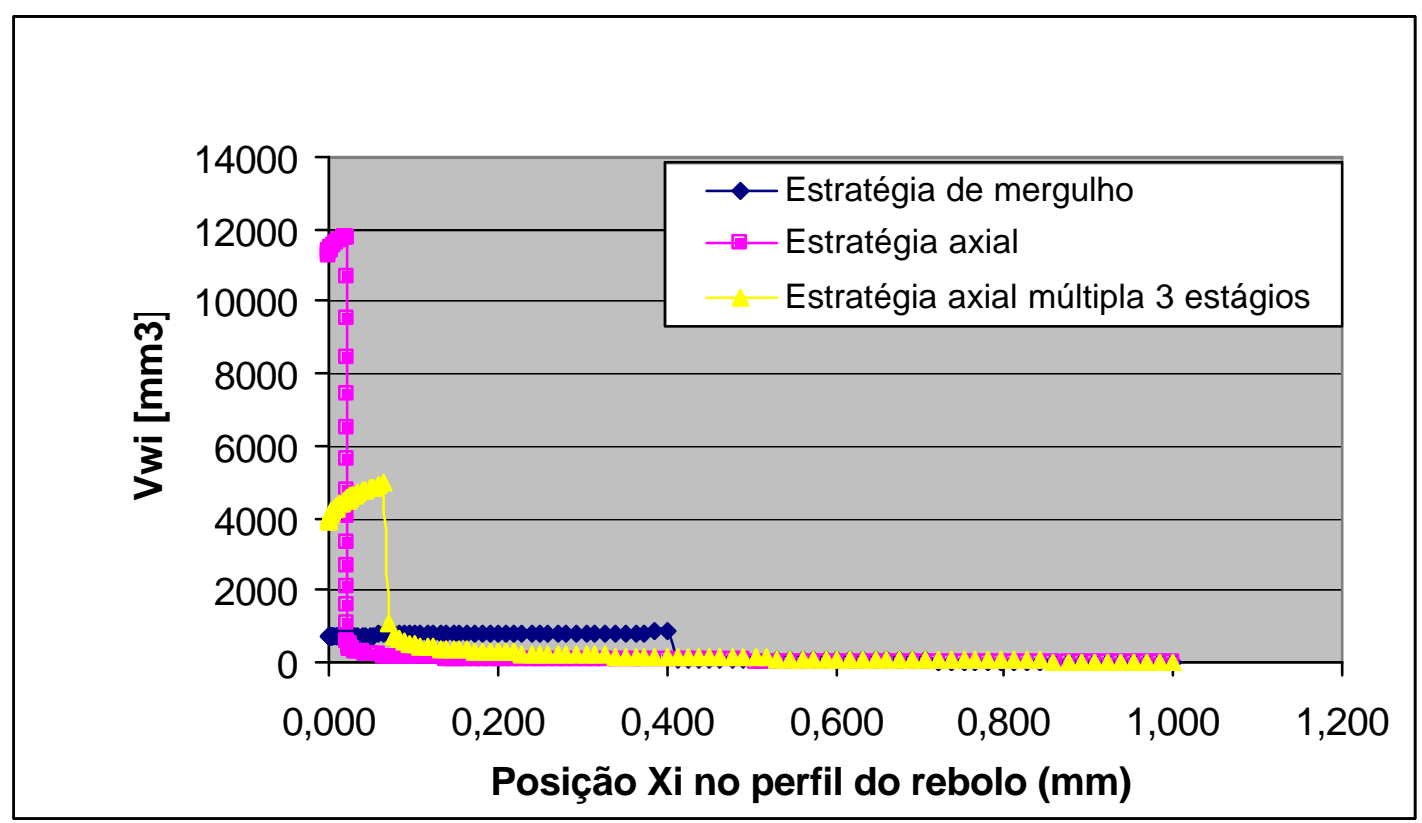

Figura 5.38 - Volumes de material removido por peça $V_{\text {wi }}$ ao longo da posição $X_{i}$ para as estratégias: mergulho, axial e axial múltipla com 3 estágios

Na Figura 5.38, o volume total de material a ser removido por peça é idêntico para as três estratégias, sendo que as diferenças observadas encontram-se no valor de $V_{\text {wi }}$ removido por cada região do perfil do rebolo. A estratégia de mergulho apresenta uma distribuição deste volume $\mathrm{V}_{\mathrm{wi}}$ mais homogênea e de menor intensidade ao longo de uma maior região do perfil do rebolo. De forma oposta, a estratégia axial é caracterizada pela concentração da quase totalidade do volume a ser removido na região correspondente ao avanço por volta na direção axial ( $\left.\mathrm{a}_{\mathrm{fr}}\right)$. A adoção da estratégia axial múltipla permite a adoção de uma situação 
intermediária entre a estratégia de mergulho e a axial, permitindo-se a redução do $\mathrm{V}_{\text {wi }}$ nas proximidades do raio com conseqüente alargamento da região de máxima solicitação do rebolo.

Com base nestes valores de $\mathrm{V}_{\text {wi }}$ e de posse das tolerâncias geométricas do perfil da peça a ser usinada (por exemplo um colo de virabrequim) é possível simular, adotando-se um valor de $\mathrm{G}$ esperado e o número de peças no lote a ser fabricado, o desgaste do perfil do rebolo ao longo da usinagem do lote.

A Figura 5.39 apresenta um conjunto de curvas que representam, em função da posição $\mathrm{X}_{\mathrm{i}}$, o perfil original do rebolo, em termos de sua dimensão do raio externo e raio de arredondamento. Adicionalmente é apresentado o máximo desvio permitido do perfil do rebolo aplicando-se ao perfil original do mesmo as máximas tolerâncias no diâmetro $(0,01$ $\mathrm{mm})$ e na face do colo a ser retificado $(0,1 \mathrm{~mm})$. Ainda nesta Figura 5.39, são apresentadas as curvas referentes aos perfis do rebolo, após a usinagem de um determinado número de peças do lote, adotando-se as três estratégias propostas: mergulho, axial e axial múltipla.

Da análise da Figura 5.39 pode-se verificar a evolução do desgaste do perfil ao longo da retificação de um lote contendo 250 peças. O gráfico para as três estratégias após a usinagem da primeira peça apresenta os perfis sem desgaste e dentro do limite de tolerância. O aumento do número de peças retificadas expõe os diferentes comportamentos de desgaste em função das estratégias adotadas.

A estratégia de mergulho apresentará a região de máximo desgaste do rebolo na posição $X_{i}=0,4 \mathrm{~mm}$, sendo igual ao sobremetal a ser removido na direção axial. Para o mesmo volume de material removido, a adoção desta estratégia implicaria, a partir da peça 250 a dressagem do perfil do rebolo, já que foi ultrapassado o limite de tolerância. Além disso, o ponto de máximo desgaste estaria localizado em uma região de campo de tolerância 
mais estreito. Neste caso, seria necessária a dressagem do raio de canto do rebolo a fim de se corrigir o seu perfil.
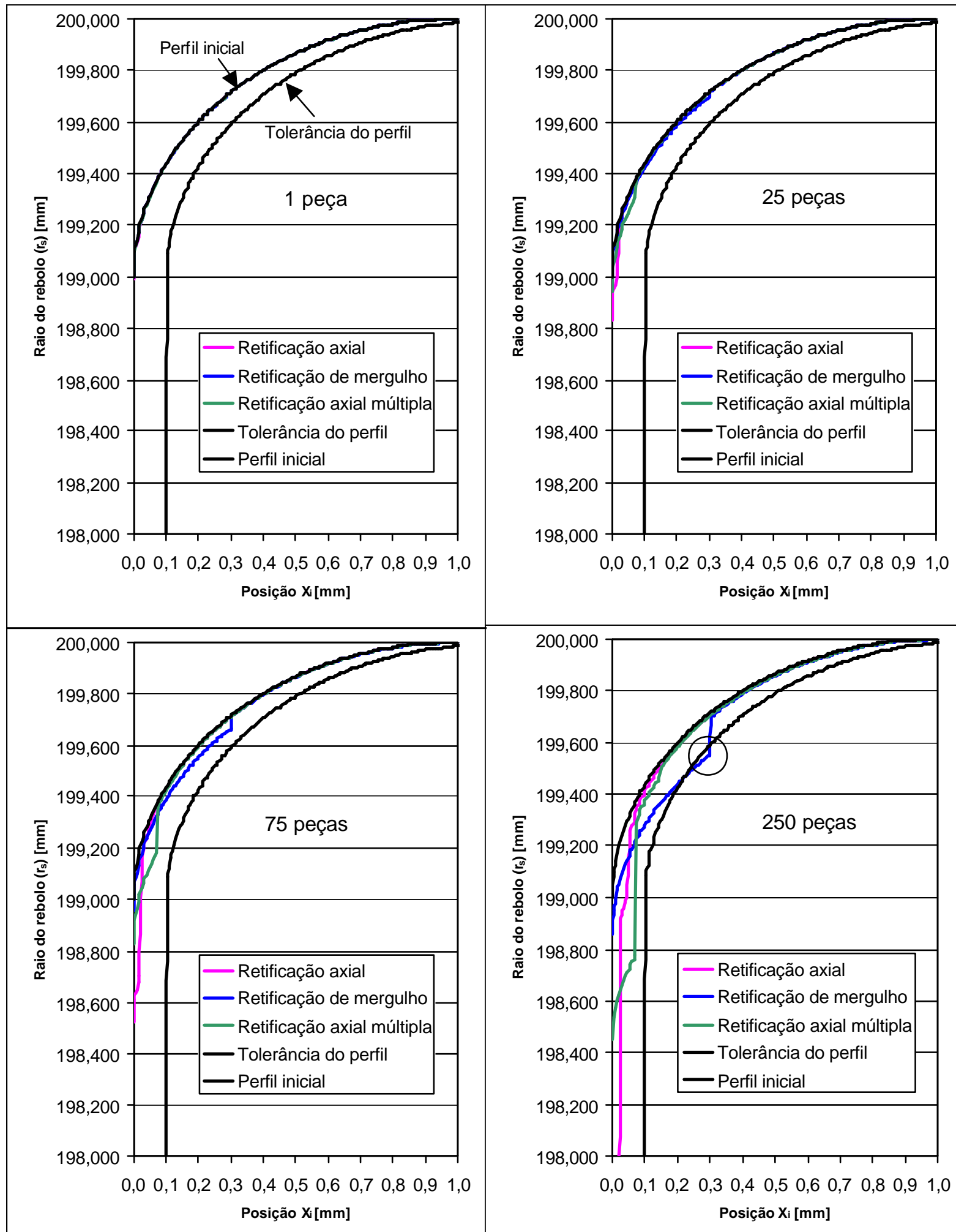

Figura 5.39 - Evolução do perfil desgastado do rebolo em função da estratégia de retificação adotada e do número de peças no lote, para uma relação $\mathrm{G}=1000$ 
Quando da utilização da estratégia de retificação axial, o comportamento do desgaste do perfil é distinto, já que se tem a concentração do erro de perfil numa região mais estreita, quando comparada com a estratégia de mergulho. Todavia, os valores de desgaste são mais elevados, o que leva a uma rápida degradação da lateral do rebolo, com trecho de máxima solicitação da ferramenta na posição $X$ igual ao avanço por volta na direção axial $\left(a_{\mathrm{fr}}=0,025\right.$ mm). Entretanto, este desgaste está concentrado em uma região de campo de tolerância mais aberto, sendo que para o número de peças em questão (250) não foi ultrapassado o limite de tolerância, o que permitiria a usinagem de um número ainda maior de peças antes da dressagem. A intensidade deste desgaste é, em ordem de magnitude, superior ao observado para a estratégia de mergulho. Isto acarretaria uma alteração no raio do rebolo para o ponto $X_{i}$ $=$ 0,025 mm passando de 199,222 para 198,893 $\mathrm{mm}$ (desgaste de 0,329 mm). A utilização desta estratégia pressupõe que a altura do recesso na lateral do rebolo seja compatível com a previsão do desgaste nesta região. Uma vantagem desta estratégia é que a dressagem pode-se limitar a lateral do rebolo, já que o perfil do raio do canto do rebolo não foi alterado. De forma análoga, a utilização da estratégia axial múltipla apresenta características similares à estratégia axial, permitindo reduzir o desgaste excessivo na lateral do rebolo, se comparado ao gerado quando da utilização da estratégia axial, deslocando esta região de maior solicitação para uma posição mais interna do perfil do rebolo.

O comportamento de desgaste simulado para as estratégias axial e axial múltipla leva em consideração, a influência do sobremetal não removido no ciclo anterior, resultado do desgaste no perfil do rebolo, na região correspondente ao avanço por volta. Este material excedente faz com que uma porção adjacente a região 1, mais interna do perfil do rebolo e de largura também igual ao avanço por volta na direção axial (região 2) passe a remover o sobremetal excedente não removido pela região desgastada 1 , resultando no aparecimento de “degraus" no perfil do rebolo (Figura 5.40). Estes degraus aumentarão as porções desgastadas 
do rebolo ao longo do perfil do rebolo, reduzindo o número de peças que poderão ser retificadas sem que seja ultrapassado o limite de tolerância do perfil.

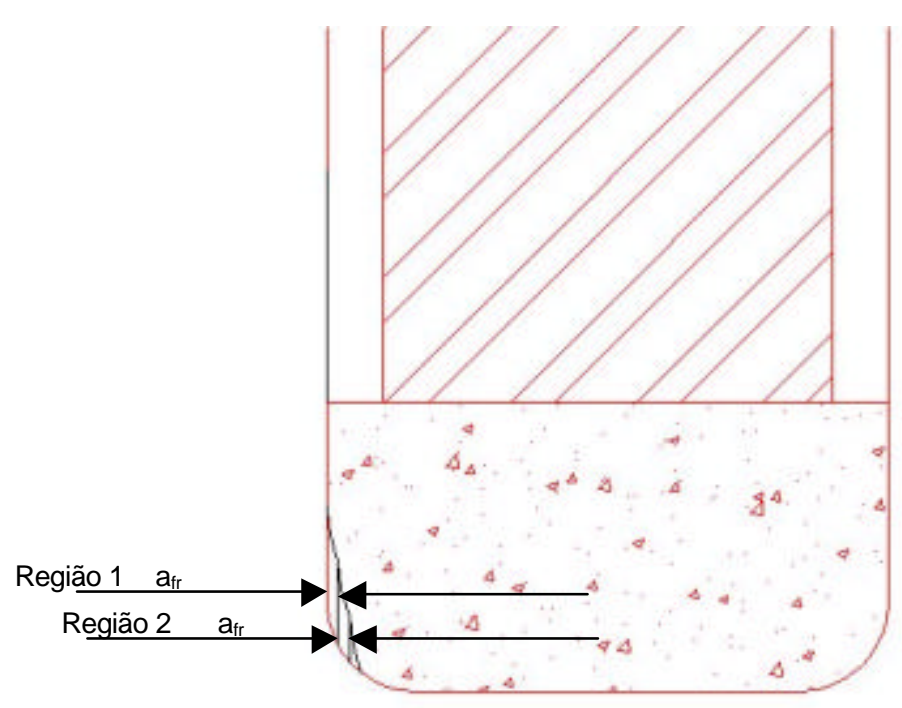

Figura 5.40 - Evolução do perfil desgastado em formato de degrau para a estratégia axial e axial múltipla

Através da adoção das diferentes estratégias é possível selecionar a região de desgaste preferencial do perfil do rebolo, ajustando-se esta região desgastada no campo de tolerância do perfil esperado.

\subsection{Quadro resumo comparativo dos resultados obtidos para as estratégias de retificação testadas}

A Tabela 5.11 apresenta um resumo comparativo dos resultados obtidos para as estratégias de retificação testadas. 
Tabela 5.11 - Resumo dos resultados obtidos para as diferentes estratégias de retificação testadas

\begin{tabular}{|c|c|c|c|}
\hline & $\begin{array}{c}\text { Retificação de mergulho } \\
\text { (estratégia A) }\end{array}$ & $\begin{array}{c}\text { Retificação axial } \\
\text { (estratégia B) }\end{array}$ & $\begin{array}{c}\text { Retificação axial } \\
\text { múltipla } \\
\text { (estratégia C) }\end{array}$ \\
\hline $\begin{array}{l}\text { Taxa de remoção } \\
\text { específica de } \\
\text { material }\left(Q^{\prime}{ }_{w}\right) / \\
\text { Volume de } \\
\text { material } \\
\text { removido ao } \\
\text { longo do perfil do } \\
\text { rebolo }\left(V_{\text {wi }}\right)\end{array}$ & $\begin{array}{l}\text { Menor valor e praticamente } \\
\text { constante (patamar) ao } \\
\text { longo da área de máxima } \\
\text { solicitação. A largura desta } \\
\text { área é limitada pelo } \\
\text { sobremetal no espelho } \\
\text { (SM) }\end{array}$ & $\begin{array}{l}\text { Máximo valor. } \\
\text { Distribuição em } \\
\text { formato de pico na } \\
\text { área de máxima } \\
\text { solicitação. Área mais } \\
\text { estreita e concentrada } \\
\text { na lateral do rebolo, } \\
\text { cuja largura é limitada } \\
\text { pelo avanço axial. }\end{array}$ & $\begin{array}{l}\text { Valor intermediário. } \\
\text { Distribuição em } \\
\text { formato de pico na } \\
\text { área de máxima } \\
\text { solicitação. Área mais } \\
\text { estreita e concentrada } \\
\text { na lateral do rebolo, } \\
\text { cuja largura é limitada } \\
\text { pelo avanço axial, o } \\
\text { qual será função } \\
\text { também do número de } \\
\text { estágios adotado. }\end{array}$ \\
\hline $\begin{array}{l}\text { Desgaste do } \\
\text { perfil do rebolo }\end{array}$ & $\begin{array}{l}\text { Menor intensidade. Area } \\
\text { desgastada do perfil mais } \\
\text { extensa. Largura da área } \\
\text { fixa e igual ao sobremetal } \\
\text { no espelho (SM) }\end{array}$ & $\begin{array}{lr}\text { Desgaste } & \text { em } \\
\text { "degraus". } & \text { Máxima } \\
\text { intensidade. } & \text { Área } \\
\text { desgastada do perfil } \\
\text { mínima. Largura da } \\
\text { área variável e } \\
\text { dependente do avanço } \\
\text { axial e da evolução do } \\
\text { desgaste } \\
\text { "degraus". }\end{array}$ & $\begin{array}{lr}\text { Desgaste } & \text { em } \\
\text { "degraus". Intensidade } \\
\text { intermediária. Área } \\
\text { desgastada do perfil e } \\
\text { largura da } & \text { área } \\
\text { variável e dependente } \\
\text { do número de estágios } \\
\text { (avanço ralr } \\
\text { resultante) e da } \\
\text { evolução do desgaste } \\
\text { em "degraus". }\end{array}$ \\
\hline $\begin{array}{l}\text { Área de contato } \\
\text { durante a } \\
\text { usinagem }\end{array}$ & $\begin{array}{llll}\text { Mínima } \quad \text { região } & 1 & \text { do } \\
\text { modelo teórico) } & & \end{array}$ & $\begin{array}{l}\text { Máxima (regiões } 1,2 \text { e } \\
3 \text { do modelo teórico) }\end{array}$ & $\begin{array}{l}\text { Intermediária (regiões } \\
1,2 \text { e } 3 \text { do modelo } \\
\text { teórico) com redução } \\
\text { do sobremetal radial } \\
\text { pela variação do } \\
\text { número de estágios }\end{array}$ \\
\hline $\begin{array}{l}\text { Esforços de corte } \\
\text { ao longo do perfil } \\
\text { do rebolo }\end{array}$ & Mínimo & Máximo & Intermediário \\
\hline $\begin{array}{l}\text { Influência do } \\
\text { sistema de } \\
\text { limpeza a alta } \\
\text { pressão }\end{array}$ & Mínima & Máxima & Intermediária \\
\hline
\end{tabular}




\section{CONCLUSÕES}

Com base nos resultados obtidos nesta pesquisa pode-se concluir que:

- O condicionamento inicial do rebolo de CBN através de uma operação de dressagem efetiva é fundamental para o desempenho da retificação de espelhos. A obtenção de uma agressividade na face do rebolo adequada é necessária para evitar o empastamento do mesmo e a queima do espelho. Para tanto, além da escolha correta da configuração e dos parâmetros de dressagem verificou-se a necessidade de um sistema de monitoramento que permita a detecção e a avaliação de possíveis nãoconformidades.

- A utilização de sistemas de fluido de corte e de limpeza a alta pressão eficientes contribuíram para a redução dos cavacos alojados na porosidade do rebolo, evitando assim seu empastamento prematuro.

- Para o volume de material removido, a utilização do sistema de limpeza reduziu os valores de energia de corte específica e os valores de rugosidade para o teste de 1 estágio (retificação axial). A utilização do sistema de limpeza do rebolo também reduziu de forma geral a tendência à aderência de cavacos nas proximidades do raio ao final dos ensaios.

- Com base no modelo teórico proposto e na simulação do desgaste do perfil do rebolo foi possível determinar-se a região de máxima solicitação do rebolo em função das estratégias adotadas, permitindo assim o planejamento e a adoção de condições de 
usinagem e estratégias mais favoráveis para a eliminação da queima da peça e do empastamento do rebolo, bem como para a redução de seu desgaste.

- Nos testes comparativos entre as estratégias verificou-se a possibilidade de utilização de ambas. Porém, cada qual apresentando suas particularidades. A taxa de remoção de material específica, a área de máxima solicitação e o desgaste da ferramenta podem ser ajustadas em função do tipo de estratégia adotada. A introdução da retificação axial múltipla permite a obtenção de uma solução intermediária entre a retificação de mergulho e axial, ajustando-se a taxa de remoção específica de material Q' ${ }_{w}$, o volume de material removido por peça $V_{w}$, o desgaste do perfil do rebolo e a posição $X$ de máxima solicitação pela variação do número de estágios, reduzindo-se a tendência de queima da peça e empastamento do rebolo. 


\section{SUGESTÕES PARA TRABALHOS FUTUROS}

- Estudo da retificação completa de colos de virabrequim.

- Avaliação da relação entre a área da região 2 e a potência consumida, avaliando a energia gasta com atrito e riscamento naquela região.

- Teste da estratégia axial múltipla para a retificação de virabrequins em ambiente industrial.

- Verificar o desgaste do rebolo em testes de retificação mais longos, com maior volume de material removido.

- Comparar os resultados de desgaste obtido para estratégias de retificação com a simulação proposta. 


\section{REFERÊNCIAS}

AWK Aachener Wekzeugmaschinen-Kolloquium'99. EVERSHEIM, W.; KLOCKE, F.; PFEIFER, T.; WECK, M.: Wettbewerbsfaktor Produktionstechnik - Aachener Perpektiven. Shaker Verlag, Aachen, 1999.

BASICS quantities in cutting and Grinding. ISO 3002-5: 1989(E).

BECK, T., Kühlschmierstoffeinsatz beim Schleifen mit CBN. , 2001, 151p. Dissertation, WZL - Aachen, Shaker Verlag, 2001.

BILDSTEIN,H.

Hochgeschwindigkeits-CBN-Punktschleifen

nachdem

Quickpointverfahren Vortag: VDI-Gesellschaft für Produktionstechnick, Stuttgart, 19.2.1987, 1987.

BILDSTEIN, H.; FURTWENGLER, D., Future orientated CNC-high-tech-grinding systems using CBN or diamond wheels. $5^{\text {th }}$ International Grinding Conference, Cincinnati, Ohio, Society of Manufacturing Engineers (SME), 1993.

BRINKSMEIER, E.; ÇINAR, Characterization of Dressing Processes by Determination of the Collision Number of the Abrasive Grits” Annals CIRP 44 (1), 1995, p. 299-304.

BÜCKER, C.; Schälschleifen mit windschiefer Achsanordnung, Dissertation RWTH Aachen 1997a.

BÜCKER, C.; Fertigbeabeitung in einem Schliff, Wirtschaftliches fertigung Mai 1997, 1997b, p. 28. 
CAI, R.; ROWE, R.B., MORGAN, M.N. The effect of porosity on the grinding performance of vitrified CBN wheels, In: Advances in Abrasives Technology V, 426p., Trans Tech Publications, ISBN 0-87849-910-5, 2002, p. 295-300.

CAMPBELL, J. D., Optimized coolant application, $\mathbf{1}^{\text {st }}$ International Machining and Grinding Conference, SME, MI, sept. 12-14, 1995, p.895-904.

CARIUS, A. C., Desenvolvimentos de produto e do mercado de CBN na América e na Europa”. Máquinas e Metais, no 403, Agosto, 1999, p. 86-103

CHEN, X.; FENG, Z. Effectiveness of laser cleaning for grinding, In: Advances in Abrasives Technology V, 426p., Trans Tech Publications, ISBN 0-87849-910-5, 2002, p. 289-294

CUI, C. Experimental Investigation of Thermo-fluids in the Grinding Zone, $\mathrm{PhD}$ Thesis, Univ. Connecticut, 1995.

DORNFELD, D. A.; CAI, H. G. An investigation of grinding and wheel loading using acoustic emission. Journal of Engineering for Industry", v. 106, February, 1984, p. 28-33.

GERENT, O. Entwicklungen zu einem ganzheitlichen Prozessmodell für das Hochleistungs-Aussenrund-Formschleifen, 2001， 151p. Tese de Doutorado, WZL Aachen, Shaker Verlag, 2001.

GESPRÄCHE mit Vertretern der Frima Ernst Winter \& Sohn, 1997, Norderstedt, 1994-1998

HEGENER, G. Technologische Grundlagen des Hochleistungs-AussenrundFormschleifen, 1999, 147p., Tese de Doutorado, WZL - Aachen, Shaker Verlag, 1999.

HITCHINER, M.P., Technological advances in creep feed grinding of superalloys with CBN. $\mathbf{3}^{\text {rd }}$ International Machining and Grinding Conference SME, Cincinnati, Ohio, October 4 $7,1999$.

HITCHINER, M.P. Advantages in production grinding with $\mathrm{CBN}$ and their influence on machine tool design". Saint Gobain Grinding Conference, São Carlos, São Paulo, Junho 2001, em CD. 
ISHIKAWA, T.; KUMAR K. V., Conditioning of vitrified bond superabrasive wheels Superabrasives '91 SME, MR91-172, 1991.

KLOCKE, F., SAXLER, W., Die Schleiftechnik in der Prozesskette der Zukunft Schleiftechnik im Wettbewerb Hrsg. von WICHARZ, W.; KLOCKE, F.; BRINKSMEIER, E.; VDI Verlag, Düsserdorf, 1997.

KLOCKE, F.; BAUS, A.; BECK, T. Coolant induced forces in high speed ginding with shoe nozzles, Annals of the CIRP, v. 49/1, , 2000, p. 241-244.

KLOCKE, F.; HEGENER, G.; DEACU, L. Hochleistung-Assenrunf-Formschleifen Innovatives Fertigungsverfahren vereint Flexibilität und Produktivität, ZWF 91 (1996) 4, p. $164-167$

KOHLI S. P., GUO, C.; MALKIN, S., Energy partition for grinding with aluminum oxide and CBN abrasive wheels". ASME Journal of Engineering for Industry, Vol. 117, 1995, p. 160-168.

KÖNIG, W.; KLOCKE, F. Schleifen mit Schleifscheiben. In:

Fertigungsverfahren Band 2, Schleifen, Honen, Läppen, 3. Edição, Düsseldorf, VDI Verlag, 1996, p. 62-198.

KÖNIG, W.; SCHRÖDER, B. Hochgeswindigkeits-Aussernrund-formschleifen mit CBNSchleifscheiben. Bericht zur 23. Arbeitsagung des Technologie-Arbeitskreises, 24.3.1994, 1994, Aachen.

KÖNIG, W.; SCHRÖDER, B., TREFFERT, C., High speed grinding of any contour using CBN wheels", $5^{\text {th }}$ International Grinding Conference, Cincinnati, Ohio, Society of Manufacturing Engineers (SME), MR93-336, 1993.

KOVACEVIC, R; MOHAN R. Effect of high speed grinding fluid on surface grinding performance. SME Technical paper MR95-213, 1995, p. 919-931. 
LAVINE, A. S., MALKIN, S.; JEN, T. C., Thermal aspects of grinding with CBN abrasives", Annals of the CIRP, Vol.38/1, 1989, p.557-560.

LEAL, J. La Filtración en los processos de retificado com muelas de borazon, Filtrations News, v. VIII, 1993, p. 1-8.

LECHLER, Digital Documentation, 2004, http://www.lechler.com

LINDSAY, R. P., The effect of contact time on forces, wheel wear rate and G-ratio during internal and external grinding. Annals of the CIRP, 33/1, 1984, p. 193-197.

MALKIN, S. Current trends in CBN grinding technology, Annals of the CIRP., 34/1, 1985, p. 557-560.

MALKIN, S. Grinding wheel wear. In: Grinding Technology - Theory and application of machining with abrasives. Ellis Horrwood Limited, 1989, p. 197-221. ISBN 0-85312-756-5.

MERBECKS, T., Prozessauslegung des Hochleistungs-Aussenrund-Formschleifens beliebiger Werkstückkonturen, Abschlussbericht, 2002, 157p. WZL - Aachen

METZGER, J., Superabrasive Grinding, Butterworth Press, 1986, ISBN 0-48-01586-1

MEYER, H. R.; KLOCKE, F. High performance grinding with CBN. Superabrasives Conference, Chicago, Illinois, 1991, Society of Manufacturing Engineers (SME), MR91-162, 1991.

MINDEK, M., Improved rotary disc truing of hot-pressed CBN grinding wheels. MSc Thesis, University of Connecticut, 1992.

MUCKLI, J. Hochgeschwindigkeitsschleifen mit keramisch gebunden CBNSchleifscheiben, 137p., Tese de Doutorado, WZL - Aachen, Shaker Verlag, 2000.

NAKAJIMA, T.; OKAMURA, K.; UNO, Y., Transverse grinding techniques for improving both productivity and surface finish, International Grinding Conference, Fontana, Wisconsin, Society of Manufacturing Engineers (SME), MR84-534, 1984. 
OLIVEIRA, J.F.G, DORNFELD, J.F.G Application of AE Contact Sensing in Reliable Grinding Monitoring, Annals of the CIRP, v.50, n.1, 2001, p.217-220.

OPTIZ, H.; FRANK, H., Richtwerte für das Aussenrundschleifen Forschungsberichte des Landes Nordrhein-Westfalen Nr. 965, 1961.

PRODUKT Information, Firmenschrift Erwin Junker Maschinenfabriken GmbH, Nordrach, 1988-1996, 1988.

REDINGTON, P.; SUllivan, W. J. What about CBN? Manufacturing Engineering, 1998, p. 76-83. October.

ROUSE, H.; ASCE, M.; HOWE, J. W.; METZLER, D. E., Experimental investigation of fire monitors and nozzles, $\mathbf{1 1 7}^{\text {th }}$ ASCE Transactions, 1952.

SALJÉ, E.; ROHDE, G., Rundschleifenmaschinen VDI-Z 124 (1982) Nr. 15/16 - August (I/II), S. M3-M19, 1982.

SHAW, M. C. Principles of abrasive grinding. Clarendon Press, Oxford, , 1996, p345, (after K Gruehring, 1967 D.Ing dissertation, Aachen), 1996.

SHELDON, D., LIU, S., 1995, "Innovative bond Technology for corner/form holding" Automotive Manufacturing International '95, 3p.

SHIH, A. J.; GRANT, M. B.; YONUSHONIS, T. M.; MORRIS, T. O.; MCSPADDEN, S. B., High speed and high material removal rate grinding of ceramics using the vitreous bond CBN wheel". Annual Meeting of American Society for Precision Engineering, October 25-30, 1998.

SILVA, E. J., Análise da influência dos tipos de fluidos de corte e rebolo na retificação do aço SAE HVN-3, 2000. 179 p. Dissertação (Mestrado em Engenharia Industrial), Faculdade de Engenharia de Bauru, Universidade Estadual Paulista Julio de Mesquita Filho - UNESP, Bauru, 2000. 
SILVA, E. J.; BIANCHI, E. C.; OLIVEIRA, J. F. G.; AGUIAR, P. R., Cutting fluids evaluation in the grinding of a martensitic valve steel with $\mathrm{CBN}$ and alumina abrasives. Preceedings of the Institution of Mechanical Engineers Part B - Journal of Engineering Manufacture, v.8, n 217, 2003, p. 1047-1055.

TAKAGI, J.; LIU, M., Fracture characteristics of grain cutting edges of CBN wheel in truing operation. Journal of Materials Processing Technology, v. 62, 1996, p. 397-402.

TAWAKOLI, T. High Efficiency Deep Grinding, Mechanical Engineering. Pub.l. London . 1993, ISBN 0852988206

TÖNSHOFF, H. K.; GRABNER, T. Cylindrical and profile grinding with boron nitride wheels" Proceedings of the 5th International Conference on Production Engineering, Tokio, 1984, p. 326-343.

TÖNSHOFF, H.K.; FALKENBERG, Y., High-speed grinding of cast iron crankshafts with CBN tools". Industrial diamond review, vol.56, April, 1998, p.115-119,.

TÖNSHOFF, H.K.; FALKENBERG, Y., FREIMUTH, T., Kontaktterosives Schärfen von metallisch gebundenen CBN-Schleifscheiben, 1996.

TSO, P., Study on grinding of Inconel 718. Journal of Materials Processing Technology, 55,1995, p. $421-426$.

VANSEVENANT, IR. E., An improved mathematical model to predict residual stresees in surface plunge grinding, Annals of the CIRP., 36, 1989, p. 413-416.

VERFAHREN und Vorrichtung zum Hochgeschwindigkeits-Profilschleifen von rotationssymmetrischen Werkstücken, 1984 Deutsches Patentamt, Offenlegungsschrift DE 3435313 A1.

VERFAHREN zum Rundschleifen von Werkstïcken, 1987 Deutsches Patentamt Offenlegungsschrift DE 3737641 A1.

VERKERK, J. Wheel wear control in grinding, Dissertation TH Delft, 1976. 
WEBSTER, J. A.; CUI, C.; MINDEK, R. B. Grinding fluid application system design, Annals of the CIRP, v. 44/1, 1995.

WEBSTER, J. Selection of coolant type and application technique in grinding. Supergrind, 1995, p. 205-218.

WEBSTER, J. Optimizing coolant application systems for high producing grinding. Abrasives Magazine, Oct. /Nov., 1999, p. 34-41.

WICK, C. Grinding multidiameter surfaces with CNC, Manufacturing Engineering, February, 1988, p. 66-73

WIRTSCHAFTLICHES Rundschleifen, Fortuna-Werke Spezialmaschinenfabrik A-G., Stuttgart - Bad Cannstadt, 4. erweiterte Auflage, 1940.

WÜNSCHE, R. C. U. Strategien zum Aussenrundlängsschleifen schlanker Werkstück, Dissertation RWTH Aachen, 1992.

YONEKURA; YOKOGAWA, Effects of tsukidashiryo of resinoid bonded borazon CBN wheels on grinding performance. Bull JSPE 17 (2), 1983, p113-118.

YUI, A.; LEE, H., Surface grinding with ultra high speed CBN wheel. Journal of Materials Processing Technology , 62, 1996, p. 393-396. 


\section{ANEXO A}

\section{Sistema de mapeamento acústico da superfície ativa do rebolo}

Oliveira e Dornfeld (2001) propuseram um sistema inovador para processamento e análise do sinal acústico do processo de retificação. Este método é baseado na análise do sinal RMS da emissão acústica (EA) em intervalos temporais bastante curtos. A emissão acústica obtida pelo contato entre dressador e rebolo (ou entre rebolo e peça, no caso de outro tipo de medição) é convertida para RMS (root mean square) e adquirida através de um computador, utilizando-se uma placa de aquisição com conversação de sinais analógico para digital. A faixa de variação da taxa de aquisição dos dados é de 60 mil até 500 mil amostras por segundo, dependendo da resolução escolhida na direção perimetral. Para os resultados obtidos, a serem apresentados, utilizou-se 2 mil amostras para mapear-se cada rotação do rebolo, o que significa uma resolução de $0,5 \mathrm{~mm} /$ amostra.

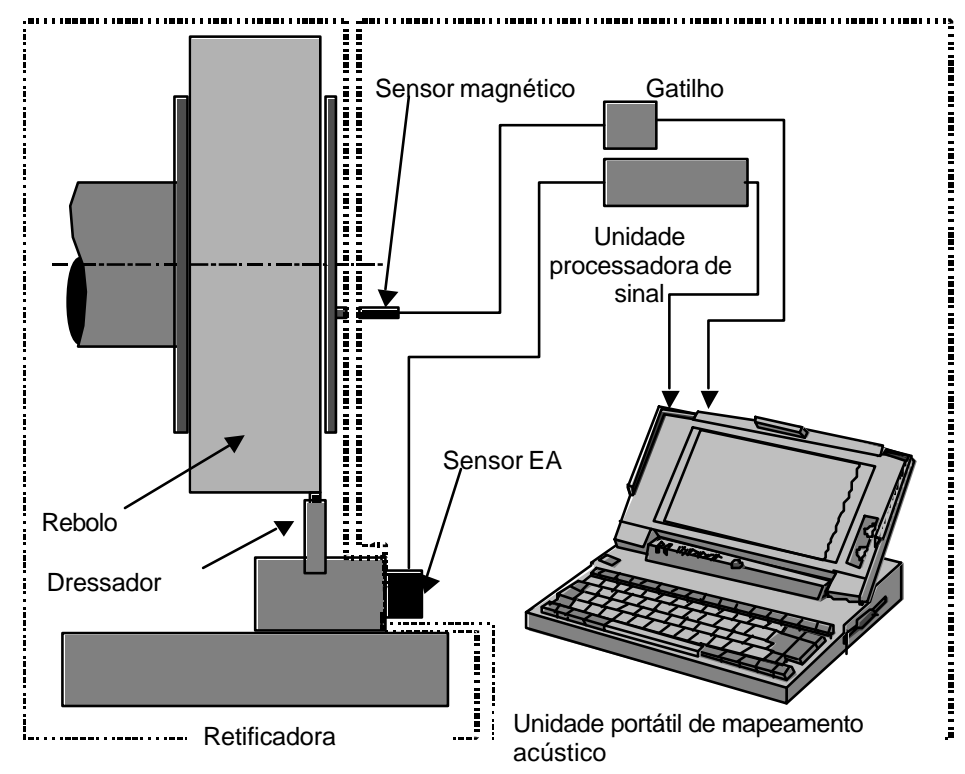

Figura A1 - Configuração básica do sistema de mapeamento por EA (Oliveira et al., 2000) 
Para que seja possível calcular-se o contato do diamante do dressador com cada grão abrasivo, o cálculo do sinal RMS deve ser feito utilizando-se uma constante de tempo extremamente rápida. Esta foi calculada como sendo o tempo médio gasto para dois toques consecutivos entre os grãos abrasivos e o diamante do dressador. Este cálculo foi efetuado para um rebolo convencional de óxido de alumínio, dureza L, estrutura 60. A distância média entre os grãos medida foi de $0,38 \mathrm{~mm}$ e velocidade de corte utilizada foi de $45 \mathrm{~m} / \mathrm{s}$. Desta forma uma constante de tempo de 10 microsegundos foi encontrada.

No processamento do sinal de EA, o cálculo do sinal RMS é feito, normalmente, após obter-se o sinal bruto filtrado. Devido à utilização de uma constante de tempo extremamente pequena, para o cálculo do sinal RMS estabeleceu-se um filtro de banda alta, com frequiência de onda limite de $100 \mathrm{kHz}$, sendo que para este sistema de mapeamento desenvolveu-se uma unidade processadora de sinal EA específica.

A aquisição dos dados é feita em grupos, onde cada vetor de dimensão unitária dos dados corresponde a uma rotação completa do rebolo. A aquisição inicia-se em cada rotação disparada por um sensor magnético, posicionado no cubo do flange do rebolo, onde um pino de referência foi instalado. Este tipo de referência foi adotado devido a sua simplicidade, sendo possível obter-se um set-up portátil para medições em campo, acoplável em qualquer retificadora. O número de amostras de cada conjunto de dados é calculado, baseando-se na resolução adotada, conforme a equação (A1):

$$
\mathrm{NS}_{\mathrm{r}}=\left(\mathrm{D}_{\mathrm{s}} \cdot \pi\right) \cdot \mathrm{R}_{\mathrm{es}}
$$

onde $\quad \mathrm{D}_{\mathrm{s}}=$ diâmetro do rebolo $(\mathrm{mm})$

$$
\begin{aligned}
& \mathrm{R}_{\mathrm{es}}=\text { Resolução do sistema (mm) } \\
& \mathrm{NS}_{\mathrm{r}}=\text { Número de amostras por rotação }
\end{aligned}
$$


A taxa de amostragem é calculada, pela equação (A2), baseando-se na velocidade de corte $\left(\mathrm{v}_{\mathrm{s}}\right)$ e no número de amostras por rotação do rebolo.

$$
\mathrm{S}_{\mathrm{r}}=\left(\mathrm{V}_{\mathrm{s}} \cdot \mathrm{NS}_{\mathrm{r}}\right) /\left(\mathrm{D}_{\mathrm{s}} \cdot \pi .\right)
$$

onde: $\quad \mathrm{v}_{\mathrm{s}}=$ velocidade de corte $(\mathrm{m} / \mathrm{s})$

$$
\mathrm{S}_{\mathrm{r}}=\text { Taxa de amostragem (Ksamples/s) }
$$

A imagem é construída através da representação do nível de EA para cada amostra adquirida, utilizando-se um gráfico tridimensional, com escala de cores. Durante a operação de dressagem uma imagem é construída em tempo real, através da adição de colunas nos vetores, como se o dressador avançasse ao longo da superfície do rebolo. A Figura A2 mostra este procedimento.

O sistema pode ser utilizado para três diferentes avaliações:

- Avaliação da dressagem: Durante a operação de dressagem, a interação dressador-rebolo pode ser acusticamente mapeada. A ausência de contado entre dressador e grão abrasivo é representada por uma área escura no mapa.

- Mapeamento topográfico: Neste caso, o mapa obtido é similar aquele para a operação de dressagem, todavia, utiliza-se uma profundidade de dressagem próxima à zero ou com valor próximo aquele da espessura do cavaco não-deformado para a operação. Desta forma, o mapa apresenta a superfície ativa do rebolo, a qual efetivamente entrará em contato com a peça durante operação de usinagem.

- Avaliação da retificação: Durante a operação de retificação de mergulho, a interação rebolo-peça pode ser avaliada. Neste caso, um mapa diferente é obtido, onde um dos eixos 
representa o tempo de retificação e o outro mostra a energia acústica média em todo seu comprimento, através de seu perímetro.

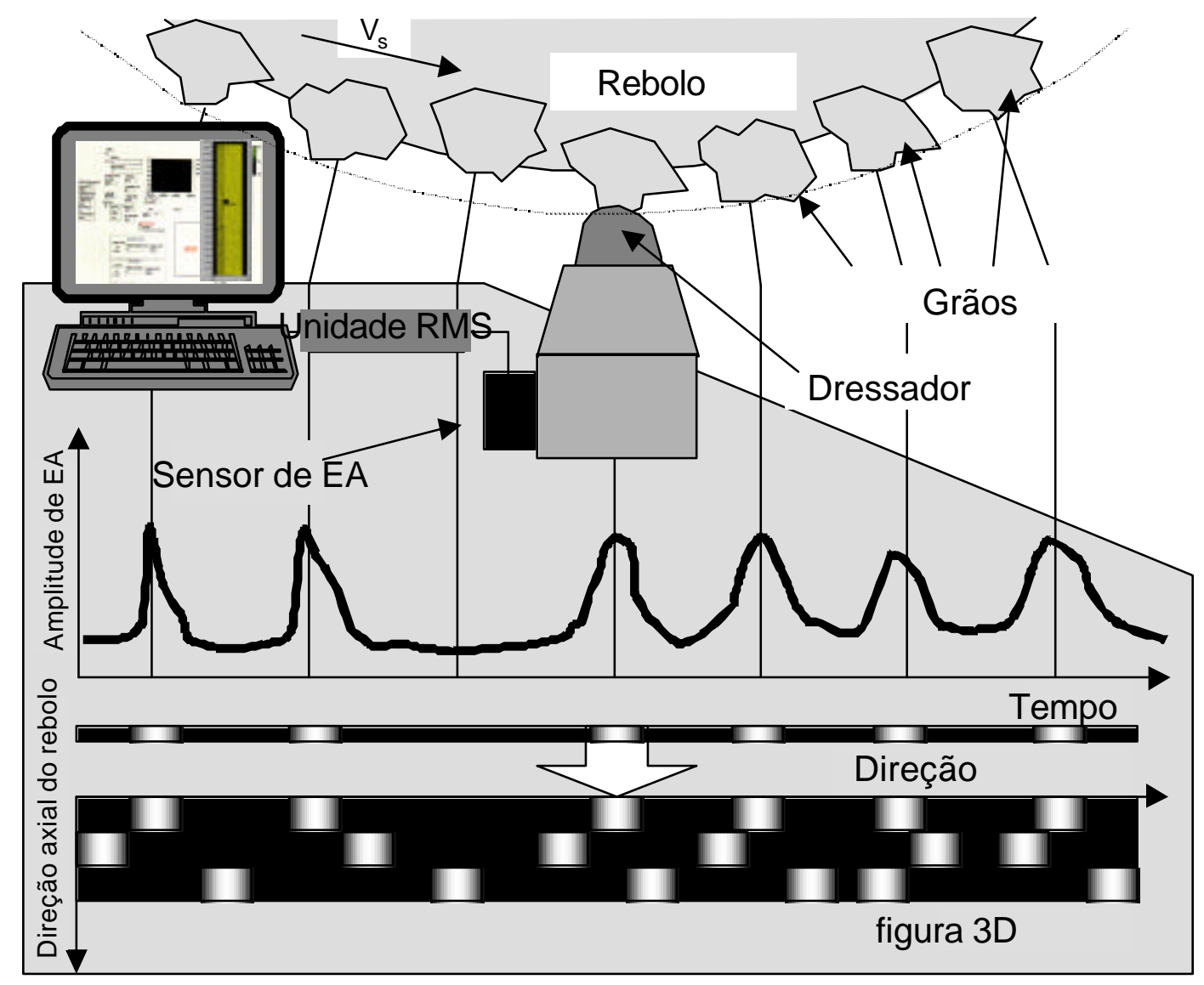

Figura A2 -Procedimento construção do mapa acústico (Oliveira et al., 2000)

A Figura A3 mostra o gráfico de saída do sistema de mapeamento acústico quando este é utilizado numa operação de dressagem. As direções vertical e horizontal são o comprimento circunferencial do rebolo e a sua largura, respectivamente. A resolução é de 2 amostras/mm. A profundidade de interação entre o dressador e o rebolo foi de $1 \mu \mathrm{m}$ (na região de contato elástico (Dornfeld e Cai, 1984)). A intensidade de cores mostra os valores de emissão acústica RMS medidos através da interação entre o dressador e os grãos abrasivos. As áreas mais escuras representam a menor energia acústica detectada pelo sensor. A marca em formato de L foi criada na superfície do rebolo a fim de checar a funcionalidade do 
sistema. A faixa escura presente no lado esquerdo do rebolo foi causada por uma operação de retificação utilizando apenas esta área do rebolo.

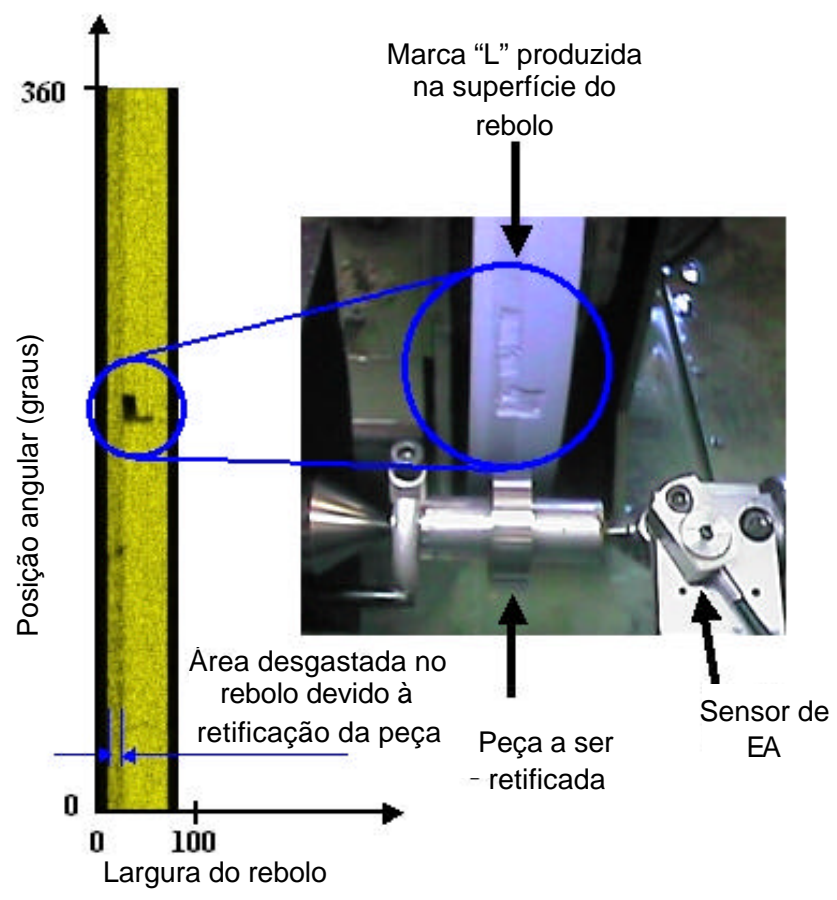

Figura A3 - Mapa acústico da superfície do rebolo utilizando o sistema de mapeamento (Oliveira et al., 2000)

A Figura A4 apresenta o mapa obtido em duas operações de retificação diferentes.
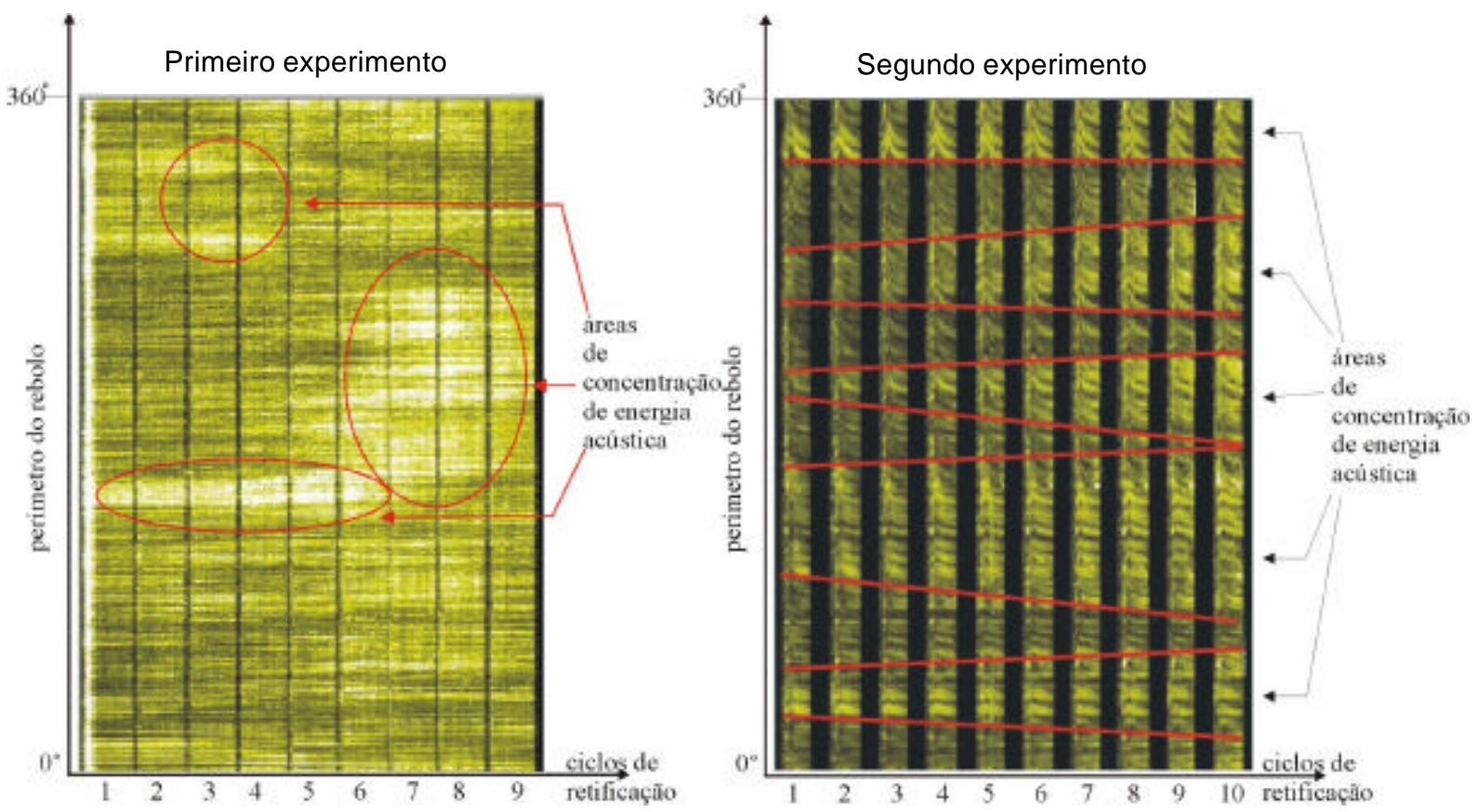

Figura A4 - Mapa obtido durante a operação de retificação, em duas condições distintas 
Na operação de retificação o mapa mostra como a energia de retificação é distribuída em torno da superfície do rebolo na unidade de tempo. Assim um mapa diferente é apresentado. A direção vertical mostra o nível médio de emissão acústica RMS em toda a largura do rebolo e a horizontal apresenta o tempo de retificação. Cada faixa no gráfico representa um ciclo único de retificação ou uma peça retificada.

O primeiro experimento apresentado na Figura A4 é uma retificação de mergulho de um aço SAE 4340 temperado utilizando um rebolo convencional de óxido de alumínio branco, com ligante de baixa dureza (AA60GV). O segundo conjunto de dados foi coletado na linha de produção de componentes para motores veiculares. O material do corpo-de-prova é o Inconel e o rebolo é um convencional de óxido de alumínio, com elevada dureza do ligante e grão de baixa friabilidade (DA80RV).

A imagem composta de várias partes mostra dois comportamentos de desgaste do rebolo distintos. No primeiro experimento, as transformações na imagem indicam que o rebolo está tendo perda diametral (soltando grãos). No segundo, a manutenção do padrão gráfico em torno do rebolo mostra que este não esta perdendo grãos. Estes resultados foram confirmados pela análise da variação dimensional da peça retificada, a qual apresentou uma tendência estável para o segundo caso e crescente para o primeiro, pela análise da temperatura da peça (crescente para o segundo e estável para o primeiro) e pela análise da potência de usinagem (crescente para o segundo e estável para o primeiro).

Uma vez que a característica principal utilizada para a avaliação do processo é a obtenção de um padrão gráfico, este sistema não é influenciado pela flutuação do RMS ao longo do tempo. A flutuação poderia levar a mudanças na intensidade ou no contraste da imagem para um dado padrão gráfico. Conseqüentemente, o diagnóstico baseado no padrão gráfico não seria influenciado pela temperatura ou por outras perturbações de longo termo na emissão acústica. 
A análise gráfica do padrão obtido pode ser diretamente relacionada com algumas anomalias de retificação, sendo que algumas delas já foram testadas e são descritas a seguir.

- Rebolo desbalanceado: O padrão mostra faixas escuras horizontais com resultado de uma baixa interação do rebolo em posições angulares de menor massa;

- Vibrações na retificação: apresentam-se padrões horizontais quando o rebolo torna-se ondulado. Apresenta padrões inclinados quando não existe sincronismo entre o rebolo e o fenômeno causador da vibração;

- Rebolo de arrasto excêntrico (para retificação centerless): o padrão obtido mostra inúmeras faixas verticais representando a ausência de contato entre o rebolo e a peça. A distância entre as faixas corresponde a uma revolução do rebolo de arrasto.

O mapeamento acústico é uma técnica eficaz a ser utilizada em inúmeras outras aplicações de retificação. Esta ferramenta é confiável uma vez que o nível de EA RMS não é a característica principal, mas sim o padrão obtido em torno do rebolo, sendo este último a base do sistema de monitoramento. 


\section{ANEXO B}

Perfil obtido nas chapas metálicas retificadas para análise do perfil desgastado do rebolo
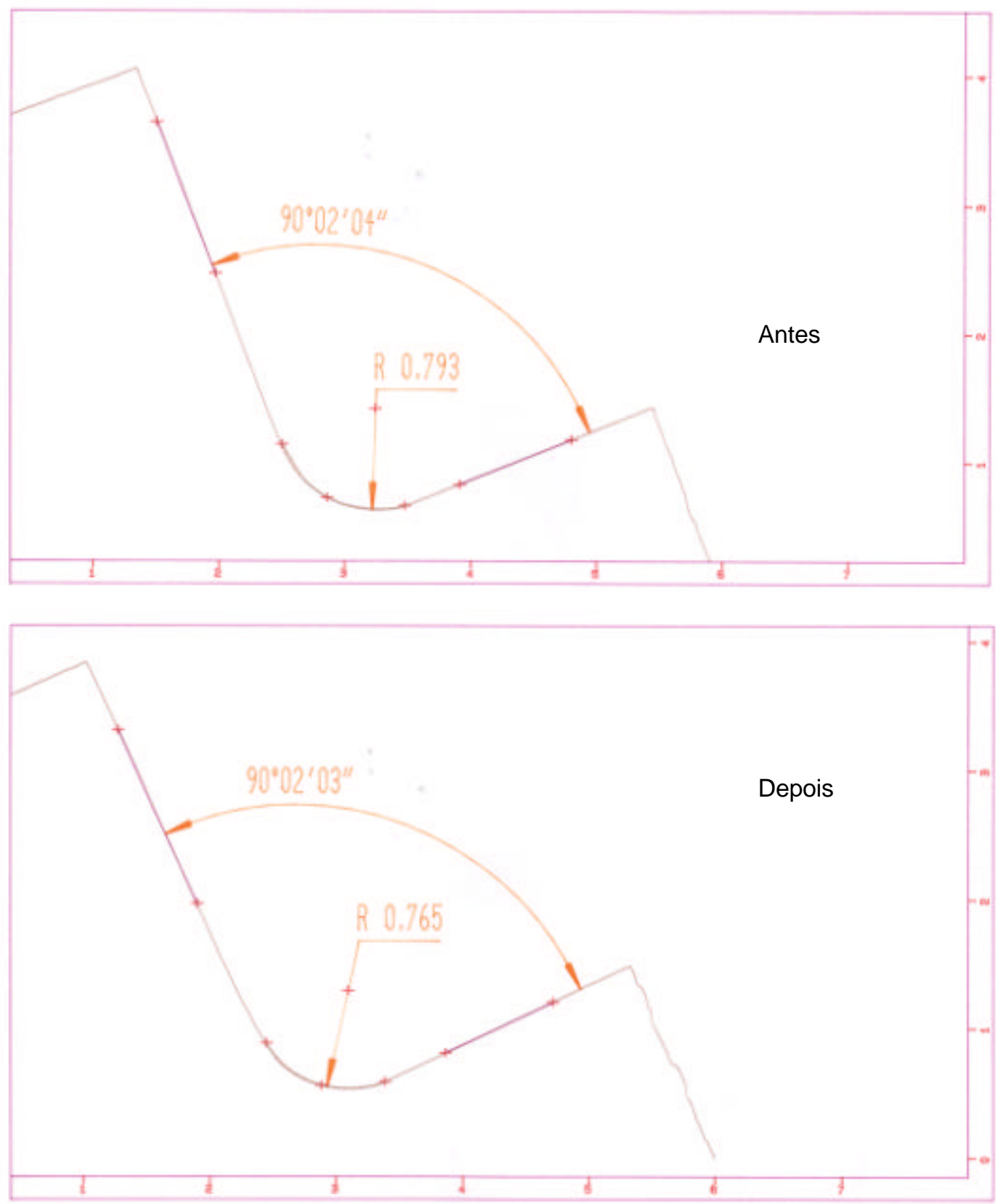

Figura A5 Perfil da lateral esquerda do rebolo antes e depois da retificação para os testes de 1 estágio com limpeza 

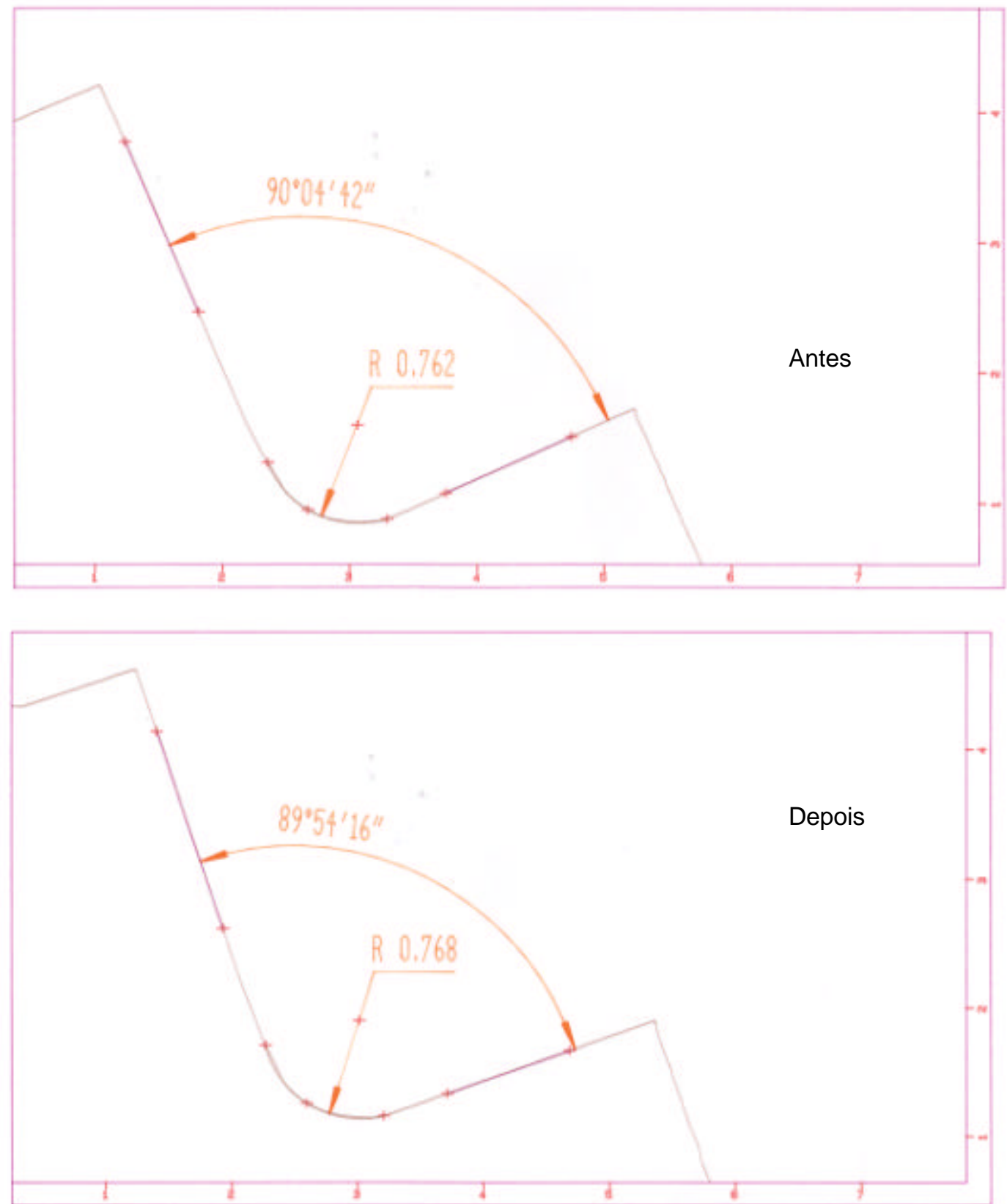

Figura A6 Perfil da lateral esquerda do rebolo antes e depois da retificação para os testes de 1 estágio sem limpeza 

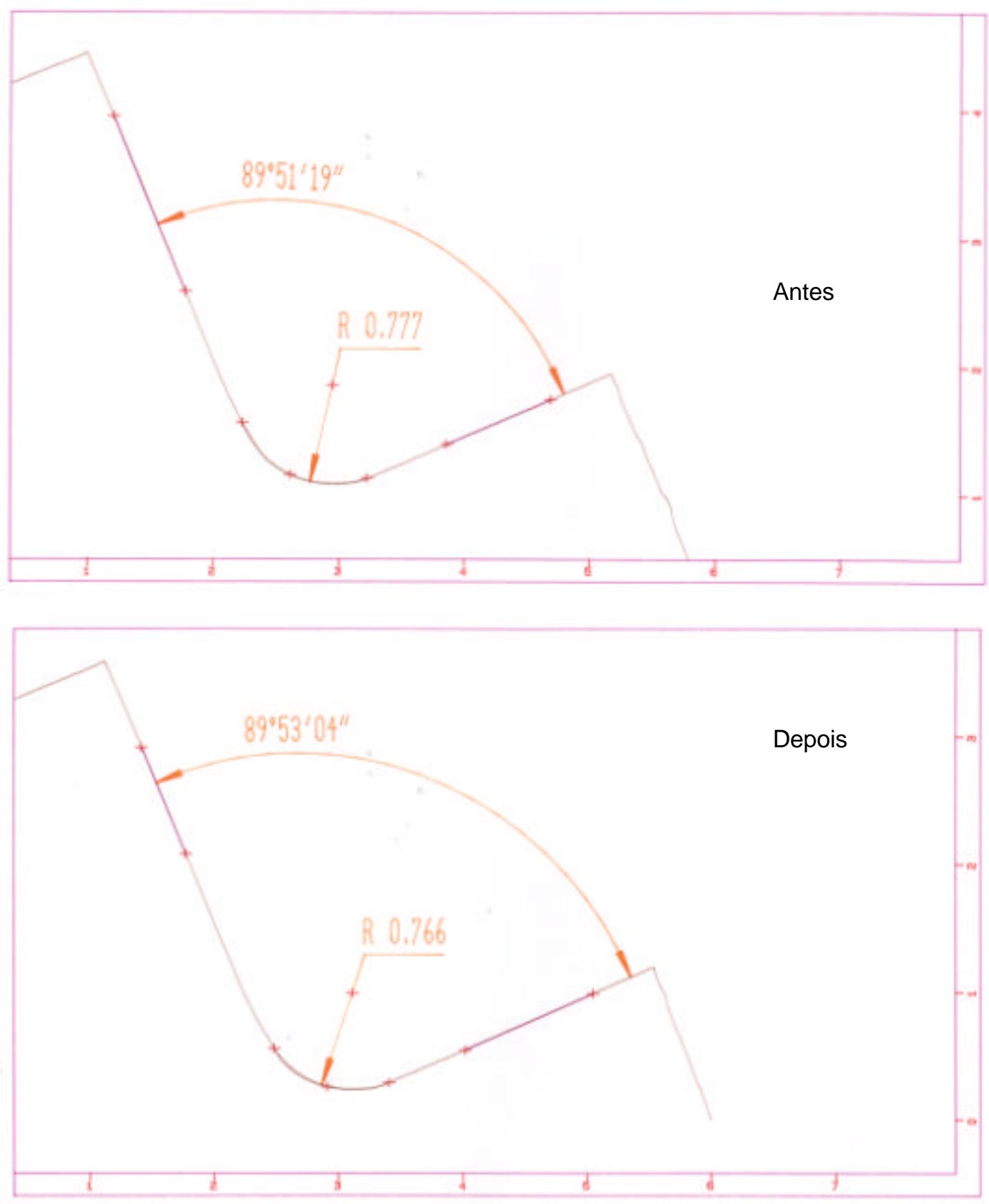

Figura A7 Perfil da lateral esquerda do rebolo antes e depois da retificação para os testes de 3 estágios com limpeza 

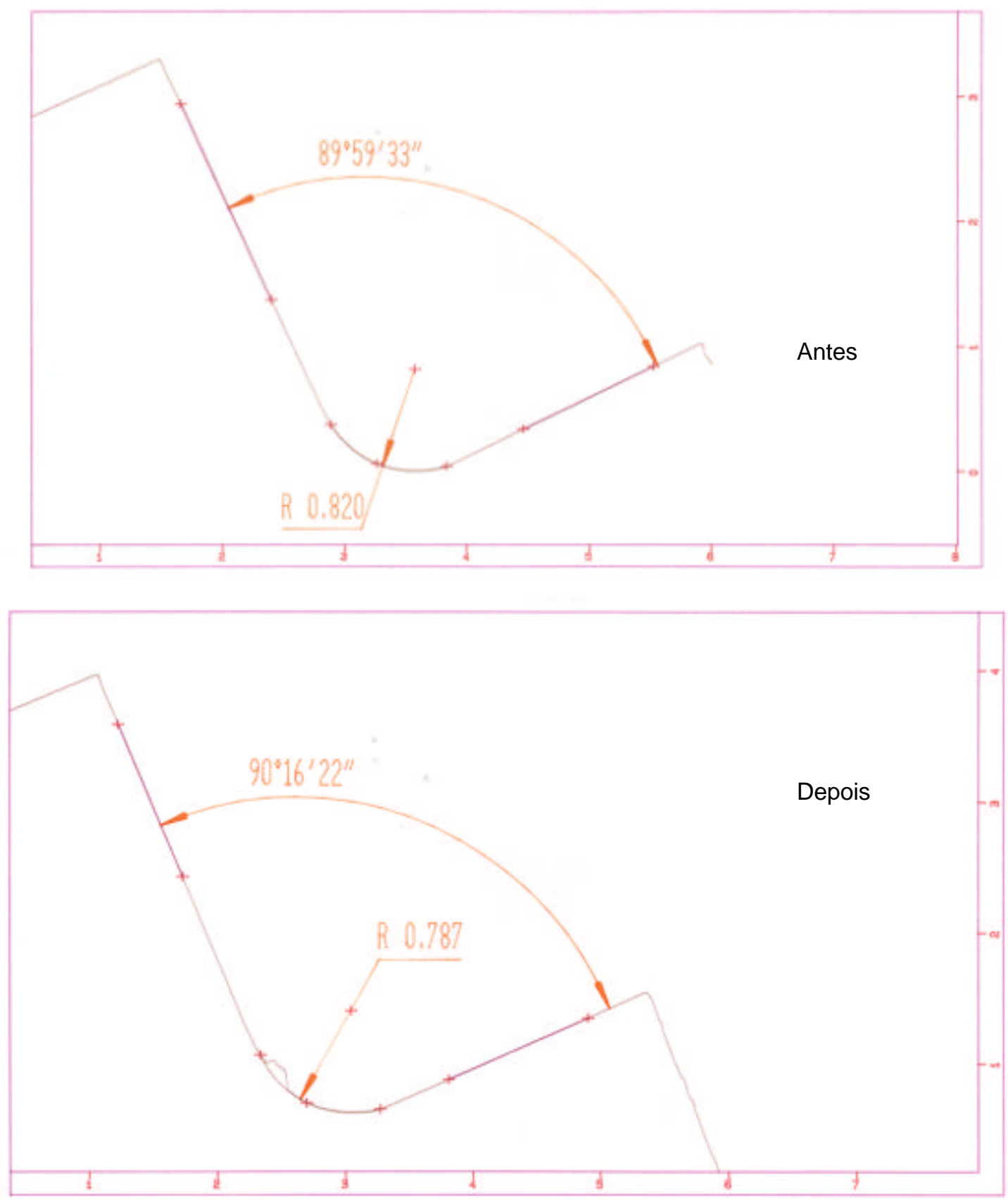

Figura A8 - Perfil da lateral esquerda do rebolo antes e depois da retificação para os testes de 3 estágios sem limpeza 

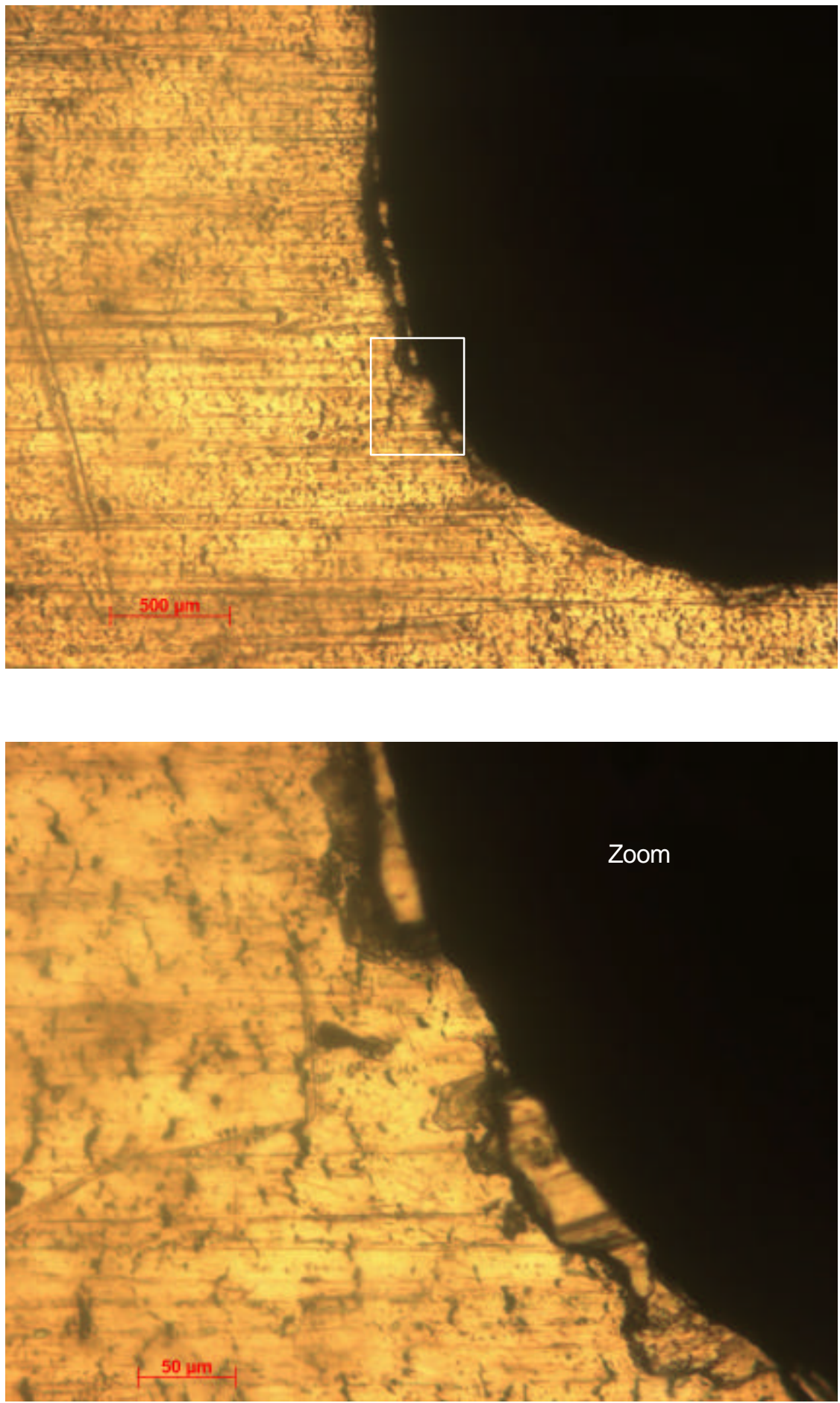

Figura A9 - Inspeção do perfil da lateral esquerda do rebolo para o teste estratégia axial (B), 1 estágio, sem limpeza 

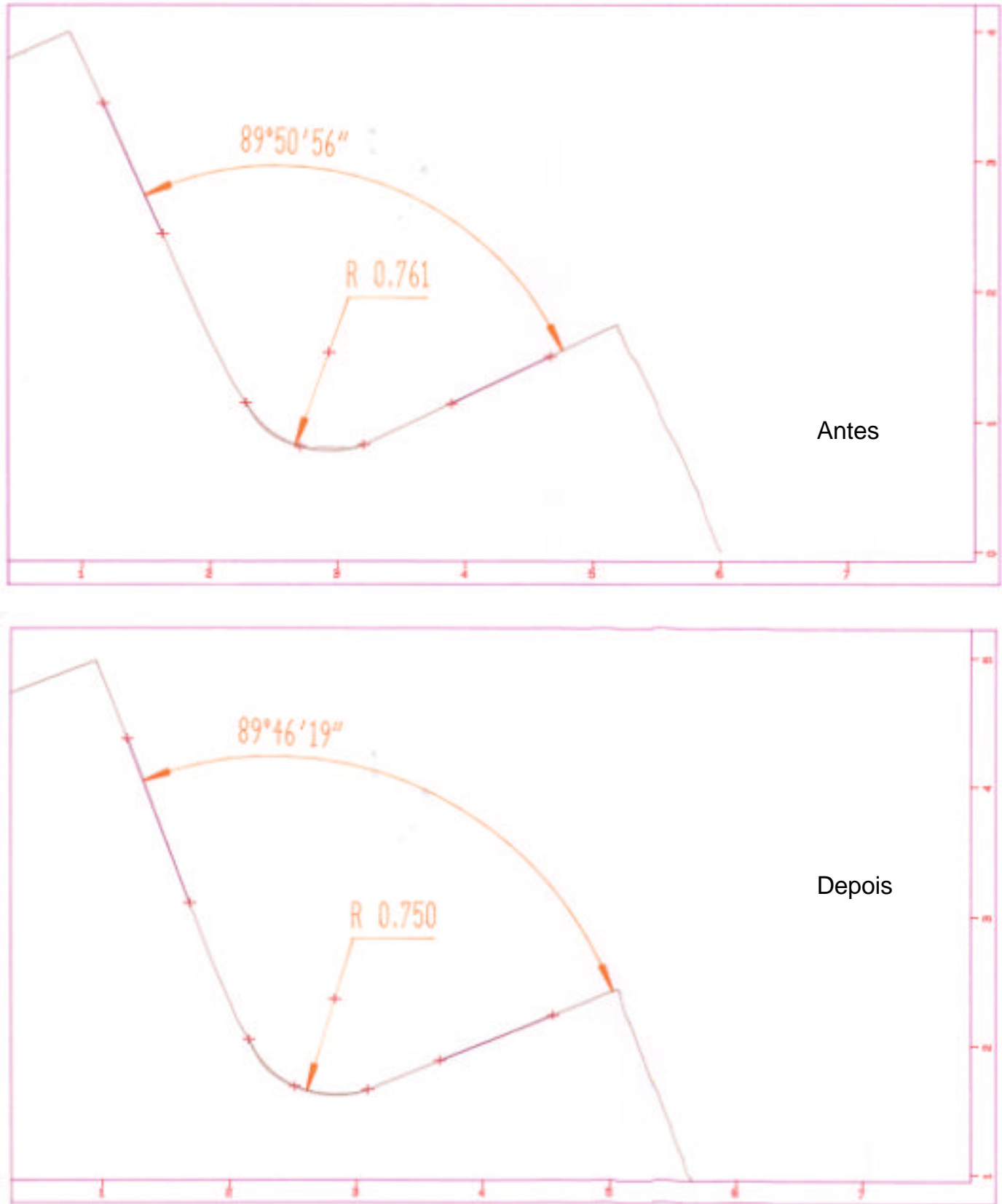

Figura A10 Perfil da lateral esquerda do rebolo antes e depois da retificação para os teste de mergulho 